PREDATION BY RESIDENT FISH ON JUVENILE SALMONIDS IN

JOHN DAY RESERVOIR, 1983- 1986

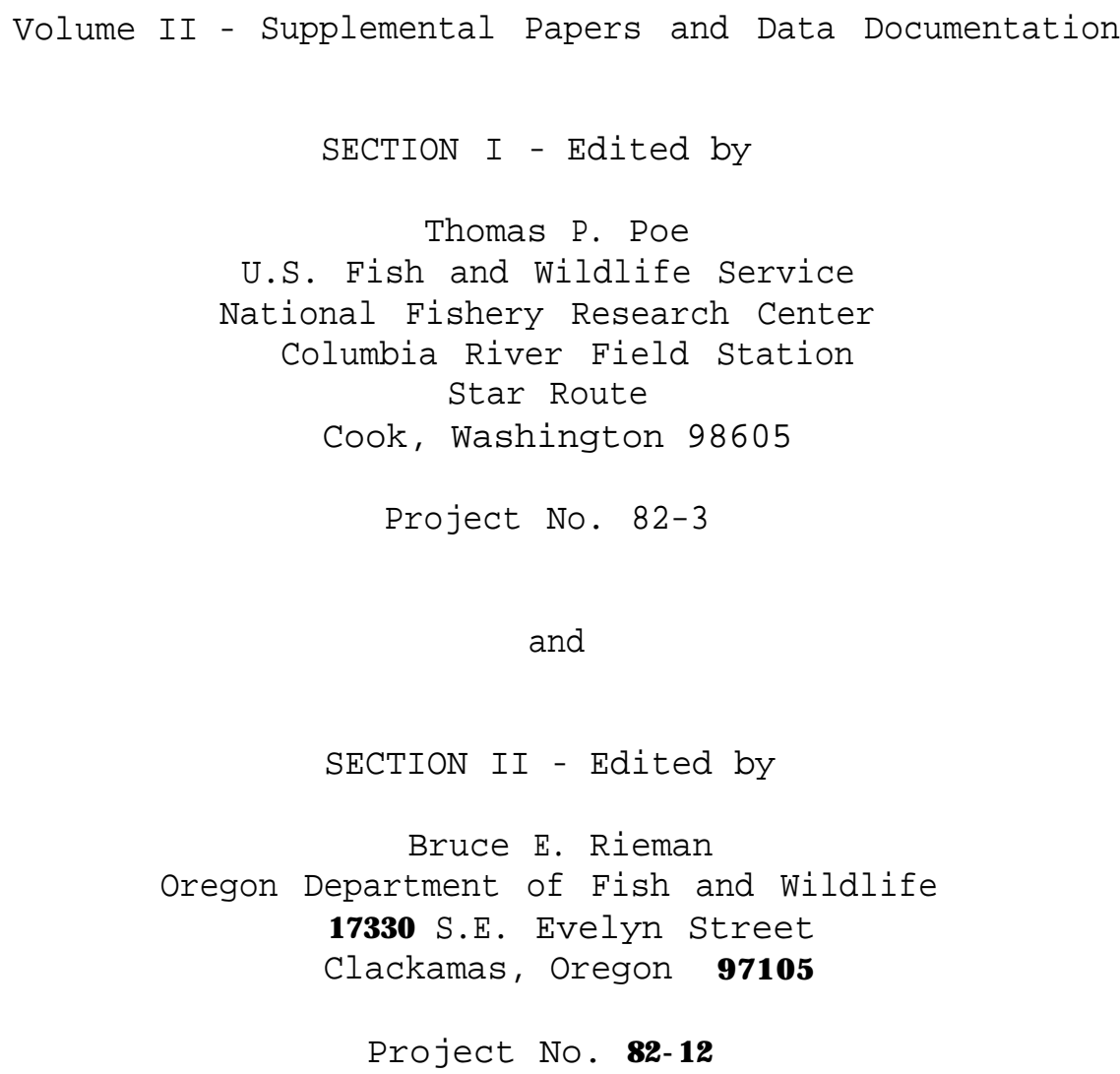

Funded by:

Fred Holm, Project Manager

U.S. Department of Energy

Bonneville Power Administration

Division of Fish and Wildlife

P.O. Box 3621

Portland, Oregon 97208

Contract Nos. DE-AI79-82BP34796 and

DE-AI79-82BP 35097

Columbia River Basin Fish and Wildlife Program Measure 404 (c)

1) 


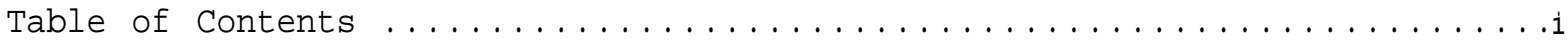

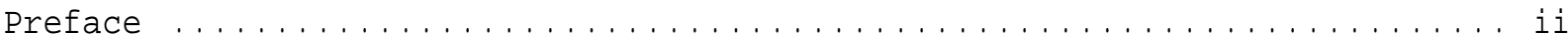

Section I - USFWS, Project No. $82-3 \ldots \ldots \ldots \ldots \ldots$

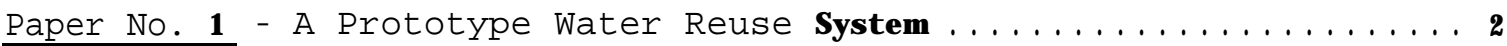

Paper No. 2 - A Method to Directly Measure Maximum Volume of Fish Stomachs in Di gestive Tracts .................... 11

Paper No. 3 - Use of Diagnostic Bones to Identify and Estimate Original Lengths of Ingested Prey Fishes .......... 33

Paper No. 4 - Variation in Capture Efficiency of a Beach Seine for

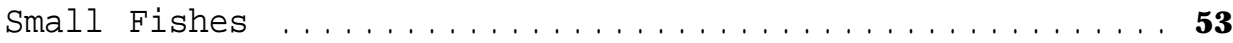

Data Documentation

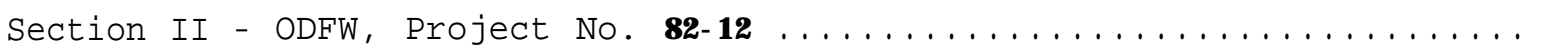

71

Paper No. 1 - Effects of Variation in Flow on Distributions of Northern Squawfish in the Columbia River below McNary Dam ..........................

Paper No. 2 - Size Selectivity and Bias in Estimates of Population Parameters of Smallmouth Bass, Walleye, and Northern Squawfish in a Columbia River Reservoir . . . . . . . . . . . . . . 90

Paper No. 3 - MOCPOP: A Flexible Simulator for Analysis of AgeStructured Populations and Stock-Related Functions . . . . . 108

Paper No. 4 - User's Guide for RESPRED: A Model of Predation by Resident Fish on Juvenile Salmonids in a Columbia

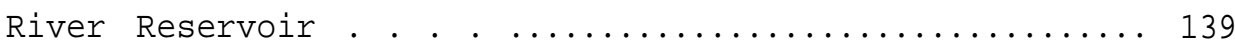

Data Set Documentation 
This document is a supplement to the final report for two research projects, funded by the Bonneville Power Administration (BPA) Project No. 82-3 conducted by the U.S. Fish and Wildlife Service (FWS) and Project No. 82-12 conducted by the Oregon Department of Fish and Wildlife (ODFW). Section I contains the research papers prepared by FWS and Section II the research papers prepared by ODFW; these papers describe how we addressed project objectives and document procedures used to obtain the study results reported in the Final Report (Volume 1). At the end of each section we also include information on how to find and use the data files and programs developed by each project. 
SECTION I

U.S. Fish and Wildlife Service National Fishery Research Center

Columbia River Field Station

Star Route

Cook, Washington 98605

Project No. 82-3 


\section{A Prototype Water Reuse System}

\section{Gino L. Lucchetti}

and

Gerard A. Gray

U.S. Fish and Wildlife Service

Seattle National Fishery Research Center

Columbia River Field Station

Star Route

Cook, Washington 98605

Published in: The Progressive Fish-Culturist Vo1.50:46-49, 1988. 
Abstract

A small scale water reuse system $(150 \mathrm{~L} / \mathrm{min})$ was developed to create an environment for making observations on fish under a variety of temperature regimes. Key concerns of disease control, water quality, temperature control, and efficiency and ease of operation were addressed. Northern squawfish (Ptychocheilus oregonensis) were held at loading densities ranging from $\mathbf{0 . 1 1}$ to $0.97 \mathrm{~kg} / \mathrm{L} / \mathrm{min}$ and at temperatures 10 to $20 \mathrm{C}$ (t 0.5 ) for six months with no disease problems or degradation of water quality in the system, and minimal system maintenance.

\section{Introduction}

In 1982 the Willard Field Station of the U.S. Fish and Wildlife Service initiated predation research on cool and warm water fishes of the Columbia River and needed a wet laboratory to perform controlled digestion rate experiments on live predator fishes. Clean water was plentiful from the Little White Salmon River, a nearby tributary to the lower Columbia River, and also from nearby springs but was extremely cold, rarely exceeding $8 \mathrm{c}$. In addition, the Little white Salmon National Fish Hatchery was located $8 \mathrm{~km}$ downstream from the proposed wet laboratory and could not tolerate diseases introduced from nonindigenous fish studied in the laboratory.

To meet those needs a water reuse system was designed to minimize costs of heating and sterilizing water, while providing a highly controlled environment for conducting research studies. This paper describes the design and operation of a small scale reuse system that has operated successfully for over two years. An extensive review of literature and existing systems was conducted prior to construction of the system and provided the basis for system design (Lucchetti and Grey, In Press).

\section{Methods and Materials}

To prevent disease problems within the system, and in the downstream hatchery, we treated both the effluent and reuse water. Sterilization was effected by two in-line UV units, each providing a minimum dose of $30,000 \mathrm{~W} /$ second/cm2 $(193,548 \mathrm{~W} / \mathrm{second} / \mathrm{in} 2)$ at 15

$\mathrm{L} / \mathrm{minute}$ ( 4 gal/minute) at $70 \%$ bulb efficiency. One unit was used to treat recirculating water and the other to treat effluent water. 
Our system integrated ion exchange and biofiltration for ammonia removal by using clinoptilolite as a medium for colonization of nitrifying bacteria. The use of clinoptilolite provided initial ammonia removal capabilities before nitrification became established, as well as insurance against failure of the nitrification process. Addition of a commercially available solution of microorganisms ensured that both types of bacteria required would be present at the proper time and in the required quantities. This was additionally important to affect loss of beneficial nitrifying bacteria when reuse water recirculated through the sterilization units. The microogranisms were added downstream of the sterilization units and upstream of the filter.

We used a packed column for oxygenation and degassing because it was simple and efficient. The column consisted of a polyvinyl chloride (PVC) pipe (1.5 m x $21 \mathrm{~cm}$ inside diameter) (4.9 Ft X 8.3 in) open at the top and about three-quarters full of $2.5 \mathrm{~cm}$ ( 1 in) koch rings. The pipe was open at the top to allow gas exchange and was capable of treating at least $\mathbf{1 5 0} \mathrm{L} / \mathrm{minute}$ (40 gal/minute) (D.E. Owsley, Dworshak/ Kooskia National Fish Hatchery Complex, P.O. Box 18, Ahsahka, Idaho, 83520, personal communication). Other methods, including mechanical agitators, oxygen pumps, and aspirators were avoided because of the potential for mechanical and plumbing failure. A pressurized sand filter, $1 \mathrm{~m}$ (3.3 ft) in diameter, treated only reuse water, because our fresh (i.e. make-up) water was extremely clean. Temperature control was achieved by using a commercially available in-line 18 KN elecctrical heater for warming and a small amount of cold spring or river water for cooling. The later provided waste water exchange and fresh water replenishment.

The system was assembled from materials that were on hand or readily available from commercial dealers. All plumbing was PVC, except for four $5 \mathrm{~cm}$ (2 in) brass valves and an aluminum foot and float valve. All wetted parts in the circulation heater and centrifugal pumps were either stainless steel or iron and all other metal or concrete surfaces were coated with neoprene rubber. The biofilter and sump were contained in a concrete pit $(4.9 \times 0.5 \times 1 \mathrm{~m})(16 \times 1.6 \times 3.3$ ft). A water chlorinator was also added to the system to treat the effluent water discharged into the Little White Salmon River in order to prevent introduction of disease in the hatchery located $8 \mathrm{~km}$ downstream. Plumbing to bypass each feature in the system was incorporated. The pathway of water through the system is shown in Fig. 1.

Our water reuse system was "conditioned" with eight adult (>250 mm (9.8 in) in total length) northern squawfish collected from the Columbia River for use in digestion rate experiments. Total flow was maintained at $150 \mathrm{~L} / \mathrm{minute}$ (40 gal/minute), equally distributed to each tank, and included a 5\% fresh (and waste) water exchange. The sand filter was backwashed once or twice a week, depending on pressure buildup. 


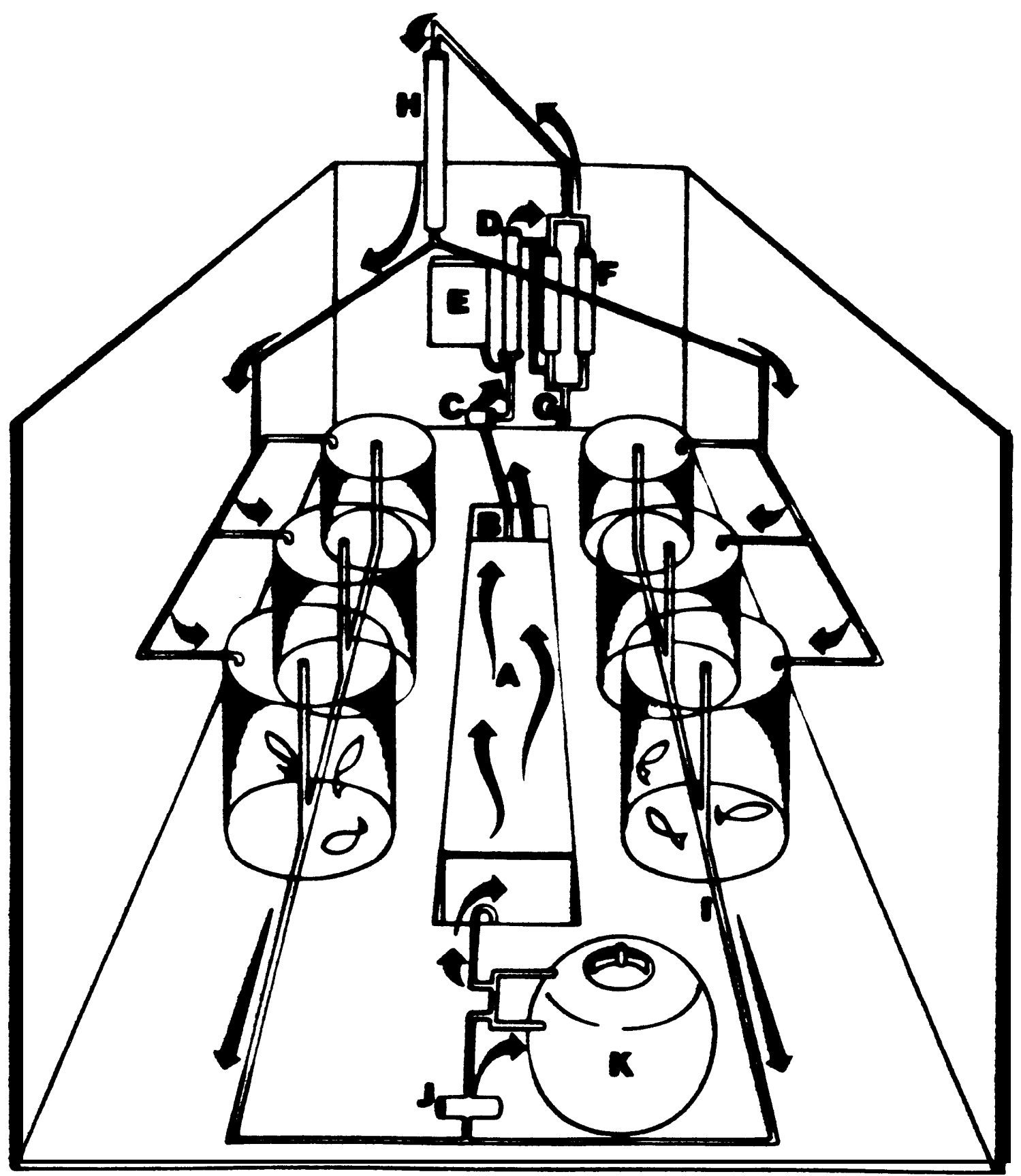

Figure I. Diagramatic view of an operational water reuse system. The pathway of water through the system was as follows: overflow water from biofilter (A) was drawn from sump (B) by centrifugal pump (C) and delivered to a-circulation heater (D) regulated by heater control panel (E). Water was then treated by UV sterilization units (F) and released as effluent (G), or directed to a packed column (H), and distributed by gravity feed to fish holding tanks. Centrifugal pump (J) distributed tank overflow water (I) through the pressurized sand filter (K) to the biofilter (A), Arrows show direction of flow. 
Regular monitoring of selected chemical variables was begun in the week starting July $\mathbf{3}$ (week 1), when we introduced $\mathbf{8 4}$ northern squawfish, total weight, $50 \mathrm{~kg}$ (110 lbs), at a loading density of $0.33 \mathrm{~kg} / \mathrm{L} / \mathrm{minute}$ (2.75 lb/gal/minute). Little maintenance work was done on the biofilter until week 20, when ammonia levels began rising as a result of channelization in the filter; this situation was remedied by gently agitating the top $\mathbf{1 5}$ to $20 \mathrm{~cm}$ (5.9 to 7.9 in) $\mathrm{cm}$ of clinoptilolite with a rake. Temperatures were maintained at experimental levels to within + 0.5C (0.9 F). Dissolved oxygen (DO), conductivity, and pH were monitored with a Hydrolab ${ }^{1}$ series 8000 placed in one of seven fish holding tanks. Starting in week 21, DO was measured with a YSI Model \#58 meter. Ammonia nitrogen $\left(\mathrm{NH}_{4}-\mathrm{N}\right)$, nitrite $\left(\mathrm{NO}_{2}\right)$, and nitrate $\left(\mathrm{NO}_{3}\right)$ were measured with a Hach kit model NI-8 for ammonia nitrogen and model NI-12 for nitrate and nitrite. Monitoring was done daily until week 17, thereafter, DO, conductivity, and $\mathrm{pH}$ were estimated weekly.

Northern squawfish in the system were fed fingerling salmon (Oncorhynchus sp.) ad libitum, 6 to 8 days per month. This diet was intended as a maintenance ration only. Loading density fluctuated as northern squawfish were sacrificed and replaced during the study. The body and viscera of sacrificed northern squawfish were examined for signs of starvation and disease.

\section{Performance of System}

Water quality was adequate throughout the 25 week observation period (Fig. 2) at loading densities averaging $0.51 \mathrm{~kg} / \mathrm{L}$ ( $4.26 \mathrm{lb} / \mathrm{gal})$. The DO varied with water temperature and ranged from 7.8 (week 4) to $13.1 \mathrm{mg} / \mathrm{L}$ (1.77 X 10 $10^{-3} \mathrm{oz} / \mathrm{gal}$ ) (week 16). Average $\mathrm{pH}$ was 6.73 , as compared with 6.9 to $\mathbf{7 . 2}$ for the water source--indicating that nitrificatioon had caused slight acidification. Conductivity averaged 0. $058 \mathrm{mhos} / \mathrm{cm}(0.147 \mathrm{mhos} / \mathrm{in})$ and varied little over the course of study.

Actual ammonia production by northern squawfish in the water reuse system was not computed because it was impractical to determine the "ammonia factor" needed for equations outlined by Piper et al. (1982). Brett and Zala (1975) showed that, even after 22 days of starvation, juvenile sockeye salmon (Oncorhnychus nerka) had an ammonia output of $7.27 \mathrm{mg} \mathrm{N} / \mathrm{kg} / \mathrm{L}\left(4.46 \mathrm{x}-10^{-4} \mathrm{oz} / \mathrm{lb} / \mathrm{gal}\right)$ that was near the basal ammonia excretion rate $(8.2 \mathrm{mg} \mathrm{N} / \mathrm{kg} / \mathrm{L})\left(5.03 \times 10^{-4} \mathrm{oz} / \mathrm{lg} / \mathrm{gal}\right)$ of salmon fed a maintenance ration. Throughout the study, northern squawfish maintained

\footnotetext{
T Reference to trade names does not imply U.S. Government endorsement of commercial products.
} 


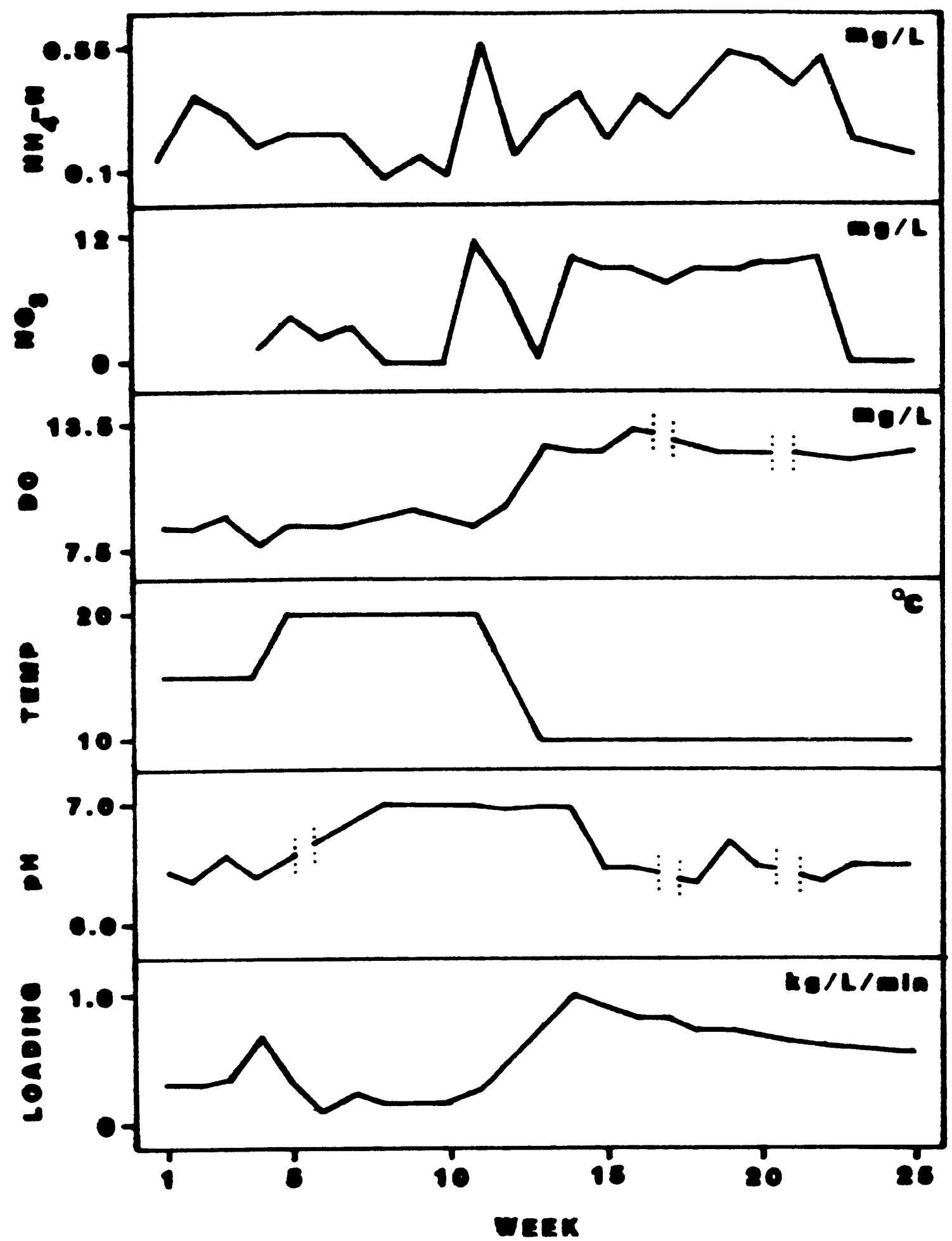

Figure 2. Temperature, water chemistry, and loading density during 25 weeks of continuous operation of the water reuse system. 
high fat content in the body cavity and showed no signs of atrophy of the gut. E.M. Dawley, (Hammond Field Station, P.0. Box 155, Hammond, Oregon, 97121, personal communication) held northern squawfish under similar conditions for 4 months without food and could not detect morphological signs of starvation; fish ate readily when offered food. Therefore, it seens likely that the basal rate of ammonia excretion by the northern squawfish should have been adequate to evaluate the system.

Ammonia nitrogen, nitrite, and nitrate levels were well below toxic levels reported for other fish species. Thurston et al. (1978) estimated 36-day median lethal concentrations (LC50) of un-ionized ammonia and nitrite for fry of cutthroat trout (Salmo clarki) to be 0.3 to $0.6 \mathrm{mg} / \mathrm{L}\left(4.06 \times 10^{-5}\right.$ to $\left.8.11 \times 10^{-5} \mathrm{oz} / \mathrm{gal}\right)$ and $0.4 \mathrm{mg} / \mathrm{L}\left(5.41 \times 10^{-5}\right.$ oz/gal), respectively. Estimates of the un-ionized portion of ammonia nitrogen during our study, based on calculations given by Emerson et al. (1975), never exceeded $2 \mathrm{~g} / \mathrm{L}\left(2.70 \times 10^{-7} \mathrm{oz} / \mathrm{gal}\right)$. Nitrite was generally undetectable. Nitrate was considerably lower (average of 5 $\mathrm{mg} / \mathrm{L})\left(6.76 \times 10^{-4} \mathrm{oz} / \mathrm{gal}\right)$, than that reported by Colt and Armstrong (1981) to have lethal or sublethal effects on fish.

No fish disease problems developed during the study, even though the northern squawfish came from the wild and were not treated for disease before the experiments, and were repeatedly stressed by handling and sorting. Mortality associated with an infestation of Ichthyopthirius sp. did arise after the study was completed.

Disinfection of the system with chlorine and quarantining of fish prior to introduction into the system has resulted in disease free operation since the end of the mortality period. C.M. Falter (University of Idaho, Moscow, Idaho, 83843, personal communication) found it difficult to maintain lake stocks of northern squawfish because the fish were infested with cestodes. Although cestodes were prevalent in virtually all northern squawfish examined, the fish never developed heavy infestations. Mats of filamentous bacteria (Sphaerotilus) and algae, as reported by other researchers (Burrows and Combs 1968; Spotte 1979), were never problems in our system. The UV treatment undoubtedly limited the concentrations of disease organisms, as well as of nitrifying bacteria, in the system Therefore addition of a small amount of commercially available bacterial solution was made to offset U.V. mortality.

Few problems in maintaining a healthy aquatic environment for studying northern squawfish were encountered with the described water reuse system. Problems that arose were generally attributable to operational. procedures. For example, high levels of ammonia detected by week $\mathbf{2 0}$ were corrected by gently stirring the top level of clinoptilolite to prevent fouling and channelization; up to that time, the filter medium required virtually no maintenance. This system was highly adaptable and took advantage of existing facilities, which 
provided more space for fish tanks. For example, the biofilter was originally a concrete pit for housing heating pipes. The system was built at a cost of \$US8,000 (1984) excluding labor.

\section{Acknowledgements}

This work was supported by the Bonneville Power Administration under contract DI-A179-82BP34796. We thank C.M. Falter, E.M. Dawley, C. Horsch, J. Holway, and particularly D.E. Owsley for providing unpublished information on various aspects of water reuse technology. We also wish to thank W.R. Nelson, J. Novotny, C.J. Johnson, P.H. Eschmeyer, and others who reviewed the manuscript. The help of $\mathrm{T}$. Poe and J. Beyer in preparing this document for publication is greatly appreciated. 
Brett, J.R. and C.A. Zala. 1975. Daily pattern of nitrogen excretion and oxygen consumption of sockeye salmon (Oncorhynchus nerka) under controlled conditions. Journal Fisheries Research Board Canada 32:2479-2486.

Burrows, R.E., and B.D. Combs. 1968. Controlled environments for salmon propagation. Progressive Fish Culturist 30:123-136.

Colt, J.E., and D.A. Armstrong. 1981. Nitrogen toxicity to fish, crustaceans and mollusks. Pages 39-42 in L.J. Allen and E.C. Kinney, eds. Proceedings of the bioengineering symposium for fish culture. Fish Culture Section, American Fisheries Society, Bethesda, Maryland.

Emerson, K., R.C. Russo, R.E. Lund, and R.V. Thurston. 1975. Aqueous ammonia equilibrium calculations: effect of $\mathrm{pH}$ and temperature. Journal Fisheries Research Board Canada 32:2379-2383.

Lucchetti, G.L., and G.A. Gray. 1988. Water reuse systems: review of principal components. Progressive Fish-Culturist (In Press).

Spotte, S. 1979. Fish and invertebrate culture: water management in closed system 2nd ed. Wiley-Interscience Co., New York, New York.

Thurston, R.V., R.C. Russo, and C.E. Smith. 1978. Acute toxicity of ammonia and nitrite to cutthroat trout fry. Transactions of the American Fisheries Society 107: 361- 368. 
A Method to Directly Measure Maximum Volume of Fish Stomachs or Digestive Tracts

Craig C. Burley and Steven Vigg

U.S. Fish and Wildlife Service

National Fishery Research Center -- Seattle

Columbia River Field Station

Star Route, Cook, Washington, 98605 USA

Submitted to: Journal of Fish Biology, 1988. 
A new method for directly measuring maximum stomach or digestive tract volume of fish incorporates air injection at constant pressure with water displacement to directly measure the internal volume of a stomach or analogous structure. The method was tested with coho salmon, Oncorhynchus kisutch (Walbaum), which have a true stomach, and northern squawfish, Ptychocheilus oregonensis (Richardson), which have a modified foregut as a functional analog. Both species were collected during JulyOctober 1987 from the Columbia River, USA. Relations between fish weight (= volume) and maximum volume of the digestive organ were best fitted to coho salmon by an allometric model and to northern squawfish by an exponential model. Least squares regression analysis of individual measurements showed less variability in the volume of coho salmon stomachs $\left(R^{2}=0.85\right)$ than in the total digestive tracts $\left(\mathrm{R}^{2}=0.55\right)$ and foreguts $\left(\mathrm{R}^{2}=\right.$ 0.61) of northern squawfish, relative to fish size. Compared to previous methods, the new technique has the advantages of accurately measuring the internal volume of a wide range of digestive organ shapes and sizes, and of having an objective measure of final inflation pressure. 


\section{INTRODUCTION}

The relationship between fish size and the volume (capacity) of its digestive tract--or true stomach in the case of most piscivores-- has three general applications to trophic research: studies of food habits; digestion and food consumption rate studies; and bioenergetics models. In food habits studies, specific food category (volume or weight) is often estimated, either subjectively or by measurement, as a percentage of total stomach contents. Describing food items in this way however, provides little information on dietary importance unless the estimate is related to stomach volume or fish size. When a food category is expressed as a percentage of stomach capacity, a mean percent volume can be calculated for the individual sample or the total percentage for the food category can be expressed as a proportion of the overall total volume of stomach contents [see Hyslope (1980) for a comprehensive review with specific applications .

Studies of digestion and food consumption rates with respect to changes in stomach fullness constitute a second application of maximum stomach volume relations (e.g. Bajkov, 1935; Windell, 1978). Daily food ration can be estimated from field observations of the diel cycle of stomach contents by modeling the time trajectory of stomach fullness (Thorpe, 1977; Sainsbury, 1986). Since stomach distention provides stimuli for digestive processes within the gastrointestinal tract, quantification of the functional relation between stomach volume and fish weight is also important to gastric evacuation studies, which make direct comparisons between fish of different sizes by feeding a constant ration (e.g. Jobling et al., 1977; Flowerdew \& Grove 1979).

Finally, in a bioenergetics model, physiological maximum ration is used to determine the upper bound in growth potential of a fish population (Stewart \& Binkowski, 1986). This maximum level, obtained from laboratory experiments on ad libitum feeding rates, is adjusted downward during simulations until the model fits the observed growth (Stewart et al., 1983). Since the physical volume of the stomach limits the maximum instantaneous meal size a fish can ingest, it represents the ultimate upper bound of the physiological maximum--given a knowledge of temperature-specific digestion rates. Thus, the relation of maximum stomach volume to fish size provides a simplified way to estimate the maximum possible daily consumption of a fish species.

Methods used to estimate maximum fish stomach capacity and to relate stomach capacity to fish size can be categorized as 
direct or indirect. Maximum physical volume has been directly measured by inflating fish stomachs to the bursting point (Kariya et al., 1968), or filling stomachs with known volumes of water (Kimball \& Helm, 1971; Jobling et al., 1977; Flowerdew \& Grove, 1979). Indirect methods, which incorporate the behavior and physiology of fish, include laboratory studies of feeding to satiation (Magnuson, 1969) and inferences based on maximum feeding observed in nature (Hellawell, 1971, 1972; Knight \& Margraf, 1982).

The purpose of this paper is threefold: First, to describe a new direct method of measuring maximum stomach or digestive tract capacity of fish by using air injection and water displacement, and to compare it with previous methods. Second, to test the technique on two piscivorous species of fish, one having a true stomach, coho salmon, Oncorhynchus kisutch (Walbaum); and one having a modified foregut (which functions as a stomach), northern squawfish, Ptychooheilus oregonensis (Richardson). Finally, we compare the species-specific

functional relation between maximum volumes of the digestive organ (stomach, total digestive tract or foregut) to fish weight. 


\section{METHODS AND MATERIALS}

\section{FISH COLLECTION}

Northern squawfish (500-1500 g) were collected from the McNary Dam tailrace on the Columbia River (USA) during July 1987 using an electrofishing boat. The fish taken were transferred alive to the laboratory and maintained on a diet of juvenile salmon in tanks at $17.0 \mathrm{C}$, for digestive tract volume analysis in September. Coho salmon (300-3800 g) were collected and stomachs immediately dissected in October 1987 during spawning at the Little White Salmon National Fish Hatchery. Each fish was weighed to the nearest gram, and fork length measured to the nearest millimeter.

\section{APPARATUS}

The volume displacement chamber, which had a working volume of 6.71 (Fig. 1), was constructed from a polyvinyl chloride pipe $(10 \times 91 \mathrm{~cm})$. A $5 \times 38 \mathrm{~cm}$ section was removed and a section of plexiglass, $0.32 \mathrm{~cm}$ thick was sealed in place with silicon sealer to form a viewing window. The base was threaded for easy removal and to facilitate cleaning. A $0.64 \mathrm{~cm}$ nozzle and plastic tube, located $2.5 \mathrm{~cm}$ from the top of the chamber, was used to transfer the displaced water to a graduated cylinder of appropriate size for accurate measurement.

Temperature inside the chamber was monitored with a digital thermometer. A constant temperature of $\mathbf{1 7 . 0} \mathrm{c}$ was maintained by changing the water after each measurement, by opening the valve near the bottom of the chamber. The chamber was attached to a ring stand with ring clamps. A standard compressed gas cylinder $\left(8.0 \mathrm{~m}^{3}\right)$ with an Airco 8400 two stage regulator having a guage with increments of 0.1 PSI $\left(0.007 \mathrm{~kg} \cdot \mathrm{cm}^{-2}\right)$, delivered air at a constant pressure. The air passed through a $0.64 \mathrm{~cm}$ plastic tube and nozzle that attached to the anterior end of the digestive organ with a hose clamp. The posterior end of the gut was sealed with a wire twist-tie. A bend was formed in the air tube and a lead weight was attached at the apex to hold the inflated digestive tract and hose under water.

* The mention of a product name does not constitute endorsement by the U.S. Government. 
Fig. 1. Volume measurement apparatus (A), with insert showing attachment of northern squawfish digestive tract (B). Components: (1) volume displacement chamber, (2) viewing window, (3) base cap, (4) outflow nozzle, (5) outflow tube, (6) graduated cylinder, (7) drain pipe, (8) valve, (9) ring stand, (10) ring clamps, (11) gas cylinder, (12) pressure gauge, (13) air hose, (14) air nozzle, (15) hose clamp, (16) twist tie, and (17) weight. 


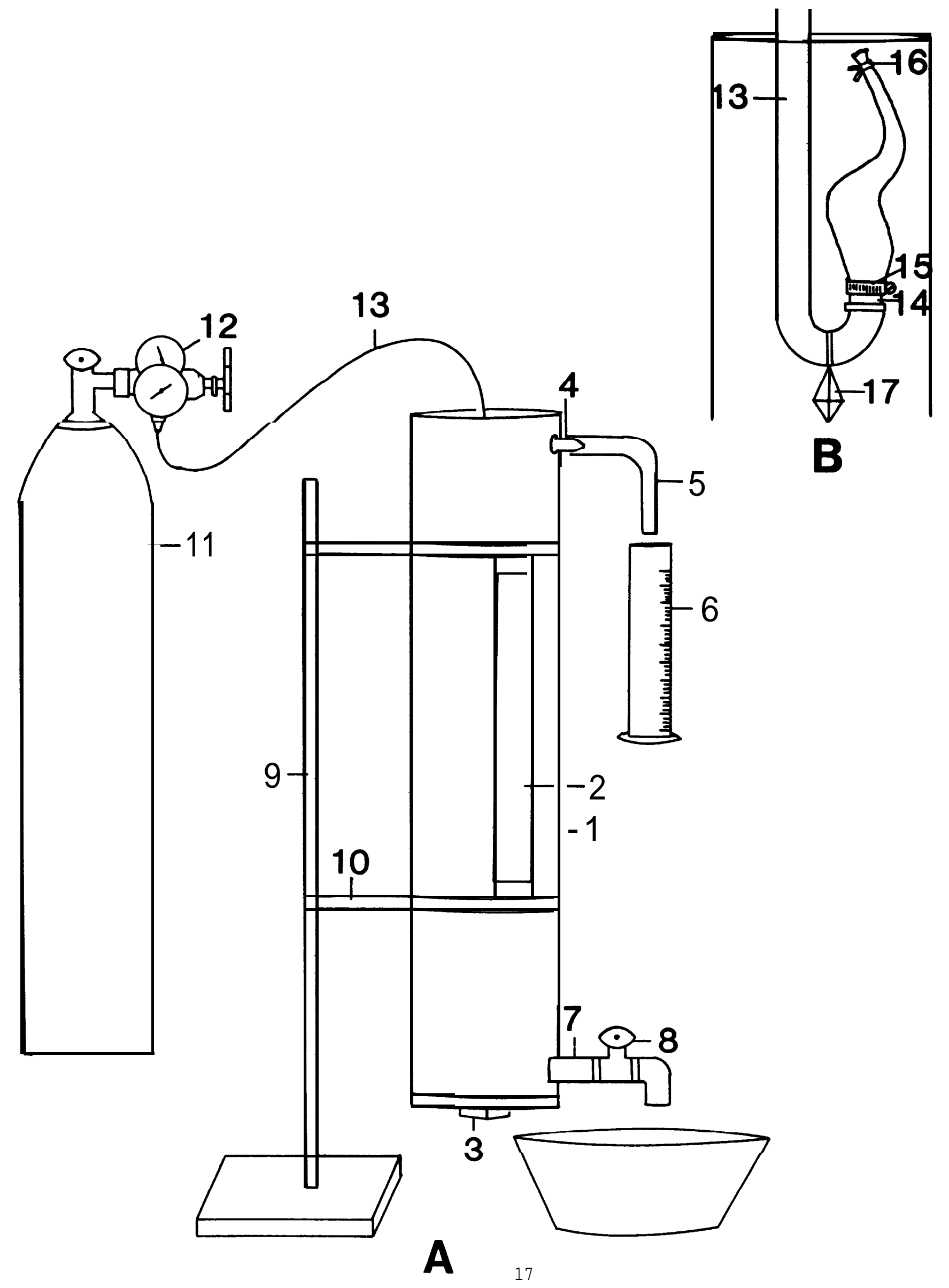


The chamber was constructed to facilitate the measurement of squawfish digestive tracts that were up to $515 \mathrm{~mm}$ in length and $137 \mathrm{ml}$ in volume. A chamber of smaller diameter was used when the volume of the digestive organ was less than $20 \mathrm{ml}$, to facilitate a more accurate measurement.

\section{DIGESTIVE TRACT MEASUREMENT PROCEDURE}

The digestive tract from each northern squawfish, and the stomach from each coho salmon were removed (Fig. 2). Northern squawfish digestive tracts were dissected anteriorly at the back of the mouth and posteriorly at the vent. Because of the unique gastrointestinal morphology of northern squawfish (Weisel, 1962), we were careful to leave the cystic duct intact when the gall bladder was removed; otherwise, a natural orifice in the wall of the foregut resulted in large air leaks. Coho salmon stomachs were dissected at the back of the mouth and posteriorly at the front of the pyloric ceca. Each digestive organ was flushed with water, placed in a labeled plastic bag and kept on ice for $24 \mathrm{~h}$ until the volume measurement were made. Before measurement the digestive organs were acclimated in a bucket, containing water at $17.0 \mathrm{c}$. A volume measurement to the nearest milliliter was made for coho salmon stomachs or northern squawfish total digestive tracts and foreguts. Each digestive organ was attached at the anterior end to the air nozzle. Residual air was forced out of the organ and the posterior end was sealed with a twist-tie. The digestive organ was placed in the chamber and the water level stabilized to the bottom of the outflow spout. Pressure was gradually increased until the digestive organ was determined by visual inspection to be fully distended. Distention was considered complete when the digestive organ walls were evenly taut along the natural contours of the organ. Pressure was measured on the regulator gauge and recorded for each fish. Air leakage from the digestive organ was monitored through the viewing window. The amount of leakage was judged by applying a subjective scale: (0) none, (1) small, (2) moderate, and (3) large. Volume measurements corresponding to digestive organs with large air leaks were omitted from the analysis. The burst pressure was then measured for comparison with inflation pressure by increasing the pressure until the digestive organ ruptured, and the corresponding pressure was recorded.

Paired measurements of body-volumes to body-weights were made for a sample of 72 northern squawfish to ascertain the quantitative relation. Volume was determined by using water displacement in a $\mathbf{1 3 . 5} 1$ chamber. 
Fig. 2. Northern squawfish digestive tract, and coho salmon stomach; $1=$ anterior cut, $2=$ posterior cut, $3=$ gall bladder cut, $4=$ foregut-hindgut cut. Abbreviations: $\mathrm{GB}=$ gall bladder, $\mathrm{CD}=$ cystic duct, and $\mathrm{PC}=$ pyloric ceca. 
Northern squawfish digestive tract

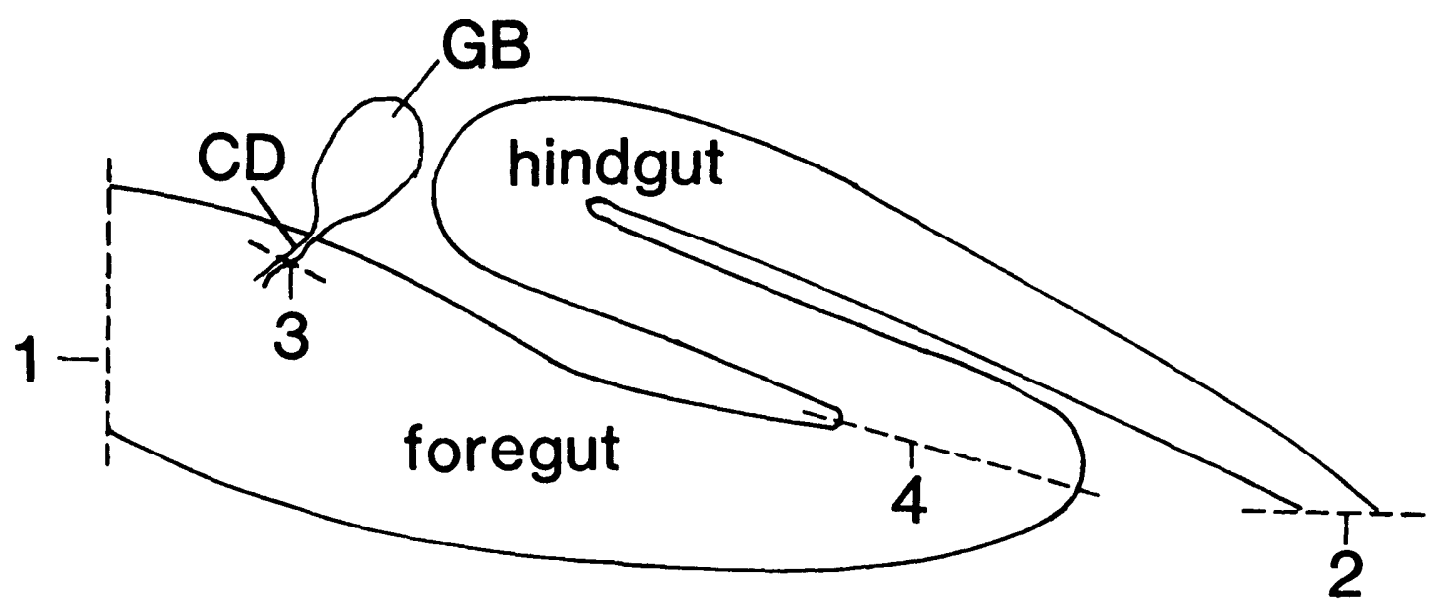

A

Coho salmon stomach

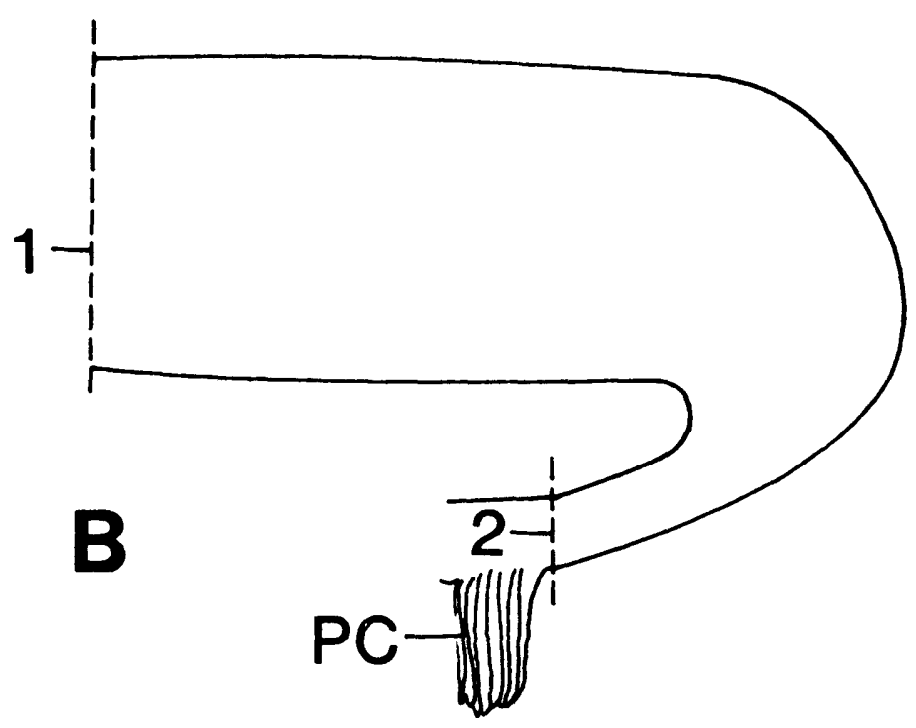


DATA ANALYSIS

Relations between fish weight (W) and stomach, total digestive tract, and foregut volume (V) were quantified by using least squares linear regression techniques. The data were fitted to three models: (1) linear, $\mathrm{V}=\mathrm{a}+\mathrm{b} \mathrm{W}$; (2) exponential, $\mathrm{V}=$ $\left.\mathrm{e}^{(\mathrm{a}}+\mathrm{b} \mathrm{W}\right)$; and (3) multiplicative or allometric $\mathrm{V}=\mathrm{a} \mathrm{w}^{\mathrm{b}}$. Selection of the "best" model was based on the highest proportion of variability in digestive organ volume explained by fish weight $\left(R^{2}\right)$, and inspection of the pattern of the residuals and their variability. 


\section{RESULTS}

Nearly half of the digestive organs tested for volume determinations were rejected due to rips, ruptures or large air leaks (43\% of coho salmon stomachs and $46 \%$ of northern squawfish digestive tracts). Of the intact structures, mean pressure required to fully inflate coho salmon stomachs $\left(\mathbf{0 . 1 2 3} \mathrm{kg} \cdot \mathrm{cm}^{-2}\right.$ ) was significantly greater $(p<0.001)$ than that required for the total digestive tracts $\left(0.097 \mathrm{~kg} \cdot \mathrm{cm}^{-2}\right)$ or foreguts $(0.058 \mathrm{~kg}$. $\mathrm{cm}-2$ ) of northern squawfish (Table I). Inflation pressure was not significantly related to either fish size or digestive organ volume $(\mathrm{R} 2<=\mathbf{0} . \mathbf{1 0})$--thus indicating that mean inflation pressure of each digestive organ adequately represented the entire range of fish sizes. There was no significant difference ( $p>0.10$ ) between mean burst pressure of coho salmon stomachs $(\mathbf{0 . 2 1 4} \mathrm{kg}$. $\mathrm{cm}-2)$ northern squawfish total digestive tracts $(0.308 \mathrm{~kg} \cdot \mathrm{cms} 2$, or foreguts $\left(\mathbf{0 . 2 8 0} \mathrm{kg} \cdot \mathrm{cm}^{-2}\right)$.

Data from individual fish fitted to three regression models (Table II) indicated that the multiplicative model best described the relation between coho salmon body weight and stomach volume $\left(\mathrm{R}^{2}=\mathbf{0 . 8 5}\right)$, whereas the exponential model best described the relation for northern squawfish total digestive tract ( $R 2=$ $0.55)$, and foregut $\left(\mathrm{R}^{2}=0.61\right)$. Maximum digestive organ volume, averaged over 500-g body weight intervals for coho salmon and 100-g intervals for northern squawfish, were regressed on mean fish weight to illustrate the differences in the digestive organ capacity relations of the two species (Fig. 3).

Northern squawfish body weight (grams) was essentially equivalent to body volume (milliliters). There was a direct linear relation between fish weight (FW, g) and fish volume (FV, $\mathrm{ml}$ ) with an intercept of zero, and slope near one: $\mathrm{FV}=0.95 \mathrm{FW}$ $\left(\mathrm{n}=\mathbf{7 2}, \mathrm{R}^{2}=0.98\right)$. 
Table I. Mean inflation and burst pressures $\left(\mathrm{kg} \cdot \mathrm{cm}^{-2}\right)$ for coho salmon stomachs, northern squawfish total digestive tracts and foreguts; measurements of digestive organs with large air leaks were omitted.

\begin{tabular}{|c|c|c|c|c|c|c|}
\hline \multirow{3}{*}{$\begin{array}{l}\text { Species and } \\
\text { digestive organ }\end{array}$} & \multicolumn{6}{|c|}{ Pressure $\left(\mathrm{kg}^{\prime} \mathrm{cm}^{-2}\right)$} \\
\hline & \multicolumn{3}{|c|}{ Inflation } & \multicolumn{3}{|c|}{ Burst } \\
\hline & Mean & SD & $\begin{array}{l}\text { Sample } \\
\text { Size }\end{array}$ & Mean & $\mathrm{Sd}$ & $\begin{array}{l}\text { Sampl } \\
\text { Size }\end{array}$ \\
\hline Coho salmon & & & & & & \\
\hline Stomach & 0.123 & 0.039 & (24) & 0.214 & 0.059 & ( 18) \\
\hline Northern squawfish & & & & & & \\
\hline Total digestive tract & 0.097 & 0.015 & $(45)$ & 0. 308 & 0.062 & (10) \\
\hline Foregut & 0.058 & 0.010 & $(30)$ & 0.280 & 0.113 & (21) \\
\hline
\end{tabular}


Table II. Regression models of coho salmon stomachs ( $\mathrm{n}=24)$ and northern squawfish total digestive tracts and foreguts $(n=32)$ on fish weight.

\begin{tabular}{|c|c|c|c|c|c|}
\hline \multirow{3}{*}{ Species } & \multirow{3}{*}{ Model * } & \multicolumn{3}{|c|}{ Coefficients } & \multirow{3}{*}{$\begin{array}{l}\text { Residual } \\
\text { Standard } \\
\text { Error }\end{array}$} \\
\hline & & \multirow[b]{2}{*}{ Intercept (a) } & \multirow[b]{2}{*}{ Slope (b) } & \multirow[t]{2}{*}{$\mathrm{R}^{2}$} & \\
\hline & & & & & \\
\hline \multicolumn{6}{|c|}{ Coho Salmon } \\
\hline & Linear & - 3.2345 & 0.0153 & 0.56 & 14.690 \\
\hline & Exponential & 1. 1537 & 0.0009 & 0.70 & 0.623 \\
\hline & Multiplicative & 0.0007 & 1. 3796 & 0.85 & 0.444 \\
\hline \multicolumn{6}{|c|}{ Northern Squawfish } \\
\hline \multicolumn{6}{|c|}{ Total digestive tract } \\
\hline & Linear & -6.3116 & 0.0652 & 0.48 & 20.836 \\
\hline & Exponential & 2. 8540 & 0.0012 & 0.55 & 0.308 \\
\hline & Multiplicative & 0.0434 & 1. 0380 & 0.54 & 0.312 \\
\hline \multicolumn{6}{|l|}{ Foregut } \\
\hline & Linear & - 8. 1261 & 0.0416 & 0.53 & 12. 078 \\
\hline & Exponential & 2. 1365 & 0.0013 & 0.61 & 0.305 \\
\hline & Multiplicative & 0.0105 & 1. 1603 & 0.59 & 0.313 \\
\hline
\end{tabular}

* Linear: $\mathrm{V}=\mathrm{a}+\mathrm{b} \mathrm{W}$ Exponential: $\left.v=e^{(a+b} \mathbf{w}\right)$ Multiplicative: $V=a w^{b}$ 
Fig. 3. Models of maximum digestive organ mean volume, by weight interval, as a function of mean fish body weight for northern squawfish total digestive tract (0), foregut (0), and coho salmon stomach ([]). 


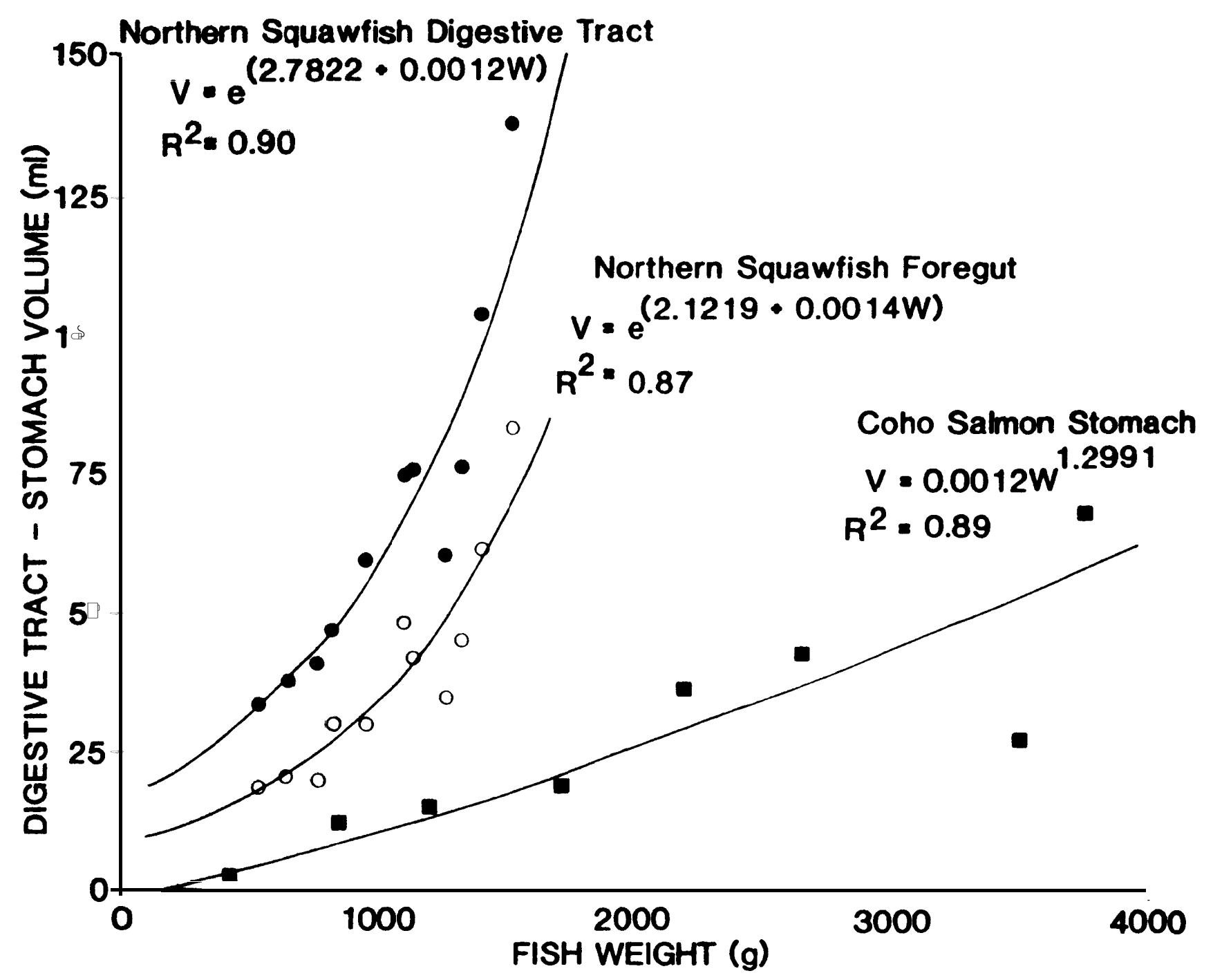


IV. DISCUSSION

\section{TEST DATA}

Mean inflation pressure of the digestive organs can be used as an objective end point when making maximum capacity determinations. For northern squawish, the low amount of variability, as indicated by the coefficient of variation (total digestive tract, $\mathbf{1 5 . 5 \%}$ foregut, $\mathbf{1 7 . 2 \%}$, showed that the subjective end point was constant. For coho salmon however, the mean inflation pressure was more variable $(\mathrm{CV}=31.7 \%)$. This variability may have been due to either (1) differences in stomach elasticity caused by atrophy of the stomachs associated with different freshwater residence times, or (2) the subjective end point of stomach distention for coho salmon occurred over a wider range of pressure because the walls of the stomach were thicker than those of the northern squawfish digestive tract. In future studies, trial tests for a given species could establish a mean inflation pressure of a sample of fish digestive organs, which could then be used as an objective end point for later determinations.

Models of northern squawish total digestive tract and foregut volumes as a function of fish weight were nearly parallel, indicating that the foregut composed a consistent proportion of the total digestive tract over the entire size range. Volume of the northern squawfish digestive tract and foregut increased at a faster rate per unit of body weight than did the stomach volume of coho salmon. This indicates that northern squawfish would be capable of consuming a higher instantaneous food ration than coho salmon and may reflect differences in digestive tract morphology of the two species. Coho salmon have a true stomach--i.e. a discrete food storage structure that is delimited posteriorly by a pyloric sphincter and contains gastric glands. In contrast, northern squawfish have a modified foregut--i.e. a swelling at the anterior portion of the intestine that functions to store and digest food, but lacks gastric glands and pyloric sphincter (Weisel, 1962). The differences in observed digestive organ capacity might also be partly explained by the two different feeding histories. When tested, the northern squawfish had been actively feeding in the laboratory. In contrast, the coho salmon were presumed not to have been feeding before the tests because (based on estimates of migration rates) the population that we sampled had been in the Columbia River for 20 to 40 days before we collected our samples. It is generally believed that Pacific salmon cease feeding when they enter fresh water, and that the stomach is reduced by autolysis when they reach the spawning grounds (Lagler et al., 1977). Thus coho salmon sampled in the open ocean may have a different relation between stomach volume and fish weight. 
The distinction must be made between direct measurement of the maximum physical capacity of the digestive organ and the indirect measurement of the physiological maximum capacity. Magnuson (1969) fed starved laboratory fish known volumes of food until satiation; total food volume ingested was plotted against fish body length and a regression line fitted above the data cluster to represent maximum values. Using starved fish, however, can give erroneous results; e.g. the stomachs of fish starved for 10 days appeared shriveled and had a lower volume:fish weight ratio than that of stomachs in freshly captured (actively feeding) fish (Flowerdew \& Grove, 1979). Stomach content volume from field collections has been plotted against fish length by using logarithmic coordinates (Hellawell, 1971, 1972); a line subjectively fitted along the upper edge of the cluster of points was interpreted as the normal volume of a full stomach. Knight \& Margraf (1982) also regressed stomach contents volumes on fish length, but assumed that the fish with the largest volume of stomach contents represented maximum stomach capacity for a size group. This method requires large sample sizes per size group, is sensitive to outliers, and masks variability of individual fish stomach capacity; data should be stratified by season to account for changes in feeding habits and physiology. Indirect methods have the advantage of incorporating the physiology and behavior of fish, thus being more readily interpreted biologically; however the effects of environmental conditions must be considered. Direct measurement of digestive organ volume provides a valid measure of maximum physical size of a stomach or digestive tract and is faster and less expensive than estimates using indirect methods.

COMPARISON WITH OTHER DIRECT MEASUREMENT METHODS

The new method has several advantages over other direct methods. Our method of inflating the digestive organ under water is an objective way of maintaining constant pressure and distention, as well as facilitating the detection of leaks in the digestive organ that could go undetected if a water injection method is used (Kimball \& Helm, 1971; Jobling et al., 1977). The use of inflation pressure is more appropriate than burst pressure used by Kauriya et al. (1968); we found that mean burst pressure for coho salmon was about twice and for northern squawish about four times that of corresponding inflation pressures--indicating that the amount of distention resulting in burst pressure would not he representative of normal stomach volume. Our method can be used to measure a wide range of shapes and sizes of digestive organs; in contrast the method of Kauriya et al. (1968) is limited 
to digestive organ morphologies that can be inflated using a thin rubber sac attached to a glass tube and inserted into the stomach. The use of a rubber sac would be limited to digestive organs of a spherical shape; e.g. it would not work on northern squawfish digestive tracts. The process of dissecting the digestive organ from a freshly killed fish and placing it on ice rather than freezing it (Jobling et al., 1977) also gives a more accurate measure of maximum volume. Flowerdew \& Grove (1979) found that stomachs from deep-frozen fish showed a higher ratio of volume to fish weight and ruptured more easily than did stomachs from freshly killed fish.

Several workers have used fish length as the variable to predict digestive organ capacity (e.g. Magnuson, 1969; Kimball \& Helm, 1971; Margraf \& Knight, 1982). For most species, fish weight is more appropriate because it is essentially equal to fish volume; therefore, stomach volume is being related to fish volume. A well documented allometric relation exists between fish length and weight; thus comparison of digestive organ volume to fish weight, eliminates the confounding effects of nonlinearity relations in fish length.

One disadvantage of our method compared with other direct methods is that it is relatively time consuming and requires expensive equipment. Also, the handling of digestive organs during dissection and attachment to the apparatus, as well as inherent weaknesses in the walls of the organs, can result in ruptures in a large portion of the tracts--thus reducing the sample size. In addition the capacity for expansion of a dissected digestive tract, removed from surrounding organs, may differ from that of the intact structure in a living fish.

In summary, our method of using air inflation with water displacement worked well on two species of fish having digestive organs of different morphologies. We found that in northern squawfish, total digestive tract and foregut volume to fish weight were parallel and increased at a faster rate than did coho salmon stomach volume to fish weight. The apparatus should be scaled to an optimum size for a given fish species, considering the size of the digestive organ and accuracy of the measurement. The physical maximum digestive organ capacity differs from the biological maximum capacity, which incorporates physiological and behavioral considerations; a researcher needs to determine which is more appropriate for his specific applications. Feeding history, health of the fish, environmental regime and methods of preserving fish samples are variables that would affect volume measurements and should be considered when determining maximum digestive organ volume. Although previous methods might be more suitable in some instances, our method has three main advantages: it uses an objective measure of constant inflation pressure, enables easy detection of leaks in the digestive organ, and is useful on digestive organs having a wide range of morphologies. 
We thank Jerry F. Novotny for reviewing the manuscript, and the Little white Salmon National Fish Hatchery for the coho salmon stomach samples. This study is a Component of a project funded by the Bonneville Power Administration, Fred Holm, Project Manager (Contract DI-A17982BP34796). William R. Nelson, Gerard A. Gray, and Thomas P. Poe (U.S. Fish and Wildlife Service) administered the project. 
Bajkov, A.D. (1935). How to esti mate the daily food consumption of fish under natural conditions. Trans. Am. Fish. Soc. 65. 288-289.

Flowerdew, M.W. \& Grove, D.J. (1979). Sone observations of the effects of body weight, temperature, meal size and quality of gastric emptying time in the turbot, scophthalmus maximus (L.) using radiography. J. Fish Biol. 14, 229-238.

Hellawell, J.M. (1971). The autecology of chub, Squalis cephalus (L.) of the River Lugg and Afon Llynfi. III. Diet and feeding habits. $\quad$ Freshwater Biol. 1, 369-387

Hellawell, J.M. (1972). The growth, reproduction and food of the roach Rutilus rutilus (L.), of the River Lugg, Herefordshire. J. Fish Biol. 4, 469-486.

Hyslop, E.J. (1980). Stomach contents analysis--a review of methods and their application. J. Fish Biol. 17, 411-429.

Jobling, M., Gwyther, D. \& Grove, D. J. (1977). Sone effects of temperature, meal size and body weight on gastric evacuation time in the dab Limanda limanda (L). $\underline{\mathrm{J}}$. Fish Biol. 10, 291- 298.

Kariya, T., Shirahata, S. \& Nakamura, Y. (1968). An experiment to estimate the satiation rate of feeding in fish. Bull. Jpn. Soc. Sci. Fish. 34, 29-35.

Kimball, D.C. \& Helm, W.T. (1971). A method of estimating fish stomach capacity. Trans. Am. Fish. Soc. 100, 572-575.

Knight, R.L. \& Margraf, F.J. (1982). Estimating stomach fullness in fishes. N. Am. J. Fish. Manage. 2, 413-414.

Lagler, K.F., Bardach, J.E. Miller, R.R. \& Passino, D.R.M. (1977) . Ichthyology. 2nd Edition. New York, London \& Sydney: John Wiley \& Sons, Inc. 
Magnuson, J.J. (1969). Digestion and food consumption by skipjack tuna (Katsuwonus pelamis). Trans. Am. Fish. Soc. 98, 379-392.

Sainsbury, K.J. (1986). Estimation of food consumption from field observations of fish feeding cycles. J. Fish Biol. 29, 23- 36.

Stewart, D.J. 6, Binkowski, F.P. (1986). Dynamics of consumption and food conversion by Lake Michigan alewives: an energeticsmodeling synthesis. Trans. Am. Fish. Soc. 115, 643-661.

Stewart, D.J., Weininger, D., Rottiers, D.V. \& Edsall, T.A. (1983). An energetics model for lake trout, Salvelinus namaycush: application to the Lake Michigan population. Can. J. Fish. Aquat. Sci. 40, 681-698.

Thorpe, J.E. (1977). Daily ration of adult perch, Perca fluviatilis L. during summer in Loch Leven, Scotland. J. Fish Biol. 11, 55-68.

Weisel, G.F. (1962). Comparative study of the digestive tract of a sucker Catostomus catostomus, and a predacious minnow, Ptychocheilus oregonense. Am. Midl. Nat. 68, 334-346.

Windell, J.T. (9978). Estimating food consumption rate of fish populations. In Methods for assessment of fish production in fresh waters. 3rd Edition(T.B. Bagenal, ed.), pp. 227-254. Oxford: Blackwell Scientific Publications. 

Use of diagnostic bones to identify and estimate original lengths of ingested prey fishes.

Hal C. Hansel, Stephen D. Duke, Peter T. Lofy and Gerard A. Gray U.S. Fish and Wildlife Service

National Fishery Research Center - Columbia River Field Station Star Route, Cook, Washington 98605, USA

Published in: Transactions of the American Fisheries Society Vol. 117: 55- 62, 1988 
Abstract - We examined and measured cleithra, dentaries, opercles, and pharyngeal arches -- bones found to persist during digestion of most prey fish -to identify 24 prey fish species and back calculate their original fork length. Eighteen of the 24 species examined could be easily distinquished, however, for certain congenerics identification was neither consistent nor reliable for all bones within the size ranges examined. Relations between bone length and fish lenqth were linear for 14 species for which the sample size was adequate (N > 30); coefficients of determination ( $r 2$ ) ranqed from 0.79 to 0.99 . Diagnostic characteristics and measurements of these bones provided reliable identification of genera and species and estimates of original fork lengths of partly digested prey fish from three predators. This method, compared with that of examining only prey fish in a measureable condition, greatly increased the amount of dietary information available from gut analysis. 
Introduction

Emphasis in the analysis of fish diets has moved away from purely descriptive studies toward the integration of food consumption rates into metabolic energetics models. When one estimates consumption rates of piscivorous fishes, several factors must be determined, including predator size and the identity, number, and original size of prey fish. Information about prey consumed must often be reconstructed from fragmentary parts. Even when the digestive process is advanced, the slower digestion of bony material and the constant relation between bone length and fish size enable reliable identification and size reconstruction for most fish.

Bones have often been used by biologists to identify otherwise unidentifiable fish and to estimate fish length, and by archaeologists to reconstruct fish length and weight from remains found at archaeological sites (Casteel 1976). Bones have been used less frequently to estimate the oriqinal lengths of partly digested prey fish for feeding ecology studies (Pikhu and Pikhu 1970; Newsome 1977; Mann and Beaumont 1980). Nevertheless, vertebral columns have been used to identify fresh and saltwater fishes and estimate prey lengths graphically (Clothier 1950; Crossman and Casselman 1969; Pikhu and Pikhu 1970); pharyngeal arches have been used in distinguishing catostomid and other fishes during stomach analysis (Eastman 1977; Mann and Beaumont 1980); lenqths of the pharyngeal arch or opercle have been used to estimate prey length by use of linear reqressions (Newsome 1977; Mann and Beaumont 1980; McIntyre and Ward 1986); and pharyngeal arches, dentaries, and otoliths have been used by Eurasian biologists to estimate prey length (Popova 1967).

Our objectives are to describe the use of diagnostic characteristics of selected bones to identify prey fishes from predator stomachs and to estimate original prey size from measurements of selected bones. We describe the application of these procedures in retrieving information for the estimation of consumption and the description of the food habits of three piscivorous fishes in the Columbia River. 


\section{Methods}

More than 700 fish less than $250 \mathrm{~mm}$ long (fork length) from 24 species (Table 1) were dissected to select diagnostic bones for identification purposes, and to determine the relations between the lengths of bones and fork length. The fish were collected in John Day Reservoir on the Columbia River or were obtained from fish hatcheries during spring and summer, 1984 - 1986. Specimens were immediately placed on ice until fork length $(+1.0 \mathrm{~mm})$ could be measured in the laboratory, and then frozen for further analysis. To remove bones, we thawed the fish and put them in boiling water for 30 to $60 \mathrm{~s}$, depending on size, until the flesh could be easily removed from the intact skeleton. The bones were then preserved in $4 \%$ buffered formalin and stored in the laboratory until measured.

Identifying characteristics of cleithra, dentaries, opercles, and pharyngeal arches, were selected for examination from a subsample of 10 prey fish (or all available fish, if fewer than 10) over the size range collected. Unique characteristics of each of the bones were identified to distinguish fishes at the lowest possible taxonomic level in stomach contents of predators. Criteria for comparison included shape of each bone; length of the longest axis; pattern and lengths of processes, arms, and lobes; and number or arrangement of teeth in pharyngeal bones and dentaries.

Simple linear regression equations were calculated to estimate original fork lengths of $\mathbf{1 4}$ fishes from nine families for which the sample size of bones $(\mathrm{N}>30)$ was adequate. Fork lengths were regressed on measurements of the left bone. Bones less than $\mathbf{1 5} \mathrm{mm}$ long were measured with an ocular micrometer at $8 \mathrm{X}$ power $(+0.16 \mathrm{~mm})$, and larger bones were measured with hand calipers (+ $0.05 \mathrm{~mm}$ ) after blotting excess moisture. Cleithra were measured diagonally, from the anteroventral tip to the posterodorsal tip (Figure 1A). Dentaries of percopsids, centrarchids, and cottids were measured from the symphysis to the posterior edge of the fork that articulates with the angular bone (Figure 2A) and dentaries of clupeids from the symphysis to the posterior edge. Salmonid dentaries were measured from the symphysis to the posterodorsal notch on the dorsal limb. Opercles of cyprinids, catostomids, percopsids, and centrarchids were measured from the anterodorsal edge to the anteroventral margin (Figure 2B). Pharyngeal arches were measured from the dorsal tip to the ventral tip (Figure 2 C).

We tested slopes of regression formulas by the F-test $(\mathrm{P}>0.05)$ to determine if they were significantly different from zero. We also calculated confidence limits (95\%) and percent error (confidence limit/ calculated length) through use of the shortest and longest bones in the sample to provide a measurement of error at the extreme ends of the data. We compared the total number of fish identified and sized from bones to the number of fish identified and measured by direct observations to 
Table 1. Species, number (N), and length of potential prey fishes collected for examination from John Day Reservoir, 1983- 1986.

Family and species Common name N Fork length (mm)

Clupeidae
Alosa sapidissima
American shad
46
$39-98$

Salmonidae

\begin{tabular}{|c|c|c|c|c|}
\hline Oncorhynchus kisutch & Coho salmon & 50 & 89 & - \\
\hline Oncorhynchus nerka & Sockeye & 53 & 78 & - \\
\hline Oncorhynchus & Chinook & 53 & 42 & - \\
\hline Prosopium williamsoni & Mountain whitefish & 9 & 66 & 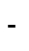 \\
\hline Salmo gairdneri & Steelhead trout & 46 & 93 & - \\
\hline
\end{tabular}

Catostomidae

Catostomus columbianus

Bridgelip sucker

52

$89-250$

Catostomus macrocheilus

Largescale sucker

58

$61-229$

Cyprinidae

Acrocheilus alutaceus

Chiselmouth

52

$98-242$

Cyprinus carpio

Common carp

3

$121-147$

Mylocheilus caurinus

Peamouth

40

$57-194$

Ptychocheilus oreqonensis Northern squawfish

50

$40-238$

Richardsonius balteatus

Redside shiner

34

$75-120$ 
Ictaluridae

\begin{tabular}{llll} 
Ictalurus nebulosus & Brown bullhead & 4 & $\mathbf{4 5}$ - $\mathbf{5 6}$ \\
\hline Ictalurus punctatus & Channel catfish & 4 & $\mathbf{1 0 9}$ - $\mathbf{1 5 1}$
\end{tabular}

Percopsidae

$\begin{array}{llll}\text { Percopsis transmontana } & \text { Sand roller } & 46 & \mathbf{3 0}-\mathbf{1 1 0}\end{array}$

Cetrarchidae

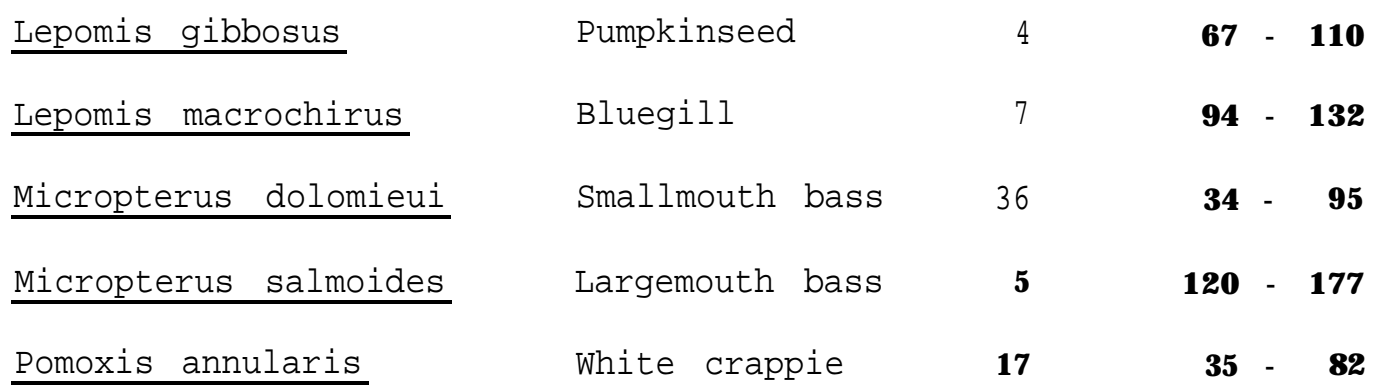

Percidae

$\underline{\text { Perca flavescens }}$

Yellow perch

15

$84-169$

Stizostedion vitreum

Walleye

13

$154-233$ vitreum

Cottidae

Cottus asper

Prickly sculpin 49

$40-137$ 
Figure 1. Lateral view of left cleithra of specimens representing nine families. A) Clupeidae, American shad; (B) Catostomidae, largescale sucker; (C) Ictaluridae, channel catfish; (D) Cottidae, prickly sculpin; (E) Cyprinidae, northern squawfish; (F) Salmonidae, chinook salmon; (G) Percopsidae, sand roller; (H) Centrarchidae, smallmouth bass; (I) Percidae, walleye. Abbreviations: $\mathrm{cl}=$ cleithrum length (measurement); $\mathrm{ss}=$ sickle-shaped process; vf = ventral fold; hl = horizontal limb; $\mathrm{vl}=$ vertical limb; $\mathbf{l s}=$ lateral shelf; $\mathbf{s p}=$ spine; $\mathrm{dpl}=$ dorsoposterior lobe. Scale bars: $2.0 \mathrm{~mm}$.

Figure 2. Representative dentary, opercle, and pharyngeal arch. (A) Left dentary of prickly sculpin; (B) Left opercle of smallmouth bass; (C) Left pharyngeal arch of northern squawfish (mesial view); (D) Left pharyngeal arch of northern squawfish (dorsolateral view). Abbreviations: $d \mathbf{l}=$ dorsal limb; $d m$ = dentary measurement; fo = foramen; sy = symphysis; $\mathrm{vl}=$ ventral limb; $\mathrm{fu}=$ fulcrum; no = notch; om = opercle measurement; pr = primary ray; $\mathbf{s r}=$ secondary ray; $\mathrm{Pl}=$ pharyngeal arch length (measurement); pt = primary teeth; st $=$ secondary teeth; $\mathrm{pw}=$ pharyngeal arch width. Scale bars: $2.0 \mathrm{~mm}$.

Figure 3. Horizontal limb of left cleithra of cyprinids. Dorsal view of horizontal limb of (A) northern squawfish; (B) redside shiner; (C) peamouth; (D) common carp. Lateral view of horizontal limb of (E) northern squawfish; (F) chiselmouth. Abbreviations; $\mathrm{ae}=$ anterior edge of lateral shelf; $\mathrm{ls}=$ lateral shelf; $\mathrm{mp}=$ medial process; at $=$ anterior tip of medial process. Scale bars: $2.0 \mathrm{~mm}$. 

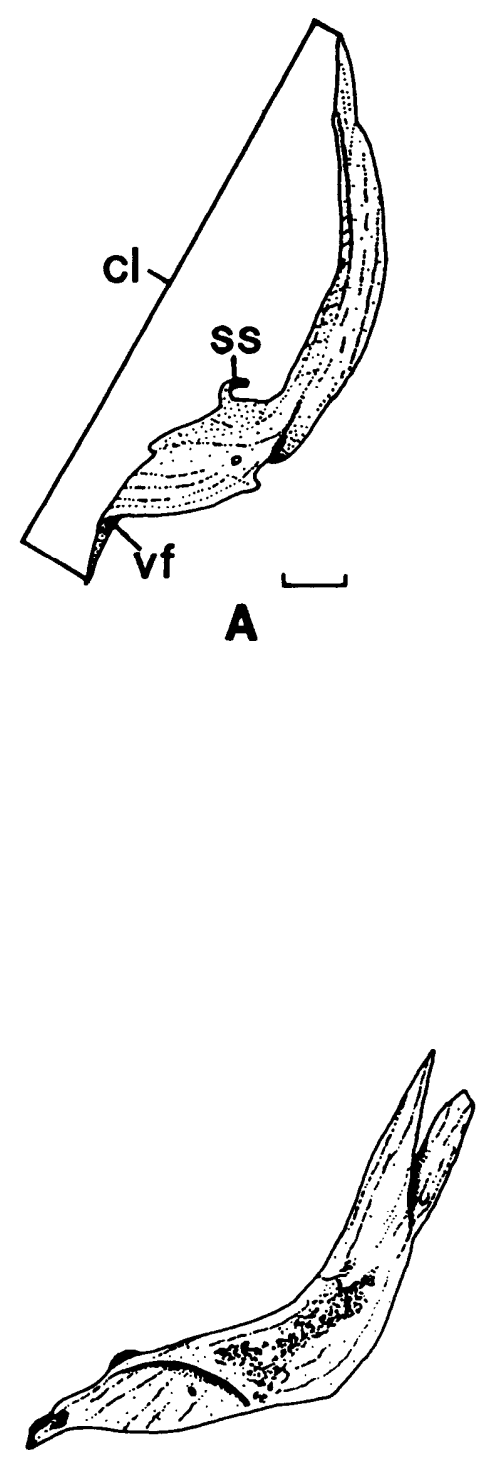

D

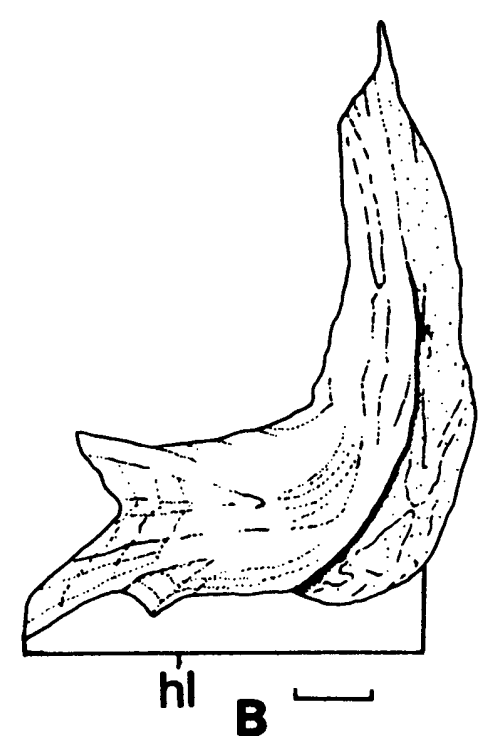

Figure 1

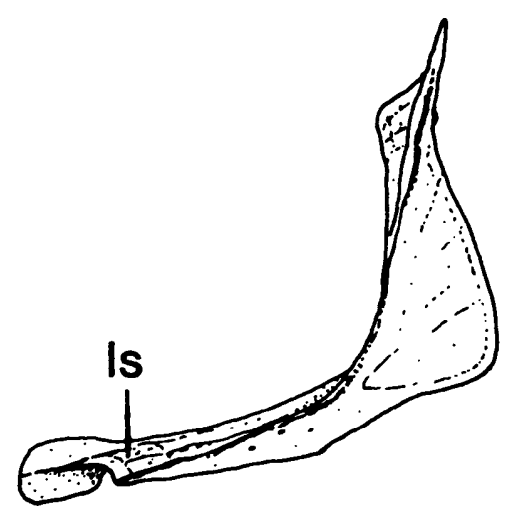

$E^{-}$
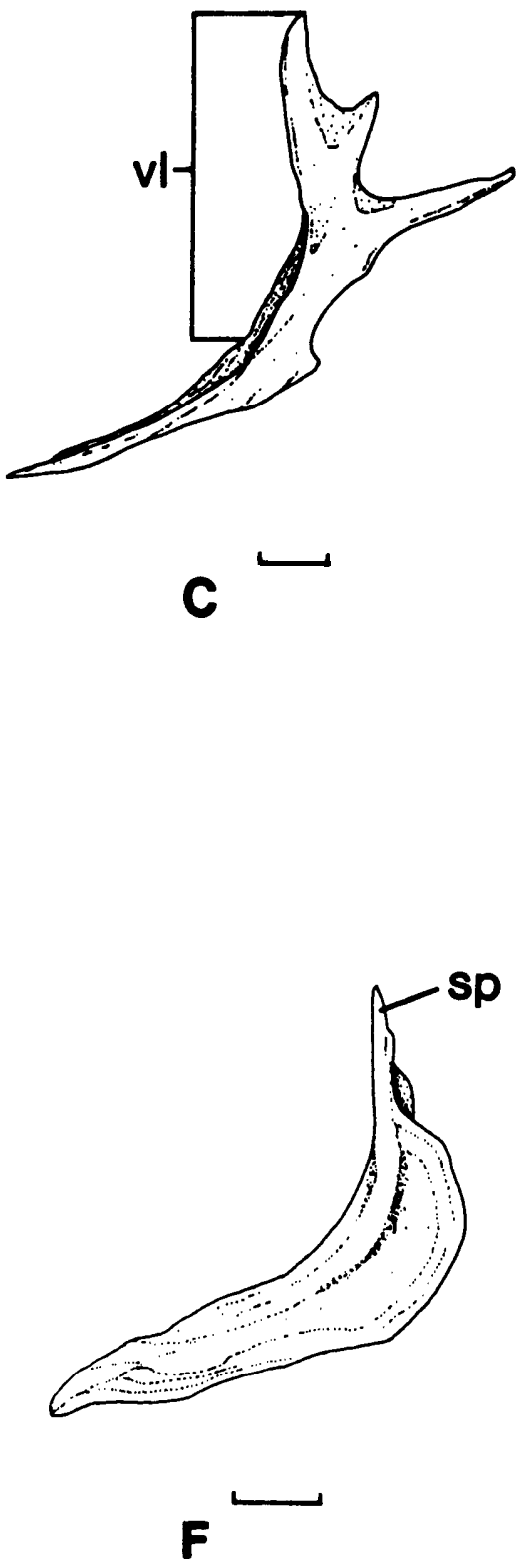

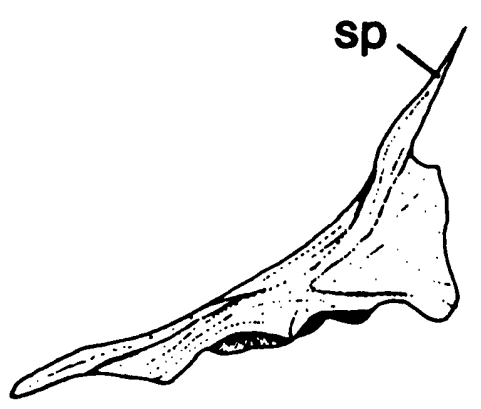

$G^{-}$
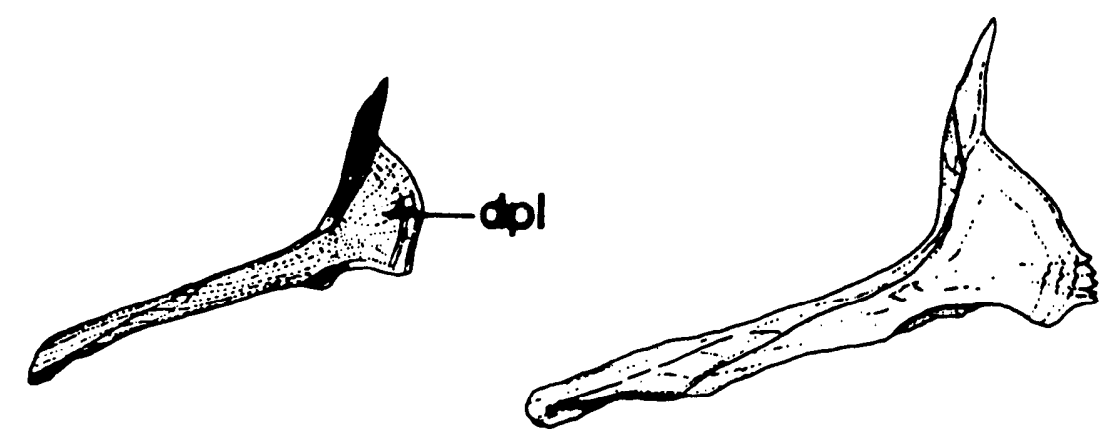

$H^{-}$ 

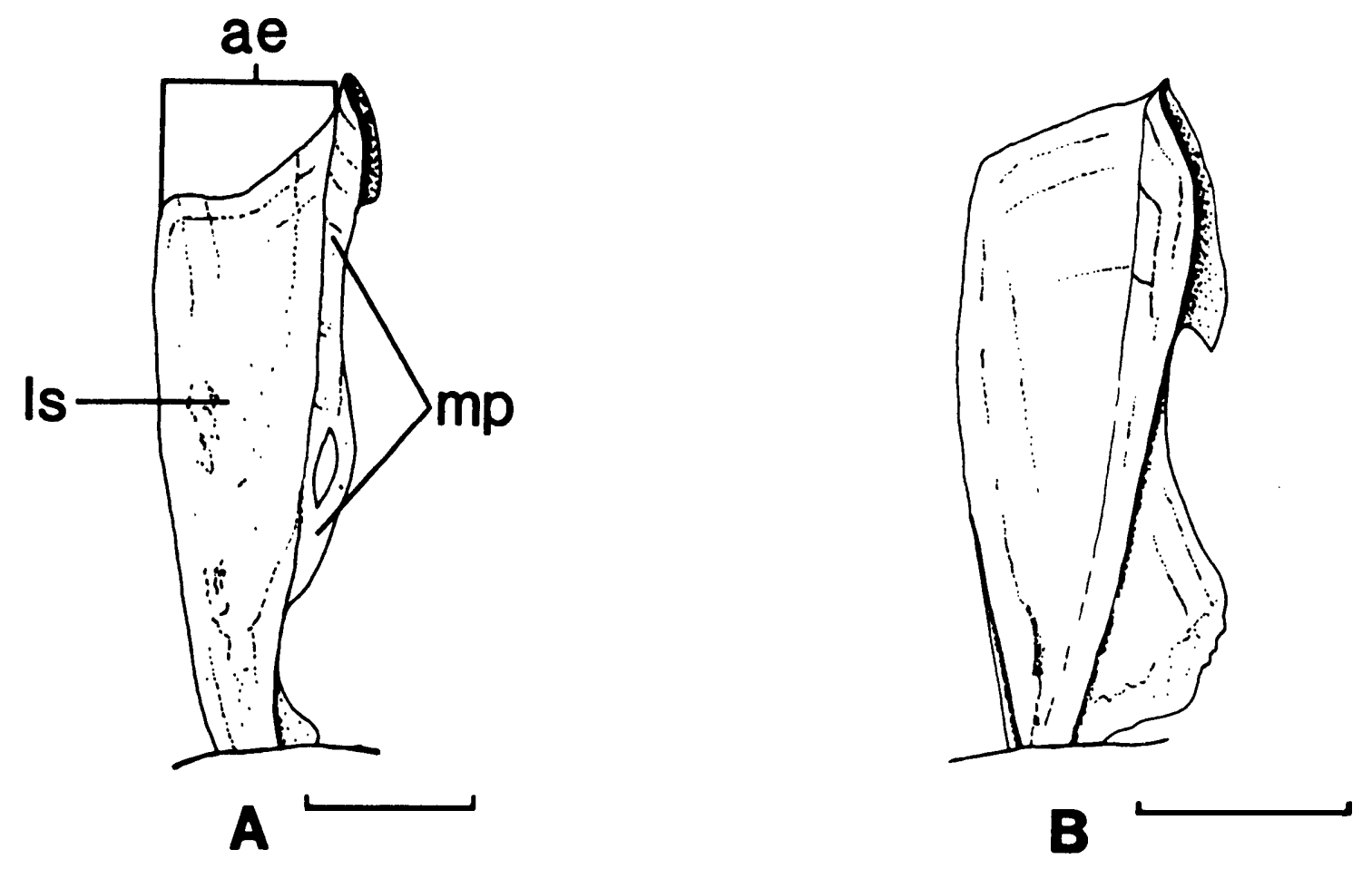

Figure 2
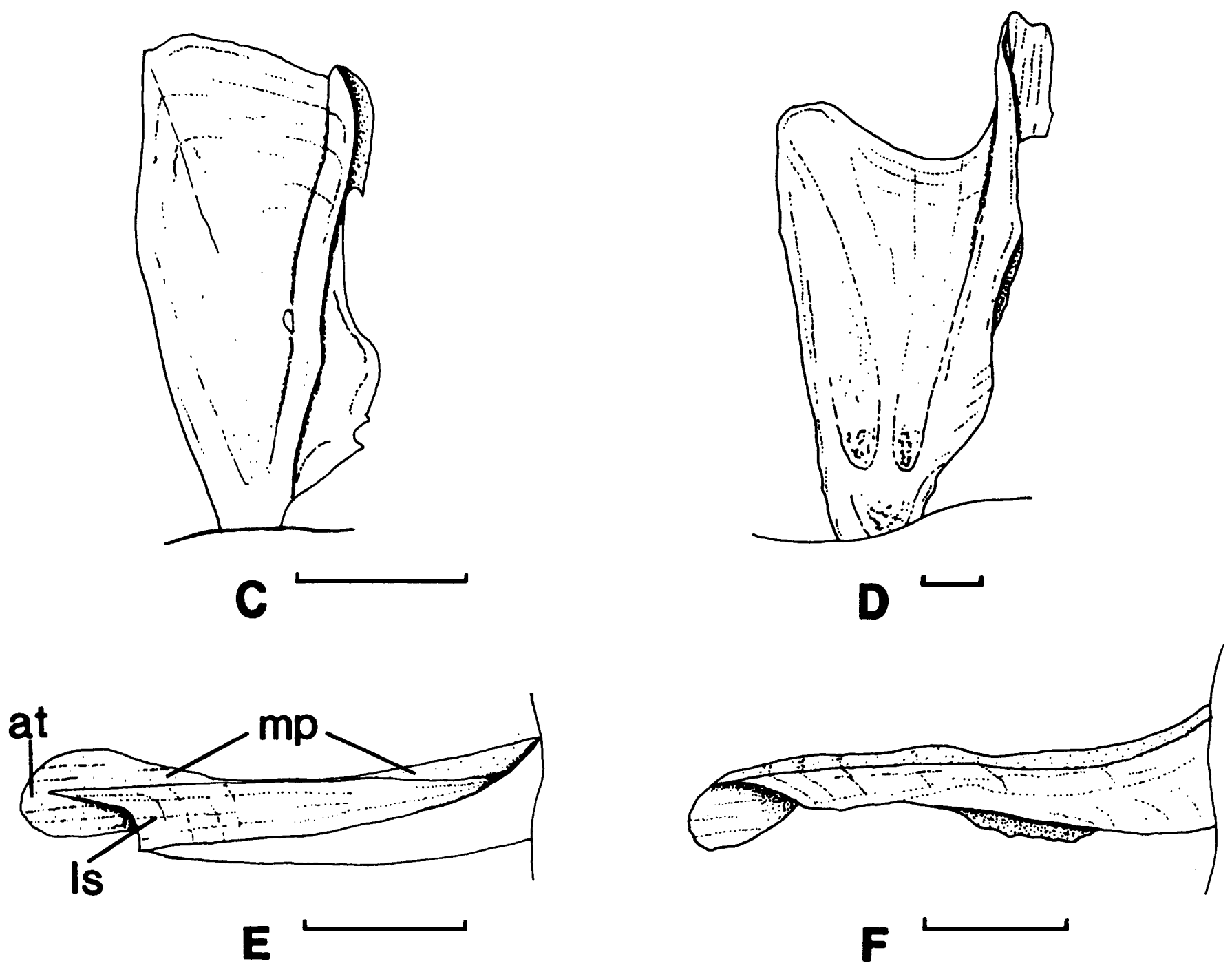

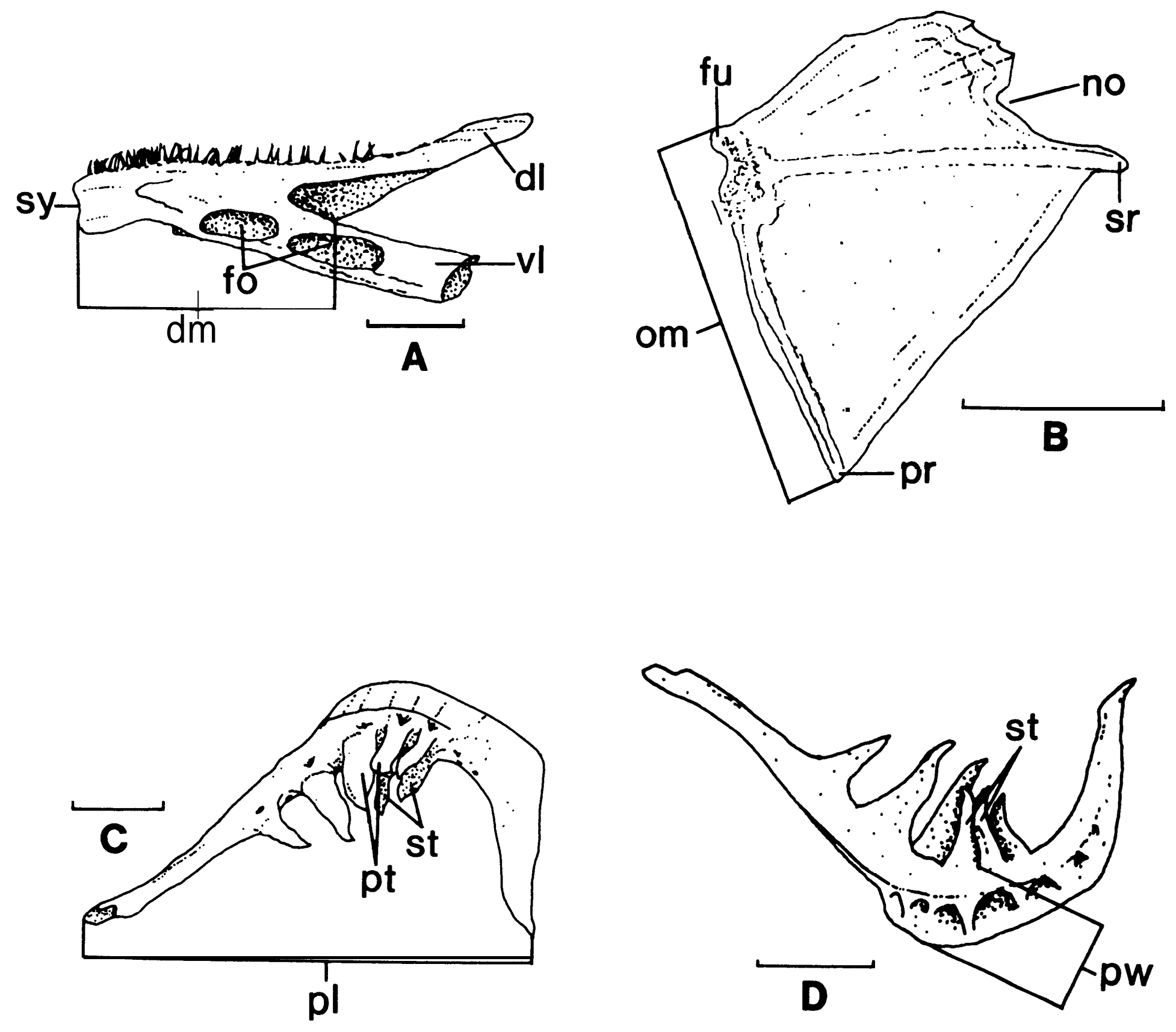

Figure 3 
demonstrate how the information base may be enhanced through analysis of hard tis sues.

Results

Identification of Prey Fish

Diagnostic characteristics of bones used to differentiate prey fish were found to be recognizable in the contents of predator stomachs. In general, resistance to digestion was greater in the larger, more robust bones used for identification, such as cleithra, opercles, dentaries and pharyngeal arches. Other bones were sometimes useful in identifying fish material (e.g., fused hypurals of the prickly sculpin and preopercles of the sand roller), but were often quickly digested, and rarely found wholly intact or in a measurable condition. Of the 24 species examined, 18 could be easily distinguished; however, for certain congenerics (Oncorhynchus; Catostomus; Lepomis; and Micropterus) identification was neither consistent nor reliable for all bones within the size ranges examined.

The cleithrum was diagnostic for all genera except those of the Salmonidae, in which steelhead could not be distinguished from the three salmon species. Other genera were separated on the basis of unique, characteristic shapes, and lengths or widths of particular features of the bone (Figure 1): in clupeids the cleithrum is fragile and has narrow limbs, a sickle-shaped process located medially, and a ventral fold (Figure $1 \mathrm{~A}$ ); in catostomids it has a horizontal limb terminating in three projections (Figure 1B); in ictalurids it has three projections on the vertical limb (Figure 1C); in cottids (prickly sculpin) it has forked vertical limbs (Figure 1D). In cyprinids, cleithra have horizontal limbs that terminate in an expanded lateral shelf (Figure 1E, 3), while in salmonids (Figure 1F) cleithra are crescent-shaped and expanded along most of both limbs. The cleithra of percopsids (sandroller), centrarchids, and percids are similarly shaped, having a narrow horizontal limb and a spine on the apex of the vertical limb (Figures 1 G,H, and I). The cleithrum of the sand roller can be distinguished from that of fish of the other families by its long spine and notched dorsoposterior lobe (Figure 1G). In centrarchids the cleithrum has a short spine and an unnotched, dorsoposterior lobe (Figure 1H), in percids it is notched along the dorsoposterior lobe (Figure 11).

Genera within a family can also be distinguished on the basis of the cleithra. The cyprinids are an example of how genera can be differentiated. Cleithra of the cyprinid species are distinguished on the basis of the shape and angle of the lateral shelf of the horizontal limb (Figure 3). For example, the lateral shelf (horizontal plane or dorsal view) is slightly convex with slightly rounded corners in the redside shiner (Figure $3 \mathrm{~B}$ ); it is essentially straight, with the anterior 
edge angling posteriorly in the peamouth (Figure 3C); and it is deeply emarginate in the common carp (Figure 3D). Cleithra of chiselmouth and northern squawfish are somewhat oblique at the anterior edge. The lateral shelf attaches at the middle of and is descendent to the medial process in northern squawfish, whereas it attaches near the top margin of the medial process in chiselmouth (Figures 3E, 3F).

Dentaries were diagnostic for all genera. They were rarely used for identification of cyprinids however, because the pharyngeal arches and cleithra were much more resistant to digestion and therefore recovered more frequently from stomachs. Dentaries were useful in distinguishing the three salmon species from steelhead; the dentary was wider and its ventral limb was relatively longer in the steelhead; than in the salmons. Other diagnostic characters of dentaries were the general shape, presence, and distribution of teeth (e.g., single row of canine teeth in steelhead versus a cardiform pad in species of Ictalurus); width of the symphysis; size and distribution of foramina; number of pores (in cyprinids); and the relative length of the dorsal and ventral limbs (Figure 2A).

Opercles, though diagnostic for all families and most genera, were less resistant than other bones to digestion. These bones differed among genera in general shape and surface of margins (smooth versus serrated), in the position of the primary and secondary rays (especially in centrarchids), and in the morphology of the fulcrum, spines, and notches (Figure 2B). The opercles of cyprinids could be distinguished from those of other families but were too similar to one another to permit differentiation of genera,

Pharyngeal arches with long, comb-like sets of teeth were diagnostic for the two species of Catostomus. Cyprinids were distinguished on the basis of the general shape of the arch and its relative width (Unyeno 1961), and on tooth formulae for the primary and secondary (and in canp, tertiary) rows of teeth (Figures 2C, 2D).

Estimates of Original Length of Prey Fish

Relations of bone length to fork length were linear and all had positive slopes that differed significantly from zero (F-test, $\mathrm{P}<0.01$ ). Regression models allowed estimates of fork lengths within $\pm 4 \mathrm{~mm}$ from bones retrieved from stomachs (Tables 2,3). From regression equations in which we used measurements of cleithra, dentaries, opercles, and pharyngeal arches of 14 species, we estimated mean fork length at the 95\% confidence level with percent errors less than 9, 10, 6, and 5\%, respectively, at the lower end of the length ranges, and less than $2 \%$ at the upper end of the length ranges. Coefficients of determination $\left(\underline{r}^{2}\right)$ ranged from 0.79 to 0.99 ; for $75 \%$ of the regression equations, 
Table 2. Regression statistics ( $\mathrm{Y}=\mathrm{a}+\mathrm{bX}$ ) relating measurements (in $\mathrm{mm}$ ) of the cleithrum, dentary, or opercle (X) and fork length (Y) for 8 to 14 prey fish species from John Day Reservoir. Ranges of estimated fork length are also shown.

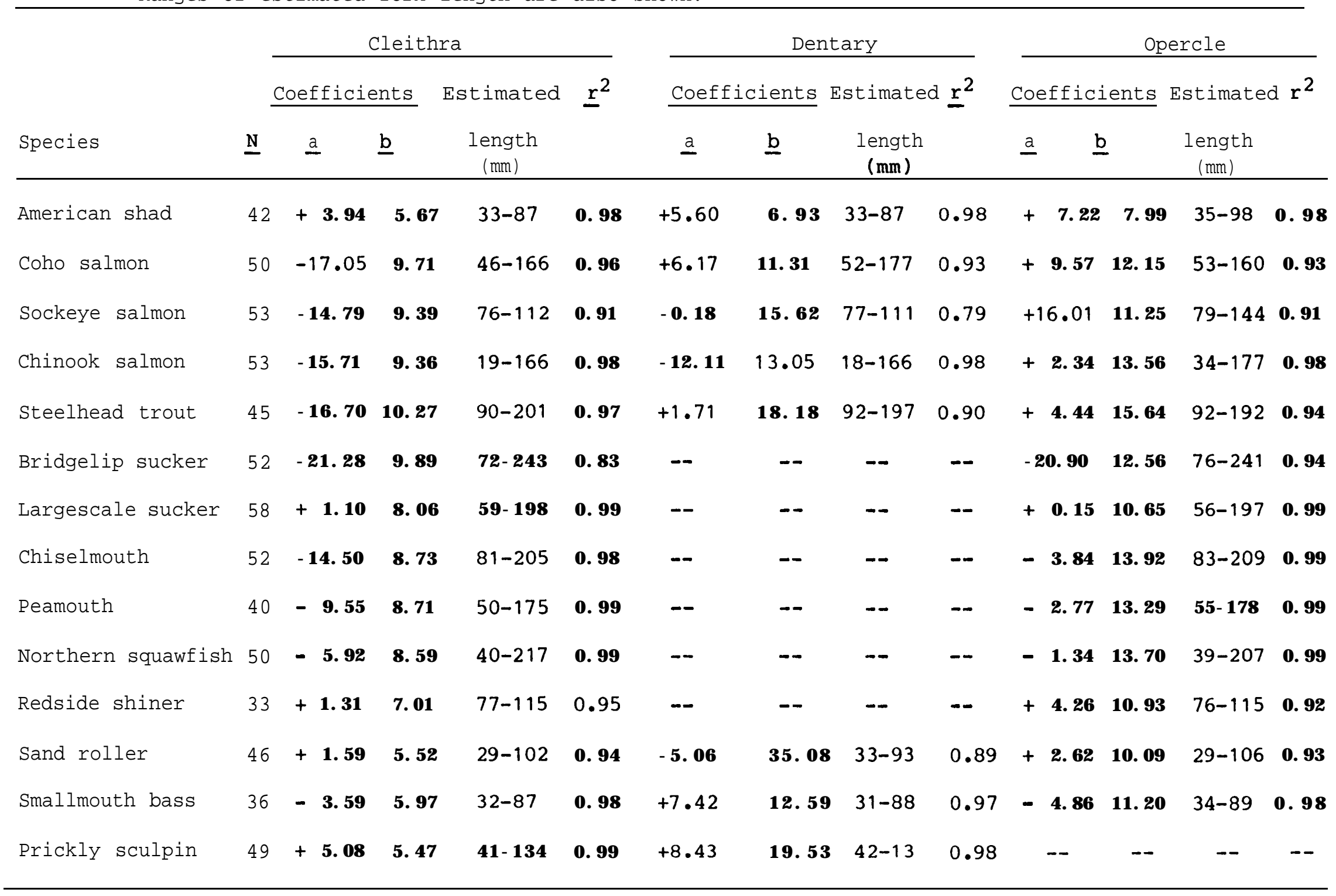


Table 3. Regression statistics $(\mathbf{Y}=\mathbf{a}+\mathbf{b X})$ relating measurements (mm) of pharyngeal arch (X) and Fork length ( $Y$ ) for two species of Catostomidae and four species of Cyprinidae from John Day Reservoir. Ranges of estimated fork lengths are also shown.

\begin{tabular}{|c|c|c|c|c|}
\hline & & Coefficients & Estimated & $\underline{x}^{2}$ \\
\hline Taxon & $\underline{N}$ & $\underline{a} \quad \underline{b}$ & $\begin{array}{l}\text { length } \\
(\mathrm{mm})\end{array}$ & \\
\hline
\end{tabular}

Catostomidae

$\begin{array}{llllll}\text { Bridgelip sucker } & 52 & \mathbf{- 2 5 . 6 1} & \mathbf{1 7 . 7 3} & \mathbf{8 1 - 2 4 2} & \mathbf{0 . 8 6} \\ \text { Largescale sucker } & 58 & -7.95 & \mathbf{1 4 . 9 8} & \mathbf{5 5 - 1 9 9} & \mathbf{0 . 9 9}\end{array}$

Cyprinidae

\begin{tabular}{|c|c|c|c|c|c|}
\hline Chiselmouth & 52 & -10.50 & 16. 95 & $84-211$ & 0.97 \\
\hline Peamouht & 40 & - 1.84 & 14. 70 & $51-180$ & 0.98 \\
\hline N. squawfish & 49 & -1.05 & 13. 24 & $38-209$ & 0.99 \\
\hline Redside shiner & 33 & - 1. 37 & 14. 33 & $77-117$ & 0.86 \\
\hline
\end{tabular}


coefficients were greater than or equal to 0.97 .

Since we could not always distinguish between congeneric species by use of these bones, we used information on the relative abundance and geographic distribution of each species to aid in consumption estimates. For example, because large scale suckers contributed $92 \%$ of total suckers collected in the reservoir (Gray et al. 1985), we used the regressions developed for this species to estimate the original length of Catostomus spp. This procedure was followed for the other species within a genera such as Micropterus, Oncorhynchus, and Lepomis.

Estimates of prey fish consumption by three fish piscivores in John Day Reservoir on the Columbia River from 1983 to 1986 (Poe et al. 1986) entailed the collection and analysis of stomach contents of more than 11, 000 fish (Table 4). The procedures for back calculation of original prey lengths from bones found in stomach samples resulted in a larger volume of information on consumption estimates, depending upon the predator species. Percentages of prey fish identifiable from only bone fragments ranged from about $\mathbf{3 8 \%}$ for walleyes to $92 \%$ for northern squawfish, and averaged 72\% for the three predators (Table 4).

\section{Discussion}

Unique characteristics of the four diagnostic bones selected for comparison and measurement facilitated identification of prey fish species collected during our study. After some familiarization with the bones, we found that even bone fragments could be used to identify prey fish during stomach analysis, although back calculation of original lengths was not possible. Unfortunately, however, it was difficult to differentiate between certain congeneric species. Comparison of bones from smaller specimens with those from larger fish did not indicate appreciable difference in bone shape or form.

Cleithra and dentaries were more persistent in the stomach contents of predators and served as the best means of identifying prey fishes. The cleithrum, because it is relatively large and is one of the first diagnostic bones to develop, was generally the most useful bone for identifying young-of-year fishes. We were able to identify small catostomids ( $<20 \mathrm{~mm}$ long) from the unique shape of the cleithrum. We found that the maintenance of a reference collection of bones of various sizes was useful, especially for identifying bone fragments.

The unique characteristics of pharyngeal arches have been well documented (Scott and Crossman 1973) and have been used for identification of cyprinid fishes whose opercles are easily digested and are therefore difficult to distinguish. Newsome (1977) encountered a similar problem in distinguishing each of the seven cyprinid prey fish he studied therefore, he used only the pharyngeal arches for identification. 
Table 4. Number and percentage (8) of prey fish whose body lengths were estimated or actually measured during stomach analysis of three predator species collected in John Day Reservoir. The lengths of ingested prey fish were estimated by use of either diagnostic bone measurements or actual body length measurements (data for 1983-1986).

\begin{tabular}{|c|c|c|c|c|}
\hline & & Total & Prey body & length \\
\hline Predator & $\begin{array}{l}\text { predator } \\
\text { stomachs }\end{array}$ & prey fish & Estimated & Actual \\
\hline Northern squawfish & 5467 & 2696 & $2480(92)$ & $216(8)$ \\
\hline Smallmouth bass & 4940 & 2894 & $1887(65)$ & $1007(35)$ \\
\hline Walleye & 1206 & 1095 & $419(38)$ & $676(62)$ \\
\hline Total $N$ or $\left(\frac{0}{0}\right)$ & 11613 & 6685 & $4786(72)$ & $1899(28)$ \\
\hline
\end{tabular}


Although the ability to estimate lengths of ingested fish on the basis of the dimensions of diagnostic bones varied among predator species, in our study the amount of information available from stomach analysis increased by $\mathbf{5 0 \%}$ to $1100 \%$, thus reducing the number of predators required in a sample to obtain a given number of prey items. The differences in the percentage of prey fishes identified from bones retrieved from different predators may have been due to differences in several factors, such as digestibility of fish versus non-fish items, the proportion of prey fishes ingested (e.g. adult walleyes are almost exclusively piscivorous in John Day Reservoir), digestion rates, or various combinations of these factors.

The linear relations of bone lengths to original body lengths observed in our study differed from those reported by Newsome (1977); the latter were curvilinear between opercle and body lengths for $\mathbf{1 0}$ prey fish species. However, our linear relations were consistent with those of Mann and Beaumont (1980) and McIntyre and Ward (1986), who estimated body lengths by use of pharyngeal arches. McIntyre and Ward (1986) found that length estimates of fathead minnow Pimephales promelas based on pharyngeal arches were more accurate than estimates of lengths of 10 prey fish species based on opercles, as judged by values of coefficients of determination (Newsome 1977). In general, we obtained slightly more accurate estimates of fish length from measurements of the cleithrum and opercle than from measurements of pharyngeal arches or dentaries.

We found no instances in the literature of cleithra and dentaries being used to estimate the lengths of prey fishes found in the stomachs of piscivores. Scott (1977), however, used cleithra to estimate the length of Atlantic cod Gadus morhua found among remains recovered from a shipwreck and White $(19 \overline{36,}$ 1953) estimated lengths of fish by comparing measurements of maxillary, dentary, and parasphenoid bones found in regurgitated gizzard pellets of the belted kingfisher Ceryle alcyon with bones from specimens of known length.

Several limitations should be considered when using diagnostic bones to estimate original lengths of ingested prey fish. The length regression equations developed in this study were from measurements on bones subjected to the effects of preservative. We therefore recommend that, prior to use of these regression statistics, future investigators follow similar preservation procedures to avoid bias resulting from the potential effects of preservatives on fish bones. One should also be aware that use of diagnostic bones may bias food habits data by favoring larger over smaller prey fish because their bones may be more resistant to digestion.

Our results suggest that the identification and measurement of cleithra, dentaries, opercles, and pharyngeal arches of prey species provide an easy and reasonably accurate method of estimating original length of prey fish in partly digested remains. These methods may enable investigators to gain useful information that might otherwise be lost when prey fish length cannot be obtained by direct measurement. 
Acknowledgments

We gratefully acknowledge Craig C. Burley for preparing the bone illustrations. Jerry Novotny, Thomas Poe, and William Nelson reviewed the manuscript and made valuable suggestions. This work was supported by the Bonneville Power Administration, U.S.

Department of Energy (Contract DI-AI79-82BP34796) and we thank Fred Holm, the Contract officer, for his assistance. 
References

Casteel, R. W. 1976. Fish remains in archaeology and paleoenvironmental studies. Academic Press, New York.

Clothier, C.R. 1950. A key to some southern California fishes based on vertebral characters. State of California, Department of Natural Resources, Division of Fish and Game, Bureau of Marine Fisheries. Fish Bulletin No. 79.

Crossman, R.J., and J.M. Casselman. 1969. Identification of northern pike and muskellunge from axial skeletons, scales, and epipleurals. Journal of the Fisheries Research Board of Canada 26: 175-178.

Eastman, J.T. 1977. The pharyngeal bones and teeth of catostomid fishes. American Midland Naturalist 97: 68-88.

Gray, G.A., D.E. Palmer, B.L. Hilton, P.J. Connolly, H.C. Hansel, and J.M. Beyer. 1985. Feeding activity, rate of consumption, daily ration, and prey selection of major predators in John Day Reservoir. Section I: Food consumption and prey abundance, 1984. Annual Report to Bonneville Power Administration by the U.S. Fish and Wildlife Service; Portland, Oregon.

Mann, R.H.K., and W.R.C. Beaumont. 1980. The collection, identification and reconstruction of lengths of fish prey from their remains in pike stomachs. Fisheries Management 11: 169-172.

McIntyre, D.B. and F.J. Ward. 1986. Estimating fork lengths of fathead minnows, Pimephales promelas, from measurement of pharyngeal arches. Canadian Journal of Fisheries and Aquatic Sciences 43: 1294-1297.

Newsome, G.E. 1977. Use of opercular bones to identify and estimate lengths of prey consumed by piscivores. Canadian Journal of Zoology 55: $\quad$ 733- 736.

Poe, T.P., and nine co-authors, 1986. Feeding activity, rate of consumption, daily ration, and prey selection of major predators in John Day Reservoir, 1986. Annual Report to Bonneville Power Administration by the U.S. Fish and Wildlife Service; Portland, Oregon.

Pikhu, E.K.H., and E.R. Pikhu. 1970. Reconstruction of the sizes of fishes swallowed by predators from fragments of their vertebral column. Journal of Ichthyology (USSR) 10: 706-709.

Popova, O.A. 1967. The "predator-prey" relationships among fish. Pages 359-373 in Shelby D. Gerking, editor. The biological basis of freshwater fish production. John Wiley and Sons, New York. 
Scott, J.S. 1977. Back-calculated fish lengths and Hg and $\mathrm{Zn}$ levels from recent and $\mathbf{1 0 0} \mathrm{yr}$-old cleithrum bones from Atlantic cod (Gadus morhua). Journal of the Fisheries Research-Board of Canada 34:147-150.

Scott, W.B., and E.J. Crossman. 1973. Freshwater fishes of Canada. Bulletin 184, Fisheries Research Board of Canada, Ottawa.

Uyeno, T. 1961. Late Cenozoic cyprinid fishes from Idaho with notes on other fossil minnows in North America. Papers of the Michigan Academy of Sciences, Arts and Letters 46: 329-344.

White, H.C. 1936. Food of kingfishers and mergansers on the Margaree river, Nova Scotia. Journal of the Biological Board of Canada $2: 299-309$.

White, H.C. 1953. The eastern belted kingfisher in the Maritime Provinces, Bulletin 97, Fisheries Research Board of Board of Canada, Ottawa. 
Variation in Capture Efficiency of a Beach Seine for Snal Fishes

Michael J. Parsley,

Douglas E. Palmer, and

Randy Burkhardt

\author{
U.S. Fish and Wildlife Service \\ National Fishery Research Center \\ Columbia River Field Station \\ Cook, Washington 98605, USA
}

Submitted to: North American Journal of Fisheries Management, 1988. 
Abstract

We tested the capture efficiency of a beach seine in an enclosed area with the objective of improving our estimates of abundance of small fishes of different taxa in littoral areas. Capture efficiency for 14 taxa representing nine families was determined by seining within an enclosure at night over fine and coarse substrates. Mean efficiency ranged from $\mathbf{1 2}$ percent for prickly sculpin (Cottus asper) captured over coarse substrates to 96 percent for peamouths (Mylocheilus caurinus) captured over fine substrates. Mean seine capture efficiency for a taxon was generally higher over fine substrates than over coarse substrates, although mean capture efficiencies over fine substrates were significantly greater for only three of ten taxa. Capture efficiency generally was not influenced by the number of fish available to the seine or by water temperature. Seine catches adjusted to account for capture efficiency showed that conclusions drawn from the apparent abundance in the catch and those drawn from catches adjusted to account for capture efficiency differed because taxa with low capture efficiencies became more important in the adjusted catch. 
Introduction

Beach seines are commonly used to assess the relative abundance of small fishes in littoral habitats, and periodic catches from the same location should provide useful information on population trends for a species. Because of differences in vulnerability to capture, however, conclusions regarding the abundance of each species captured in a seine haul cannot be drawn unless the capture efficiency (CE) of the seine used is known for each species captured. Capture efficiency has been defined as the number of fish captured divided by the number of fish actually present in the area sampled (Lyons 1986). If CE is known, the number of fish captured can be adjusted to improve the estimate of the number of fish actually present in the area sampled.

Seine CE is known to differ widely among fish species (Moav and Wolfarth 1970; Richkus 1980; Lyons 1986) and may differ within species for fish captured by different seining techniques or under different environmental conditions such as temperature, water clarity, and substrate type (Lyons 1986; Hunter and Wisby 1964). Differences in $\mathrm{CE}$ are caused by variations in the behavioral responses of fish, seining techniques, or physical conditions. In the few investigations of seine $\mathrm{CE}$, variation related to differences in substrate has not been examined.

As part of a study to estimate the number of juvenile salmonids and other prey consumed by piscivorous predators in John Day Reservoir on the Columbia River, we wished to accurately estimate the abundance of prey-sized fish in littoral areas (Gray et al. 1985). We here describe how different substrates, number of fish available to the seine, and water temperatures influence seine $\mathbf{C E}$ and demonstrate how a knowledge of $\mathbf{C E}$ can be used to increase the accuracy of estimates of the abundance of fish present at the time of the sampling. 
Methods

The CE of a beach seine was tested at four sites in the littoral zone in John Day Reservoir, a 20,235 - hectare impoundment on the Columbia River. The reservoir was created in $\mathbf{1 9 6 8}$ when the United States Army Corps of Engineers completed construction of John Day Dam for hydroelectric power generation. The experiments, conducted from April to August in $\mathbf{1 9 8 5}$ and 1986, consisted of $\mathbf{1 7}$ tests conducted over fine substrates and $\mathbf{1 5}$ over coarse substrates at water temperatures of $8^{\circ}$ to $26^{\circ} \mathrm{C}$. The fine substrates were composed of sand (particle size $\leq 2 \mathrm{~mm}$ ) and the coarse substrates were dominated by cobble (particle size 64-250 mm), combined with smaller amounts of gravel (particle size 2-64 mm) and sand.

Capture efficiency of the beach seine used (a bag seine $30.5 \mathrm{~m}$ $\times 2.4 \mathrm{~m}$ made of $6.4 \mathrm{~mm}$ knotless nylon mesh) was determined by quadrant seining at night within a square enclosure formed by using a block net $(92.5 \mathrm{~m} \times 3.1 \mathrm{~m}$ of $6.4-\mathrm{mm}$ knotless nylon mesh) for three sides and the shore for one side. The number of floats and leads per unit of length in the block net was double that in the seine; floats and leads were spaced $305 \mathbf{~ m m}$ apart on the block net and $\mathbf{6 1 0} \mathrm{mm}$ apart on the seine. The enclosure was constructed during a period of about $20 \mathrm{~min}$ at sunset, and seining began 10-30 min after the enclosure was completed. Maximum depth within the enclosure never exceeded $2.4 \mathrm{~m}$. The seine was deployed perpendicular to the shore, along one side of the enclosure. An extension rope was then used to haul the outside end to shore. After 4 to $\mathbf{1 0}$ hauls were completed from alternate sides of the enclosure, we hauled the block net into shore as a seine to remove the remaining fish. Fish $\leq 250 \mathrm{~mm}$ fork length (FL) were identified to the lowest taxon possible; larger fish were discarded and fish < $30 \mathbf{~ m m F L}$ were not counted, because we believed that sone of them could pass through the meshes of the seine and block net.

Seine capture efficiency (CE) for each taxon captured was calculated by the equation:

$$
\mathrm{CE}=\frac{\underline{\mathrm{C}}}{\underline{\mathrm{T}} \times 0.64}
$$

where $\mathrm{C}$ is the catch of fish of a given taxon in the first haul; $\mathrm{T}$ is the total number of fish of that taxon removed from the enclosure; and 0.64 is the ratio of the average area sampled by the seine on the first haul to the area enclosed by the block net. Polar planimetry was used to determine the average area sampled within the enclosure in a single seine haul. The quantity $\underline{T} \times 0.64$, which estimates the 
number of fish available to the seine on the first haul, was rounded to the nearest integer. We assumed uniform distribution of fish within the enclosure and did not calculate CE when $\mathbf{T}$ was <3. When we caught more fish in the first haul than were estimated to be available to the seine -- indicating a violation of our assumption of uniform distribution and resulting in an estimate of $\mathrm{CE}>1.0$, CE was said to equal one.

Data collected in 1985 and 1986 were pooled for comparisons among taxa and between substrate types. We required at least three estimates of CE to yield a useful mean for each taxon for each substrate. All estimates were normalized by an arcsine transformation ( $\operatorname{Zar} 1984$ ). The statistical software package SPSS/PC ${ }^{+}$ (SPSS Inc., 1983) was used for all analyses. A t-test was used to test the hypothesis that $C E$ for a given taxon was equal ( $P>=0.05$ ) over the fine and coarse substrates. If this hypothesis was not rejected at the stated level of significance, a weighted mean CE was determined by combining the data from both substrate types (Zar 1984).

Differences in seine CE among taxa for each substrate type were assessed by one-way analysis of variance (ANOVA) and Newman-Keuls multiple range tests. We used regression analysis to determine if the number of fish available to the seine or water temperature caused changes in $\mathrm{CE}$.

To demonstrate the effect of $\mathrm{CE}$ on catch composition of a beach seine, we adjusted the catches in beach seine hauls that had been conducted in other work. These extra seine hauls were made at night with a seine identical to that used for the CE experiments. The catch of each taxon was divided by the appropriate mean CE estimate and rounded to the nearest integer. This provided an estimate of actual abundance for that taxon, which could be compared to estimates of actual abundance for other taxa captured. 
Results

Mean $C E$ estimates obtained for 14 taxa representing nine families ranged from $12 \%$ for the prickly sculpin (Cottus asper) captured over coarse substrates to $96 \%$ for the peamouths (Mylocheilus caurinus) over fine substrates (Table 1). Generally, mean seine CE for a taxon was higher over fine substrates than over coarse substrates; it was significantly greater ( $t$-test, $\underline{\mathrm{P}}<0.05$ ) over fine substrates than over coarse substrates for chinook salmon (Oncorhynchus tshawytscha), suckers (Catostomus spp.) and prickly sculpin. Mean CE for crappies (Pomoxis spp.), however, was significantly greater over coarse substrates than over fine substrates (Table 1).

Mean CE did not differ significantly between substrates for chiselmouth (Acrocheilus alutaceus), northern squawfish (Ptychocheilus oregonensis), sand roller (Percopsis transmontarä), sunfishes (Lepomis spp.), sinal lmouth bass (Micropterus dolomieui), or yellow perch (Perca flavescens). We therefore calculated a weighted mean $C E$ for these taxa. Mean CE's for coarse substrates were not determined for four species -- American shad (Alosa sapidissima), peamouth, brown bullhead (Ictalurus nebulosus), and largemouth bass (Micropterus salmoides) because fewer than three estimates were obtained for these species over this substrate.

The results of our experiments indicated that mean $\mathrm{CE}$ differed significantly among taxa within each substrate type (ANOVA, $\mathrm{P}<0.05$ ); however, Newman-Keuls tests to determine where the differences occurred showed overlapping sets of similarities for all taxa over both substrate types.

Generally, the CE for a taxon was not influenced by the total number of $f i s h$ of that taxon available to the seine or by water temperature. However, we found a significant relation between the number of brown bullheads available to the seine and $C E(r=0.912, P<$ 0.05 ) over fine substrates, and a highly significant though weak relation between water temperature and $C E$ for suckers captured over fine substrates $(r=0.681, \underline{P}<0.01)$.

To deinonstrate the effect of $C E$ on estimated abundance we adjusted seine catches of fish collected from a backwater area of John Day Reservoir (Table 2) in $\mathbf{1 2}$ seine hauls ( 2 hauls over a fine substrate

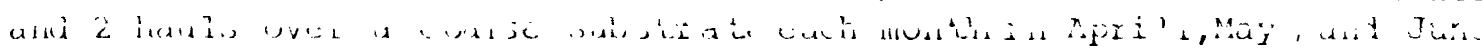
1985). The catch of edch taxon in each haul was divided by the upropriate CE estimate to provide an adj usted es timate of abunda nce for that taxon. Cat hes of tish from taxa with significant ly difterent

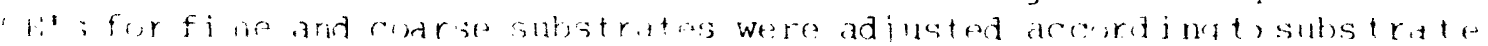


Table 1. Mean seine capture efficiency ( $\overline{C E})$, $95 \%$ confidence intervals (in parentheses), and number of estimates (N) for prey taxa captured over fine and coarse substrates in John Day Reservoir, 1985 and 1986. The results are back-transformed from arcsine normalized data. Asterisks denote significant differences $(P<0.05)$ in seine $C E$ between the smooth and coarse substrates. Dashes indicate that insufficient data were collected to obtain a mean.

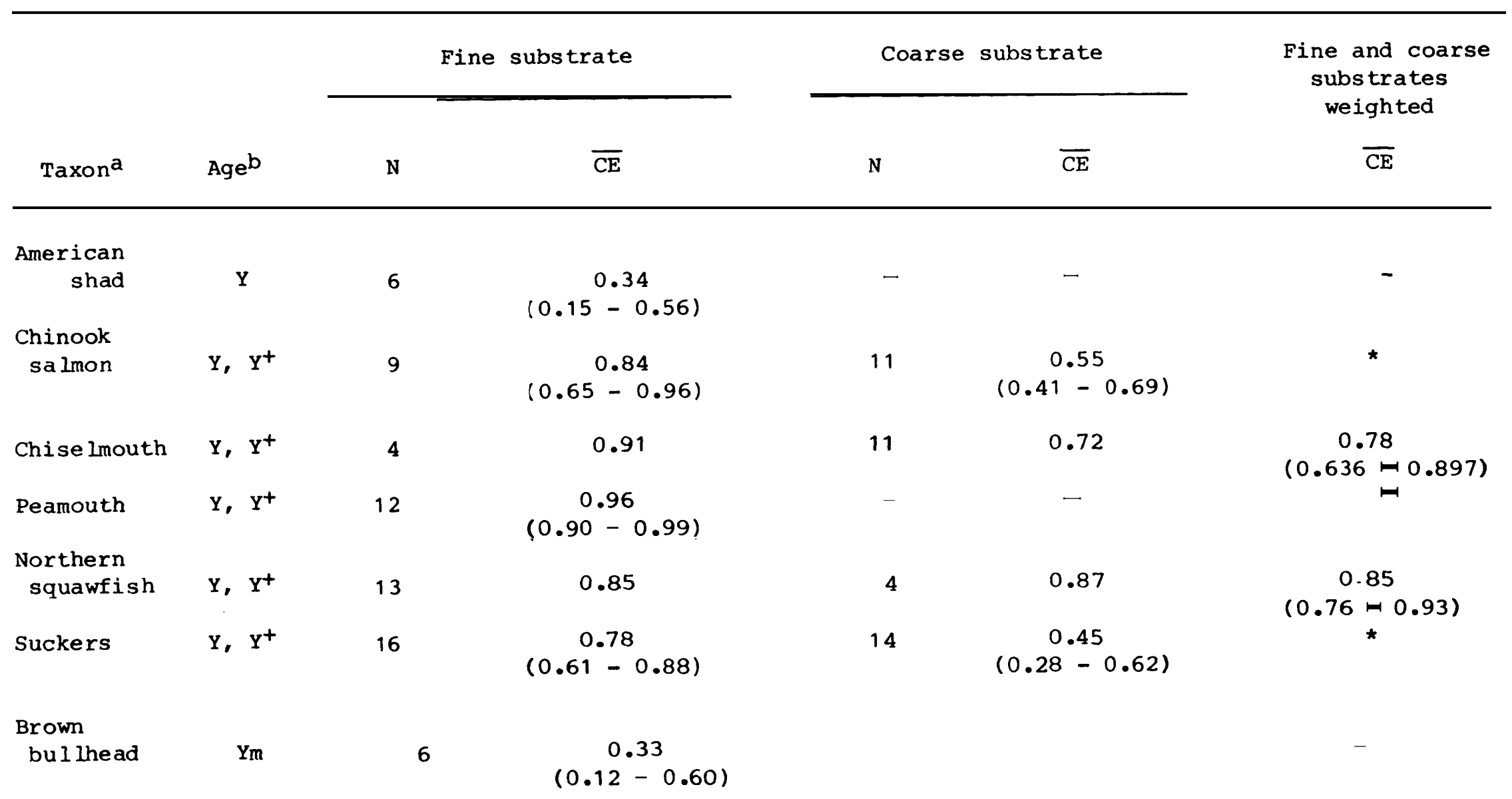


Table 1. $(\operatorname{con} ' t)$.

Fine substrate

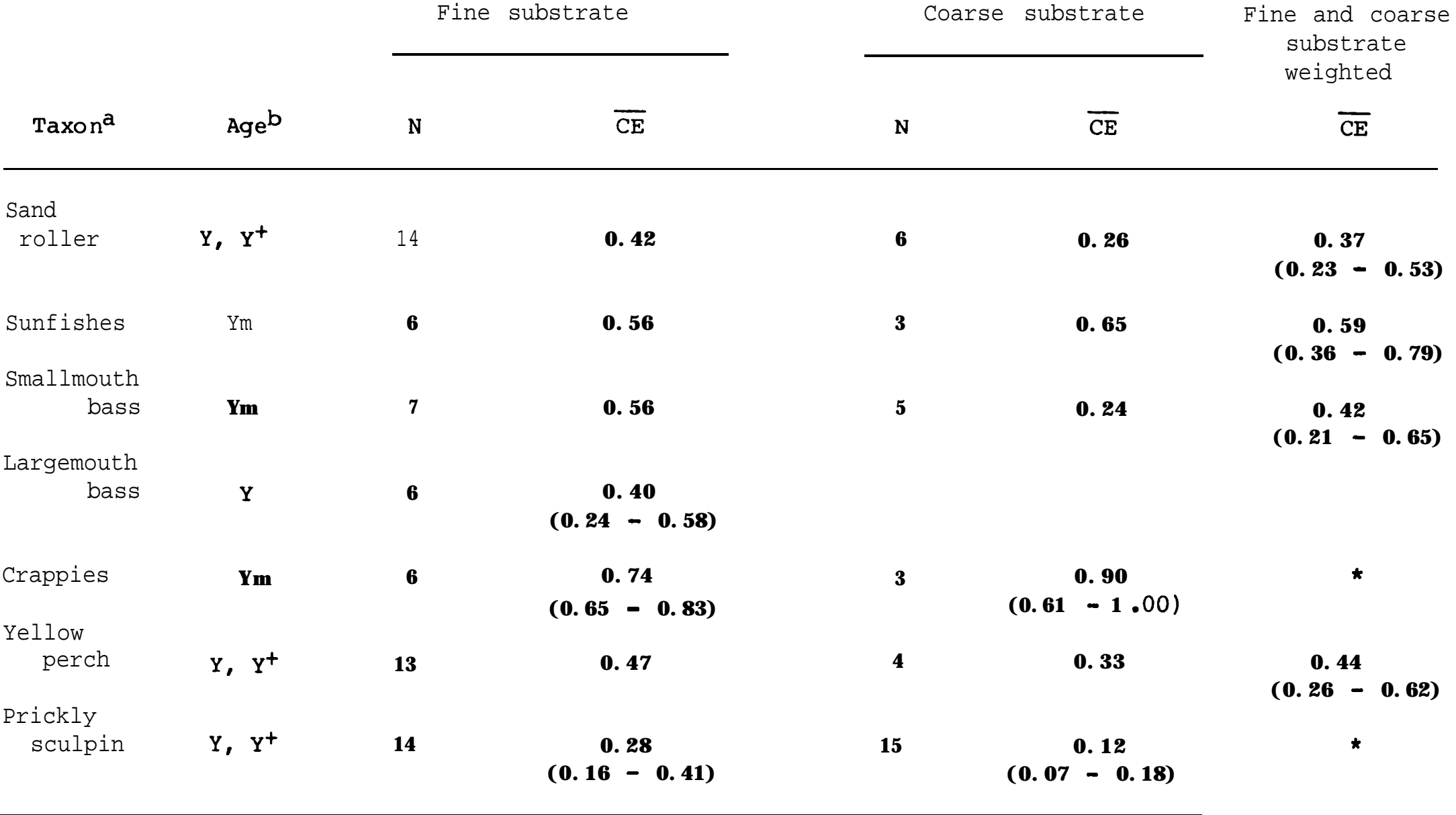

a Suckers = largescale sucker (Catostomus macrocheilus) and bridgelip sucker (C. columbianus); sunfishes = bluegill (Lepomis macrochirus) and pumpkinseed (L. gibbosus); crappies = black crappie (Pomoxis nigromaculatus) and white crappie (P. annularis).

b $\mathbf{Y}=$ young-of-the-year, Ym = mostly young-of-the-year, $\mathbf{Y}^{\mp}=$ older than young-of-the-year. 
type. For example, the 39 chinook salmon captured over fine substrates were divided by 0.84 (the capture efficiency for chinook salmon over a fine substrate) and the $\mathbf{1 3}$ chinook salmon captured over coarse substrates were divided by 0.55 (the capture efficiency for chinook salmon over a coarse substrate). The combined estimated abundance of $\mathbf{7 1}$ chinook salmon in all hauls was 36\% greater than the actual total catch of 52 .

The estimated abundance of all taxa captured in these seine hauls increased after the catches were adjusted to account for CE (Table 2). The estimated abundance for taxa with high CE's increased little, but estimated abundance increased substantially for taxa with low CE's. Roughly equal numbers were taken of the three most abundant taxa: yellow perch, 167; suckers, 155; and sand rollers, 148 . Catches of fish of each of the other taxa were less than 75. After catches were adjusted to account for seine $\mathrm{CE}$, sand rollers and yellow perch remained the most abundant species, their estimated abundance being 402 and 381, respectively. However, the adjusted estimated abundance of suckers (272) was less, and narrowly exceeded that of prickly sculpin (246). Mean CE's for other taxa captured were relatively high, and estimated abundances were less than 85 fish per taxon. 
Table 2. Number of fish of each of nine taxa captured in 12 seine hauls, their estimated abundance, and percent change between total number captured and adjusted estimated abundance after the catch of a taxon was divided by the appropriate estimate of seine capture efficiency.

\begin{tabular}{|c|c|c|c|c|c|c|c|}
\hline \multirow[b]{2}{*}{ Taxon } & \multicolumn{2}{|c|}{ Number of fish captured } & \multirow[b]{2}{*}{ Total } & \multicolumn{2}{|c|}{ Capture efficiency } & \multicolumn{2}{|c|}{ Combined estimated abundance } \\
\hline & $\begin{array}{l}\text { Fine } \\
\text { substrate }\end{array}$ & $\begin{array}{c}\text { Coarse } \\
\text { substrate }\end{array}$ & & $\begin{array}{c}\text { Fine } \\
\text { substrate }\end{array}$ & $\begin{array}{c}\text { Coarse } \\
\text { substrate }\end{array}$ & Number & $\begin{array}{c}\text { Change in } \\
\text { estimate } \\
(\xi)\end{array}$ \\
\hline \multicolumn{8}{|l|}{ Chinook } \\
\hline salmon & 39 & 13 & 52 & 0.84 & 0.55 & 71 & 37 \\
\hline \multicolumn{8}{|l|}{ Northern } \\
\hline squawfish & 29 & 10 & 39 & \multicolumn{2}{|c|}{0.85} & 46 & 18 \\
\hline Suckers ${ }^{a}$ & 82 & 73 & 155 & 0. 76 & 0.45 & 272 & 76 \\
\hline \multicolumn{8}{|l|}{ Sand } \\
\hline roller & 117 & 33 & 150 & \multicolumn{2}{|c|}{ 0. 37} & 402 & 168 \\
\hline Sunfishes ${ }^{a}$ & 6 & 30 & 36 & \multicolumn{2}{|c|}{0.56} & 61 & 69 \\
\hline Crappies ${ }^{a}$ & 22 & 46 & 68 & 0.74 & 0.90 & 82 & 17 \\
\hline $\begin{array}{l}\text { Yellow } \\
\text { perch }\end{array}$ & 52 & 115 & 167 & \multicolumn{2}{|c|}{0.44} & 381 & 128 \\
\hline $\begin{array}{l}\text { Prickly } \\
\quad \text { sculpin }\end{array}$ & 47 & 9 & 56 & 0.28 & 0.12 & 246 & 339 \\
\hline
\end{tabular}

a See footnote a, Table 1, for species. 
Discussion

Vulnerability to capture with a seine at night varied among taxa and was influenced by substrate type for some taxa. Differences in $\mathrm{CE}$ between species and, over different substrates within species may be due to variation in nocturnal behavior of different species -including differences in distribution in the water column, foraging and resting behavior, and fright response. Emery (1973) and Helfman (1981) reported that many species of freshwater fish move inshore after dark and become inactive, often resting directly on the substrate; most species they observed could be approached closely $(<0.5 \mathrm{~m})$ at night by a diver, and many could be touched before they darted away. This nocturnal torpidity in conjunction with fright response of torpid fish (a tendency to dart up from the substrate and away from the disturbance) and net avoidance behavior of active fish (Hunter and Wisby 1964; Leggett and Jones 1971) may result in increased vulnerability of certain taxa to capture in a seine. The preference of a fish for rocks as cover when it is either resting or frightened, or its ability to escape under the lead line, may also explain why $\mathrm{CE}$ differed among taxa and why it was for some taxa lower over coarse than over fine substrates.

The estimates of $\mathrm{CE}$ we obtained may have been overestimated because some fish undoubtedly avoided capture by both the seine and block net. However, we believe that the number of escapes from the enclosure were small because the areas were seined repeatedly, and the block net (with double the number of floats and leads that were on the seine) was retrieved through the sampling area. Our technique should not have impeded fish from avoiding capture by the seine; fish could escape under the lead line, over the float line, or around the outside end of the seine, just as during routine quadrant seining.

Generally, neither the number of fish of a taxon available to the seine nor water temperature influenced $\mathrm{CE}$. However, the number of brown bullheads (mostly schooling young-of-the-year) available to the seine over smooth substrates was directly related to $\mathrm{CE}--$ an indication that brown bullheads were more vulnerable to capture by a seine when in a school. A direct relation was also observed between water temperature and $\mathrm{CE}$ for suckers taken over fine substrates but not, over coarse substrates. Other taxa captured showed no such relation.

Hunter and Wisby (1964) reported that schooling common carp (Cyprinus carpio) avoided capture by a moving net en masse, and that common carp tested in a group were more successful in escaping a moving net than were those tested individually. They also noted that loose schools of common carp were better able to escape a moving net 


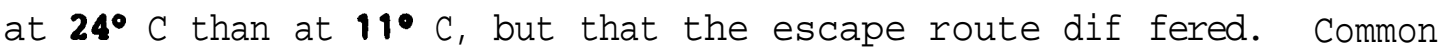
carp in the cooler water used a bottom escape route whereas those in warmer water used a top escape route. The suckers we captured over a smooth substrate may have used similar escape routes, making them more vulnerable to capture in warmer water. The net avoidance experiments of Hunter and Wisby (1964) showed that common suckers (Catostomus canmersoni) tested at water temperatures of $13-16^{\circ} \mathrm{C}$ rarely used the bottom escape route.

Seine CE may be influenced by size (or age) of fish captured, but not enough samples were collected in the present study to test for differences. In as much as behavior of young-of-the-year fish has been shown to differ from that of older fish of the same species, it is likely that size of fish affects seine CE (Emery 1973; Helfman 1981).

Increase in estimated abundance was greater in taxa with low seine CE's than those with high CE's because $\mathrm{CE}$ and adjusted catch were inversely related. Therefore, the overall effect that $\mathrm{CE}$ has on adjusted catches is more pronounced when the species complexes studied are composed of several taxa with different CE's.

The need for evaluating capture efficiency of a seine depends on the intended use of the data collected. If an accurate assessment is required of forage fish, as in our study of predator-prey interactions in John Day Reservoir, or in the abundance of juvenile fishes, an evaluation of capture ef ficfency is paramount. In evaluating capture efficiencies it is important that the seining experiments duplicate the techniques used and environmental conditions encountered when the data are collected to which the results are to be applied. 
Acknowledgments

- We thank C. Burley for his assigtance in the field work; and W.R. Nelson, T.P.. Poe, and D.R. Rondorf for reviewing . manuscript. The work was sponsored by Bonneville Power Administration, Contract DI-AI79-82BP 34796 . 
Emery, A.R. 1973. Preliminary comparisons of day and night habits of freshwater fish in Ontario lakes. Journal of the Fisheries Research Board of Canada 30:761-774.

Gray, G.A. D.E. Palmer, B.L. Hilton, P.J. Connolly, H.C. Hansel, J.M. Beyer, and G.M. Sonnevil. 1985. Feeding activity, rate of consumption, daily ration, and prey selection of major predators in the John Day Pool. Annual Report to the Bonneville Power Administration. National Fishery Research Center, Cook, Washington, USA.

Helfman, G.S. 1981. Twilight activities and temporal structure in a freshwater fish community. Canadian Journal of Fisheries and Aquatic Sciences 38: 1405- 1420.

Hunter, J.R. and W.J. Wisby. 1964. Net avoidance behavior of carp and other species of fish. Journal of the Fisheries Research Board of Canada $21: 613-633$.

Leggett, W.C. and R.A. Jones. 1971. Net avoidance behavior in American shad (Alosa sappidissima) as observed by ultrasonic tracking techniques. Journal of the Fisheries Research Board of Canada 28:1167-1171.

Lyons, J. 1986. Capture efficiency of a beach seine for seven fresh-water fishes in a north-temperate lake. North American Journal of Fisheries Management 6:288-289.

Lyons, J. In press. Di stribution, abundance, and mortality of smal I littoral-zone fishes in Sparkling Lake, Wisconsin. Environmental Biology of Fishes.

Moav, R., and W.G. Wohlfarth. 1970. Genetic correlation between seine escapability and growth capacity in carp. Journal of Heredity $61: 153-157$.

Richkus, W.A. 1980. Problems in monitoring marine and estuarine fishes; Pages 83-118 in C.H. Hocutt and J.R. Stauffer, Jr., editors. Biological monitoring of fish. D.C. Heath, Lexington, Massachusetts.

SPSS Inc. 1983. SPSS/PC+ for the IBM PC/XT/AT. SPSS Inc., Chicago.

Zar, J.H. 1984. Biostatistical analysis (second edition). Prentice-Hall Inc., Englewood Cliffs, New Jersey. 


\title{
Data Documentation
}

Steven Vigg

\author{
U.S. Fish and Wildlife Service \\ National Fishery Research Center \\ Columbia River Field Station \\ Star Route \\ Cook, Washington 98605
}




\title{
COLUMBIA RIVER PREDATOR DIET ANALYSIS \\ COMPUTER PROGRAM
}

\begin{abstract}
An IBM BASIC computer proqram was created to organize food habits, data files (see Table 1) and produce summaries according to various criteria determined by the operator in interactive mode.

The proqram was designed in eight interconnected modules:

(1) "START" selects the desired subproqram,

(2) "FOODINPT" creates stomach content data files and inputs data,

(3) "FOODED IT" corrects data files,

(4) "FOODLIST" lists each data record in a file,

(5) "SMOLTLST" summarizes consumption of juvenile salmonids,

(6) "FOODSLCT" (a) selects conditionals by which data are sorted

(7) "FOODCALC" calculates summary statistics, and

(8) "FOODPRNT" prints out summary tables.
\end{abstract}

Using "FOODSLCT" food habits data was processed according to six criteria: predator species (northern squawfish, walleye, smallmou th bass, or channel catfish); predator size (minimum and maximum lenqth 1; collection gear (electroshocker, bottom qill net, trawl, or combination); location (five major locations, each with sever al subareas, or a combination of locations); sample period (any interva 1 between specified dates or entire year); time of day (any die1 period within the 24-hour sampling regime).

The data set delimited by the selected conditionals is described with various statistics by "FOODCALC." These include sample size, number of stomachs with and without contents, mean predator size, organisms consumed, and total number and weight of food contents. Additionally, for each food item, the number of stomachs containing it (percent and frequency of occurrence), number of individual organisms (total, mean, and percent), weight of food item (total, mean, and percent), and the Index of Relative Importance are calculated. Although this proqram was desiqned specifically for Columbia River species composition and sampling stations, it could readily be modified for other applications. Thus, it may he useful to workers conducting food habits research at field stations equipped with minicomputers. 
List of FWS data files $(*$. DAT = diet data files and * . CON = consumption data files) for all predator species and years sampled including sample size (n) and bytes per file.

Data Files n no. Bytes

\begin{tabular}{|c|c|c|c|}
\hline $\mathrm{CHC}$ & $1 / 82$ & 69 & 33,327 \\
\hline $\mathrm{CHC}$ & -83 & 189 & 91,287 \\
\hline $\mathrm{CHC}$ & 84 & 161 & 77,763 \\
\hline $\mathrm{CHC}$ & 85 & 176 & 85,008 \\
\hline $\mathrm{CHC}$ & 86 & 162 & 78,246 \\
\hline SMB & $2 / 82$ & 941 & 454,503 \\
\hline SMB & -83 & 1, 063 & 513,429 \\
\hline SMB & 84 & 1,246 & 601,818 \\
\hline SMB & 85 & 1,676 & 809,508 \\
\hline SMB & 86 & 955 & 461,265 \\
\hline SQF & $3 / 82$ & 1, 059 & 511,497 \\
\hline SQF & 83 & 1,655 & 799,365 \\
\hline SQF & 84 & 1,087 & 525,021 \\
\hline SQF & 85 & 1,043 & 503,769 \\
\hline SQF & 86 & 1,682 & 812,406 \\
\hline WAL & $4 / 82$ & 253 & 122,199 \\
\hline WAL & 83 & 501 & 241,983 \\
\hline WAL & 84 & 339 & 163,737 \\
\hline WAL & 85 & 292 & 141,036 \\
\hline WAL & 86 & 74 & 35,742 \\
\hline \multicolumn{4}{|c|}{ All Years Combined } \\
\hline $\mathrm{CHC}$ & 89 & 526 & 254,058 \\
\hline SMB & 80 & 3,985 & $1,924,755$ \\
\hline SQF & 89 & 3,785 & $1,828,155$ \\
\hline WAL & 80 & 1,132 & 546,756 \\
\hline
\end{tabular}

$1 / \mathrm{CHC}=$ channel catfish

2/ $\mathrm{SMB}=$ smallmouth bass

3/ $\mathrm{SQF}=$ northern squawfish

4/ WAL = walleye 
Computer programs written in BASICA for IBM-PC compatible microcomputers were developed to estimate consumption from stomach contents data based on a technique originated by W.A. Swenson in 1972 (Ph.D. dissertation, University of Minnesota). This method synthesizes empirical diel samples of predators' diets with experimentally determined evacuation rates in order to estimate daily consumption rates of juvenile salmonids in terms of (1) grams of prey per average predator, (2) milligrams prey per gram of predator, and (3) number of prey per average predator. The product of the latter statistic and predator population size (estimated by ODFW) yields an absolute daily consumption estimate.

The consumption analysis is accomplished with two programs. The first program converts diet data files (including date, location, time of collection, predator weight, temperature, and the sample weight of each prey item) to a new file, having the additional variables necessary for consumption calculations: original preyfish length and weight, mass evacuated, percent digested, digestion time, and time of ingestion. Original preyfish lengths and weights are estimated from body length or bone measurements using species-specific regression equations. Mass evacuated and percent digestion are back-calculated from the difference in original and digested weights. Duration of digestion for each preyfish is estimated from evacuation rate regressions; time of ingestion can subsequently be back-calculated from time of collection. The second program performs the actual consumption calculation from grams of juvenile salmonids consumed per prey size, group and diel time period, and the numbers of potential predators in corresponding strata.

To date, separate programs have been written to estimate daily prey consumption by northern squawfish, walleye, smallmouth bass and channel catfish. All diet and consumption data files and program listings are stored on magnetic disks (5-1/4" IBM format) and copies are available at cost from the:

U.S. Fish and Wildlife Service

Columbia River Field Station

Star Route

Cook, WA 98605 
SECTION II

Oregon Department of Fish and Wildlife 17330 S.E. Evelyn Street

Clackamas, Oregon $\mathbf{9 7 1 0 5}$

Project No. $82-12$ 
Effects of Variation in Flow on Distributions of Northern Squawfish in the Columbia River below McNary Dam

\author{
Micheal P. Faler \\ U.S. Fish and Wildlife Service \\ Seattle National Fishery Research Center \\ Columbia River Field Station \\ Star Route \\ Cook, WA 98605
}

\begin{abstract}
and
Lawrence M. Miller and Kurt I. Welke Oregon Department of Fish and Wildlife Columbia River Research Office

17330 S.E. Evelyn St.
\end{abstract}

Clackamas, OR 97015

Published in: North American Journal of Fisheries Management Vo1.8: 30-35, 1988 
The movements of northern squawfish (Ptychochelius oregonensis) were monitored using radio-telemetry below a Columbia River hydroelectric dam during the outmigration of juvenile anadromous salmonids in 1984 and 1985. Northern squawfish were associated with protected shoreline areas in spring and early summer when discharge rates were high (above $5,664 \mathrm{~m}^{3} / \mathrm{sec}$ ) but moved into close proximity of the dam and the juvenile by-pass outflow area in mid to late summer when discharge rates decreased (below $5,664 \mathrm{~m}^{3} / \mathrm{sec}$ ). Similar trends in northern squawfish movements were found when abrupt changes in discharge occurred. Movements out of protected areas and into the main river channel were observed in 4 out of 5 northern squawfish monitored during short-term spill closures.

Northern squawfish appeared to avoid high velocity ( $>100 \mathrm{~cm} / \mathrm{sec}$ ) areas. Surface water velocity measurements taken at $\mathbf{8 1}$ locations where northern squawfish occurred in June, July and August, 1985, ranged from 0 to $70 \mathrm{~cm} / \mathrm{sec}$ with a mean of $24.5 \mathrm{~cm} / \mathrm{sec}$. These results suggest that predation by northern squawfish at fish passage facilities may be reduced by placing by-pass outflows in areas of high water velocity. 
INTRODUCTION

Impoundments on rivers containing stocks of anadromous salmonids have necessitated the development of facilities to by-pass downstream migrant juvenile trout and salmon around the dams. One concern at these by-pass facilities is that conditions created by dams can concentrate predators by intensifying their foraging efficiency on juvenile salmonids. Sacramento squawfish were more abundant at Horseshoe Bend's fish release site than at control sites in the Peripheral Canal, California (Anonymous 1980). The by-pass facility at Red Bluff Diversion Dam, California, was found to induce stress on downstream migrants and attract predators which resulted in high mortality due to predation (Vogel and Smith, 1984). Gray et al. (1983) noted that the frequency of occurrence of salmonids in diets was higher for northern squawfish collected near mid-Columbia River dams than for those collected in other areas.

The objectives of this study were to: (1) describe the distribution of northern squawfish in McNary tailrace, (2) determine how different flow regimes affected the distribution of northern squawfish and (3) determine implications of predator distribution on the design of fish passage facilities.

\section{STUDY AREA}

McNary Dam is a hydroelectric facility located on the mid-Columbia River between Washington and Oregon (Fig. 1). The smolt by-pass outlet is situated in the center of the dam between the spillgates and turbines. Water discharge at McNary Dam varies with snow melt from the surrounding mountains of the Columbia Basin. Between March and mid-July, water discharge past McNary Dam may reach $11,400 \mathrm{~m} 3 / \mathrm{sec}$. Maximum turbine outflow at McNary is $5,664 \mathrm{~m} 3 / \mathrm{sec}$, hence all discharge in excess of this must be passed through the spillgates and fishways. By mid-July, runoff is substantially reduced and water is no longer spilled. Water discharge is stable from late summer through fall, and increases slowly throughout winter until the spring runoff surge requires spillgate operations.

The majority of juvenile salmon and steelhead pass McNary Dam between March and August. The highest numbers of outmigrants, however, are usually not found in the by-pass system until mid to late summer when discharge is reduced and the spillgates are closed. At this time the outmigrants attempt to pass primarily through the turbines.

Traveling screens in the turbine gatewells (Bates 1970) guide the 


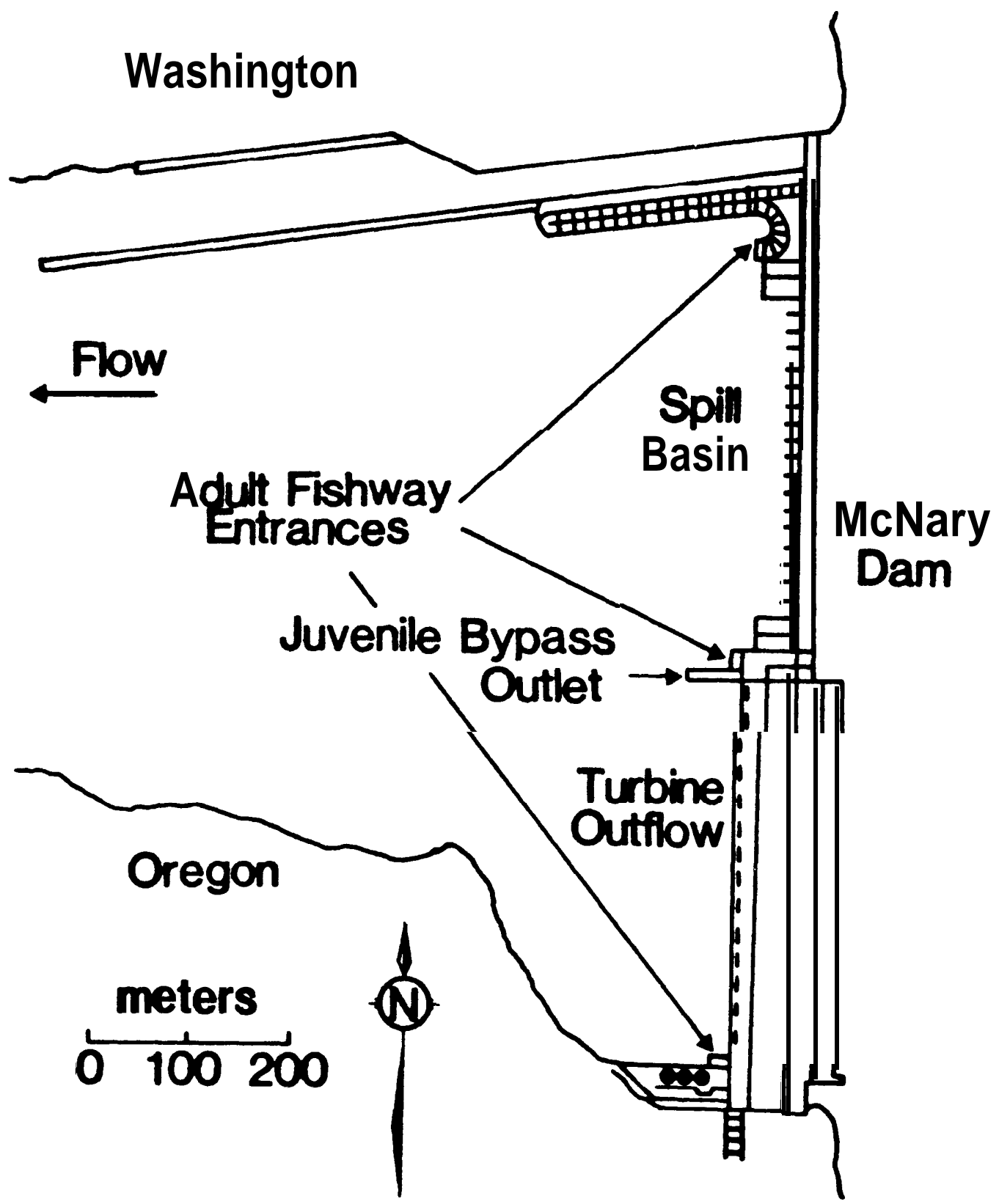

Figure 1. Locations of the juvenile bypass outlet, spill basin, outflow, and fishway entrances at McNary Dam. turbine 
juveniles away from the turbines and into the by-pass system where the fish are subsampled, identified and enumerated. The juvenile salmonids are then either released through the by-pass outlet into McNary tailrace or transported by barge or truck to the Bonneville tailrace and released.

\section{METHODS}

The movements and distribution of northern squawfish in McNary tailrace were monitored using radio-telemetry equipment obtained from Advanced Telemetry Systems ${ }^{1}$ of Bethel, Minnesota. ATS "Challenger 200" receivers were equipped with David Clark noise attenuating headsets, and were capable of scanning programmed frequencies between 48 and $50 \mathrm{mhz}$. Transmitters had a life expectancy of 150 days, weighed $28 \mathrm{~g}$ in air, were cylindrical and trailed a $35 \mathrm{~cm}$ fine wire antenna from one end. Frequencies were separated by $10 \mathrm{kHz}$ increments (Table 1) to allow for easy identification of individual fish and compensate for frequency drift when battery power declined.

Northern squawfish were collected by electrofishing in McNary tailrace (10 in March, 1984 and $\mathbf{1 3}$ in April and May, 1985) and surgically implanted with a radio-transmitter. Upon capture, fish were anesthetized in a $105 \mathrm{mg} /$ liter solution of TricaineMethane-Sulfonate (MS-222). Each fish was weighed and measured (mm). (Table 1).

Surgical procedures were similar to those used by Hart and Summerfelt (1975) except an additional $0.5 \mathrm{~cm}$ incision was made in the abdominal cavity to allow for protrusion of a flexible wire antenna. The antenna exit hole was closed with a single suture. Sutured areas were swabbed with Betadine antiseptic, and the fish moved to fresh water for recovery. After the fish regained equilibrium and resumed swimming activity it was released at the point of capture.

Two antenna types were used to receive signals. Bidirectional loop antennas were affixed beneath the wing of an aircraft for aerial monitoring. Antennas were oriented with the peak receiving end directed forward. The unit was insulated from metal contact with the wing surface, and coaxial antenna wire was securely taped to the underwing and led into the cabin through an air vent. Boat tracking was conducted from a $\mathbf{2 1}$ foot fiberqlass boat using a 4 element Yagi antenna (long range) attached to a telescoping $\mathbf{1 2}$ foot mast with $360^{\circ}$ rotational capability. Hand held bidirectional loop antennas (short range) were also used in the boat and from shore. Once a signal was

'Mention of commercial services or equipment does not constitute U.S. Government endorsement. 
Table 1. Descriptive data on 23 northern squawfish radiotagged and released in McNary tailrace, 1984 and $\mathbf{1 9 8 5 .}$

\begin{tabular}{|c|c|c|c|c|c|}
\hline Year & $\begin{array}{l}\text { Transmitter } \\
\text { Frequency } \\
\quad(\mathrm{MHz})\end{array}$ & $\begin{array}{c}\text { Fork } \\
\text { Length } \\
(\mathrm{mm}) \\
\end{array}$ & $\begin{array}{l}\text { Weight } \\
(\mathrm{g})\end{array}$ & Date & of Release \\
\hline \multirow[t]{10}{*}{1984} & 48. 184 & 470 & 1,450 & & 3- 14 \\
\hline & 48. 210 & 500 & 1,910 & & 3- 15 \\
\hline & 48. 334 & 517 & 1,625 & & 3- 15 \\
\hline & 48. 373 & 467 & 1,370 & & 3- 15 \\
\hline & 48. 412 & 480 & 1,400 & & 3- 15 \\
\hline & 48. 493 & 465 & 1,440 & & 3- 20 \\
\hline & 48. 551 & 495 & 1,620 & & 3- 20 \\
\hline & 48. 637 & 481 & 1,330 & & 3- 22 \\
\hline & 48. 657 & 447 & 1,375 & & 3- 27 \\
\hline & 48. 678 & 466 & 1,380 & & 3- 27 \\
\hline \multirow[t]{13}{*}{1985} & 48. 184 & 460 & 1,475 & & 4- 10 \\
\hline & 48. 209 & 501 & 1,702 & & 4- 10 \\
\hline & 48. 333 & 505 & 2,185 & & 4- 10 \\
\hline & 48. 373 & 469 & 1,559 & & 4- 10 \\
\hline & 48. 414 & 479 & 1,502 & & 4- 14 \\
\hline & 48. 492 & 485 & 1,587 & & 4- 14 \\
\hline & 48. 553 & 445 & 1,530 & & 4- 14 \\
\hline & 48. 638 & 456 & 1,530 & & 4- 14 \\
\hline & 48. 658 & 474 & 1,587 & & 4- 14 \\
\hline & 48. 679 & 464 & 1,474 & & $5-3$ \\
\hline & 49. 598 & 453 & 1, 531 & & 6- 4 \\
\hline & 49. 779 & 455 & 1,418 & & 6- 5 \\
\hline & $* 48.209$ & 450 & 1,474 & & 5- 3 \\
\hline
\end{tabular}

*Indicates transmitter was returned by an angler and subsequently implanted in a second fish. 
received, the axis of maximum signal strength was followed. A reduction of the $\mathrm{RF}$ gain would take place until the observer was confident he had obtained an accurate location (fix).

The radio-tagged fish were monitored from aircraft, boat, and shoreline two to four times weekly from their time of release (Table 1) through August. Individual fixes were recorded in respect to distance and direction from known landmarks, and classified as either inshore (< 100mfrom a natural shoreline) or offshore (> 100 $\mathbf{1 0}$ from a natural shoreline). Each fix was assigned an $x$ and $y$ coordinate from $a$ Cartesian grid system (150 m/side) overlaid upon a U.S. Geological Survey map of the study area.

The movements of 5 northern squawfish were also monitored during short term spill closures in May, 1985 to determine how abrupt changes in water discharge my affect predator distributions. The fish were monitored at 5-10 minute intervals for $\mathbf{1 - 2}$ hours after the spill closures.

Surface water velocity measurements were taken with a MarshMcBirney digital flowmeter at 63 randomly chosen locations in McNary tailrace during July and August, 1985 to map the tailrace flow regime. Individual measurements were triangulated to known landmarks with a Davis Mark IV sextant. Measurements were plotted on a U.S. Geological Survey map of the study area using a 3-arm protractor. Contour lines were drawn connecting points of similar surface water velocity.

Locations of radio-tagged northern squawfish were separated by time periods corresonding to mean daily discharge rates. Since preliminary results indicated that the presence or absence of spillgate discharge se ens to effect the distribution of predators in the tailrace, maximum possible turbine flow $\left(5,664 \mathrm{~m}^{3} / \mathrm{sec}\right)$ was chosen to delineate periods of high and low discharge (Fig. 2). Periods of high discharge were defined as those in which mean daily discharge rates exceeded $5,664 \mathrm{~m}^{3} / \mathrm{sec}$, and periods of low discharge refer to mean daily discharge rates $<5,664 \mathrm{~m}^{3} / \mathrm{sec}$. Distributions of the predators within high and low discharge periods were examined, and a chi-square analysis was used to compare inshore-offshore movements during these periods. It should be noted, however, that mean daily discharge rates in excess of the maximum possible turbine flow do not imply consistent spillgate operations due to navigation and fish passage needs, and water availability.

\author{
RESULTS AND DISCUSSION
}

In both 1984 and 1985 radio-tagged northern squawfish were usually distributed in smal backwaters and protected shoreline areas during hi gh water discharge $\left(>5,664 \mathrm{~m}^{3} / \mathrm{sec}\right)$ and spillgate operations (Fig. 3), 


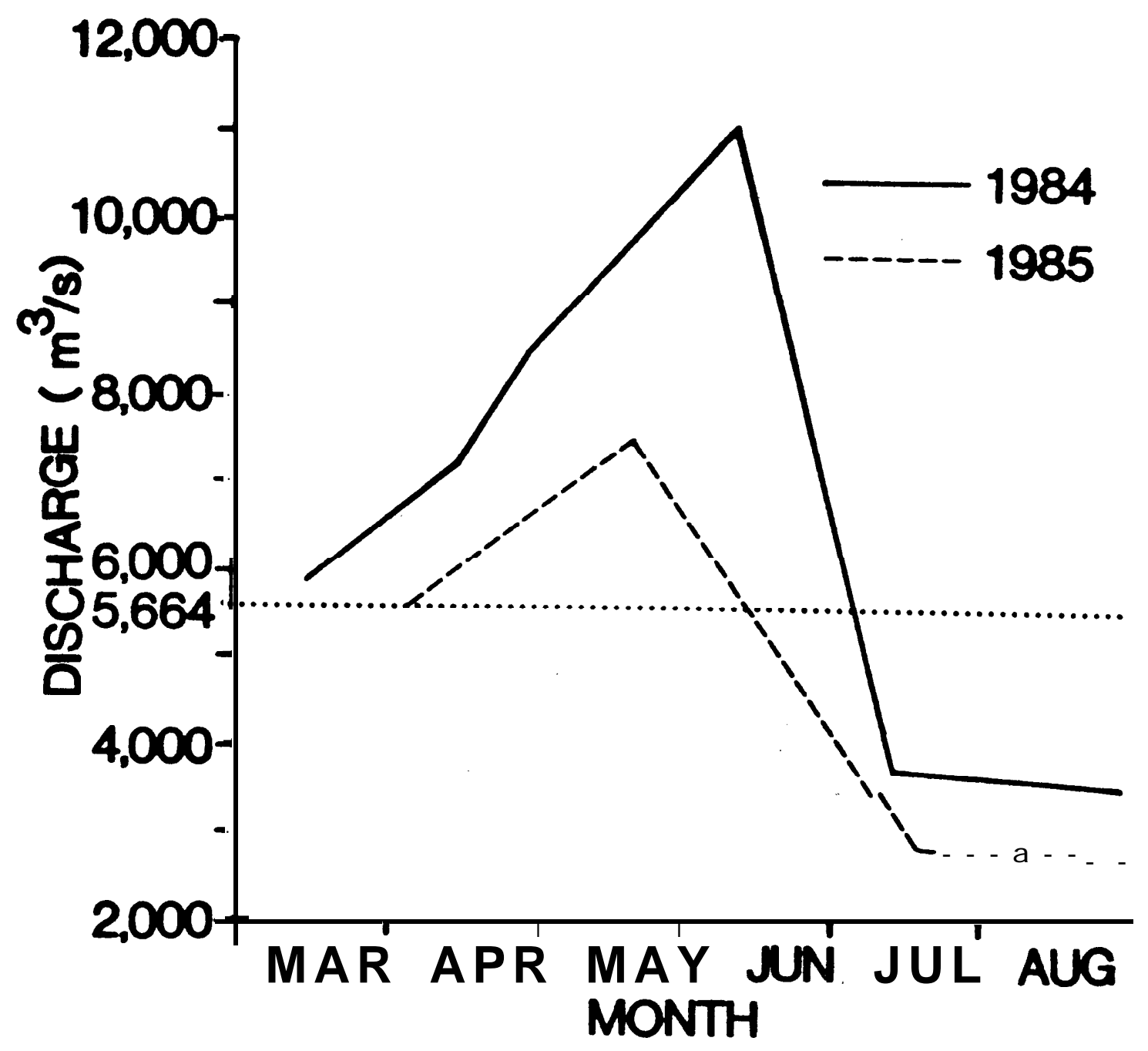

Figure 2. Mean daily discharge rates, illustrating time periods when discharge exceeded maximum turbine outflow $\left(5,664 \mathrm{~m}^{3} / \mathrm{s}\right)$, McNary Dam, March-August 1984 and 1985. 

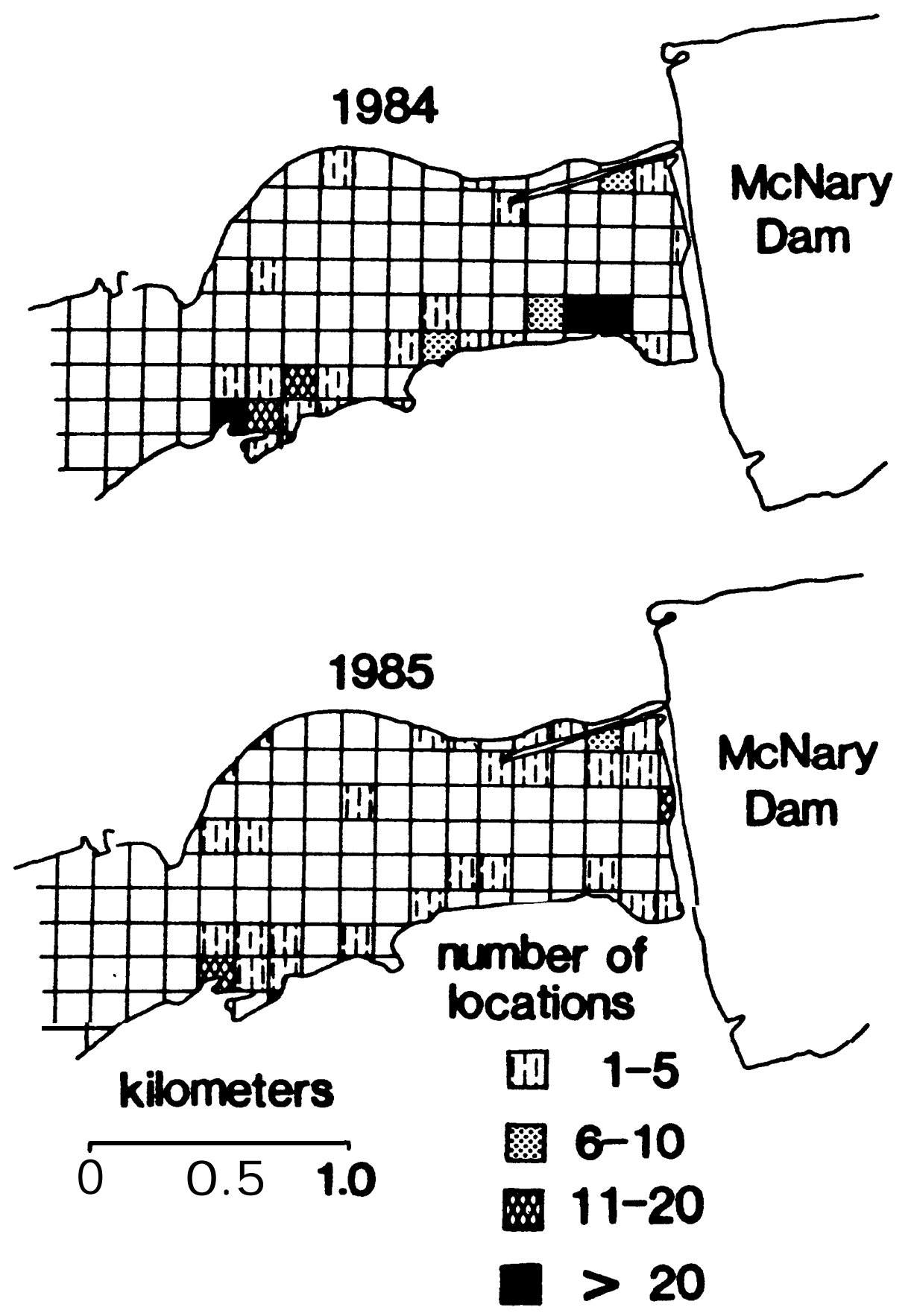

Figure 3. Distributions of radio-ta ged northern squawfish during high discharge rates $\left(>5,664 \mathrm{~m}^{3} / \mathrm{s}\right)$ in McNary tailrace, March 14 July 18, 1984, and April 17 - June 20, 1985. 
but moved into the main river channel and near the dam when discharge decreased $\left(\leq 5,664 \mathrm{~m}^{3} / \mathrm{sec}\right)$ and spillgates were closed (Fig. 4).

Chi-square analysis showed a significant difference ( $p<0.01$ ) between the frequency of inshore and offshore observations during high and low discharge rates in both 1984 and 1985 (Table 2). In spring and early summer when discharge was high, northern swuawish were often located a considerable distance downstream from the dam. In 1984,

7 northern squawfish (70\%) were located farther than $\mathbf{2 . 5} \mathrm{km}$ from McNary Dam. Locations from these fish outside the tailrace comprised 17.6\% of all observations taken in 1984; $98.6 \%$ of these occurred when discharge exceeded $5,664 \mathrm{~m}^{3} / \mathrm{sec}$. Nine northern squawfish (75\%) were located $>2.5 \mathrm{~km}$ downstream from the dam in 1985. Again, this occurred primarily when discharge rates were high and spillgates were open. These locations comprised 38.6\% of all observations in 1985, and $63.4 \%$ of these took place when discharge exceeded $5,664 \mathrm{~m}^{3} / \mathrm{sec}$. All 7 northern squawfish which left the tailrace in 1984, and 5 of the 9 which left in 1985 returned to $<2.5 \mathrm{~km}$ from the dam by late July.

In mid to late summer when discharge was low, the predators were primarily distributed in the spill basin (Fig. 4). During this period high concentrations of predator locations occurred near the smolt by-pass outflow and the Washington adult fishway entrance.

observations near the by-pass and fishway entrance comprised $\mathbf{7 0 . 4 \%}$ of all locations taken during low water discharge in $\mathbf{1 9 8 4}$ and $\mathbf{3 1 . 3 \%}$ in 1985. The occurrence of predators observed away from the dam during low water discharge was more common in $\mathbf{1 9 8 5}$ than in $\mathbf{1 9 8 4 .}$

Northern squawfish distributions seemed to be associated with the surface velocity regimes in the tailrace. Water velocity data from July and August, 1985 demonstrates a pattern typical of late summer when spillgates are consistently closed (Fig. 5). A large area immediately downstream from the turbine outflow and a smil area immediately downstream from the Washington fishway entrance had velocities in excess of $\mathbf{1 0 0} \mathbf{~ c n d ~ s e c . ~ V e l o c i t i e s ~ r a n g i n g ~ f r o m ~ 5 0 - 0 0 ~}$ $\mathrm{cm} / \mathrm{sec}$ were observed bordering those areas in excess of $\mathbf{1 0 0} \mathbf{~ c m} \mathbf{s e c}$. The slowest water velocities in the tailrace were observed below the spill basin and along the oregon shore downstream from the turbine outflow; velocities in these areas ranged from $0-49 \mathrm{sm} / \mathrm{sec}$. A comparison of northern squawfish distributions to the current velocity regime indicates that the predators prefer areas with slow water velocity or flow shears bordering high velocity areas.

In order to confirm this hypothesis we looked at surface velocity measurements at 81 northern squawfish locations taken in June, July and August, 1985 during the day, crepuscular and nightime hours.

Individual velocity measurements at predator locations ranged from 0-70 $\mathrm{cm} / \mathrm{sec}$ and averaged $24.2 \mathrm{~cm} / \mathrm{sec}$. Since a large proportion of the tailrace has velocities in excess of $\mathbf{7 0} \mathbf{c n d s e c}$ we believe this data confirms the avoidance of high water velocities by northern squawfish. The data did not reveal any preference for specific velocities by the 
Table 2. Frequency of inshore-offshore location at low ( $\left.\leq 5664 \mathrm{~m}^{3} / \mathrm{sec}\right)$ and high $\left(>5664 \mathrm{~m}^{3} / \mathrm{sec}\right)$ discharge rates for radio-tagged northern squawfish in McNary tailrace, $1984(\mathrm{n}=346)$ and 1985 ( $\mathrm{n}=286$ ).

\begin{tabular}{cccc}
\hline Year & Discharge & Inshore & Offshore \\
\hline $\mathbf{1 9 8 4}$ & low & $\mathbf{6 6}$ & $\mathbf{4 1}$ \\
& high & $\mathbf{2 1 4}$ & $\mathbf{2 5}$ \\
$\mathbf{1 9 8 5}$ & low & $\mathbf{1 1 0}$ & 99 \\
& high & $\mathbf{6 6}$ & $\mathbf{1 1}$ \\
\hline
\end{tabular}



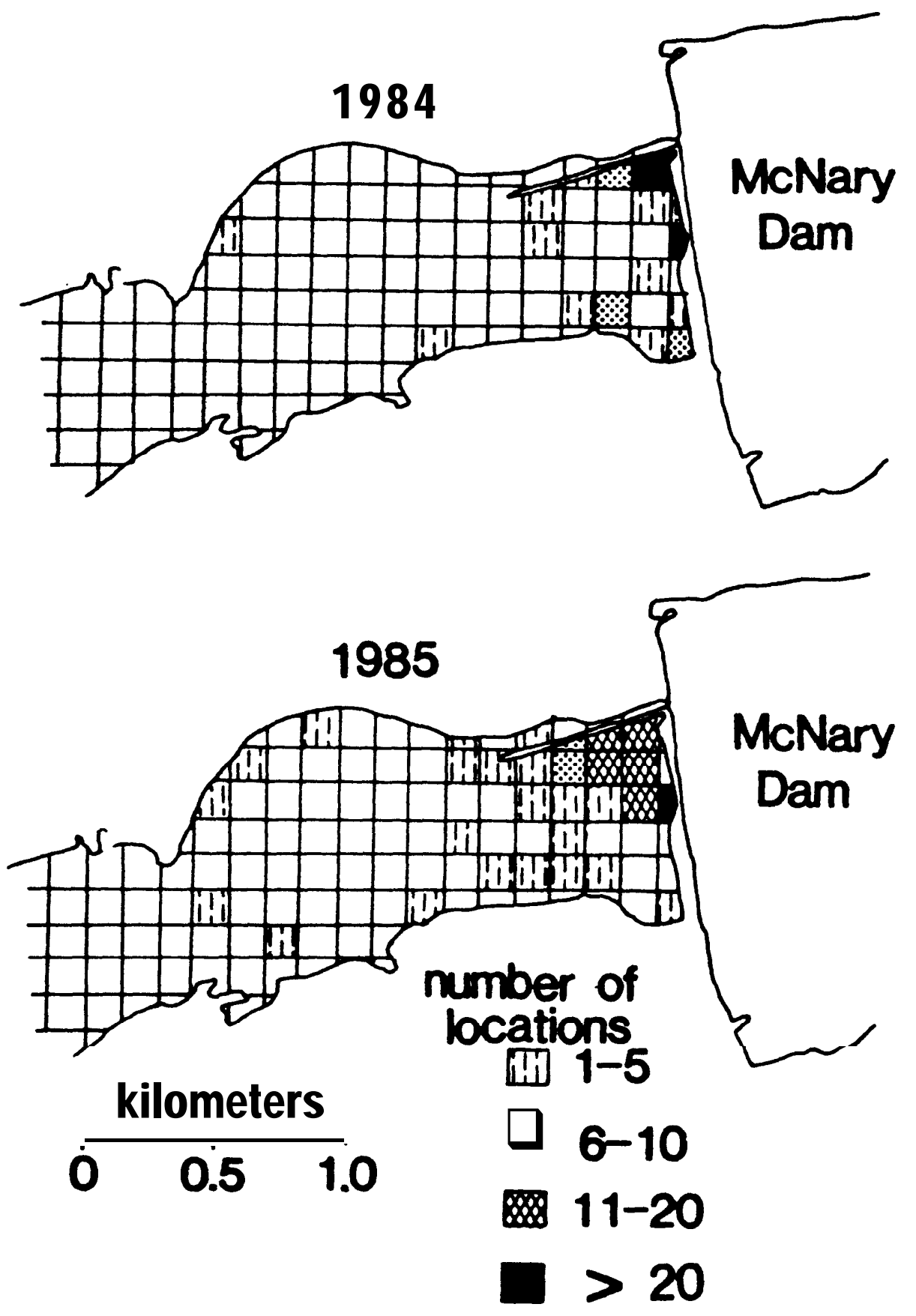

\footnotetext{
Figure 4. Distributions of radio-tagged northern squawfish during low discharge rates $\left(<5,664 \mathrm{~m}^{3} / \mathrm{s}\right)$ in McNary tailrace, July 19 - August 31, 1984, and June 21 - August 31, 1985.
} 


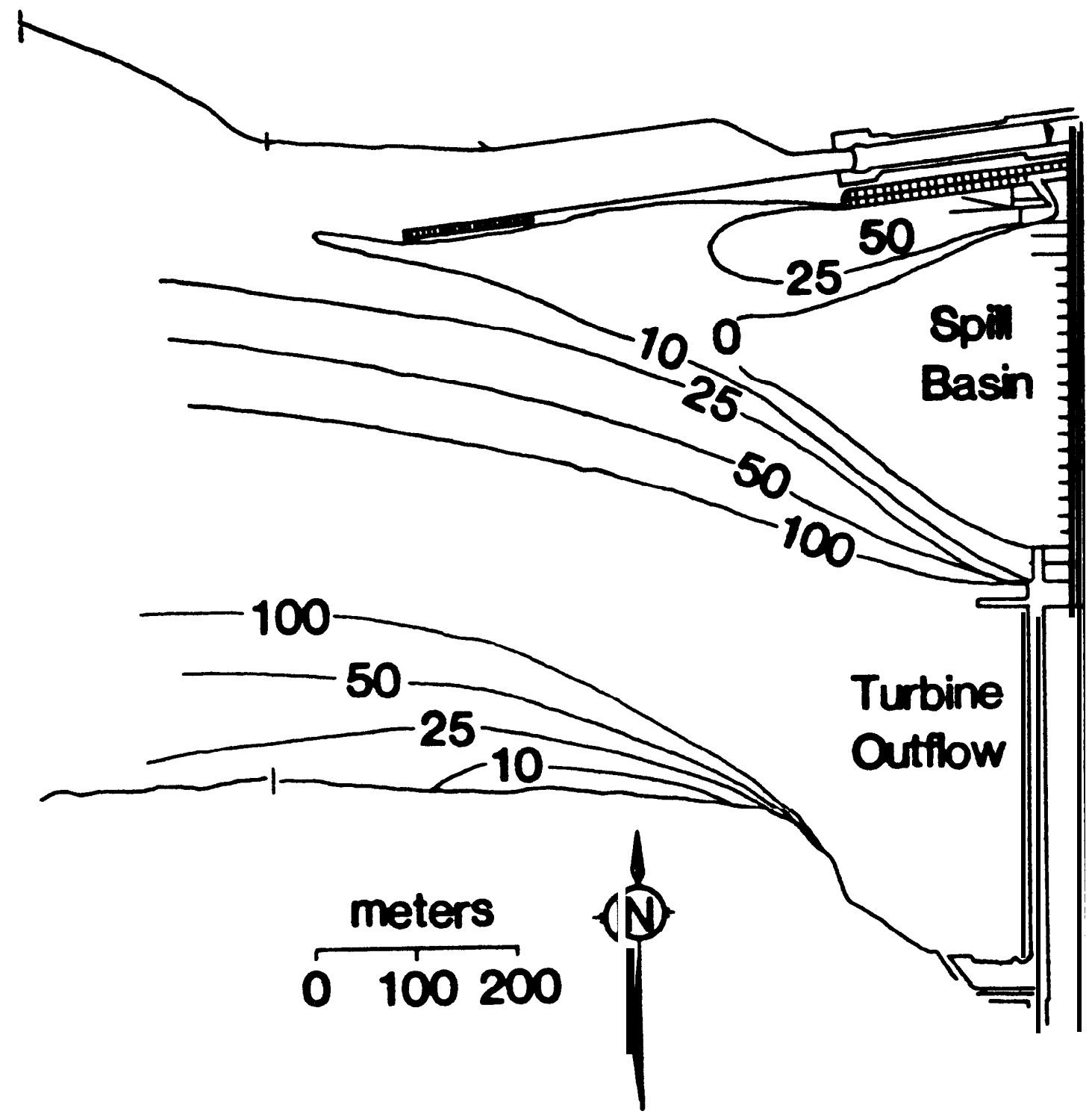

Figure 5. Typical isopleths of water velocities $(\mathrm{cm} / \mathrm{s})$ in McNary 
predators, however 79.0\% of the locations occurred in water velocities less than $50 \mathrm{~cm} / \mathrm{sec}$.

In spring and early summer, turbulence from spillgate operations and excessive discharge rates provided conditions that were not conducive to mapping velocities in the tailrace. We assume that velocities during high discharge rates and spillgate operations are invariably in excess of $\mathbf{1 0 0} \mathrm{cm} / \mathrm{sec}$ throughout the tailrace except for a small back-eddy mid-way along the navigation lock wall, a large slack-water area on the Oregon shore downstream of the turbine outflow and the slack-water area in the navigation lock channel. However, back-eddies or slack-water areas may exist in the spill basin if only a portion of the spillgates are opened, leaving points along the face of the dam without an origin of discharge. These conditions were common in 1985. Northern squawfish observed in the spill basin during periods of high discharge were either in a back-eddy along the spillgates or were located there during a period of spill closure.

The movements of northern squawfish were also monitored during short term spill closures to determine how abrupt changes in discharge can affect their distribution. Four out of 5 northern squawfish monitored during short term spill closures in May, 1985, moved out of protected areas and into the main river channel shortly after the spillgates closed. Two of these fish who were initially located along the navigation lock wall moved into close proximity of the by-pass outflow and the Washington shore adult fishway entrance (Fig. 6). Those fish that moved into the main river channel were observed the following day back in protected areas after the spillgates were reopened. Small sample sizes precluded the use of statistical analyses on spill closure movements.

SUMMARY AND CONCLUSION

Northern squawfish were associated with protected shoreline areas during periods of high water discharge, but moved into the main river channel and near the by-pass outflow when discharge decreased.

Northern squawfish were commonly observed in areas of low water velocity. These results imply that predation by northern squawish at fish passage facilities may be reduced by placing by-pass outflows in areas such that they are surrounded by high water velocity. The existing system at McNary Dam is efficient for reducing predator-prey interactions only during high discharge rates and spilling. Without spillgate operations, the north side of the by-pass outflow is exposed to a large slackwater area where northern squawfish were often located. However, by late summer when northern squawfish are congregated near the dam, all juvenile salmonids collected at the by-pass facility are transported by barge or truck; all outmigrants entering the tailrace do so through the turbines or adult fishways. 


\section{Evening}

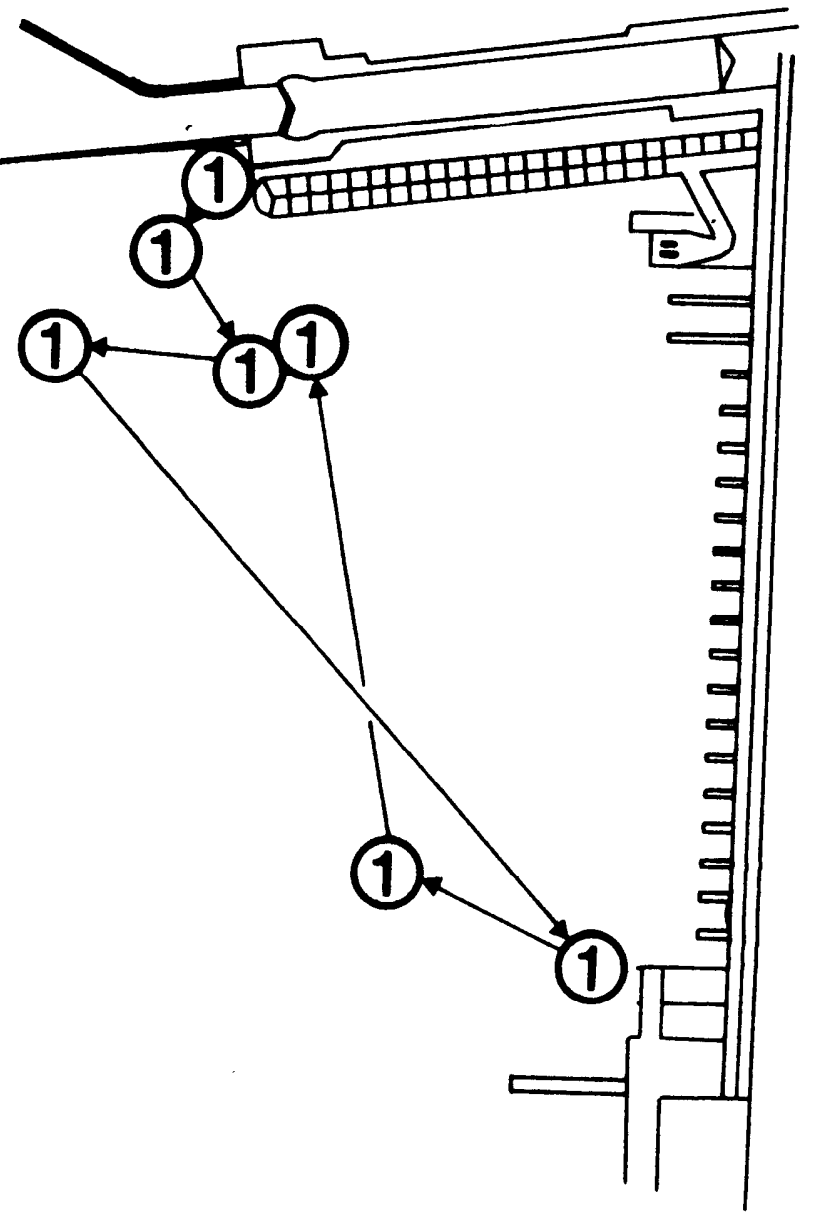

Morning

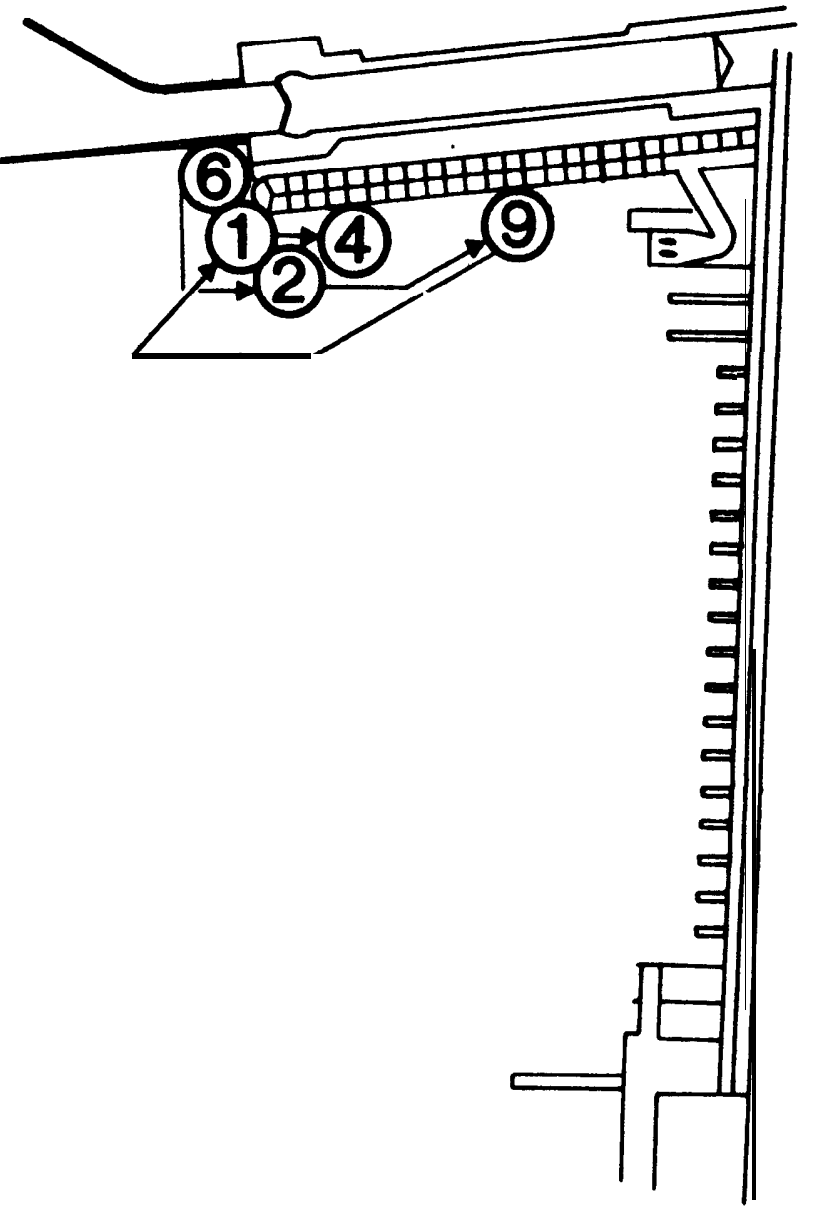


The predators seem to stage at flow shears along the turbine outflow and adult fishway entrances, and are likely to be taking advantage of outmigrants passing through these facilities. However, the effects of the flow regime on predator distributions imply that only those outmigrants who drift toward the exterior boundaries of high velocity areas are subject to spatial interaction with northern squawfish. No evidence was found to document the movement of northern squawfish into high flow areas where they might prey on juvenile outmigrants. Snol by-pass facilities with outlets that open into high velocity turbine outflows are currently in use at Bonneville and John Day dams on the Columbia River. Predator distributions in these areas should be examined to evaluate the effectiveness of this design in reducing the interaction of northern squawfish and juvenile salmonids during dam passage. Flow velocities at by-pass outlets need to be considered in the future design and location of by-pass facilities. 


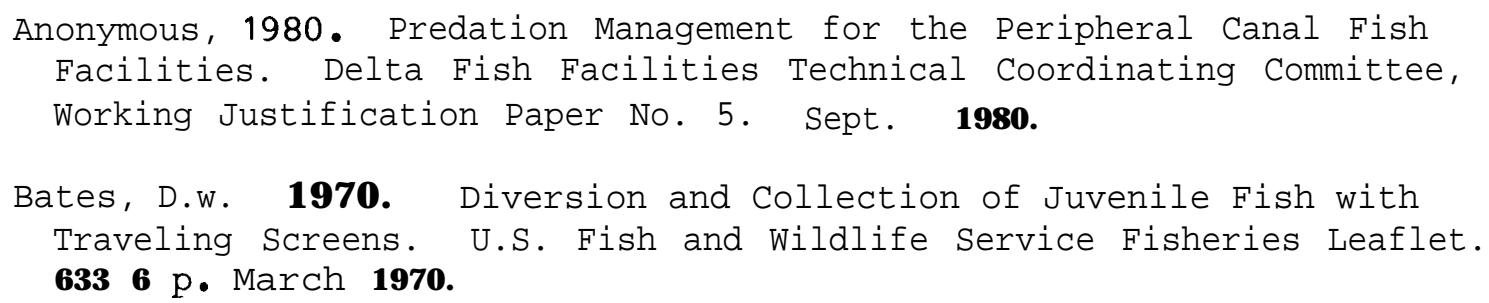

Gray, G.A., D.E. Palmer, B.L. Hilton, P.J. Connolly, H.C. Hansel, J.M. Beyer, and G.M. Sonneville. 1983. Feeding activity, rate of consumption, daily ration, and prey selection of major predators in the John Day Pool. Annual Report to the Bonneville Power Administration by U.S. Fish and Wildlife Service, Contract Number DI-A179-82BP34796, Portland, OR, USA.

Hart L.G. and R.C Summerfelt. 1975. Surgical Procedures for Implanting Ultrasonic Transmitters into Flathead Catfish (Pylodictis olivaris). Transactions of the American Fisheries Society. 104

\section{(1) : $\quad$ 56-59.}

Vogel. D.A. and J.G. Smith. 1984. Fish Passage Action program for Red Bluff Diversion Dam. Annual Progress Report. Fisheries Assistance Office, U.S. Fish and Wildlife Service, Red Cluff, CA, USA.

Winter, J.D., V.B. Kuechle, D.B. Siniff, and J.R. Tester. 1978. Equipment and methods for radio-tracking freshwater fish. University of Minnesota Institute of Agriculture, Miscellaneous Report 152, St. Paul, MN, USA. 
Size Selectivity and Bias in Estimates of Population Parameters of Smallmouth Bass, Walleye, and Northern Squawfish in a Columbia River Reservoir

RAYMOND C. BEAMESDERFER AND BRUCE E. RIEMAN

Oregon Department of Fish and Wildlife

17330 SE Evelyn Street, Clackamas, Oregon 97015, USA 
Si ze sel ecti vi ty of sampl i ng gear is a wi del y recogni zed probl em i n fi sheri es (Hayes 1983; Hubert 1983; Lagl er 1978; Reynol ds 1983; Ri cker 1975). A I sampl i ng gear are sel ecti ve to sone degree (Gul I and 1980) because of i ntri nsi c or extri nsi c factors (Lagl er 1978). I ntri nsi c factors such as $f i$ sh behavi or or habitat-pref erences, determi ne whi ch fi sh encounter the gear. Extri nsi c factors, i ncl udi ng constructi on of the gear and nethod of operation, determine if fish that encounter the gear are retai ned. If i gnored, unequal vul nerability of fish of different si zes to capt ure can resul $t$ in bi ased esti nates of popul ation parameters such as abundance, si ze structure, and mortal ity (Ham ey 1975; Ri cker 1975).

Bi as coul d be el i mated if differences i $n$ vul nerabi I ty could be neasured ( Lagl er 1978). Unf ort unatel y, si ze sel ecti vi ty is di ffi cul t to neasure ( Hanl ey 1975). Mbst neasurenents are based on i ndi rect observations such as si ze frequenci es and are expressed rel ati ve to the nost vul nerable si ze group (Hamley and Regi er 1973). However, where a vari ety of gear are used, rel ative vul nerabilities within a gear cannot be conbi ned to esti mate the net vul nerability to al gear wi thout an esti mate of anong gear di fferences i $n$ vul nerabi I ity. The nost vul nerabl e si ze groups are of ten assuned to be equal I y vul nerabl e to capt ure in each gear but thi s assumpti on is sel dom net (Hanl ey and Regi er 1973). Di rect esti mates of vul nerability to gear based on mark and recapt ure studies can be conbi ned to cal cul ate the net sel ectivity for each size of fish in a pool ed sample but di rect esti nates of vul nerability have been made onl y for a few fish in sel ected habi tats (Hanl ey and Regi er 1973).

I nstead of neasuring and adj usting for differential vul nerability, sampling is often desi gned to mi mize sel ectivity. Sel ectivity may be mi ni med by excl udi ng fi sh near the I i mits of vul nerability, usi ng l ess sel ecti ve types of gear, di vi di ng samples into subcategori es, or using a vari ety of gear ( Lagl er 1978, Ri cker 1975). These al ternati ves to measuring and adj usti ng for si ze sel ecti vi ty may sacrifice preci si on and may not el i mate bi as. Sample si zes are of ten I i mited and excl uding sampl es from near the li mits of vul nerability to a sel ected gear my sacrifice inf ormation. Seber (1982) describes the I oss of precisi on in esti mating abundance that resul ts when a popul ati on is spl it into subcategories to el i mate vul nerability differences and sample si zes are reduced. Sample si zes and preci si on al so are reduced when use of nore effective gear is precl uded by thei $r$ sel ective nat ure. Using several gear types may broaden the range of si zes sampled but may not el i mate si ze bi as because i ndi vi dual gear bi ases may not of $f$ set each other.

We recentl y compl eted a study of fish popul ations in a Col unbi a Ri ver reservoi $r$ where a mul ti gear sampl ing approach was adopted i $n$ an attempt to compensate for si ze-rel ated sel ectivity and represent popul at $i$ on structures for rout $i$ ne popul at $i$ on anal yses. The obj ect $i$ ves 


\begin{abstract}
We sampl ed smal I nouth bass (Micropterus dolomieui), ual I eye (Stizostedion vitreum), and northern squauf i sh (Ptychocheilus oregonensis) in J ohn Day Reservoi $r$ on the Col umbi a Ri ver from 1983-86 with five types of gear: two types of gill nets, boat el ectrofishers, trapnets and angl i ng. Di fferent gears sel ecti vel y sampl ed di fferent si zes of each speci es. Recapt ure rates i ndi cated that di fferent si zes of fi sh renai ned di fferenti al I y vul nerabl e to capt ure i n pool ed gear sampl es. Vul nerabi I ty of smal I mouth bass and wal l eye decl i ned wi th i ncreasi ng si ze. Vul nerabi I ity of northern squauf $\mathrm{i}$ sh i ncreased with si ze. Si ze sel ecti vi ty of gear resul ted i n esti mates of abundance potential Iy bi ased by 2 to $16 \%$ esti mates of proportional stock density ( si ze structure) bi ased by 11 to $46 \%$ and esti mates of annual rate of nortal ity bi ased by 17 to $69 \%$ The bi as uas negati ve i n esti mates of abundance and varied i n esti nates of si ze structure and nortal ity dependant on the pattern of vul nerability. In any I ong term noni tori ng of a popul ation, investigation of the nat ure of the bi as resulting from si ze sel ecti vity nould seem prudent.
\end{abstract}


$N$
$\uparrow$
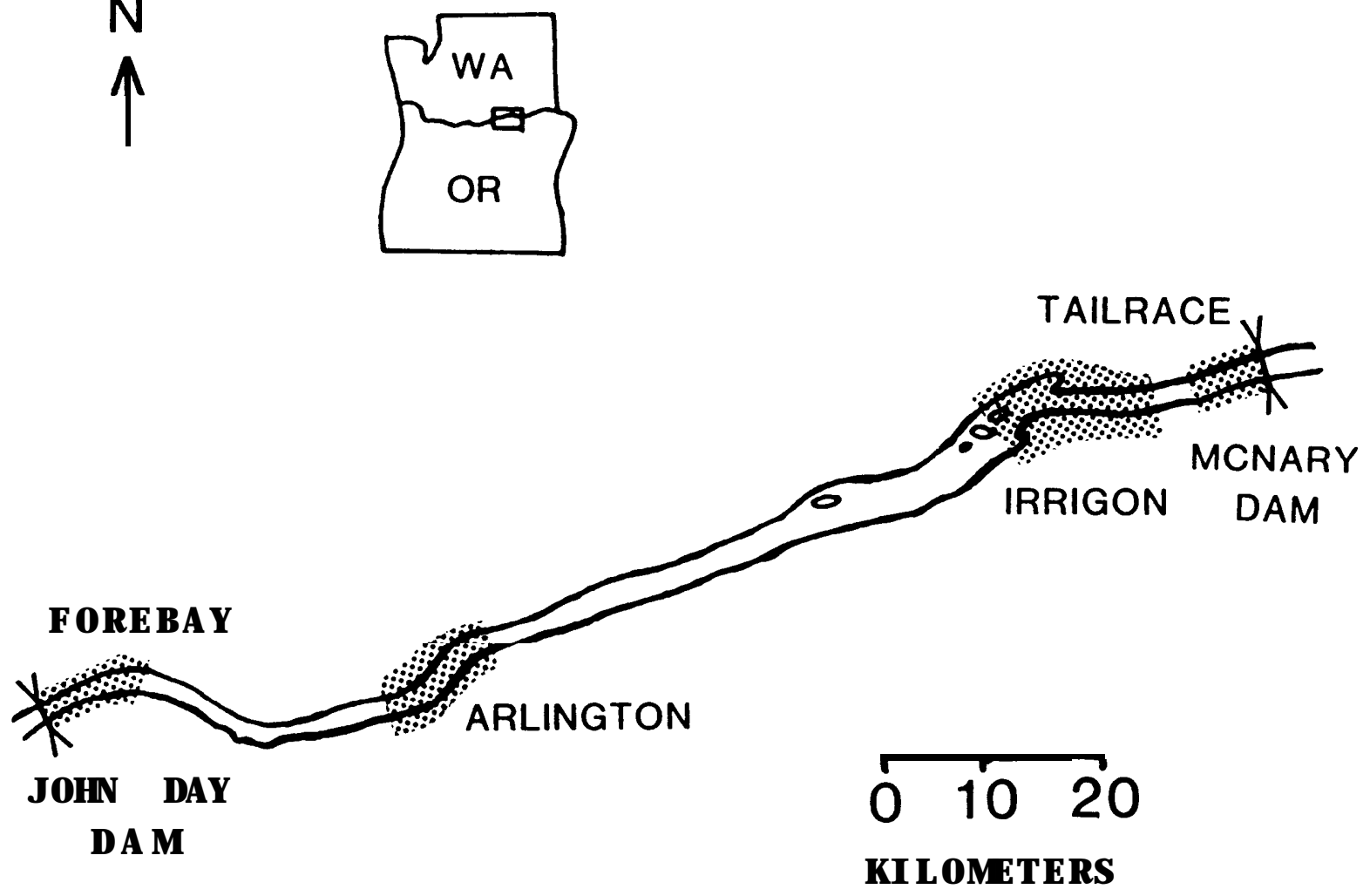

Fi gure 1. J ohn Day Reservoi r, Col unbi a Ri ver. Sampl ed areas are shaded. 
of thi s paper are to 1) describe size sel ectivity of five gears used to sampl e snal I nouth bass (Micropterus dolomieui), wal I eye (Stizostedion uviteum), and northern squauf i sh (Ptychocheilus oregonensis)) i n a Col unbi a $R$ i ver reservoi $r, 2$ ) descri be si ze sel ecti vity present i n conbi ned gear samples, and 3) determine potenti al bi ases in esti mates of abundance, size structure, and mortality if size sel ectivity vere i gnored.

\section{Study Si te}

J ohn Day Reservoi $r$ is one of a seri es of i mpoundments operated for hydroel ectric power generation, navi gati on and fl ood control on the I ouer Col unbi a Ri ver bet ween Oregon and Whshi ngt on ( Fi gure 1). The reservoi $r$ is $123-\mathrm{km}$ l ong, up to $3,5 \mathrm{~km}$ wi de, and has a surface area of about 20, 000 hectares. The reservoi $r$ is bounded by John Day ( Rkm 348) and MtNary (Rkm 471) Dans. A vari ety of habi tats occur in John Day Reservoi $r$. The upper reservoi $r$ is nore riverine al though high infl ous resul $t$ i n measureabl e current throughout the reservoi $r$." Of f shore depths range from $10 \mathrm{~min}$ the upper end of the reservoi $r$ to $50 \mathrm{~m}$ i $\mathrm{n}$ the I ower section. Shorel i nes are typical ly steep and I ittoral zone is I i mited.

\section{Methods}

We sampl ed four porti ons of J ohn Day Reservoi $r$ from Apri I through J une, 1983 to 1986 (Fi gure 1). Each area was sampl ed wi th equal effort duri ing each of $f i$ ve consecut $i$ ve, t wo- week peri ods. Fi sh were col l ect ed with two types of nonofilament gi II nets (45.6- $\mathrm{ml}$ ong by 2.4- $\mathrm{m}$ deep with al ternating panel s of 3.2, 4. 4, and 5.1-cm mesh and 45.6- $\mathrm{m} /$ ong by $2.4-\mathrm{m}$ deep with al ternating panel s of 6.4 and 7,6- $\mathrm{cm}$ mesh), Lake Eri e styl e trap nets ( 3 or 5- $\mathrm{m}$ deep wi th $61-\mathrm{m}$ l ong l eads of 3.2 or $3.8-\mathrm{cm}$ bar mesh), el ectrof i shi ng boats, and by angl ing from J ohn Day and MtNary Dans. Units of sampling effort were one hour for gi II nets, 24 hours for trapnets, and 15 mi nut es current-on ti ne for el ectrof $i$ shers. G II nets were set on the bottom near and perpendicul ar to shore. Trapnets vere set perpendi cul ar to shore with the lead end abutting the beach. El ectrof i shi ng runs were made al ong shorel i nes and dam faces. Al I sampl ing was done at ni ght. In addition, we exami ned the catch of sport angl ers fi shing in forebay, I rrigon and tai I race areas.

Snal I nouth bass, northern squauf $\mathrm{i}$ sh and wal I eye were capt ured, counted and measured. Fi sh i n good condi ti on were rel eased after narki ng with numbered spagetti tags and pel vic fi $\mathbf{n}$ cli ps or opercle punches. Tagging was I i mited to smal I mouth bass at l east $200 \mathrm{~mm}$ i $\mathrm{n}$ fork I ength and northern squauf i sh and wal I eye at l east $250 \mathrm{~mm}$ i $\mathrm{n}$ fork l ength. Subsequent recapt ures of marked $f i$ sh were counted. Scal es were col l ected from a subsample of $\mathrm{fi}$ sh and aged using standard methods (J earl d 1983).

We compared I ength frequenci es of each speci es anong gear to determine whether any gear sel ecti vel y sampl ed fi sh with respect to size ( Lagl er 1978). Si gni fi cant $(p<0.05)$ di f ferences in I ength frequenci es 

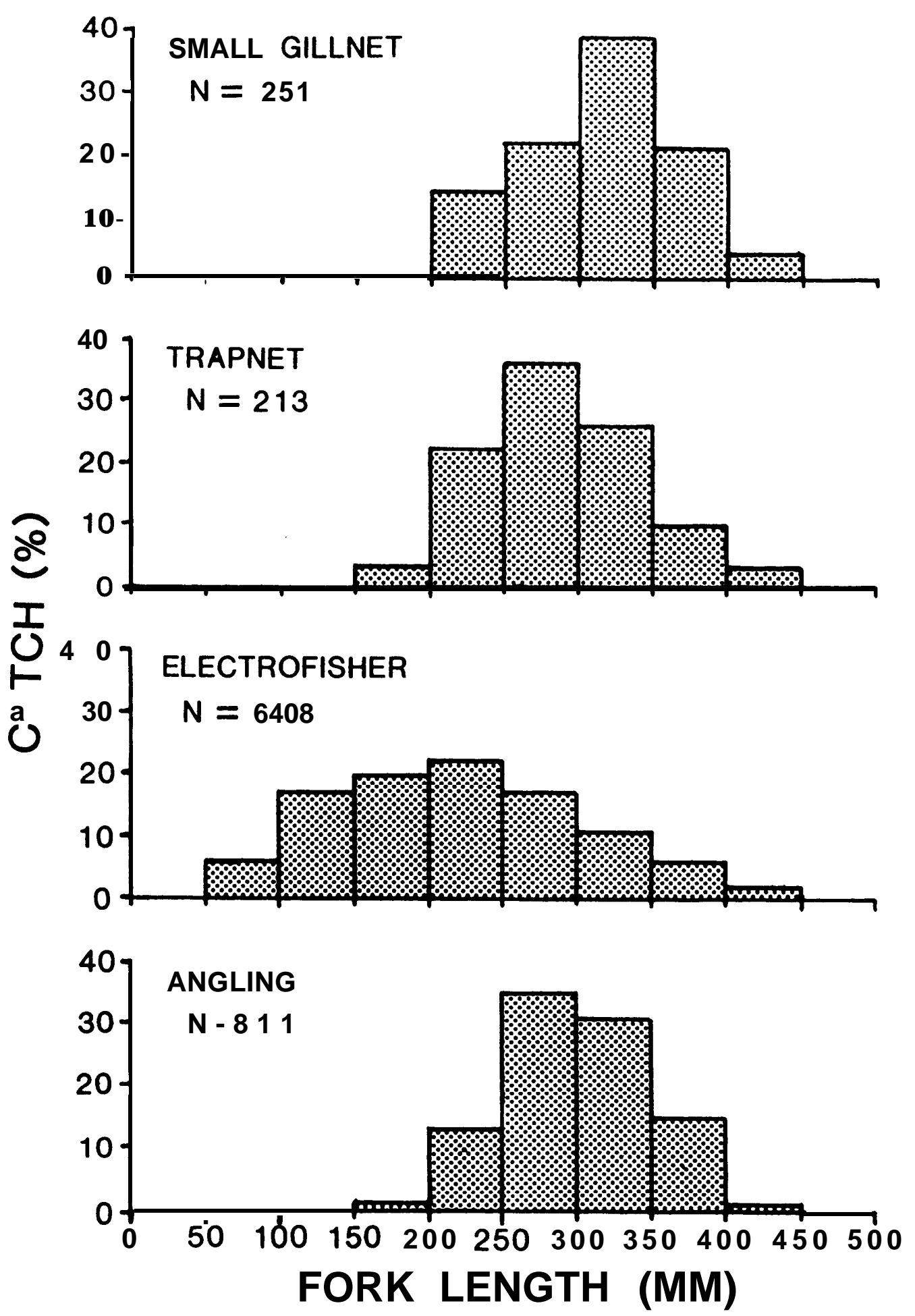

Fi gure 2. Length-frequency di stri buti ons of smal I nouth bass col l ected i n John Day Reservoi $r$ by four gears. 
anong gear were i dentifi ed wi th chi-square tests for i ndependence bet ween gear and I engtth(Steel and Tor ri e 1980). Sampl es whi ch contri buted I ess than $100 \mathrm{fi}$ sh were excl uded from compari sons because tests were i nval id at I ow sample si zes.

To deterni ne if a sample i ncl udi ng al I gear sel ected for di fferent si zes of $f i s h$, we compared numbers of recapt ures to marked $f i$ sh avai I abl e anong 50- $\mathrm{mm}$ si ze groups (Lagl er 1978). Si gni fi cant differences anong different sized fish were identified with chi-square cont i ngency tests (Youngs and Robson 1978). Sampl es from al I two- week sampl ing peri ods were pool ed for a tuo- way anal ysi s. Li nes describing rel ationships between vul nerability and size were fit with least squares regressi ons (Steel and Torrie 1980).

We esti mated the potenti al i nfl uence of si ze sel ectivity on esti nates of abundance, popul ati on si ze struct ure, and nortal i ty rate by comparing esti mates made with and wi thout corrections for size sel ecti vity. Abundance was esti mated from mark and recapt ure i nf or mati on wi th Chapnan's modi fi cati on of the Schnabel net hod (Seber 1982). To correct for si ze sel ecti vity, we made separate esti mates of abundance for si ze cl asses where vul nerability appeared si milar (Ri cker 1975). We report an average of annual esti mates of abundance made from 1984-86.

Popul ati on si ze st ruct ure was est i mated from a I ength f requency di stributi on (1983-86 sampl es pool ed). Si ze structure was descri bed as a proporti onal stock densi ty (PSD) (Anderson 1980). St ock and qual i ty si zes were arbitrarily defi ned as $18 \mathrm{~cm}$ and $28 \mathrm{~cm}$ for snal I nouth bass, $25 \mathrm{~cm}$ and $38 \mathrm{~cm}$ for wal l eye, and $25 \mathrm{~cm}$ and $38 \mathrm{~cm}$ for northern squaufi sh. Data uere corrected for si ze sel ecti vity by di vi di ng the observed frequency i $n$ each si ze cl ass by its rel ati ve vul nerabi li ty ( Lagl er 1978).

Mortal i ty was esti mated by catch curve ( Ri cker 1975) usi ng age f requenci es cal cul ated from I ength frequenci es and age at I ength i nf or mati on (Ketchen 1950). Sel ectivity effects on nortality uere corrected using l ength frequenci es adj usted for si ze sel ectivity by di vi di ng each frequency by the rel ati ve vul nerability to capt ure for that si ze.

\section{Results}

Smallmouth Bass

We col I ected di fferent si zes of smal I nouth bass wi th different gear (Figure 2). Differences in I ength frequencies were significant for fish I arger than $200 \mathrm{~mm}$ (X2=285. 9; df-15; P<0. 01).

We al so found di fferential si ze vul nerabi lity of smal I mouth bass i $n$ our pool ed gear sample (Figure 3). Differences in ratios of recapt ures to narked-fi sh-at-I arge rati os were si gni fi cant anong 50- $\mathrm{mm}$ si ze groups $\left(X^{2}=26.0 ;\right.$ df $\left.=5 ; \quad P<0.01\right)$. Vul nerabi I i ty decl i ned I i nearl y $\left(r^{2}=0.86\right)$ wi th 


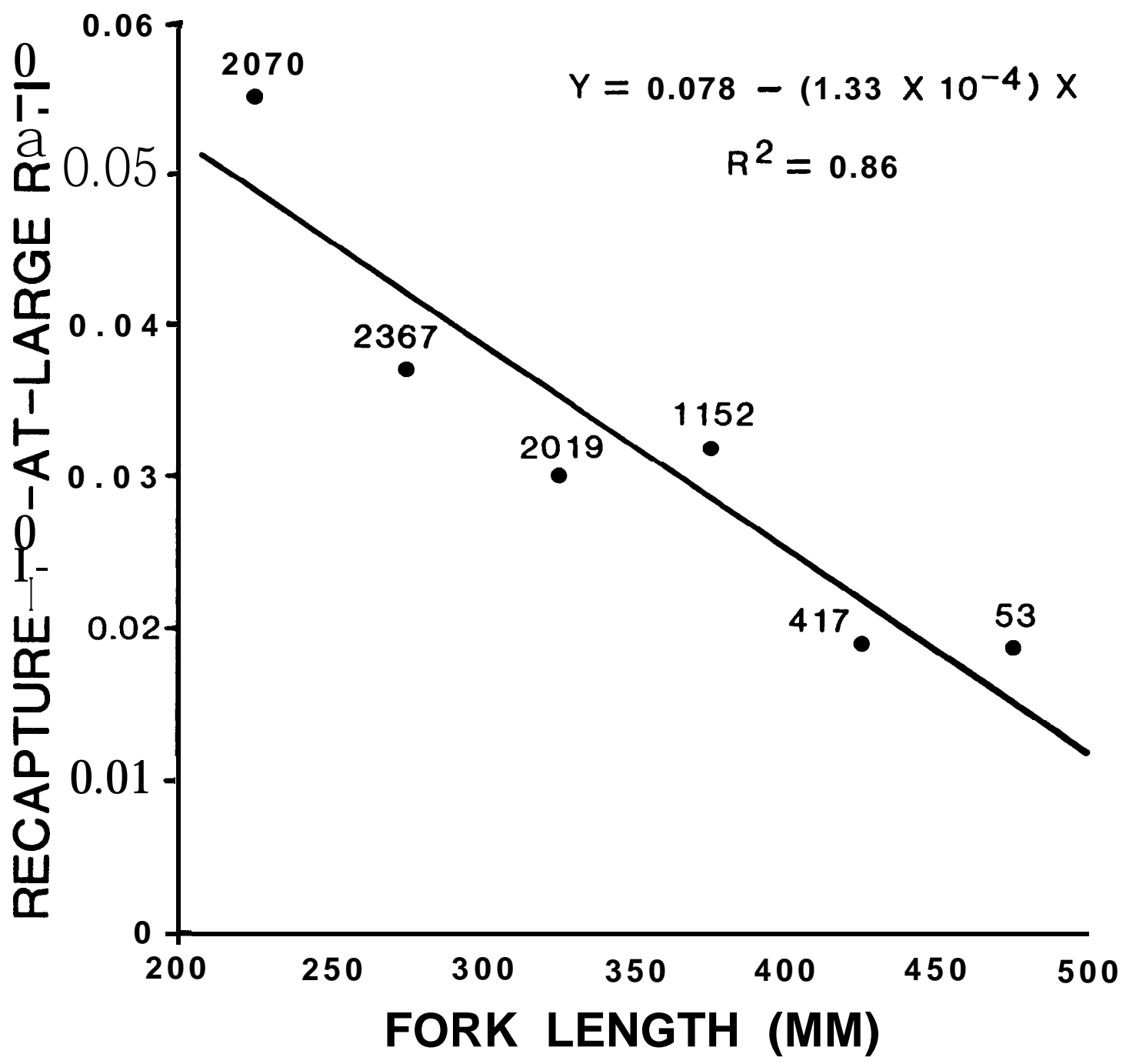

Fi gure 3. Ratio of recapt ures to marks at-I arge (vul nerability) for snal I nouth bass by I ength i nterval, John Day Reservoi $r$, Apri I-J une 1983-86. Numbers of narks at-I arge sumed for 24 tno- neek peri ods are i ncl uded for each point. A straight I i ne describing the rel ationshi $p$ was fit to ratios with the least squares method. 
i ncreasi ng size (Fi gure 3). The l east vul nerable si ze cl ass (451-500 mi) was one thi rd as vul nerable as the nost vul nerable si ze cl ass (201-250 m).

A I popul ati on parameters of smal I nouth bass were potent i al I y bi ased by size sel ecti vity of the combi ned gear (Table 1). Abundance esti mates corrected for vul nerability differed by less than $2 \%$ Potenti al bi as uas I arger in esti mates of PSD and annual nortality. Under-representati on of I arge snal I nouth bass in our catch resul ted i n bi ases of $-20 \%$ in the esti mate of PSD and $+22 \%$ in the esti mate of annual mortality rate.

Walleye

Si ze of nal l eye sampl ed al so vari ed by gear (Fi gure 4). Differences in I ength frequencies were signi ficant for fi sh I arger than $200 \mathrm{~mm}(X 2=726.2 ; d f=33 ; P<0.01)$.

Our data suggest that di fferential vul nerabi Iity to capt ure uas not el i mi nated in the pool ed gear sample (Figure 5). Di fferences i n recapt ure-t o- at- I arge rati os vere si gni fi cant anong 50-mm si ze groups $\left(x^{2}=103.8 ; d f=10 ; p<0.01\right)$. Vul nerability appeared to decrease dranati cal I y with i ncreasi ng wal l eye si ze above $450 \mathrm{~mm}$ (Fi gure 5). We esti mate that fish I arger than $500 \mathrm{~mm}$ may have been one thi $\mathrm{rd}$ as vul nerable as fish in the 351 to $450-\mathrm{mm}$ si ze group. Esti nates of vul nerability of wal l eye I ess than $351 \mathrm{~mm}$ were excl uded because of smal I sample sizes. A normal curve appeared to descri be the si ze-vul nerability rel ati onshi p anong wall eye (Fi gure 5).

Est i mates of wal I eye abundance, PSD, and nortal ity were i nf I uenced by the apparent si ze sel ecti vity of our gear (Table 2). Abundance was underesti mated by $16 \%$ PSD was underesti mated by $11 \%$. Esti nated annual mortal ity uas overesti nated by $17 \%$

N orthern Squawfish

Different gears took different si zes of northern squaufi sh (Fi gure 6). Di f f erences i $n$ I ength f requenci es were si gni $f i$ cant for fi sh I arger than $250 \mathrm{~mm}(\mathrm{X} 2=2634.7 ; \mathrm{fd}=15 ; \mathrm{P}<0.01)$. Di fferences in si ze- rel at ed vul nerability al so uere not el i mated in our pool ed gear sample (Figure 7).

Differences in recapt ure to at-I arge ratios were significant anong 50- $\mathrm{mm}$ si ze groups ( $X^{*}=15$. 1; df $\left.=4^{\prime} P<0.01\right)$. Vul nerabi I ity appeared to i ncrease with size anong northern squaufi sh up to $450 \mathrm{~mm}$ (Fi gure 7). Fi sh in the 401 to $450-\mathbf{m m s i} z e$ range were approxi matel y three ti mes more vul nerabl e than fish smal ler than $350 \mathrm{~mm}$ A normal curve appeared to describe the size-vul nerability rel ationshi $p$ anong northern squaufish ( Fi gure 7). 
Tabl e 1. Parameters of the smal I nouth bass popul at i on i $\mathbf{n}$ J ohn Day Reservoi $r$ based on esti mates with and wi thout corrections for si ze sel ecti ve sampl ing.

Popul ati on Paraneter

Correcti ons I ncl uded?

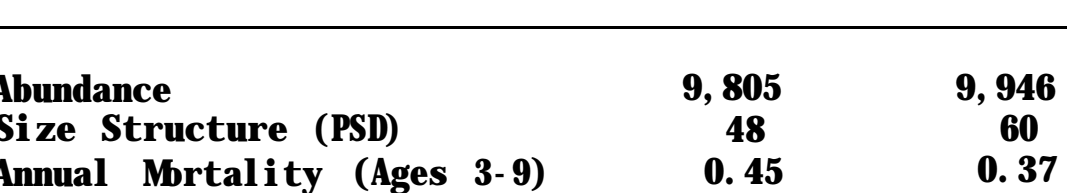

Tabl e 2. Parameters of the wal I eye popul ati on i $\mathbf{n}$ J ohn Day Reservoi $\mathbf{r}$ based on esti mates with and wi thout corrections for si ze sel ecti ve sampl i ng.

\begin{tabular}{|c|c|c|}
\hline Popul at i on Paranet er & $\frac{\text { Correcti ons }}{\mathrm{Nb}}$ & $\begin{array}{c}\text { I ncl uded? } \\
\text { Yes }\end{array}$ \\
\hline $\begin{array}{l}\text { Abundance } \\
\text { Si ze St ructure (PSD) } \\
\text { Annual Mbrtal ity (Ages 6-9) }\end{array}$ & $\begin{array}{c}16,212 \\
88 \\
0.56\end{array}$ & $\begin{array}{c}19,387 \\
99 \\
0.48\end{array}$ \\
\hline
\end{tabular}

Tabl e 3. Parameters of the northern squauf $i$ sh popul ati on in John Day Reservoi $r$ based on esti mates with and wi thout corrections for si ze sel ecti ve sampl ing.

Popul at i on Paranet er \begin{tabular}{cc} 
Correcti ons & I ncl uded? \\
\hline $\mathrm{Nb}$ & Yes
\end{tabular}

\begin{tabular}{|c|c|c|}
\hline $\begin{array}{l}\text { ture (PSD) } \\
\text { tal ity (Ages 5-13) }\end{array}$ & $\begin{array}{c}87,513 \\
51 \\
0.04\end{array}$ & $\begin{array}{c}97,084 \\
35 \\
0.13\end{array}$ \\
\hline
\end{tabular}



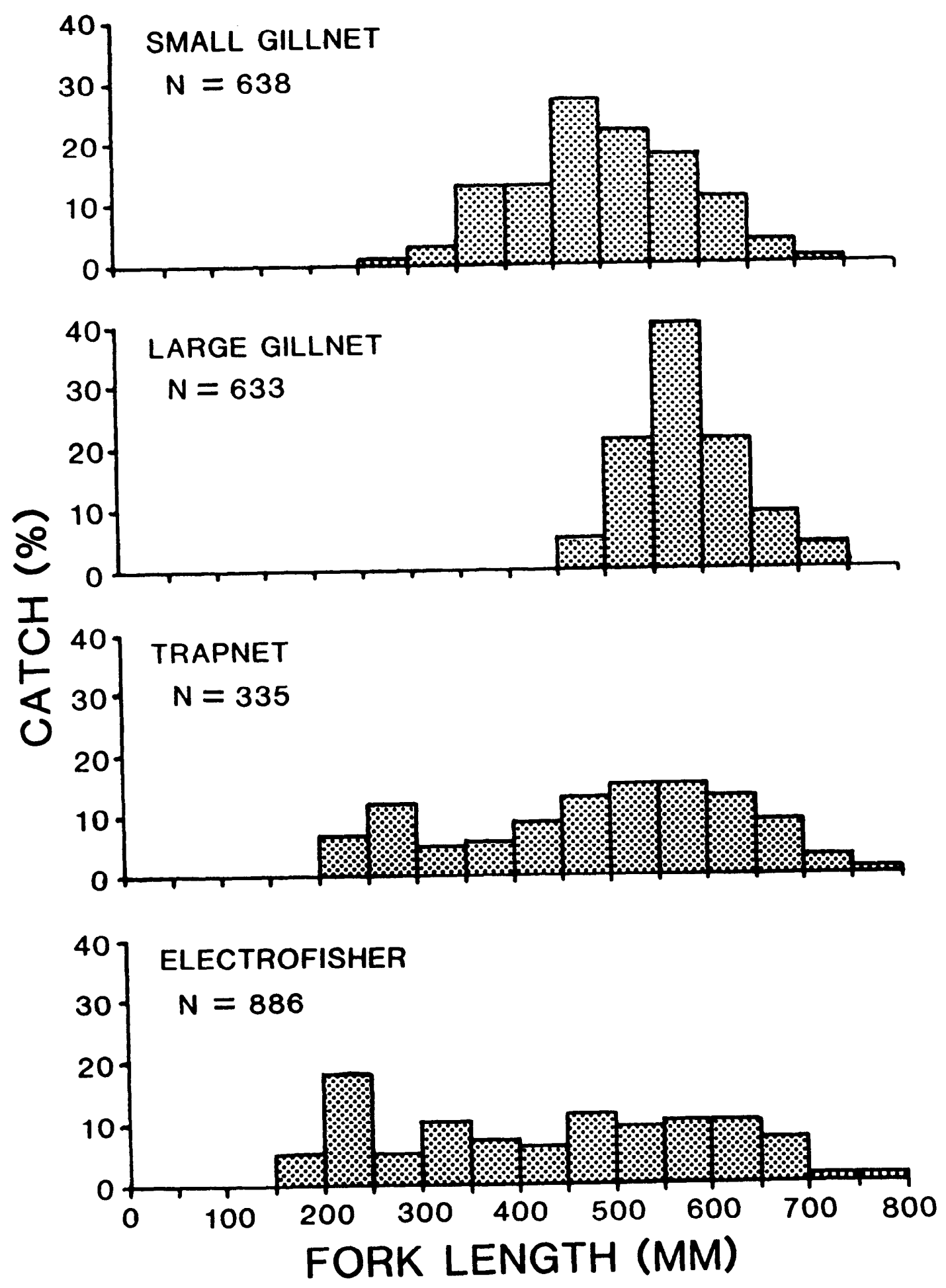

Figure 4. Length-frequency distributions of walleye collected in John Day Reservoir by four gears. 


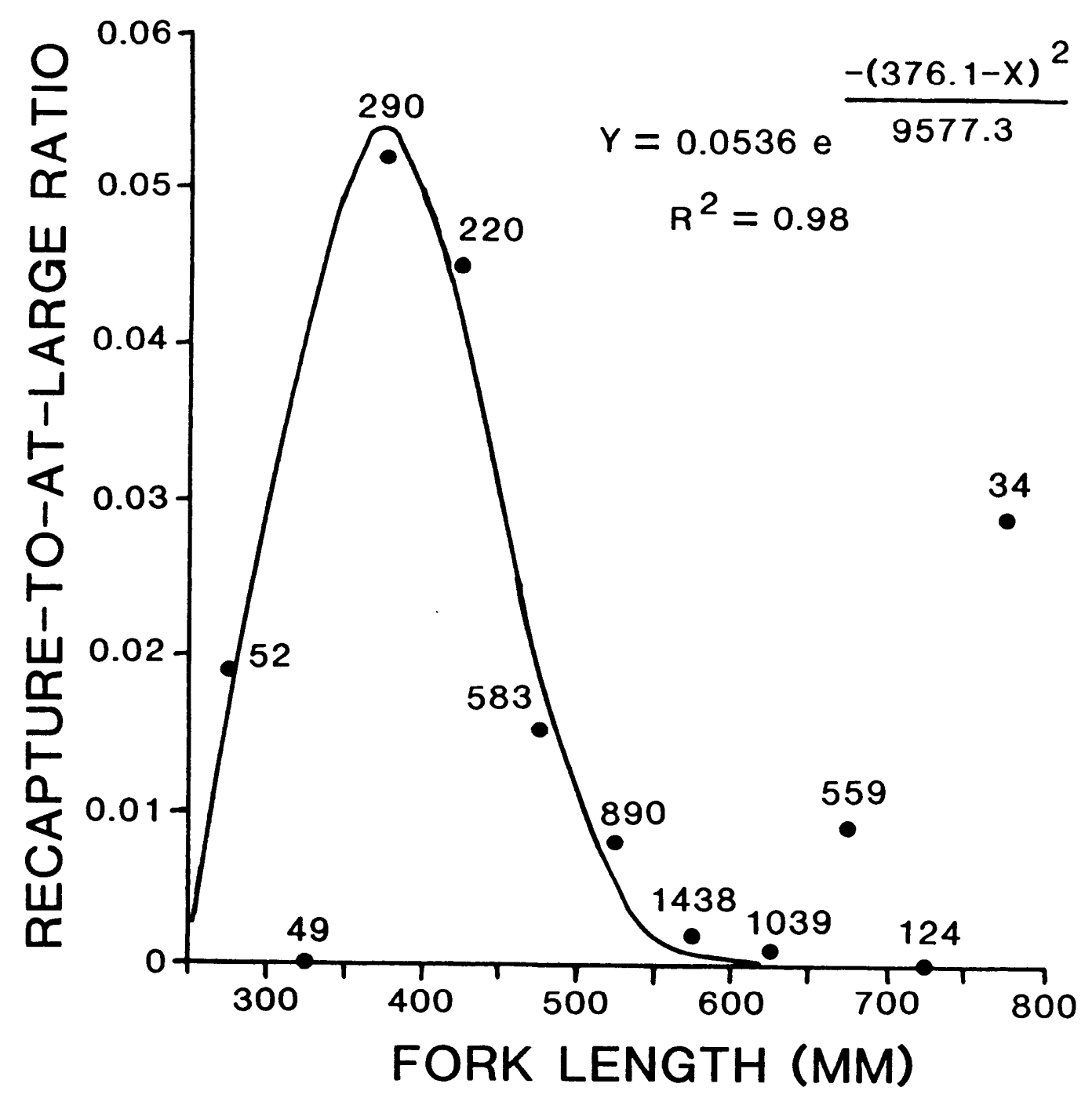

Figure 5. Ratio of recaptures to marks at-large (vulnerability) for walleye by length interval, John Day Reservoir, April-June 1983-86. Numbers of marks at-large summed for a 1124 two-week periods are included for each point. A normal curve describing the relationship was fit to ratios with the least squares method omitting points at 325 and $800 \mathrm{~mm}$. 

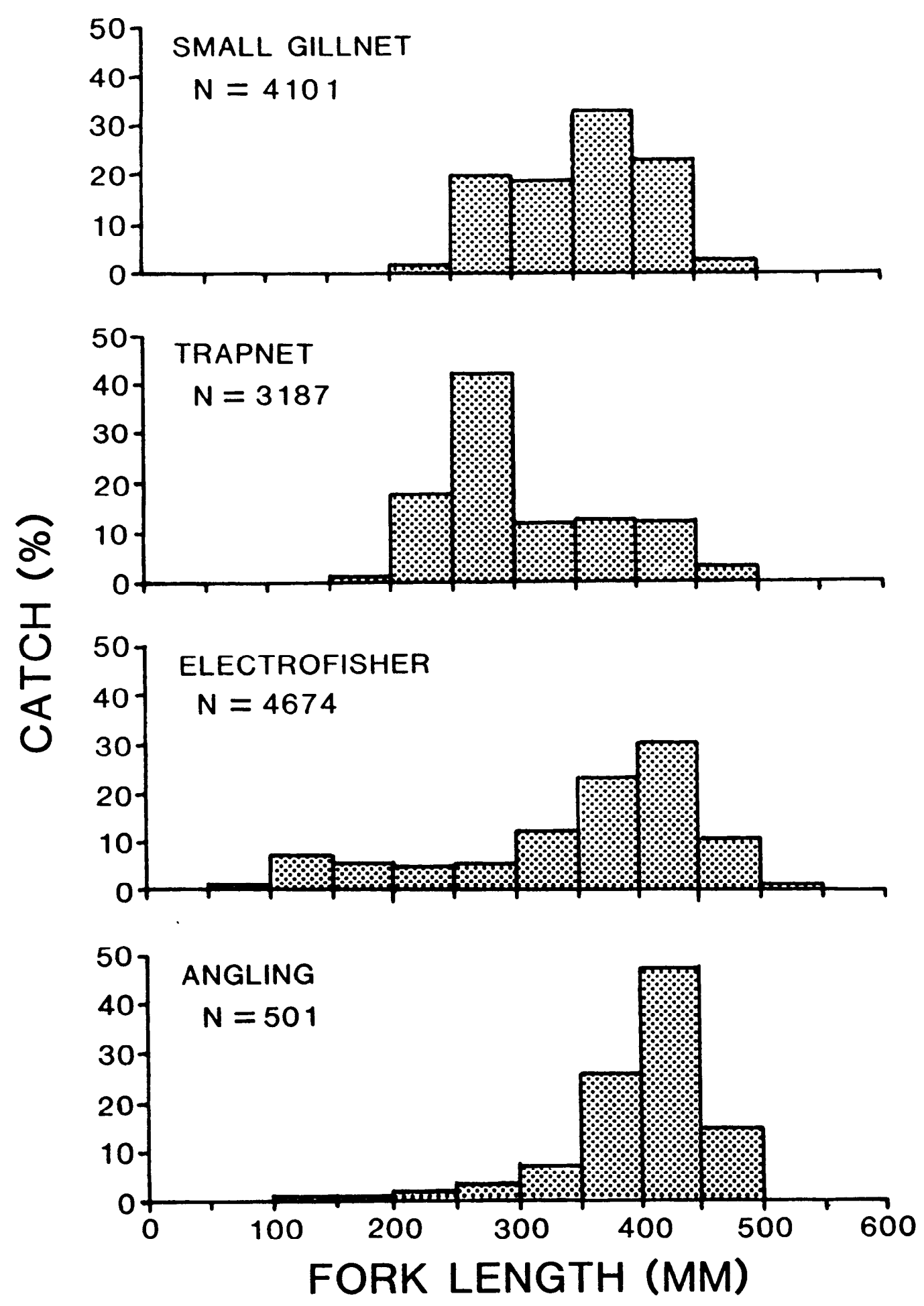

Figure 6. Length-frequency distributions of northern squawfish collected in John Day Reservoir by four gears. 


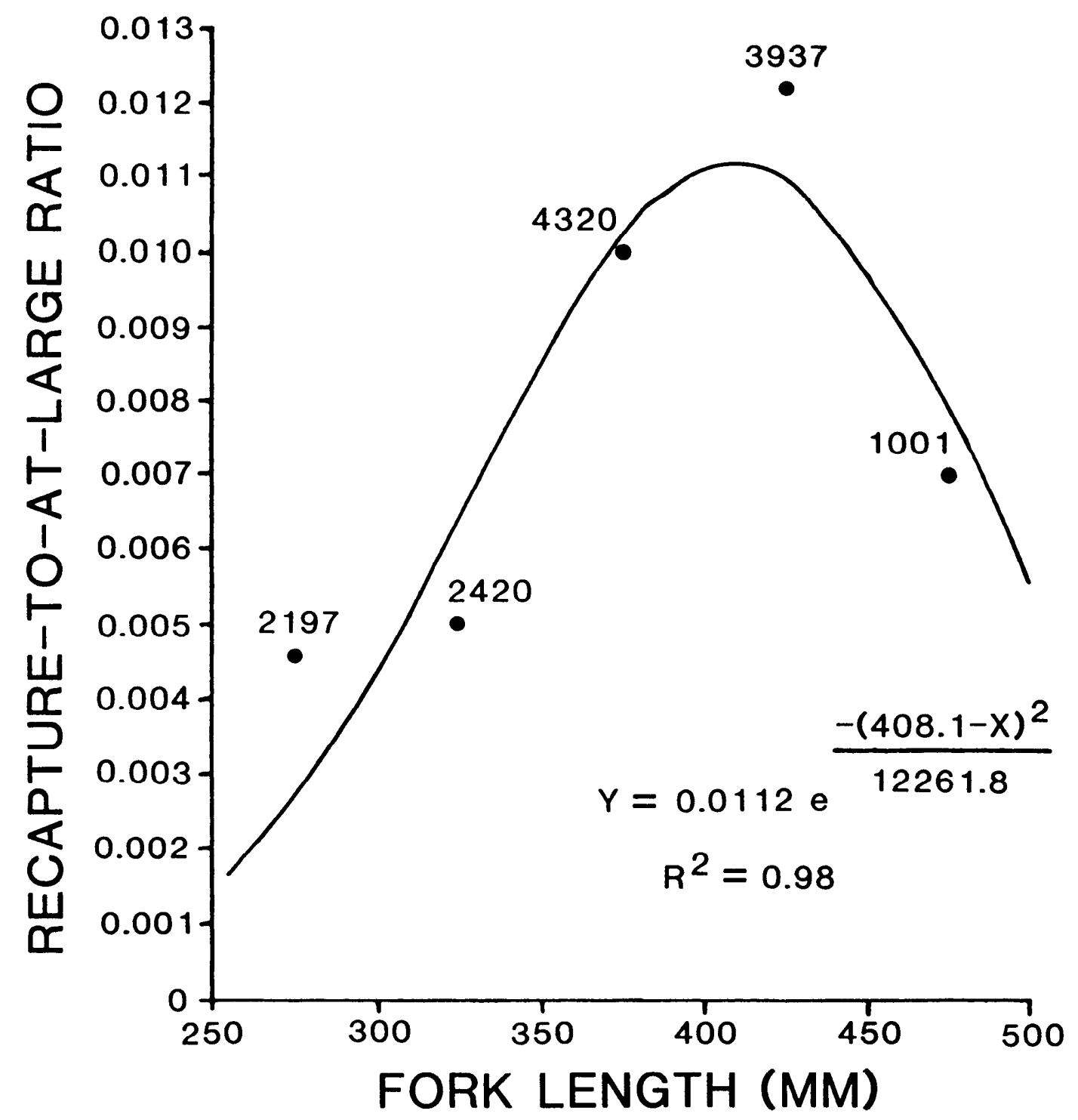

Figure 7. Ratio of recaptures to marks at-large (vulnerability) for northern squawfish by length interval, John Day Reservoir, Apri1-June 1983-86. Numbers of marks at-1arge summed for 24 two-week periods are included for each point. A normal curve describing the relationship was fit to ratios with the least squares method. 
Apparent si ze sel ecti vity of gear resulted i n potenti al l y bi ased esti mates of northern squauf $i$ sh abundance, si ze struct ure, and annual rate of mortal ity ( Table 3 ). Corrected and uncorrected abundance differed by $10 \%$, PSD esti mates differed by $46 \%$, and annual nortality esti nates differed by $69 \%$

\section{Discussion}

Differences in recapt ure to at-I arge rati os indi cate pool ing sampl es from si ze sel ective gear did not el i mi nate sel ectivity in the combi ned sample for any of the popul ations examined. Sel ectivity nould be el i mated onl y if sel ectiviti es of each gear bal anced exactl y, i e. each gear sel ected for a different size range of $f i s h$ at an equal rate. Thi s is probabl y an unreasonabl e expect ati on i $n$ al most any sampl ing si nce the rel ative sel ectivities cannot be predicted in advance.

Low recapt ure numbers and hi gh vari abi I ity of recapt ure-to- at-I arge ratios Ii mited our ability to describe changes in vul nerability with size, especially for wall eye and northern squaufi sh. Thi s problem was nost acute near the extrenes in si zes vul nerabl e to our col l ecti ve sampling because snal I sample si zes bi ased recapt ure-to-at-I arge rati os t owards zero.

The pattern of si ze selectivity was species specific. Vul nerabi i ity to capt ure decl i ned gradual I y wi th i ncreasi ng si ze anong smal I nouth bass, decli ned abruptly with i ncreasing si ze anong wal l eye and i ncreased abruptly over a snal I si ze range anong northern squauf $i$ sh.

Decreasi ng vul nerabi I ity of smal I nouth bass and wal I eye to capt ure wi th i ncreasing si ze may have been a resul $t$ of $I$ arger $f i$ sh using a broader range of habitats or areas than smaller fish. Reduced vul nerabi I i ty anong I arger fi sh would be expl ai ned if I arger fi sh spent l ess ti me near shore where most samples were taken or if I arge fi sh were nore I i kel y to nove outsi de sampl ed sections of the reservoi $r$. Offshore novements have been found to reduce catchabi I ity of I argenouth bass (Micropterus salmoides)( Van Den Avyl e 1976). Sex differences in si ze of maturity and behavi or duri ng spawni ng may al so have contri buted to differences i n vul nerabi I ity of wal l eye. Mal e wal l eye nat ure at snaller sizes than femal es, arrive at spauning sites earlier, and stay l onger ( Col by et al. 1979). Mal es coul d have been over-represented in the catch if sampling were concentrated near spawni ng si tes.

We have no explanation for the i ncreased vul nerability of northern squaufish with size. The shift may be rel ated to feeding acti vity and di stri buti on. Northern squauf $i$ sh becone al nost ent i rel y pi sci vor ous i n the si ze range where vul nerability changes (Gray and el even coauthors 1986). A correspondi ng change in foragi ng behavi or wi th i ncreased si ze may have resulted in fish spending more ti ne in areas we sampled. Larger northern squaufi sh were i ncreasi ngly pi sci vorous and may have spent nore ti me near shore where snall fi sh appeared nost abundant and our sampl ing was concentrated. 
Esti mates of abundance, popul ati on size structure, and annual nortal ity rates for al I three speci es uere susceptable to si ze sel ecti ve bi as. Bi as i $n$ esti mates of abundance ranged from $2 \%$ to $16 \%$ and were si mil ar to those reported in Ricker (1975) for comparabl e experi ments. Esti nates of PSD were bi ased by 11 to $46 \%$ Esti mates of annual nortal ity were bi ased by as mich as $69 \%$ The rel ati vel y smal I bi as i $n$ abundance esti nates may not uarrant correcting for si ze sel ectivity. Precision is sacrificed by making separate esti nates for differentially vul nerable si ze cl asses (Seber 1982) and the I oss of preci si on must be uei ghed agai nst the desi re for i ncreased accuracy.

The pattern of sel ectivity determi ned the di rection of the bi as except in esti mates of abundance. $B i$ as was al ways negati ve in esti mates of abundance when sampling was size sel ective. In esti mates of PSD, bi as was negati ve where vul nerabi I ity decl i ned wi th i ncreasi ng si ze and posi ti ve where vul nerabi I ity and si ze were i nversel y correl ated. Annual mortal ity was overesti mated when gear sel ected agai nst I arger fi sh and under est i mated when gear sel ected agai nst smal l er fi sh.

Our data show that substanti al bi as can resul $t$ i $n$ esti mates of popul ati on characteri stics when sampling is based on si ze sel ecti ve gear. Pool ing gear types in an ef fort to represent several speci es and habi tat types did not el iminate the potential for error, particularly for esti mates of PSD and mortal ity based on rel ati ve si ze structure of our sampl es. Our data al so show that the di recti on and magni tude of the bi as nay vary dranatically by species.

Fi shery managers routi nel y col l ect popul ati on age or si ze struct ure data. Often sample si ze is I i mited or data are col l ected i $n$ an i nconsi stent fashi on, maki ng esti mates of si ze-rel ated vul nerability i mpractical. Fi sheri es managers shoul d exerci se cauti on in the use of such data. In any I ong term moni tori ng of a popul at $i$ on, i nvesti gati on of the nature of the bi as woul $d$ seem prudent.

\section{Acknowl edgments}

We thank D. H Bennett, $\mathrm{HW} \mathrm{Li}$, and A A N gro for revi ew of this manuscri pt. Thi s research was f unded by the Bonnevi I l e Power Admi ni st rati on under cont ract DI-AI79-82BP35097.

\section{References}

Anderson, R. Q 1980. Proporti onal St ock Densi ty (PSD) and

Rel at i ve Wei ght $(W r)$ : i nterpreti ve i ndi ces for fi sh

popul ati ons and commini ti es. Pages 27-33 in S. G oss and B. Shupp, editors. Proceedings of the First Annual Wbrkshop, Practical Fi sheri es Managenent: More with I ess in the 1980's. New York Chapter, Aneri can Fi sheri es Soci ety. 
Col by, P.J., R. E. McNicol, and R. A Ryder. 1979. Synopsis of bi ol ogi cal data for wall eye, Stizostedionvitreum (Mi tchel I 1818). Food and Agri culture Organi zati on of the Uni ted Nations Fi sheri es Synopsi s Number 119.

Gray, G A, and el even coauthors. 1986. Feedi ng acti vity, rate of consumption, daily ration, and prey sel ecti on of maj or predators i n John Day Reservoi r, 1984. U. S. Fi sh and Vil dl ife Servi ce Annual Report to Bonnevi I I e Power Admi ni strati on, Contract DE-AI7982BP34-796, Port I and, Oregon.

Gulland, J .A 1980. General concepts of sampling fi sh. Pages 7- 12 in T. Backi el and R. L. Welcomme, edi tors. Gui del i nes for sampl ing fi sh i n i nl and waters. European I nl and Fi sheri es Advi sory Commi ssi on Techni cal Paper 33. Food and Agri cult ure Organi zation of the Uni ted Nations, Rone I tal y.

Han ey, J.M. 1975. Revi ew of gillnet sel ectivity. Journal of the Fi sheri es Research Board of Canada 32:1943-1969.

Hanl ey, J.M, and H A Regi er. 1973. Di rect esti mates of gillnet sel ectivity to ual l eye. J ournal of the Fi sheri es Research Board of Canada 30:817-830.

Hayes, M L. 1983. Acti ve fi sh capt ure methods. Pages 123-146 in L. A $\mathrm{N}$ el son and D. L. Johnson, edi tors. Fi sheri es techni ques.

Aneri can Fi sheri es Soci ety, Bet hesda, Maryl and.

Hubert, WA 1983. Passi ve Capt ure Techni ques. Pages 95-122 in L. A $\mathbf{N}$ el son and D. L. J ohnson, edi tors. Fi sheri es techni ques. Aneri can Fi sheri es Soci ety, Bethesda, Maryl and.

J earl d, A.,Jr. 1983. Age determi nati on. Pages 301-325 in L. A $\mathbf{N}$ el son and D. L. Johnson, edi tors. Fi sheri es techni ques. Aneri can Fi sheri es Soci ety, Bethesda, Mryl and.

Ketchen, K. S. 1950. St ati fi ed subsampl i ng for determi ni ng age di stri buti ons. Transacti ons of the Aneri can Fi sheri es Soci ety $79: 205-212$.

Lagl er, K. F. 1978. Capt ure, sampl ing and exami nati on of fi shes. Pages 7-47 i n T. Bagenal, edi tor. Methods for assessnent of fi sh producti on in fresh waters, 3rd edi ti on. Bl ackwel I Sci enti fic Publ i cati ons, London.

Reynol ds, J.B. 1983. El ect r of i shi ng. Pages 147- 164 in L. A $\mathbf{N}$ el son and D. L. J ohnson, edi tors. Fi sheri es techni ques. Aneri can Fi sheri es Soci ety, Bethesda, Maryl and.

Ricker, WE. 1975. Computati on and i nterpretati on of bi ol ogi cal statistics of $\mathrm{f} i$ sh popul ati ons. Fi sheri es Research Board of Canada Bul l eti n 191. 
Seber, G A F. 1982. The esti nati on of ani mal abundance and rel at ed paraneters, 2nd Editi on. MacMII an Publ i shi ng Company, I nc., New York.

Steel , R. G. D. and J.H Torrie. 1980. Pri nci pl es and procedures of stati stics. MtGraw HII, New York.

Van Den Avyle, M.J. 1976. Anal ysi s of seasonal di stri buti on patterns of young I argenouth bass (M icropterus salmoides) by use of frequency- of-capt ure data. J ournal of the Fi sheri es Research Board of Canada 33:2427-2432.

Youngs, WD. , and D. S. Robson. 1978. Est $i$ nat $i$ on of popul at $i$ on nunber and nortality rates, 3rd edition. Pages 137-164 in T. Bagenal, editor. International Bi ol ogi cal Programe Handbook Number 3. Bl ackuel I Sci ent i fi c Publ i cations, Oxf ord. 
MOCPOP: A Flexible Simulator for Analysis of Age-Structured Populations and Stock-Related Functions

RAYMOND C. BEAMESDERFER

Oregon Department of Fish and Wildlife

17330 SE Evelyn Street, Clackamas, Oregon 97015, USA 


\section{WHAT IS MOCPOP?}

MOCPOP is a program for simulating annual variation in a population of organisms based on recruitment, mortality, and growth. Commonly used models of population dynamics (Vaughan et al. 1982), including stock-recruitment, logistic (surplus production), dynamic pool (yield), and Leslie matrix or combinations or portions of these models can be approximated with MOCPOP. MOCPOP tracks population size in numbers and biomass, and also calculates numbers of particular interest to harvest managers including yield, number of harvestable individuals, and an index of population size structure.

I wrote this software to simplify use of the computer in modeling populations. It provides the flexibility to simulate a variety of populations and population processes with a minimum of experience with. microcomputers and no knowledge of computer language or programming. MOCPOP was adapted from population models outlined by Taylor (1981) and Walters (1969) but with greater flexibility in reproduction and recruitment processes. Programming was built around processing to aide manipulation of input population parameters and inspection of simulation results.

HOW TO RUN MOCPOP

To run MOCPOP you must:

1. Boot machine with PC-DOS or MS-DOS.

2. Place diskette containing model in default drive.

3. Start the model (type MOCPOP10 after > prompt and press Enter).

The program may be interrupted by pressing Control+Break or exited by selecting the Quit Option (\#13) in the Output Options Menu (See page $3)$.

MOCPOP is written in compiled Microsoft QuickBASIC v4.0 to run on IBM and IBM-compatible machines. Graphics require an IBM color graphics adaptor or a functional equivalent. Hercules monochrome graphics cards are not supported.

HOW MOCPOP WORKS

MOCPOP is organized into 3 parts. The input section prompts the user to select processes that describe their population and to supply appropriate starting numbers and parameters. The processing section runs the appropriate simulation. The output section displays the results of the simulation. 
Each time MOCPOP is executed, it writes inputs to a data file on the MOCPOP diskette. You are prompted for a name for this data file to which MOCPOP adds the extension .MPK. File names may be up to 8 characters long, typed in upper or lower case, and may include spaces. You may create any number of these data files with MOCPOP, but you must use the DOS command ERASE <filename> to remove them from your diskette. Instead of re-entering inputs each time you use MOCPOP, you may edit your earlier inputs and run a new simulation or you may rerun a simulation with inputs entered previously. MOCPOP will check the diskette for files with the extension .MPK, list these files, and prompt you to select one.

Execution of the program is controlled from two main menus and one submenu. The "Run Option Menu" is displayed when the program is started and controls the input process. Run Options include:

1. BUILD A NEW MODEL.

2. EDIT SELECTED INPUTS IN AN EXISTING MODEL.

3. RUN EXISTING MODEL WITH DEFAULT OR EDITED INPUTS.

Run Option \#1 builds a new model from scratch. Run Option \#1 prompts for a name to assign the file in which inputs for the new model are to be saved, then steps through each input one at a time before starting the simulation. The Build a New Model Option (Run Option \#1) has no provision for going backward; you must press Ctrl+Break and restart if you make an entry error. Run Option \#2 uses inputs from a previous simulation but allows changes before the simulation starts. Run Option \#2 displays names of files containing inputs from previous simulations, prompts you to select a file, gives you the option of renaming the file, then displays a list of inputs that may be changed in an "Edit Options Submenu". You select the desired inputs, make changes, and start the simulation from the "Edit Options Submenu" (See page 4). The Edit Selected Inputs Option (Run Option \#2) lets you go back and change inputs you've already passed by reselecting the same option from the menu. Run Option \#3 immediately starts the simulation after prompting you for the name of the file containing desired inputs.

The "Output Options Menu" is displayed when the simulation is completed. Output Options include:

1. LIST INPUT INFORMATION.

2. LIST REPRODUCTION BY AGE.

3. LIST POPULATION BY AGE.

4. LIST HARVEST, YIELD, AND EFFECT BY AGE.

5. LIST POPULATION BY YEAR. 
6. CALCULATE SUMMARY STATISTICS FOR POPULATION OVER TIME.

7. PLOT SELECTED VARIABLES.

8. WRITE BY-AGE RESULTS TO FILE.

9. WRITE BY-YEAR RESULTS TO FILE.

10. CONTINUE PRESENT SIMULATION WITH NEW PARAMETERS.

11. RETURN TO START FOR NEW SIMULATION.

12. TEMPORARY RETURN TO DOS (SHELL).

13. QUIT.

Output Option \#1 displays a summary of inputs upon which the current results are based. Output Options \#2-4 list age-specific numbers in the last year of the simulation. Output Option \#5 lists a summary of population numbers in each year of the simulation. output Option \#6 calculates mean, range, and standard deviation of population numbers over a selected time interval. Output Option \#7 plots simulation results as a line graph. Output Options \#8-9 write simulation results to a diskette file. Output Option \#10 allows the current simulation to be continued after returning to the input section and changing parameters. Output Option \#11 returns to the Run Option Menu to start a new simulation. Output Option \#12 allows a temporary return to DOS without losing simulation results. Output Option \#13 ends execution of MOCPOP and returns to DOS. A more detailed discussion of Output Options \#1-10 can be found in the section on output.

INPUT

In the input section, MOCPOP sequentially prompts you to select processes that describe your population and to enter appropriate starting numbers and parameters. Default values for each input are read from the data file you selected and are displayed in brackets. Default values are also displayed for menu options to speed execution of the program. Defaults can be accepted by pressing Enter or changed by typing in a new value and pressing Enter. Inappropriate numbers will not be accepted and you will have to enter a new number. Commas in numbers are not accepted. Decimal fractions may or may not be preceeded with a zero. As appropriate inputs are entered, MOCPOP automatically advances to the next input or moves to the next screen.

Inputs are organized into seven categories, and each category corresponds to one screen in the input section. These screens are accessed in order by Option \#1 in the Run Option Menu (build a new model) and are accessed selectively by Run Option \#2 (edit selected inputs). Selection of Run Option \#2 displays a listing of these 
categories in the Edit Options Submenu. Input screens-categories in order are:

1. YEARS TO RUN.

2. MAXIMUM AGE AND STARTING POPULATION SIZE.

3. RECRUITMENT.

4. MORTALITY.

5. LIFE HISTORY PARAMETERS.

6. AGE SPECIFIC WEIGHTING FACTORS.

7. AGE STRUCTURE INDEX.

Input Screen \#1 prompts for the number of years to run the simulation. The starting year is year 1. A maximum of 300 years may be run.

Input Screen \#2 prompts for maximum age and a starting population. The number of individuals must be entered for each age class. A maximum of 100 age classes may be entered. If the population has no age structure, enter a maximum age of 1.

Input Screen \#3 prompts for the mechanism of recruitment and associated parameters. Recruitment is defined as the number of age 1 individuals at the start of the year. Recruitment can be varied independently or as a function of parental stock size.

Nine Recruitment Options exist:

1. CONSTANT AT NUMBER ENTERED AS AGE 1 NUMBER ABOVE.

2. CONSTANT AT AGE 1 INPUT EXCEPT FOR BIG YEAR CLASSES AT FIXED INTERVALS.

3. CONSTANT AT AGE 1 INPUT EXCEPT FOR BIG YEAR CLASSES AT RANDOM INTERVALS.

4. RANDOM WITH EQUAL CHANCE OVER A SPECIFIED RANGE.

5. RANDOM NORMAL WITH SPECIFIED MEAN AND STANDARD DEVIATION.

6. STOCK RELATED--PROPORTIONAL TO REPRODUCTIVE POTENTIAL.

7. STOCKRELATED--BEVERTON-HOLTRELATIONSHIP.

8. STOCK RELATED--RICKER RELATIONSHIP.

9. STOCK RELATD-CUSHING RELATIONSHIP. 
Recruitment Options \#1-3 use the number of age 1 individuals entered in the starting population screen as an average condition. Recruitment Options \#2-3 allow replacing this average recruitment with a severalfold increase at fixed or random intervals. If Recruitment Option \#2 or \#3 is selected, you will be prompted for this multiplication factor. For Recruitment Option \#2, you will also be prompted for the interval at which big year classes occur and the first year of a big year class. For Recruitment Option \#3 you will be prompted for the average frequency with which big year classes occur. The probability of a big year class in any given year would thus be the inverse of this frequency.

Recruitment Options \#4 and \#5 select recruitment as random either with equal probability between a specified minimum and maximum (Option \#4) or with varying probability distributed normally with a specified mean and standard deviation (Option \#5).

Recruitment Options \#6-9 select recruitment as a function of stock size, and factor in parental stock size indirectly by calculating reproductive potential for each parental age class. Recruitment at age 1 is calculated as the product of this potential egg deposition, and an egg-to-age-l survival rate calculated from an input on the mortality rate screen (Input Option \#4). In Recruitment Option \#6, recruitment is thus calculated directly from reproductive potential. In Recruitment Options \#7-9, a realized egg deposition is calculated from the potential egg deposition using the density dependent relationship indicated. Age 1 numbers are then calculated as the product of this realized egg deposition and the egg-to-age-1 survival rate.

Density-dependant relationships between reproductive potential and realized egg deposition include those described by Beverton-Holt, Ricker and Cushing.

The Reverton-Holt equation is

where

$$
R=1 /(a+b / P)
$$

$R=$ actual egg deposition,

$\mathrm{P}=$ potential egg deposition, and

$a, b=$ parameters describing the shape of the curve. If you select this equation, you will be prompted for "a" and "b".

The Ricker equation is

$$
\left.R=P e^{a(1-P / P}\right)
$$

where

$\mathrm{e}=2.718$

$\mathrm{a}=\mathrm{a}$ parameter describing the shape of the curve, and 
$\operatorname{Pr}=$ replacement egg deposition at equilibrium.

You will be prompted for "Pr" and "a" if you select this option. See Ricker (1975) for a discussion of these functions and methods for estimating parameters.

The Cushing equation (Kimura et al. 1984) is

$$
R=\operatorname{Emax}\left(P / P_{\max }\right)^{c}
$$

where

$P=$ population size,

Emax = maximum egg deposition,

$P \max =$ population size at Emax, and

$\mathrm{c}=\mathrm{a}$ constant describing strength of relationship.

If you select this option, you will be prompted for "Emax", "Pmax", and "c".

Input Screen \#4 prompts for mortality rates. Two sources of mortality are allowed: natural and exploitation. If you selected a stock related Recruitment Option, you will be prompted for a mortality rate from egg to age 1 . You have the following options for egg-to-age-1 mortality:

1. CONSTANT.

2. RANDOM WITH EQUAL CHANCE OVER A SPECIFIED RANGE.

3. RANDOM NORMAL WITH A SPECIFIED MEAN AND VARIANCE.

You will be prompted for numbers appropriate for the option you select. You are also prompted for a series of natural mortalities for ages 1 and above. Enter the conditional annual rate. After each rate you will be asked for the maximum age to which it applies. The minimum age is 1 greater than the maximum for the previous entry. You will continue to be prompted until you enter the maximum age individuals may reach (but the maximum number of age-specific entries is 20). You may thus enter a mortality rate for all ages without having to type in a number for each, or you may choose to enter a number for each age. In addition, you are prompted for the minimum and maximum exploitable sizes, and the annual rate of exploitation. You may enter exploitation for up to 20 , nonoverlapping size classes.

Input Screen \#5 prompts for life history parameters related to calculations of length and weight at age and of reproductive potential. Included are parameters for a von Bertalanffy age-length equation (Linf, $\mathrm{k}$, to), an exponential length-weight equation (coefficient and exponent), an exponential length-fecundity equation (coefficient and exponent), the age at which females first mature, the proportion of the population over the age of maturity that is female, and the proportion 
of mature females that spawn in any year. You will be prompted for a series of proportions of females spawning in any year. After each entry you will be asked for the maximum age to which it applies. The minimum age is 1 greater than the previous entry except for the first entry where the minimum age is the age at which females first mature. You will continue to be prompted until you enter the maximum age individuals may reach (but the maximum number of entries is 20). You may thus enter a proportion for all ages without having to type in a proportion for each, or you may choose to enter a proportion for each age.

Input Screen \#6 prompts for age-specific weighting factors that can be used to project the effect of the population on another component of the system (the weighted effect). Weighting factors are input for each age. You are also prompted for the expression of population size or growth that is to be weighted. Choices include number, biomass, and production.

Input Screen \#7 prompts for sizes used in calculating an index of population size structure analagous to proportional stock density (PSD) (Anderson 1980). The index is calculated as the number of individuals within one pair of minimum and maximum sizes (the numerator) divided by the number within a second pair of minimum and maximum sizes (the denominator).

\section{PROCESSING}

Processing is based on a series of difference equations. Given a number of individuals at the start of the year, the sequence of events is reproduction, exploitation, and death from natural causes.

The age-specific numbers of individuals at the start of the first year of the simulation are an input. Age-specific numbers of individuals (Nx) after the first year are calculated by the equation

$$
N_{x+1, t+1}=\left(N_{x}, t\right)\left(S_{x}\right)
$$

where

Sx $=$ age-specific annual survival rate, and

$\mathrm{t}=$ year.

Age-specific annual survival is calculated as

$$
S x=1-\left(m_{x}+n_{x}-\left(m_{x}\right)\left(n_{x}\right)\right)
$$

where

$m x=$ exploitation (harvest mortality rate), and

$\mathrm{nx}=$ conditional natural mortality rate. 
Biomass present in each age class $\left(\mathbf{B}_{\mathbf{x}}\right)$ is estimated

$$
\mathrm{Bx}, \mathbf{t}=\left(\mathbf{N}_{\mathbf{x}}, \mathbf{t}\right)\left(\mathbf{W}_{\mathbf{x}}\right)
$$

where

$\mathbf{W}_{\mathbf{x}}=$ age-specific weight (units same as those supplied in length-weight equation).

Age-specific weights are calculated with age-length and length-weight equations using input parameters

$$
\begin{gathered}
L x=L_{1 n f}\left(1-e^{-k(x-t 0)) \text { a nd }}\right. \\
W_{x}=(a w)\left(L_{x} b_{w}\right)
\end{gathered}
$$

where

Lx $=$ length at age,

$L_{1} \mathbf{n} f=$ von Bertalanffy equation length at infinity,

$\mathbf{k}=$ von Bertalanffy equation parameter,

to $=$ von Bertalanffy equation parameter,

$\mathrm{aw}=$ length-weight equation coefficient, and

bw = length-weight equation exponent.

Reproductive potential of each age class $\left(\mathbf{P}_{\mathbf{x}}\right)$ at or above the age of female maturity is estimated by

$$
P x, t=\left(N_{x}, t\right)\left(F_{x}\right)(p f)\left(p s_{x}\right)
$$

\section{where}

$\mathbf{F x}=$ age-specific fecundity of females,

pf = proportion of population that is female, and

psx $=$ age-specific proportion of females that spawn in any year.

Fecundity is estimated by

$$
F x=(a f)\left(L x^{b f}\right)
$$

where

af = length-fecundity equation coefficient, and
bf = length-fecundity equation exponent.

The net reproductive potential of all ages in any given year is

$$
P=\operatorname{Sum}\left(P_{x}\right) .
$$

This is the number upon which stock-related recruitment functions, discussed in the Input section (Page 5), operate to calculate recruitment at age $1\left(\mathbf{N}_{1}\right)$. 
All animals are harvested at one time. Harvest in number (catch) and weight (yield) from an age class are calculated by

$$
\begin{aligned}
& H x=\left(N_{\mathbf{x}}\right)\left(\mathbf{m}_{\mathbf{x}}\right) \text { and } \\
& \mathbf{Y}_{\mathbf{X}}=\left(\mathbf{N}_{\mathbf{X}}\right)\left(\mathbf{m}_{\mathbf{x}}\right)\left(\mathbf{W}_{\mathbf{X}}\right)
\end{aligned}
$$

where

$\mathrm{Hx}=$ age-specific numbers of individuals removed by exploitation, and $Y_{\mathbf{x}}=$ age-specific weight of individuals removed by exploitation.

Annual production of any age class $\left(P D_{\mathbf{x}}, t\right)$ is calculated by

$$
P D_{x, t}=\left(\left(N_{x+1}, t+1 W_{x+1}+N x, t W_{x}\right) / 2\right)\left(\log W_{x+1}-\log W_{x}\right) .
$$

The weighted effect of any age class $\left(\boldsymbol{E}_{\mathbf{x}}\right)$ is calculated by

$$
\mathrm{Ex}=\left(\mathrm{N}_{\mathbf{x}}\right)\left(\mathbf{W} \mathbf{F}_{\mathbf{x}}\right)
$$

where

$W F_{\mathbf{x}}=$ age-specific weighting factor.

\section{OUTPUT}

The Output Option Menu was listed on page 2. Simulation results in the form of tables, summary statistics, or graphs may be displayed from this menu. Examples of these outputs follow. You may get a hard copy of any of the output tables and summary information by pressing Shift+PrtXc when the desired information is displayed. You may get a hard copy of a plot by pressing $P$ when the plot is displayed.

\section{Output Option \#1 \\ (List Input Information)}

This option lists a short summary of processes, starting numbers, and parameters upon which the current simulation is based. It also lists the name of the file containing this input information, the date, and the time. These lists may be printed and attached to simulation results for reference. 
Output Option \#2

(List Reproduction by Age)

LISTING OF AGE-SPECIFIC REPRODUCTION INFORMATION IN YEAR 8

\begin{tabular}{|c|c|c|c|c|c|c|c|c|}
\hline AGE & LENG & WGT & NUM & FECUND & P FEM & P SPN & PER FISH & EGGS \\
\hline 1 & 76 & 4 & 10000 & 76 & 0.50 & 1.00 & 38 & $0.3803 E+06$ \\
\hline 2 & 137 & 28 & 5000 & 137 & 0.50 & 1.00 & 69 & $0.3432 E+06$ \\
\hline 3 & 191 & 79 & 2500 & 191 & 0.50 & 1.00 & 95 & $0.2386 E+06$ \\
\hline 4 & 238 & 160 & 1250 & 238 & 0.50 & 1.00 & 119 & $0.1487 \mathrm{E}+06$ \\
\hline 5 & 279 & 266 & 900 & 279 & 0.50 & 1.00 & 140 & $0.1256 \mathrm{E}+06$ \\
\hline 6 & 315 & 392 & 648 & 315 & 0.50 & 1.00 & 158 & $0.1021 \mathrm{E}+06$ \\
\hline 7 & 347 & 532 & 467 & 347 & 0.50 & 1.00 & 173 & $0.8091 E+05$ \\
\hline 8 & 375 & 680 & 336 & 375 & 0.50 & 1.00 & 187 & $0.6291 E+05$ \\
\hline \multirow{2}{*}{\multicolumn{3}{|c|}{ TOTAL }} & \multirow{2}{*}{\multicolumn{2}{|c|}{21100.48}} & & & \multirow{2}{*}{\multicolumn{2}{|c|}{$\begin{array}{ll}\text { POTENTIAL } & 1482315 \\
\text { REALIZED } & 1482315\end{array}$}} \\
\hline & & & & & & & & \\
\hline
\end{tabular}

where

LENG = length in units from age-length equation ( $L x)$,

WGT $=$ weight in units from length-weight equation $\left(W_{\mathbf{x}}\right)$,

$\mathrm{NUM}=$ number of individuals in population $\left(\mathbf{N}_{\mathbf{x}}\right)$,

FECUND $=$ fecundity of females in age class $\left(\boldsymbol{F}_{\mathbf{x}}\right)$,

$\mathbf{P F E M}=$ proportion of population that is female (pf)

$\mathbf{P}$ SPN $=$ proportion of females that spawn in any year $(\mathbf{p s} \mathbf{x})$,

PER FISH $=$ fecundity per individual in population $\left(\left(\boldsymbol{F}_{\mathbf{x}}\right)(\mathbf{p f})\left(\mathbf{p s}_{\mathbf{x}}\right)\right)$, and

EGGS $=$ reproductive potential in age class $(\mathbf{P})$. 
Output Option $\mathbf{3}$

(List Population by Age)

LISTING of AGE-SPECIFIC POPULATION INFORMATION IN YEAR 8

\begin{tabular}{|c|c|c|c|c|c|c|c|c|c|}
\hline AGE & LENG & WGT & START & EXPL & NTRL & SURV & NEW & BIOMASS & PROD \\
\hline 0 & & & 1482315 & & 0 & 1 & & & \\
\hline 1 & 76 & 4 & 10000 & 0.00 & 0.50 & 0.500 & & 42089 & 169926 \\
\hline 2 & 137 & 28 & 5000 & 0.00 & 0.50 & 0.500 & 5000 & 138368 & 177032 \\
\hline 3 & 191 & 79 & 2500 & 0.00 & 0.50 & 0.500 & 2500 & 198136 & 139752 \\
\hline 4 & 238 & 160 & 1250 & 0.10 & 0.20 & 0.720 & 1250 & 199929 & 111938 \\
\hline 5 & 279 & 266 & 900 & 0.10 & 0.20 & 0.720 & 900 & 239571 & 95802 \\
\hline 6 & 315 & 392 & 648 & 0.10 & 0.20 & 0.720 & 648 & 254256 & 76673 \\
\hline 7 & 347 & 532 & 467 & 0.10 & 0.20 & 0.720 & 467 & 248372 & 58493 \\
\hline 8 & 375 & 680 & 336 & 0.10 & 0.20 & 0.000 & 336 & 228542 & 0 \\
\hline \multicolumn{2}{|c|}{ TOTAL } & \multicolumn{3}{|c|}{21100} & & \multicolumn{3}{|r|}{$15493 \mathrm{E}+02$} & 829616 \\
\hline
\end{tabular}

where

$\mathrm{AGE}=0$ refers to reproductive potential,

LENG $=$ length in units from age-length equation (Lx),

WGT $=$ weight in units from length-weight equation $\left(w_{x}\right)$,

START $=$ number of individuals at the start of the year $\left(\mathbf{N}_{\mathbf{x}}, \mathbf{t}\right)$,

EXPL $=$ ex[ploitation or harvest mortality rate $(\mathrm{mx})$,

NTRL $=$ conditional natural mortality rate $\left(n_{\mathbf{x}}\right)$,

SURV = age-specific annual survival rate $\left(S_{\mathbf{x}}\right)$,

NEW = number of individuals surviving to the start of the next year from the previous age class $\left(\mathbf{N}_{\mathbf{x}}, \mathbf{t}+\mathbf{1}\right)$,

BIOMASS $=$ weight of all individuals at the start of the year $\left(B_{\mathbf{x}}, t\right)$, and

PROD = production of biomass by age class including individuals that di e $\left(P D_{x}\right)$. 
Output Option \#4

(List Harvest, Yield, and Effect by Age)

LISTING OF HARVEST, YIELD, AND EFFECT IN YEAR 8

\begin{tabular}{|c|c|c|c|c|c|c|c|c|c|}
\hline \multicolumn{2}{|c|}{ AGE LENG } & WGT & \multicolumn{3}{|c|}{ START EXPL CATCH } & YIELD & WT VAR & FACTOR & EFFECT \\
\hline 1 & 76 & 4 & 10000 & 0.00 & 0 & 0 & 0 & 0.00 & 0 \\
\hline 2 & 137 & 28 & 5000 & 0.00 & 0 & 0 & 0 & 0.00 & 0 \\
\hline 3 & 191 & 79 & 2500 & 0.00 & 0 & 0 & 0 & 0.00 & 0 \\
\hline 4 & 238 & 160 & 1250 & 0.10 & 125 & 19993 & 0 & 0.00 & 0 \\
\hline 5 & 279 & 266 & 900 & 0.10 & 90 & 23957 & 0 & 0.00 & 0 \\
\hline 6 & 315 & 392 & 648 & 0.10 & 65 & 25426 & 0 & 0.00 & 0 \\
\hline 7 & 347 & 532 & 467 & 0.10 & 47 & 24837 & 0 & 0.00 & 0 \\
\hline 8 & 375 & 680 & 336 & 0.10 & 34 & 22854 & 0 & 0.00 & 0 \\
\hline & OTAL & & 21100 & & 360 & 117067 & & & 0 \\
\hline
\end{tabular}

where

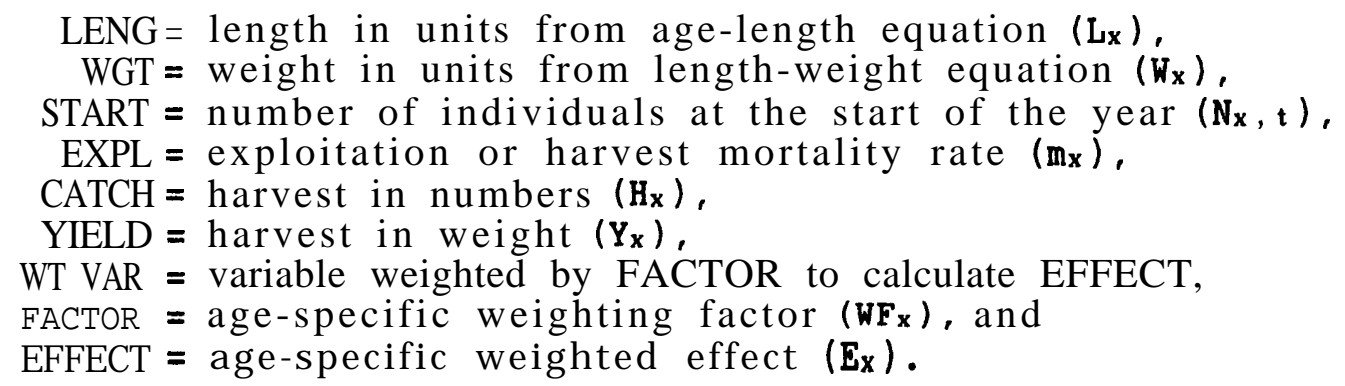

LENG = length in units from age-length equation ( $\left.L_{x}\right)$,

WGT $=$ weight in units from length-weight equation $\left(\boldsymbol{W}_{\mathbf{x}}\right)$,

START $=$ number of individuals at the $\operatorname{start}$ of the year $\left(\mathbf{N}_{\mathbf{x}}, \mathbf{t}\right)$,

EXPL $=$ exploitation or harvest mortality rate $\left(\mathbf{m}_{\mathbf{x}}\right)$,

$\mathrm{CATCH}=$ harvest in numbers $\left(\mathrm{H}_{\mathbf{x}}\right)$,

YIELD $=$ harvest in weight $\left(Y_{\mathbf{x}}\right)$,

WT VAR $=$ variable weighted by FACTOR to calculate EFFECT,

FACTOR = age-specific weighting factor $\left(W_{\mathbf{x}}\right)$, and

EFFECT $=$ age-specific weighted effect $\left(E_{x}\right)$. 
Output Option \#5

(List Population by Year)

SUMMARY OF ANNUAL POPULATION INFORMATION BY YEAR

YEAR NUM BIOM REPRO RECRUT CATCH YIELD HARNUM PROD EFFECT PSD

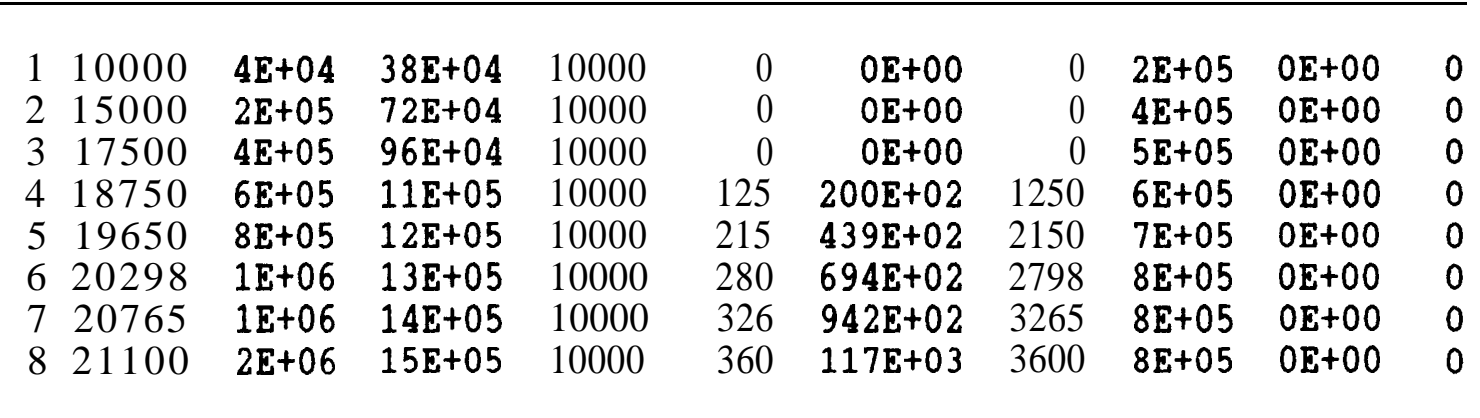

where

$\mathrm{NUM}=$ total number of individuals in population (Sum $\mathbf{N}_{\mathbf{x}}$ ),

$\mathrm{BIOM}=$ total weight of all individuals in population (Sum $B_{\mathbf{x}}$ ),

REPRO = realized egg deposition of all ages (R),

RECRUT $=$ number of age 1 individuals $\left(N_{1}\right)$,

$\mathrm{CATCH}=$ total numbers of inividuals harvested $\left(\right.$ Sum $\left.\mathbf{H}_{\mathbf{x}}\right)$,

YIELD $=$ total weight of individuals harvested (Sum $\left.Y_{\mathbf{x}}\right)$,

HARNUM $=$ number of individuals in the harvestable size range (should be proportional to catch per unit effort in the fishery),

$\mathrm{PROD}=$ total production of biomass $\left(\right.$ Sum $\left.\mathrm{PD}_{\mathrm{x}}\right)$,

EFFECT $=$ total effect of population weighted by age, and

$\mathrm{PSD}=$ size structure index (relative numbers of individuals in 2 size classes). 


\section{Output Option \#6 \\ (Calculate Summary Statistics for Population Over Time)}

Summary statistics include mean, standard deviation, minimum, and maximum for annual summary variables selected from a list. The same variables displayed in Output Option \#5 may be selected. Statistics are calculated over a range of years ending with the last year of the simulation. You also have the option of beginning at a year greater than 1 if you wish to allow a population to reach some equilibrium.

\section{Output Option \#7 \\ (Plot Selected Variables)}

You may plot yearly totals versus time, yearly totals versus each other, age-specific results in the last year of the simulation versus age, or age-specific results versus each other. When you choose this option, you are prompted to select age-specific or year-specific results. Variables that can be plotted for each option are displayed once you make your selection. You must enter variables for $\mathrm{x}$ and $\mathrm{y}$ axes. $\mathrm{X}$-axis variables are automatically sorted from minimum to maximum. Plotable variables and definitions correspond with those listed in tables. The plot is automatically scaled so that the plot fills the Y-axis. You may print graphs by pressing $P$ after the plot is drawn on the screen. (This option was programmed for an IBM graphics printer and may not work on other printers.)

\section{Output Option \#8 \\ (Write By-Age Results to File)}

This option writes age-specific results in the last year of the simulation to 'a data file on diskette. These results are then available for other applications such as plotting with graphics software. When this option is selected, you are prompted for a name for the file in which results are saved. You may enter a name up to 8 characters long or accept the default name of BYAGE. MOCPOP will add the extension ,DAT to whatever name you select. All age-specific variables included in tables listed by Output Options \#2-4 will be written to the file and the first line in the file will contain variable names.

\section{Output Option $\# 9$ \\ (Write By-Year Results to File)}

This option writes year-specific results to a data file on diskette, These results are then available for other applications such as plotting with graphics software. When this option is selected, you are prompted for a name for the file in which results are saved. You may enter a name up to 8 characters long or accept the default name of BYYEAR. MOCPOP will add the extension. DAT to whatever name you select. All year-specific variables included in the table listed by Output 
Option \#5 will be written to the file and the first line in the file will contain variable names.

\section{Output Option \#10 \\ (Continue Present Simulation With New Parameters)}

This option returns you to the Run Options Menu so that you may extend the current simulation for more years. You may select Run Option \#3 to double the number of years in the simulation or you may change inputs by selecting Run Option \#2 and using the Edit Options Submenu. Two possibilities exist for restarting the simulation after edits have been made. You may run directly from the Edit Options Submenu by selecting Edit Option \#9 (Run) in which case the default input file will not be updated with any changes you have made. You may also run by selecting Edit Option \#8 (Return to Run Option Menu), followed by Run Option \#3 (Run Existing Model). Restarting the simulation from the Run Option Menu rather than from the Edit Option Menu will update the default input file with current values for all inputs including age-specific numbers in the last year of the simulation you are continuing.

\section{EXAMPLE APPLICATIONS}

Problem \#l--Yield

Estimate yield at $10 \%$ exploitation for a population with the following characteristics:

1. Maximum age, 8 .

2. Recruitment constant at 10000 age 1 individuals.

3. Natural mortality: age 1 through age 3, 50\% per year: age 4 through age $8,20 \%$ per year.

4. Harvestable size range, 200-400 $\mathrm{mm}$.

5. von Bertalanffy age-length $(\mathrm{mm})$ equation coefficients:

$L_{\text {inf }}=571 ; \mathrm{k}=0.132:$ to $=-0.083$.

6. Length (mm)-weight ( $\mathrm{gm})$ equation coefficients:

intercept $=0.0000042 ;$ slope $=3.19$. 
Start MOCPOP. MOCPOP automatically advances through input parameters as you type a value for each and press Enter. Select Run Option \#l (Build a New Model) from the Run Option Menu by typing 1 after the question mark and pressing Enter. You are then prompted for a name for the file in which inputs will be saved. Name the new model "YIELD" by typing YIELD and pressing Enter.

\section{RUN OPTION MENU}

(1) BUILD A NEW MODEL

(2) EDIT SELECTED INPUTS IN AN EXISTING MODEL

(3) RUN EXISTING MODEL WITH DEFAULT OR EDITED INPUTS

SELECT RUN OPTION [2]: ? 1

NAME CURRENT VERSION []

? YIELD

Next set years to run at 8 on Input Screen \#1. Type 8 , press Enter.

HOW MANY YEARS DO YOU WANT TO RUN IN THIS SIMULATION $[0]$

i8 
Set maximum age at 8 on Input Screen \#2 Type and enter 10000 for age 1 and 0 for ages 2-8. Remember, you may press Enter to accept the default value displayed in brackets or you may introduce a new value.

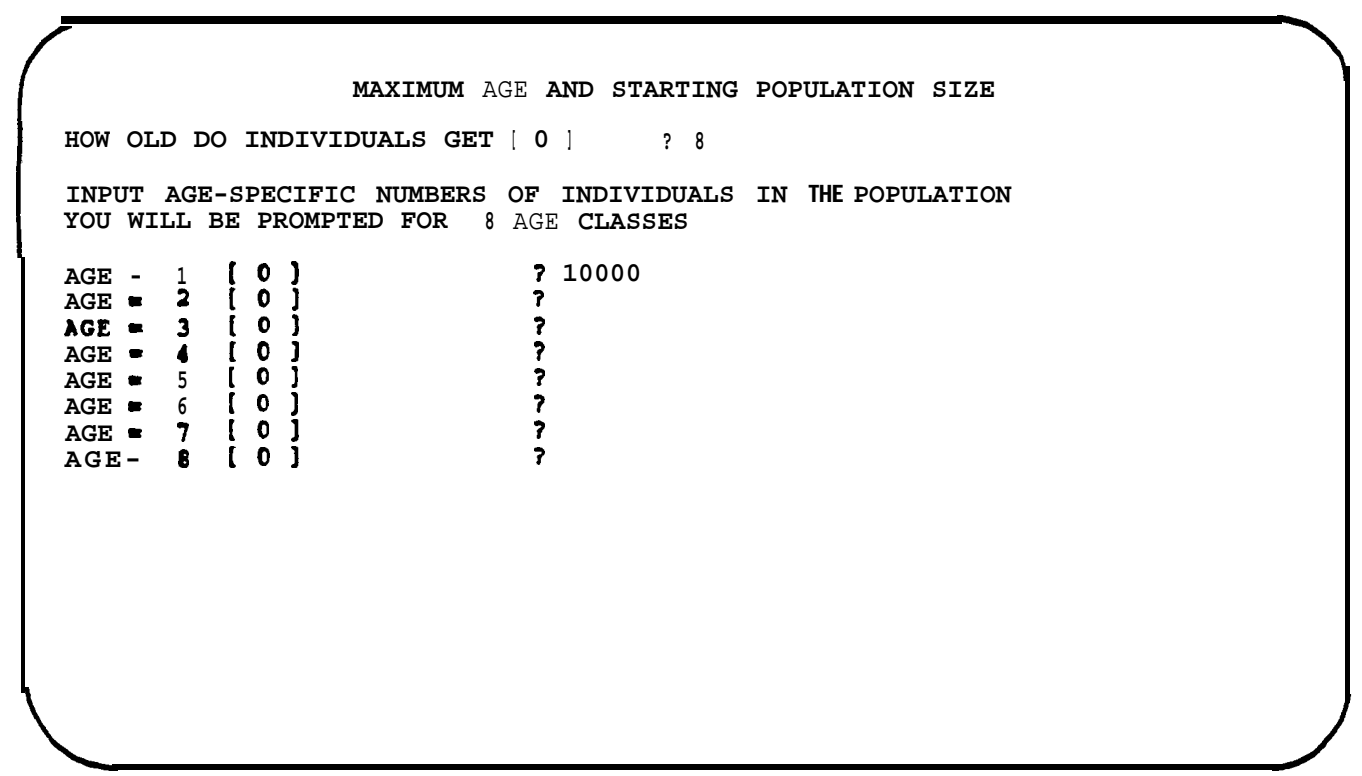

Select Recruitment Option \#1 on Input Screen \#3 to fix annual recruitment at 10000 .

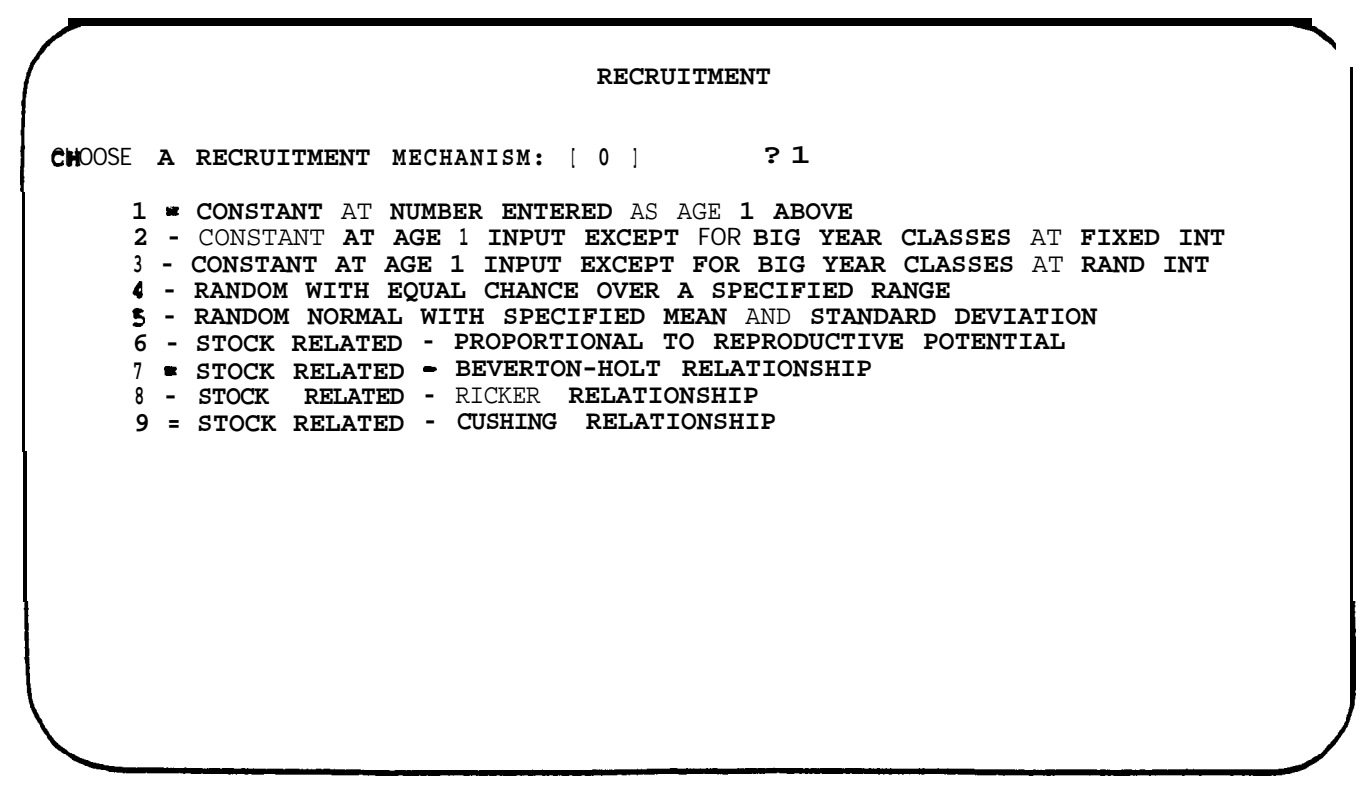


Type 0.5 and press Enter for the first natural mortality rate on Input Screen \#4. Type 3 and press Enter when prompted for the upper age. This sets natural mortality for ages 1 to 3 at $50 \%$ annually. To set mortality of age 4 to 8 individuals at 20\%, type and enter 0.2 and 8 where prompted.

To set exploitation at $10 \%$ for a specified size range, type and enter size class, 1; minimum size, 200; maximum size, 400; and rate 0.1. Size units may be anything desired but you must be consistent. For instance if you use millimeters here you must supply length-weight equation coefficients also based on millimeters.

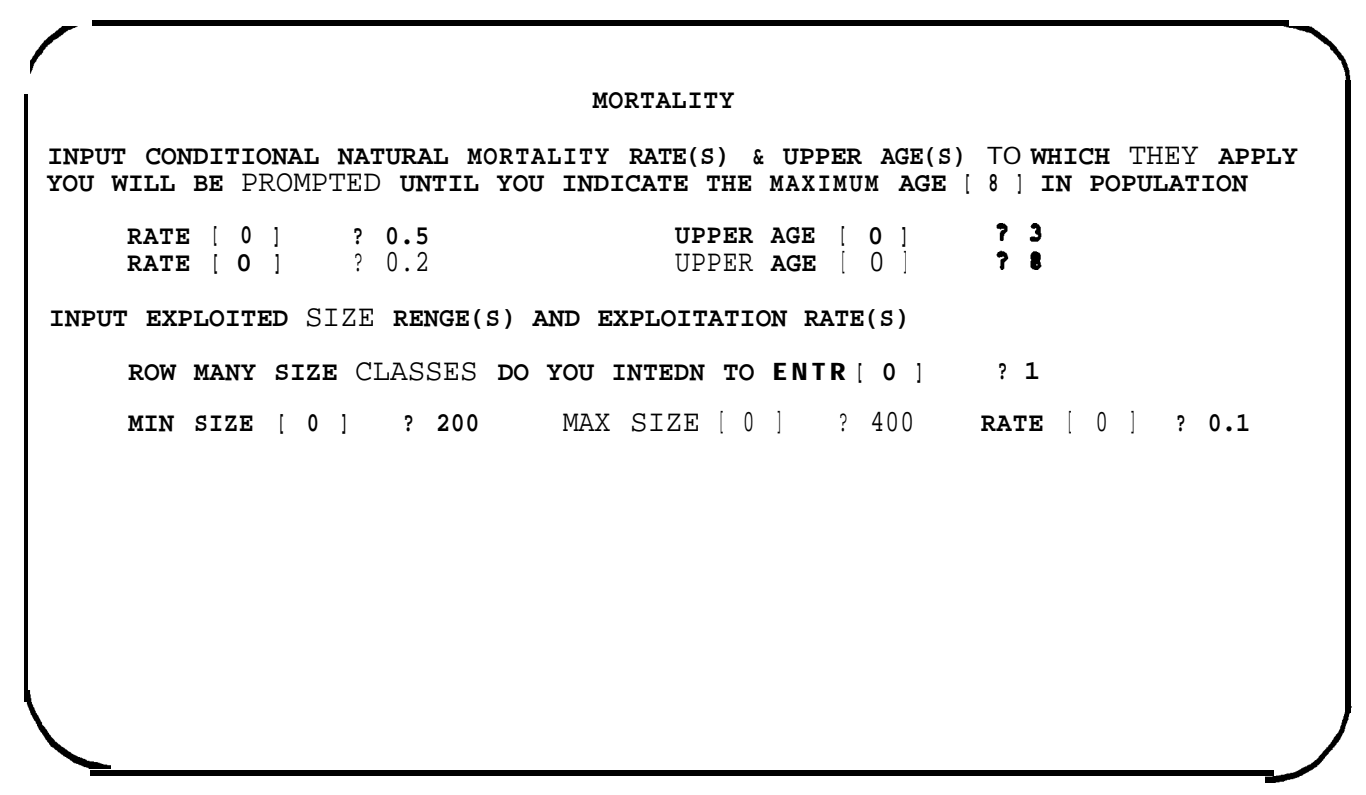


Now type and enter parameters for age-length and length-weight equations as indicated on Input Screen \#5. This concludes the inputs necessary to solve the yield problem, but MOCPOP will continue to prompt you for additional inputs related to reproduction. These inputs are not used in this example but would be needed if recruitment was a function of stock size Enter arbitrarily selected values of 1 for age of maturity of females, 0.5 for proportion of population that is female, 1 for proportion of females that spawn in any year and 8 for upper age to which proportion applies.

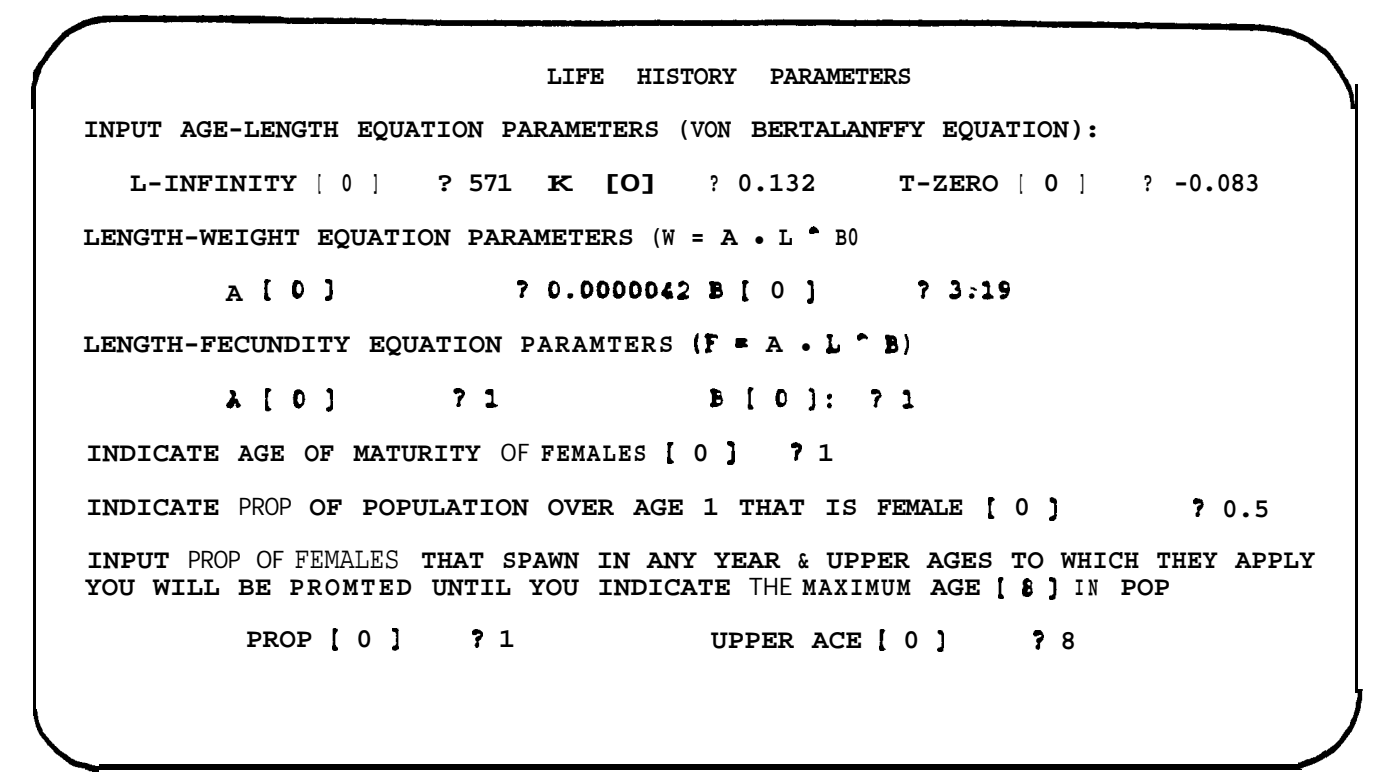

You will also be prompted for information used to calculate weighted effects and a size structure index. This information is not needed to solve the yield problem, so accept defaults. After you have completed inputs, the model will automatically run the simulation you indicated and display the output options menu when done.

Instead of using the Build a New Model Option (\#1), you may choose to enter inputs by using the Edit Selected Inputs Option (\#2) of the Run Option Menu. That way you don't have to deal with inputs, such as weighted effect and PSD, which don't matter in this example and you can go back and change inputs you've already passed.

You will find the answer to this yield problem under Output Option \#4 (List Harvest, Yield, and Effect by Age). Yield for this example is $117,067 \mathrm{gm}$. The example output tables shown on pages 10-13, correspond to this simulation. 


\section{Problem \#2--Uncertainty}

Estimate the range over which a population may vary as a result of variable recruitment. Use inputs as in Problem \#l (page 15) except set recruitment to include big year classes that occur every 4 years on the average and are 3 times greater than normal.

Start MOCPOP and select Run Option \#2 to begin entering inputs. When prompted for the name of the input file to edit, press Enter to accept the displayed default (YIELD). When prompted for a name for the current version, type UNCERT and press Enter.

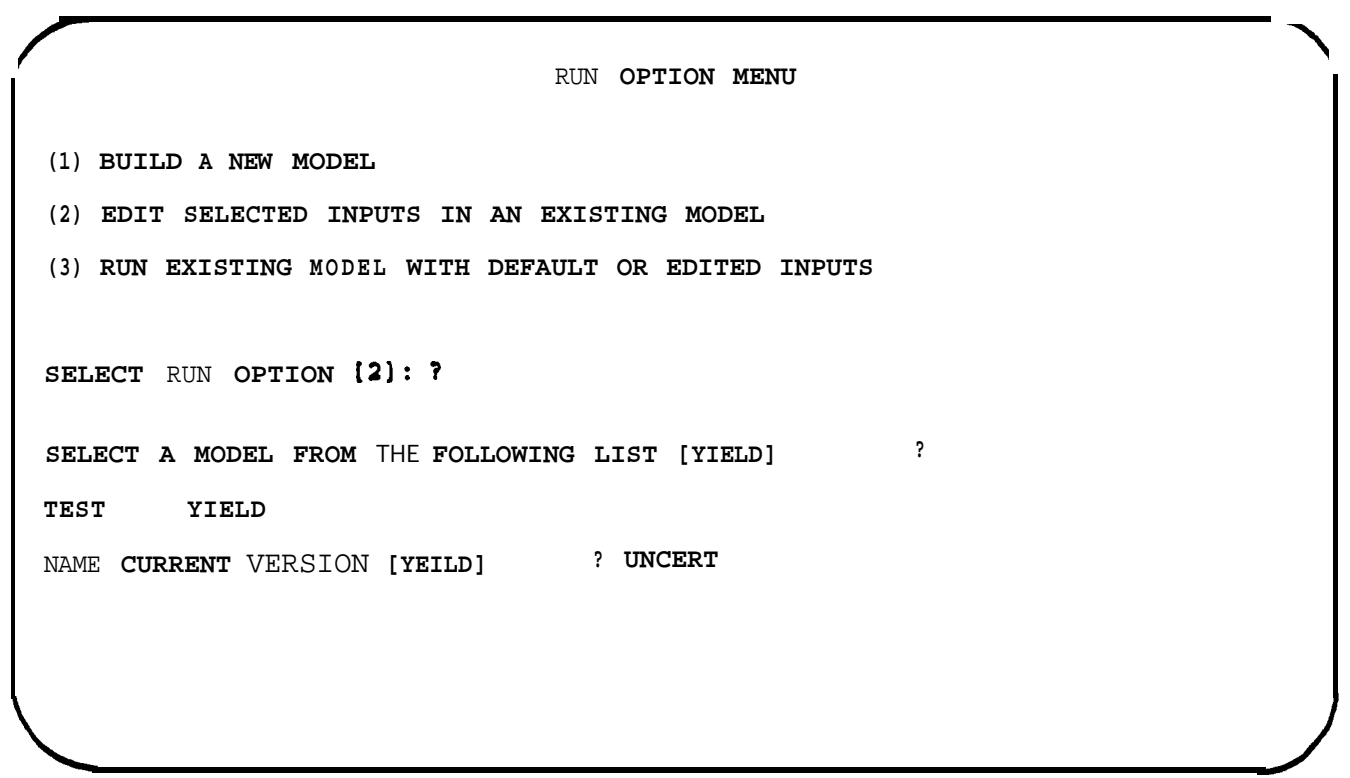

The Edit Options Submenu is displayed after you enter a new file name. First edit years to run by typing 1 and pressing Enter.

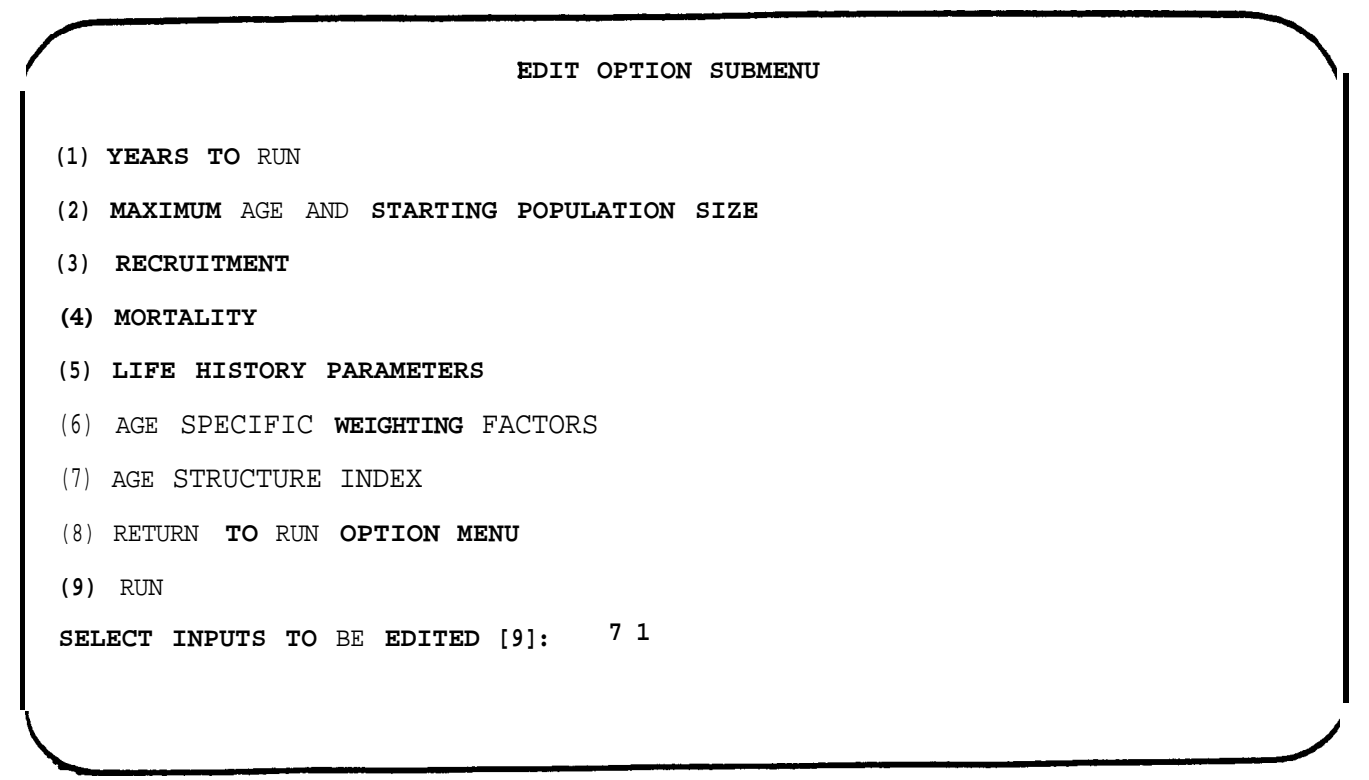


Set years to run at a large number, for instance 100 .

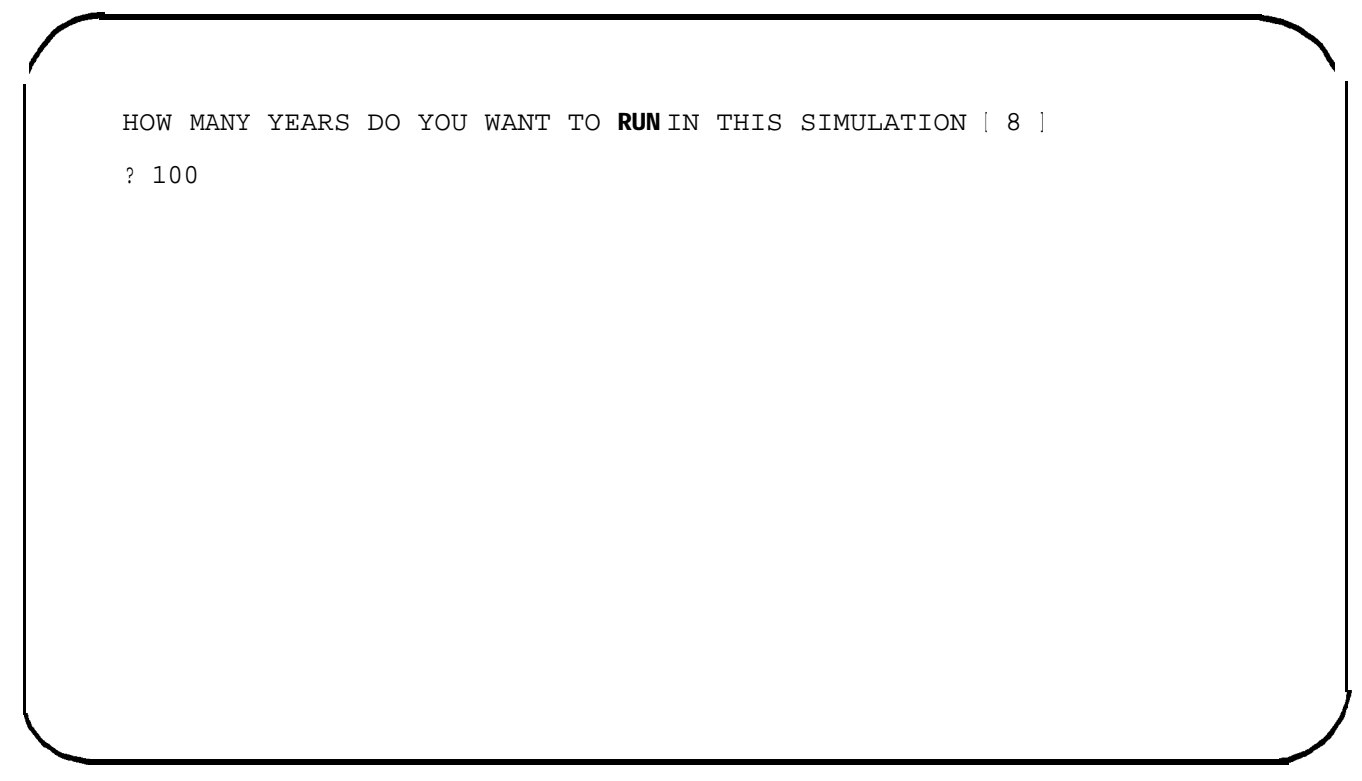

After you complete entries on each screen, you are automatically returned to the Edit Options Submenu. You may then sequentially edit desired inputs by entering the appropriate option number. Next edit recruitment inputs by selecting Edit Option \#3 and Recruitment Option \#3* Indicate relative frequency and size of big year classes.

\section{RECRUITMENT}

CHOOSE A RECRUITMENT MECHANISM: [ 1 \} ? 3

1 = CONSTANT AT NUMBer ENTERED AS AGE 1 ABOVE

2 = CONSTANT AT AGE 1 INPUT EXCEPT FOR BIG YEAR CLASSES A? FIXED INT

3 - CONSTANT AT AGE 1 INPUT EXCEPT FOR BIG YEAR CLASSES AT RAND INT

4 - RANDOM WITH EQUAL CHANCE OVER A SPECIFIED RANGE

5 - RANDOM NORMAL WITH SPECIFIED MEAN AND STANDARD DEVIATION

6 - STOCK RELATED - PROPORTIONAL TO REPRODUCTIVE POTENTIAL

7 - STOCK RELATED - BEVERTON-HOLT RELATIONSHIP

8 = STOCK RELATED - RICKER RELATIONSHIP

9 = STOCK RELATED - CUSHING RELATIONSHIP

INDICATE FREQUENCY WITH WHICH BIG YEAR CLASSES OCCUR ON THE AVG 10 ] 4

INDICATE HOW MANY TIMES LARGER THAN AVG BIG YEAR CLASSES ARE (0): ? 3 
Run the simulation by entering Option \#9 in the Edit Options Submenu. After doing so, you might wish to plot numbers versus years to examine the pattern of variation. Select Output Option \#7 and indicate year-specific results, an $\mathrm{x}$-axis variable of "YEAR", a y-axis variable of "NUM", and a monitor resolution of " 1 ".

\section{PLOT SELECTED VARIABLES}

SELECT THE TYPE OF RESULTS YOU WANT TO PLOT [1]

(1) YEAR-SPECIFIC
(2) AGE-SPECIFIC

YOU HAVE A CHOICE OF THE FOLLOWING VARIABLES:

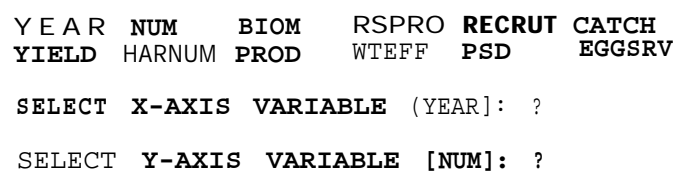

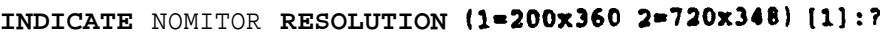

A figure similar to the following is displayed. Figures will vary because the years when big year classes occur are randomly selected.

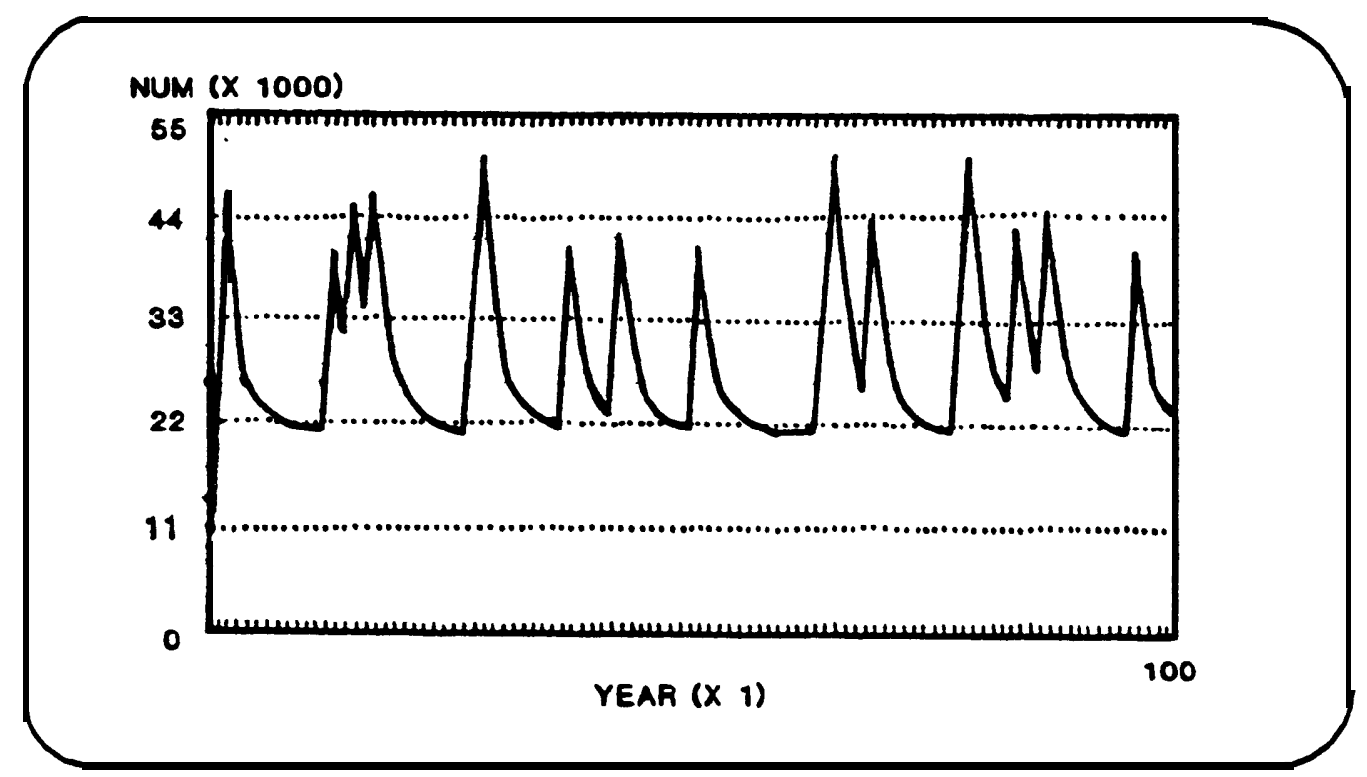

You see that numbers started low and increased as a population containing all age classes was built. After that, the population fluctuated as big year classes occurred and moved through the population. 
You may also use the Summary Statistics Option (\#6) in the Output Options Menu to calculate the mean, standard deviation, and range over which population numbers varied. In this example, we start with year 9 to avoid including years before all age classes were represented in the population.

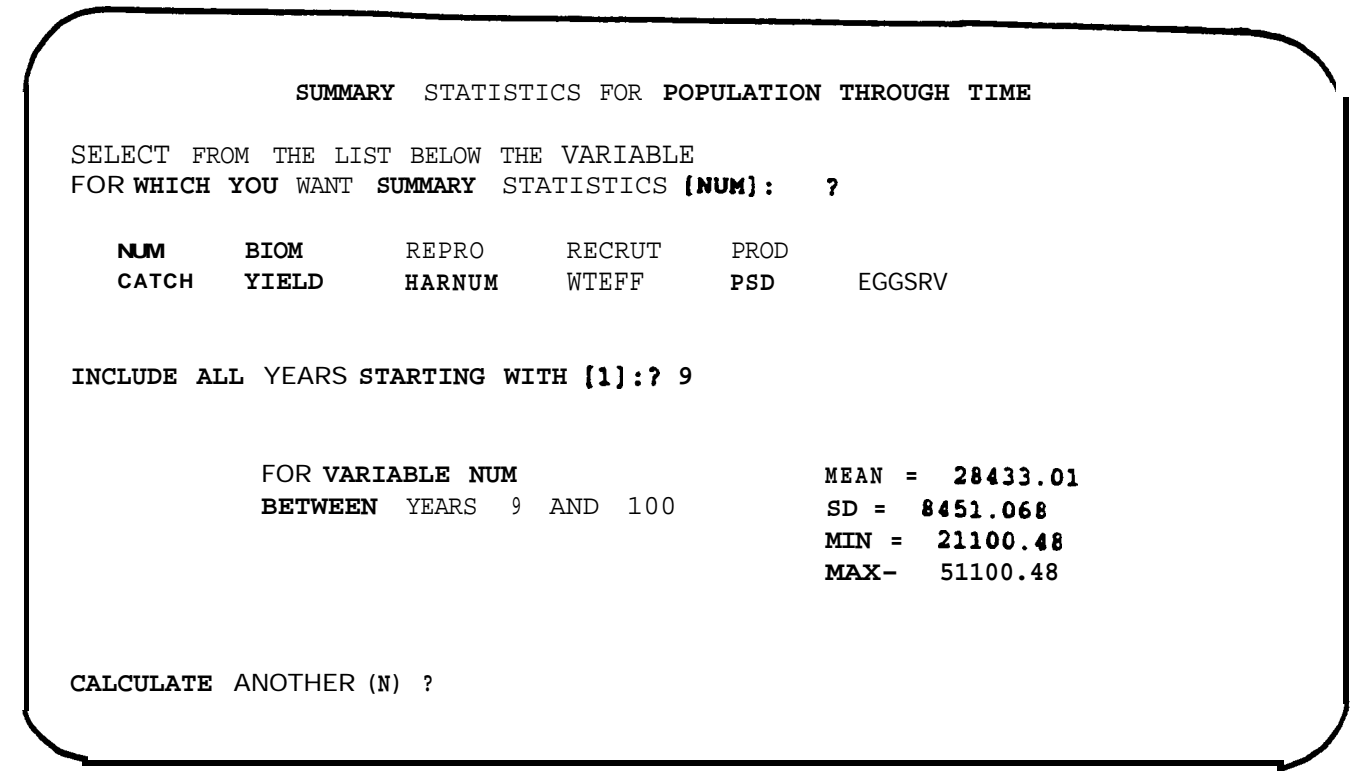

Problem \#3 Response- Time

Estimate how quickly a population will recover after a reduction of $50 \%$. Assume a Beverton-Holt stock-recruitment relationship of low to moderate resilience $(A=0.2)$ (See Ricker (1975), page 292). Assume no age structure, weights and lengths as in problems 1 and 2 , fecundity equal to length, and a sex ratio of 1:1 with all females spawning.

This situation approximates a simple stock-recruitment-type model, but instead of calculating a progeny stock size directly from parental stock size, MOCPOP works by calculating a reproductive potential for parental stock, then multiplying that potent i al by an egg-to-adult survival rate. You must supply reproductive potential at equilibrium (alpha in the Beaverton-Holt equation) and egg-to-adult (age 1) mortality to run this simulation. You can use MOCPOP to simplify calculation of these numbers by first running a one year simulation to calculate reproductive potential, then solving for the mortality rate that will give you the starting stock size you supplied. 
Start the model and select Run Option \#2 to begin entering inputs. When prompted for the name of the input file to edit, press Enter to accept the displayed default (UNCERT). When prompted for a name for the current version, type RESPTIME and press Enter. The Edit Options Submenu is displayed after you enter a new file name. First edit years to run after typing 1 and pressing Enter. Set years to run to 1.

HOW MANY YEARS DO YOU WANT TO RUN IN THIS SIHULATION | 100 |

$? 1$

Next choose Edit Option \#2 and enter a maximum age of 1 and a starting population of 10000 .

MAXIMUM AGE AND STARTING POPULATION SIZE

HOW OLD DO INDIVIDUALS GET | 8 | ? 1

INPUT AGE-SPECIFIC NUMBERS OF INDIVIDUALS IN THE POPULATION

YOU WILL BE PROMPTED FOR 1 AGE CLASSES

AGE - $1: 10000$ 
Choose Edit Option \#3 and select the constant recruitment option $(\# 1)$.

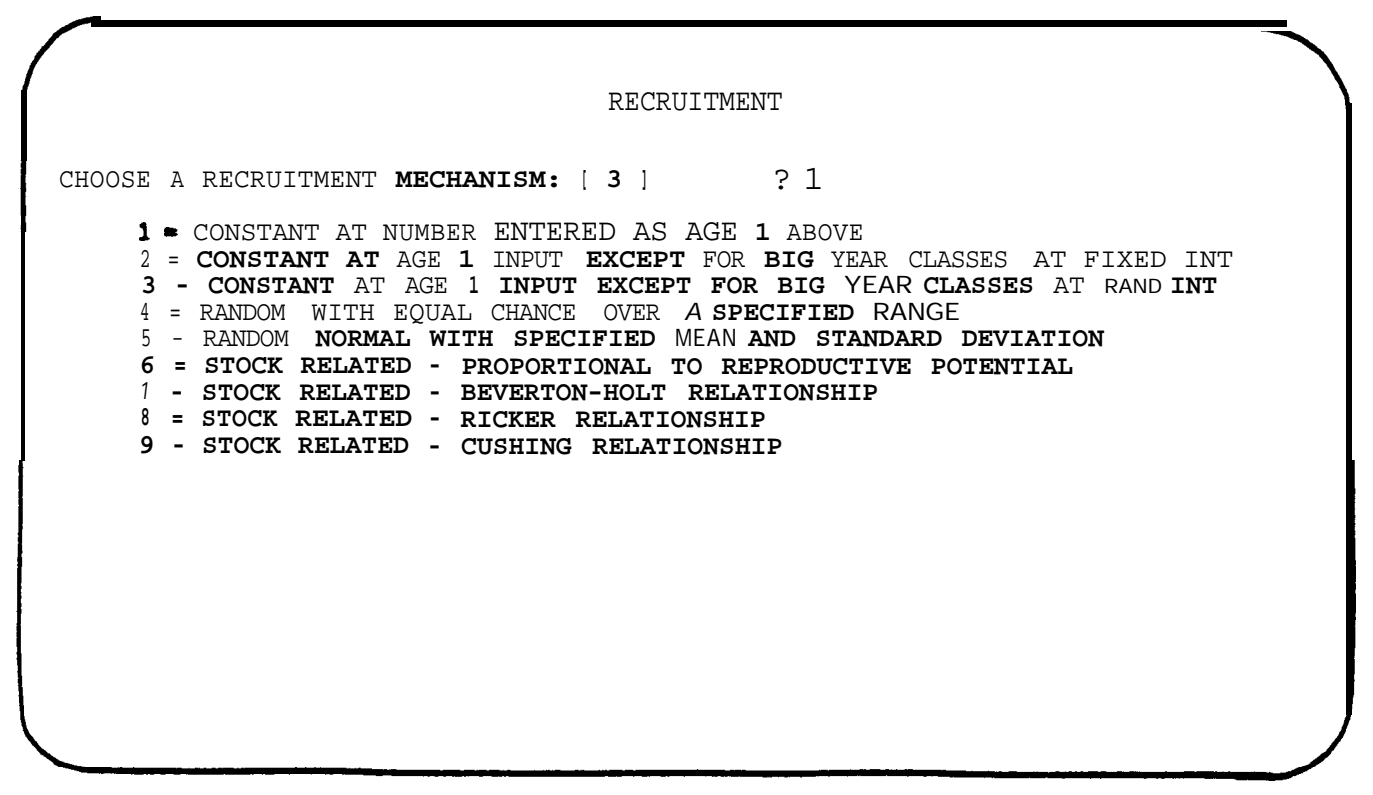

Choose Edit Option \#5 and edit life history parameters as indicated.

\section{LIFE HISTORY PARAMETERS}

INPUT AGE-LENGTH EQUATION PARAMETERS (von Bertalanffy EQUATION) :

$$
\text { L-INFINITY [ } 571 \text { ] ? } \mathbb{K}[.132\} ? \text { T-ZERO }[-.083\} ?
$$

LENGTH-WEIGHT EQUATiON PARAMETERS (

$$
\text { A [ } .0000042] \text { B [ } 3.19] \text { ? }
$$

LENGTH-FECUNDITY EQUATION PARAMETERS (F $=\mathbf{A} \cdot \mathbf{L} \cdot \mathbf{B})$
2 [ 1 ]
$?$
B (1): ?

INDICATE AGE OF MATURITY OF FEMALES $1 \mathbf{l}$ ] $?$

INDICATE PROP OF POPUlation OVER AGE 1 THAT IS FEmale $(.5)$ ?

INPUT PROP OF FEMALES THAT SPAWN IN ANY YEAR UPPER ACES TO WHICH THEY APPLY

YOU WILL BE PROMPTED UNTIL YOU INDICATE THE MAXIMUM AGE $\{1\}$ IN POP

PROP $[1$ ] ? UPPER AGE [ 8 ] ? 1 
For the present you may ignore inputs for mortality as these are not needed in the 1 year simulation. After running the simulation (Edit Option 19$)$, inspect the age-specific reproduction information screen (Output Option *2).

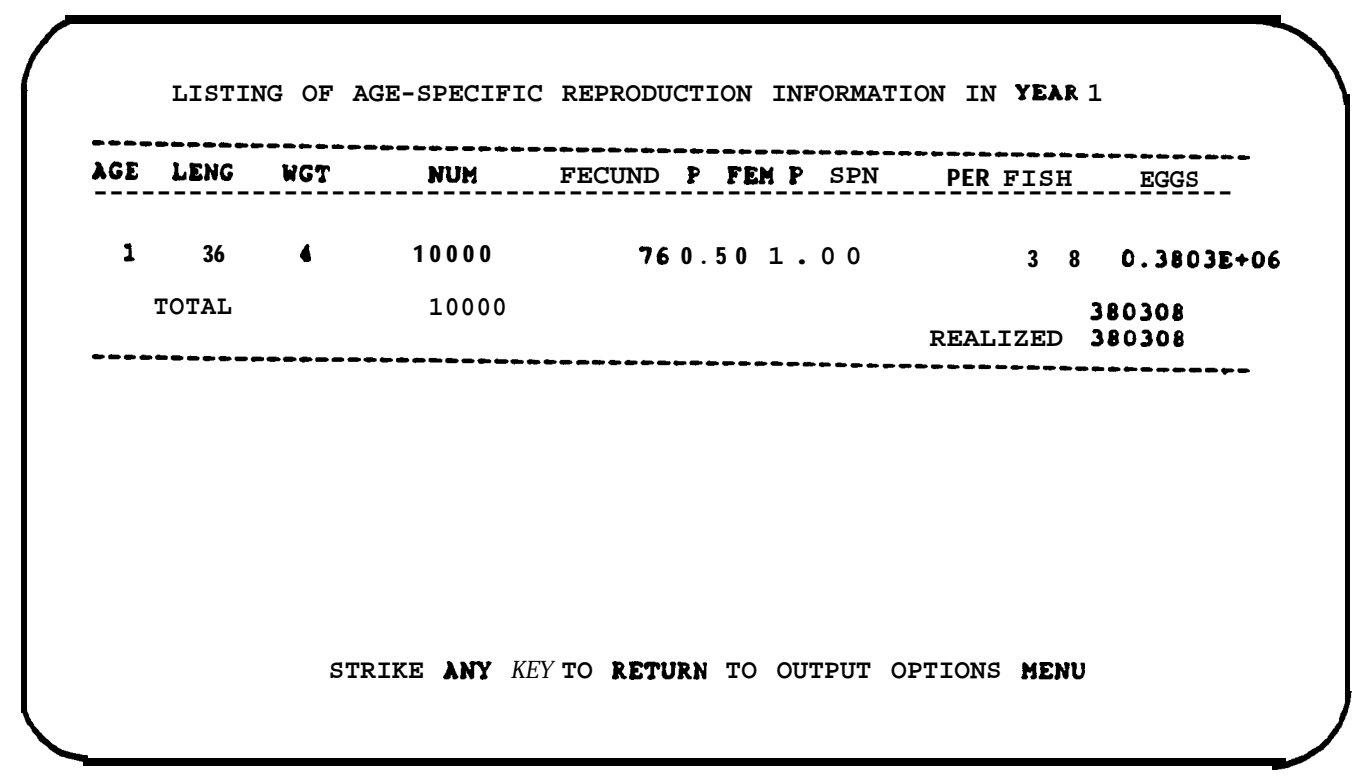

The reproductive potential of the population you input is 380,308 .

Now return to the Run Options Menu to run a new simulation to determine how long it will take for the population to recover from a $50 \%$ reduction. Do so by entering Output Option \#11. Select Run Option \#2 to begin entering inputs. When prompted for the name of the input file to edit, press Enter to accept the displayed default (RESPTIME). When prompted for a name for the current version, press Enter to continue saving changes in the file RESPTIME. The Edit Options Submenu is displayed after you enter a new file name. First increase the number of years to run to 50 (Edit Option \#1).

HOW MANY YEARS DO YOU WANT TO RUN IN THIS SIMULATION $\mid \begin{array}{ll}1 & 1\end{array}$

? 50 
Next, reduce starting population size to 5000 (Edit Option \$2).

\section{MAXIMUM AGE AND STARTING POPULATION SIZE}

HOW OLD DO INDIVIDUALS GET 1 : 1 i $\mathrm{j}$ ?

INPUT AGE-SPECIFIC NUMBERS OF INDIVIDUALS IN THE POPULATION

YOU WILL BE PROMPTED FOR 1 AGE CLASSES

$\mathrm{AGE}=1|10000| ? 5000$

Indicate that recruitment (Edit Option \#3) is based on a Beverton-Bolt equation (Recruitment Option \#7) and supply parameters.

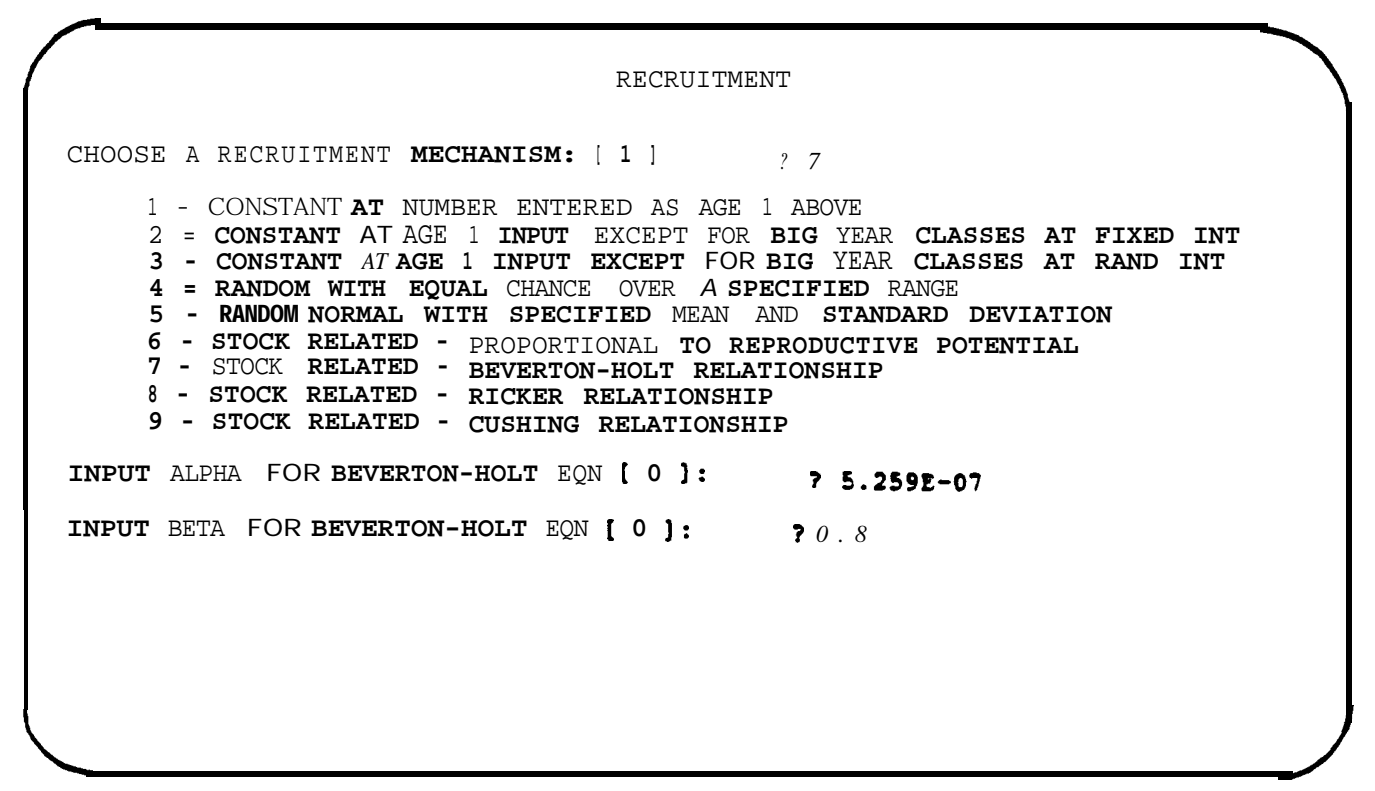

Parameters are calculated:

$$
\begin{gathered}
\text { Alpha }=A / P_{r}=0.2 / 380308=5.259 E-07 \\
\text { Beta }=1-A=1-0.2=0.8
\end{gathered}
$$


Lastly, edit mortality inputs (Edit Option Y4) and input the egg mortality rate.

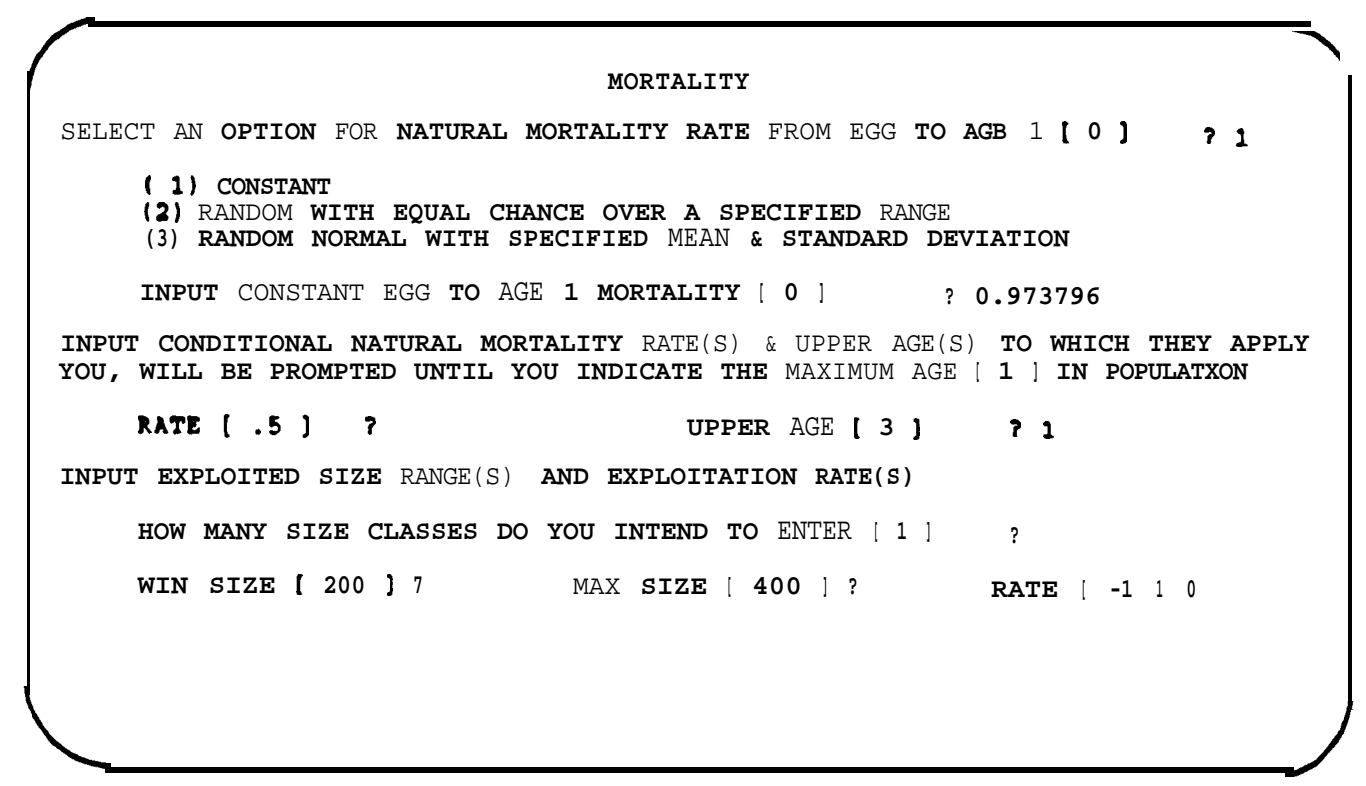

This rate is calculated as

$$
\text { Rate }=1-10000 / 380308=0.973796
$$

You are also prompted for natural and harvest mortality rates on the mortality screen, but these numbers are not used in our simulation because no fish live past age 1 . Age 1 mortality is automatically set to $100 \%$ by MOCPOP regardless of what you enter here because 1 is the maximum age.

You are now ready to run the simulation. Do so by typing "9" and pressing Enter. When the simulation is complete and the Output Options $\mathrm{Mnu}$ is displayed, plot numbers versus years. Do so by selecting Output Option \#7, indicating year-specific results, entering an $\mathrm{x}$-axis variable of "YEAR", entering a y-axis variable of "NUM", and entering a monitor resolution of " 1 . 
You see approximately 25 years are required for our population to recover to equilibrium levels.

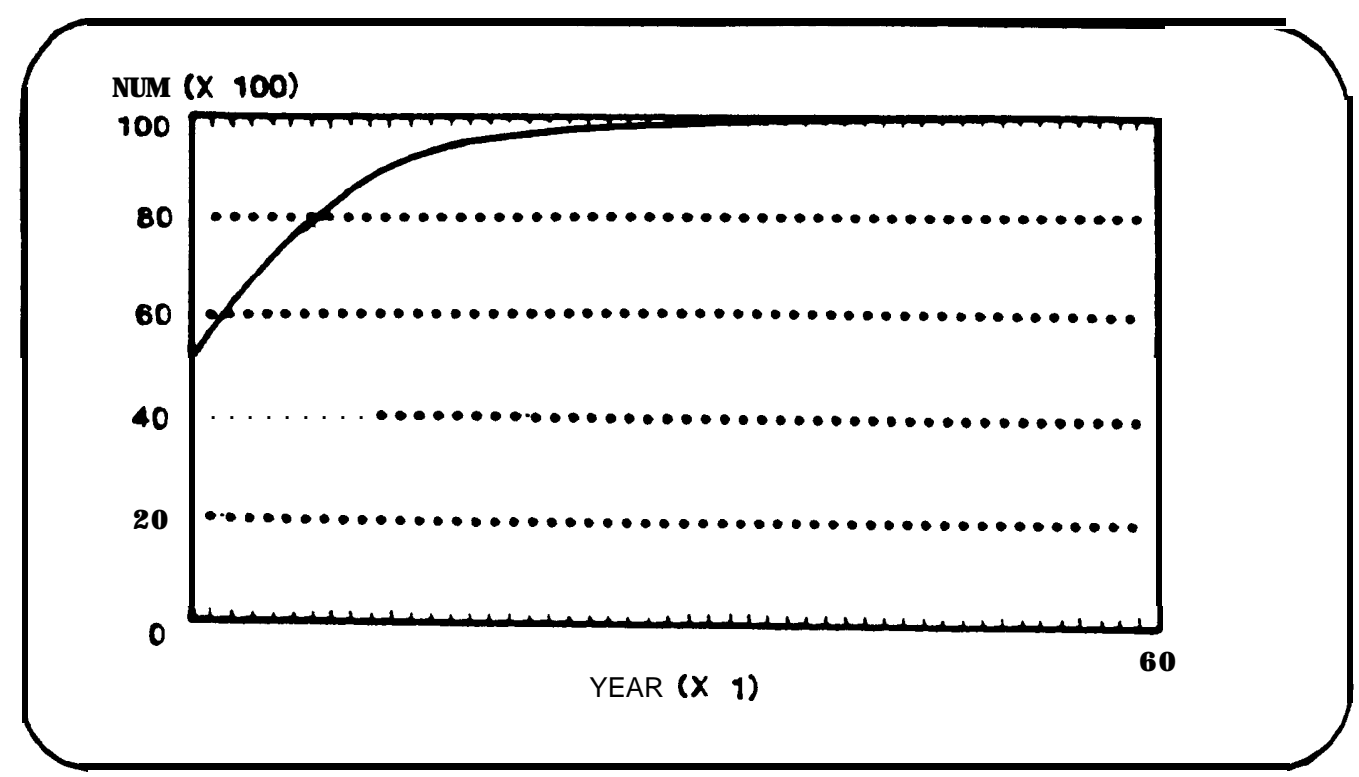

COPIES AND BUGS

A copy of MOCPOP may be obtained by sending a diskette and self-addressed mailer with stamp to the author. MOCPOP may be copied and distributed freely and no person or organization is authorized to charge any fee or price for MOCPOP. MOCPOP includes the following files

1. MOCPOP10.EXE: the executable program file.

2. MOCPOP10.LIB: a library file containing introductory text.

3. MOCPOP10.DOC: an ASCII file containing a copy of the documentation.

4. MPTEST.MPK: a file containing example input data.

MOCPOP is distributed without warranty. If you find a bug, I will repair it in future versions if you notify me in writing. 


\section{ACKNOWLEDGEHWTS}

I thank B.E. Rieman and W.A. Burck for thoughtful review of this program and documentation. This work was supported by funding from the Bonneville Power Administration (Contract DE-AI79-82BP35097).

\section{REFEREMCES}

Anderson, R.O. 1980. Proportional Stock Density (PSD) and Relative Weight (Wr) : interpretive indices for fish populations and communities. Pages 27-33 in S. Gloss and B. Shupp, editors. Proceedings of the First Annual Workshop, Practical Fisheries Management: More with less in the 1980's. American Fisheries Society, New York Chapter.

Kimura, D.K. J.W. Balsiger, and D.H. Into. 1984. Generalized stock reduction analysis. Canadian Journal of Fisheries and Aquatic Sciences 41:1325-1333.

Ricker, W.E. 1975. Computation and interpretation of biological statistics of fish populations. Fisheries Research Board of Canada Bulletin 191.

Taylor, M.W. 1981. A generalized inland fishery simulator for management biologists. North American Journal of Fisheries Management 1:60-72.

Vaughan, D.S., R.M. Yoshiyama, J.E. Breck, and D.L. DeAngelis. 1982. Review and analysis of existing modeling approaches for assessing population-level effects of multiple stresses on fish and shellfish. Oak Ridge National Laboratory, Environmental Sciences Division, Publication 1979.

Walters, C.J. 1969. A generalized computer simulation model for fish population studies. Transactions of the American Fisheries Society $98: 505-512$. 
User's Guide for PRSPRED: AModel of Predation by Resident Fish on Juvenile Salmonids in a Columbia River Reservoir

RAYMONDC.BEAMESDEREFER

Oregon Department of Fish and Wildlife

17330 SE Evelyn Street, Clackamas, Oregon 97015, USA 
Production of salmon Oncorhynchus spp. and steelhead Salmo gairdneri in the Columbia River system is drastically reduced by mortality during outmigration (Ebel 1977). Predation by resident fish species accounts for much of the previously unexplained mortality in John Day Reservoir (Rieman et al. 1988). Predation mortality is dynamic, varying in time and space.

RESPRED incorporates factors we know or suspect regulate predation mortality of juvenile salmonids in John Day Reservoir. This model was written to organize our understanding of processes that regulate mortality of salmonids, to predict changes in predation over time with normal variation of the regulating factors, and to evaluate alternative strategies for reducing predation (Beamesderfer et al. 1988). Programming was built around processing to aide manipulation of input population parameters and inspection of simulation results.

\section{MODEL DESCRIPTIOIW}

The model consists of a system of difference equations solved at daily intervals for a 150 -day period that corresponds to the April through August period of salmonid outmigration. In the model, John Day Reservoir is divided into two areas: the tailrace immediately below McNary Dam at the upper end of the reservoir (the boatrestricted-zone, or BRZ), and the remaining body of the reservoir (Figure 1).

Number of predators in the entire reservoir is an input. The reservoir-wide predator population is reduced during the season by a daily rate of mortality (Table 1, Equation 1). Predators from the entire-reservoir population are apportioned each day into areas (Figure 2) Predator distribution may be input directly, varied by time of year (Table 1, Equations 2 and 5), and/or scaled in response to number of prey in the BRZ to simulate the effects of a hypothetical numerical response (Equation 4) (Krebs 1985). The model also provides an option to apportion number of predators between active and inactive compartments in each area (Table 1, Equation 6). Activity proportions may be input directly or related to water discharge (flow).

Prey enter the reservoir at McNary Dam and pass through each area in sequence (Figure 2). Prey number may be input directly or generated as a normally distributed function of time (Equation 7). The number of prey in the reservoir is regulated by number entering and residence time (Table 1, Equation 8). Numbers entering the BRZ correspond to passage past McNary Dam. Residence time in the BRZ is ignored. Number of prey entering the reservoir body include those salmonids that pass McNary Dam which survive predation in the BRZ. Residence time in the reservoir is represented as an exponential decay function in which some proportion of the prey population left the reservoir daily. Days when 50\% of a cohort of prey remained corresponded to an average passage time (Table 1, Equation 9). Residence time can be input directly or can be described as a 

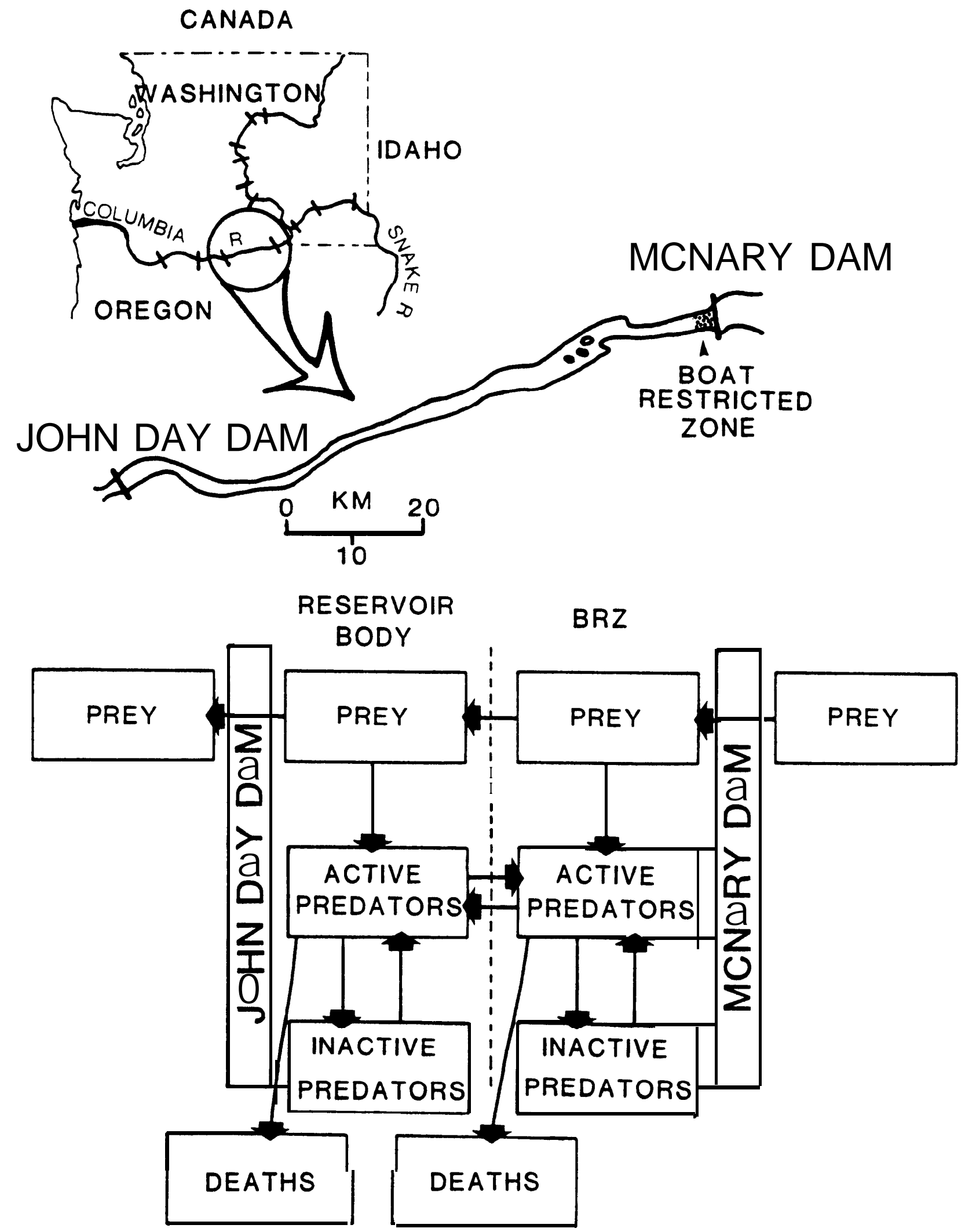

Figure 1. Conceptual model of predation by northern squawfish on juvenile salmonids in John Day Reservoir. 
Table 1. Definitions of state and driving variables included in a

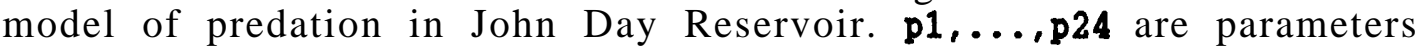
defined in Table 2.

Variable

Definition

Equation

Number

$\operatorname{Pn}(t) \quad$ Number of predators in population at time $t$

$=\operatorname{Pn}(t-1) \operatorname{RDm}(t-1)$

RDm ( $t$ ) Fraction of population that dies daily

Pnl $(t) \quad$ Number of predators in boat-restricted-zone

$=\operatorname{Pn}(t) \operatorname{RBrz}(t)$

$\mathbf{R B r z}(\mathbf{t}) \quad$ Fraction of predator population in BRZ

$\operatorname{RNr}(t) \quad$ Proportion to adjust distribution for prey number (to approximate numerical response)

$\operatorname{Pn} 2(t) \quad$ Number of predators in reservoir body

$=\operatorname{Pn}(t)-\operatorname{Pn} 1(t)$

APni( $t) \quad$ Number of predators in area $i(i=1$ is BRZ, $i=2$ is reservoir body) that are actively feeding $=\operatorname{Pni}(t) \operatorname{RAci}(t)$

RAci $(t)$ Fraction of predator population in area $i$ that is actively feeding.

Jvl ( $t) \quad$ Number of juvenile salmonids in BRZ $(=\operatorname{DJv}(t))$

DJv(t) Number of juvenile salmonids passing McNary Dam

Jv2 (t) Number of juvenile salmonids in reservoir body

$=\operatorname{Jv} 2(t-1)-J v 2(t-1) / R \operatorname{Tm} E(t-1)-\operatorname{sC2}(t-1)$

$+\operatorname{DJv}(t)-\operatorname{SC} 1(t)$

$\operatorname{RTmE}(t) \quad$ Exponential residence time for prey in the reservoir

$=\operatorname{RTm}(t) /-\operatorname{Ln} 0.5$

$\operatorname{RTm}(t) \quad$ Average residence time (days)

DFl $(t) \quad$ Flow rate $\left(10^{3} \mathrm{CFS}\right)$ at dam

sC1 $(t) \quad$ Number of prey consumed by predators in BRZ

$=\operatorname{APn} 1(t) \operatorname{RCn} 1(t)$ 
Table 1. Continued.

Variable

Definition

Equation

Number

$R C n 1(t)$ Consumption rate of prey per predator in BRZ

$=R C n_{\max }(t) /\left(1+p 14 e^{-p 15 J v 1}(t)\right)$

$\mathbf{R C n}_{\max }(t)$ Maximum potential consumption rate (prey per predator per day)

DTp (t) Temperature (degrees centigrade) in reservoir at time $t$

$=\mathrm{p} 21+\mathrm{p} 22 \mathrm{t}$

SC2 $(t) \quad$ Number of prey consumed by predators in reservoir body

$=\operatorname{APn} 2(t) \operatorname{RCn} 2(t)$

RCn2( $t$ ) Consumption rate of prey per predator in reservoir body

$=R C n_{\max }(t) /\left(1+p 23 e^{-p 24 J v 2(t)}\right)$ 
Table 2. Definitions of parameters and values used in a model of predation in John Day Reservoir.

\begin{tabular}{|c|c|c|}
\hline $\begin{array}{l}\text { Reference } \\
\text { equation } \\
\text { number }\end{array}$ & $\begin{array}{l}\text { Symbol } \\
\text { of } \\
\text { parameter }\end{array}$ & Description of parameter \\
\hline 3 & $\begin{array}{l}\text { p1 } \\
\text { p2 }\end{array}$ & $\begin{array}{l}\text { Intercept for proportion in } \mathrm{BRZ} \\
\text { Slope for proportion in BRZ }\end{array}$ \\
\hline 18,19 & $\begin{array}{l}\text { p3 } \\
\text { p4 } \\
\text { p5 }\end{array}$ & $\begin{array}{l}\text { Change in proportion }(+) \text { with specified range in } \\
\text { passage number } \\
\text { Minimum daily passage } \\
\text { Maximum daily passage }\end{array}$ \\
\hline 7 & $\begin{array}{l}\text { p6 } \\
\text { p7 } \\
\text { p8 }\end{array}$ & $\begin{array}{l}\text { Number of salmonids in run } \\
\text { Day of peak passage } \\
\text { Index of run duration (days in one standard } \\
\text { deviation from day of peak passage) }\end{array}$ \\
\hline 10 & $\begin{array}{l}\text { p9 } \\
\text { p10 }\end{array}$ & $\begin{array}{l}\text { Intercept for residence time } \\
\text { Slope for residence time }\end{array}$ \\
\hline 11 & $\begin{array}{l}\mathrm{p} 11 \\
\mathrm{p} 12 \\
\mathrm{p} 13\end{array}$ & $\begin{array}{l}\text { Maximum discharge at McNary Dam } \\
\text { Day of maximum discharge } \\
\text { Days in one standard deviation from day of } \\
\text { maximum discharge }\end{array}$ \\
\hline 13 & $\begin{array}{l}\mathrm{p} 14 \\
\mathrm{p} 15\end{array}$ & $\begin{array}{l}\text { Constant refering to intercept for consumption } \\
\text { rate in BRZ } \\
\text { Constant refering to response rate to increasing } \\
\text { prey for consumption rate in BRZ }\end{array}$ \\
\hline 14 & $\begin{array}{l}\text { p16 } \\
\text { p17 } \\
\text { p18 } \\
\text { p19 } \\
\text { p20 }\end{array}$ & $\begin{array}{l}\text { Coefficient for maximum potential consumption } \\
\text { rate versus temperature } \\
\text { Coefficient for maximum potential consumption } \\
\text { rate versus temperature } \\
\text { Coefficient for maximum potential consumption } \\
\text { rate versus temperature } \\
\text { Coefficient for maximum potential consumption } \\
\text { rate versus temperature } \\
\text { Coefficient for maximum potential consumption } \\
\text { rate versus temperature }\end{array}$ \\
\hline 15 & $\begin{array}{l}\text { p21 } \\
\text { P22 }\end{array}$ & $\begin{array}{l}\text { Intercept for temperature } \\
\text { Slope for temperature }\end{array}$ \\
\hline
\end{tabular}


Table 2. Continued.

\begin{tabular}{|c|c|c|}
\hline $\begin{array}{l}\text { Reference } \\
\text { equation } \\
\text { number }\end{array}$ & $\begin{array}{l}\text { Symbol } \\
\text { of } \\
\text { parameter }\end{array}$ & Description of parameter \\
\hline 17 & p24 & $\begin{array}{l}\text { Constant refering to intercept for consumption } \\
\text { rate in reservoir } \\
\text { Constant refering to response rate to increasing } \\
\text { prey for consumption rate in reservoir }\end{array}$ \\
\hline 4 & $\begin{array}{l}\text { p25 } \\
\text { p26 }\end{array}$ & $\begin{array}{l}\text { Intercept for numerical response } \\
\text { Slope for numerical response }\end{array}$ \\
\hline 20 & $\begin{array}{l}\text { P27 } \\
\text { p28 }\end{array}$ & $\begin{array}{l}\text { Intercept for proportion active versus flow } \\
\text { Slope for proportion active versus flow }\end{array}$ \\
\hline 21,22 & $\begin{array}{l}\text { p29 } \\
\text { p30 } \\
\text { p31 }\end{array}$ & $\begin{array}{l}\text { Change in proportion }(+) \text { with specified range in } \\
\text { flow } \\
\text { Minimum flow } \\
\text { Maximum flow }\end{array}$ \\
\hline 23 & $\begin{array}{l}\text { p32 } \\
\text { P33 }\end{array}$ & $\begin{array}{l}\text { Intercept in maximum potential consumption versus } \\
\text { temperature } \\
\text { Slope in maximum potential consumption versus } \\
\text { temperature }\end{array}$ \\
\hline 24 & P35 & $\begin{array}{l}\text { Intercept in functional response response rate } \\
\text { parameter versus temperature } \\
\text { Slope in functional response response rate } \\
\text { parameter versus temperature }\end{array}$ \\
\hline
\end{tabular}




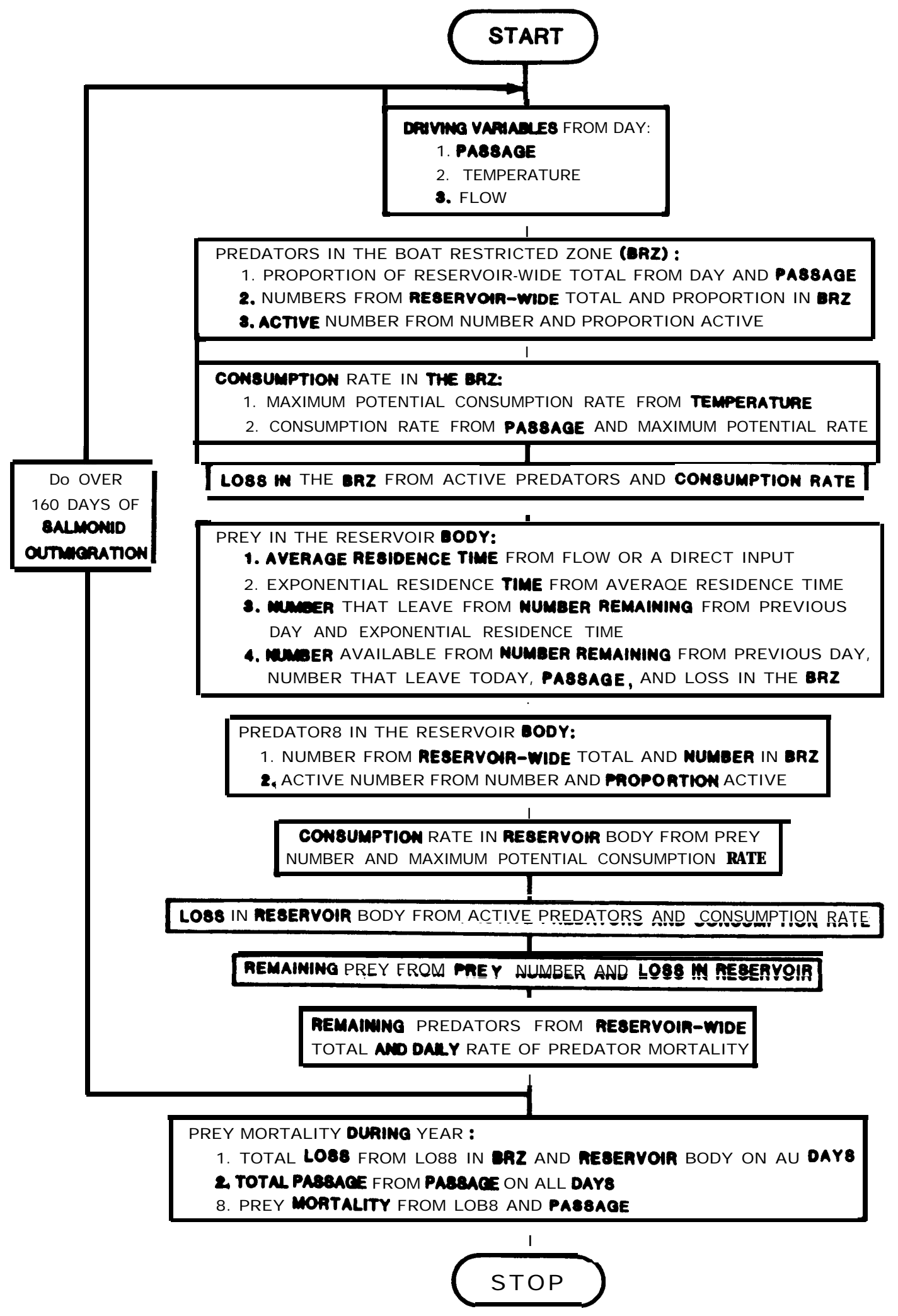


function of flow (Equation 10). Water discharge past McNary Dam may be input directly or described as a normal function of time (Equation $11)$.

Prey consumption rate per predator per day is modeled as a logistic function of prey number (Type III "functional response"). Consumption rate is related to passage number in the BRZ (Table 1, Equation 13) and number of prey calculated from passage and residence time in the reservoir (Table 1, Equation 17). Predation in the BRZ is thus assumed to be a lie-in-wait process where predators have one chance to capture a salmonid as it passes. Predation in the reservoir is simulated as a rover-predator process where prey are continuously exposed to predators until they pass from system.

Options are provided to incorporate effects of seasonally changing temperature on consumption rate by describing functional response equation parameters (Table 1, Equations 13 and 17)) as functions of temperature. The function relating temperature to the parameter describing maximum rate of consumption may be linear or a sixth degree polynomial (Equation 14). The function relating temperature to the parameter describing the rate of response to increasing prey number may be linear. Temperature may be input directly or described as a linear function of time (Equation 15).

Loss of prey to predators is estimated in each area on each day as the product of number of active predators and daily consumption rate (Table 1, Equations 12 and 16). Mortality is estimated by dividing total loss to predators in a time period by the number of salmonids entering the reservoir in that time period.

\section{HOW TO RUN RESPRED}

To run RESPRED you must:

1. Boot machine with PC-DOS or MS-DOS.

2. Place diskette containing model in default drive.

3. Start the model (type RESPREDl after > prompt and press Enter).

The program may be interrupted by pressing Control+Break or exited by selecting the Quit Option (\#8) in the Output Options Menu (See page $3)$.

RESPRED is written in compiled Microsoft QuickBASIC v4.0 to run on IBM and IBM-compatible machines. Graphics require an IBM color graphics adaptor or functional equivalent. Hercules monochrome graphics cards are not supproted. 


\section{HOU RESPRED MORKS}

RESPRED is organized into 3 parts. The input section prompts the user to supply initial state variables and parameters that describe conditions in the reservoir from April through August during the 150-day period of salmonid outmigration. The processing section calculates losses and mortality of the salmonid prey to a resident predator. The output sections displays the results of the simulation in tabular or graphical form.

Instead of re-entering inputs each time you use RESPRED, you may rerun a simulation with inputs entered previously or you may edit your earlier inputs and run a new simulation. Each time RESPRED is executed, it reads a data file containing inputs supplied in the previous run and updates the file with any changes you make in the current run. This file is called RESPRED1.KEY.

Execution of the program is controlled from two main menus and one submenu. The "Run Options Menu" is displayed when the program is started and controls the input process. Run Options include:

\section{BUILD A NEW MODEL OR SEQUENTIALLY EDIT DEFAULT INPUTS.}

\section{EDIT SELECTED INPUTS IN AN EXISTING MODEL.}

3. RUN EXISTING MODEL WITH DEFAULT OR EDITED INPUTS.

Run Option \#l steps through each input one at a time and starts the simulation when the last input is entered. Run Option \#l has no provision for going backward; you must press Ctrl+Break and restart if you make an entry error and all the inputs you entered in the current run are lost. Run Option \#2 uses inputs from the last simulation but allows changes before the simulation starts. When you select the Edit Selected Inputs Option (Run Option \#2), a list of inputs that may be changed is displayed in an "Edit Options Submenu". You select the desired inputs, make changes, and start the simulation from the "Edit Options Submenu'* (See page 4). Run Option \#2 lets you go back and change inputs you've already passed by reselecting the same option from the menu. Run Option \#3 immediately starts the simulation using inputs from the previous simulation which are contained in the default data file.

The "Output Options Menu" is displayed when the simulation is completed. Output Options include:

\section{LIST SUMMARY OF INPUTS.}

2. LIST SUMMARY OF RESULTS.

3. LIST SUMMARY OF RESULTS BY AREA.

4. LIST ENVIRONMENT AND PREDATOR INFORMATION BY DAY.

5. LIST JUVENILE SALMONID INFORMATION BY DAY. 


\section{PLOT SELECTED VARIABLES.}

\section{RETURN TO START FOR NEW SIMULATION.}

8. QUIT.

Examples of output generated by options are contained in the section on output.

\section{INPUT}

In the input section you are sequentially prompted to supply initial state variables and parameters that describe conditions that affecting mortality of juvenile salmonids to a resident predator during the 150-day period of salmonid outmigration. Default values for each input are read from the data file updated during the last simulation, and are displayed in brackets. Default values are also displayed for menu options to speed execution of the program.

Defaults can be accepted by pressing Enter. Inappropriate numbers may not be accepted and you may have to enter a new number. Commas in numbers are not accepted. Decimal fractions may or may not be preceeded with a zero. All characters must be entered in capital letters. As appropriate inputs are entered, RESPRED automatically advances to the next input or moves to the next screen.

Inputs are organized into 5 categories, and each category corresponds to a screen in the input section. These screens are accessed in order by Option \#1 in the Run Options Menu (build a new model) and are accessed selectively by Run Option \#2 (edit selected inputs). Selection of Run Option \#2 displays a listing of these categories in the Edit Options Submenu. Input screens-categories in order are:

'1. PREDATOR ABUNDANCE AND DISTRIBUTION.

2. PREDATOR ACTIVITY LEVELS.

3. PREY - NUMBERS ENTERING AND RESIDENCE TIME.

\section{TEMPERATURE AND FLOW.}

\section{FUNCTIONAL RESPONSE:}

Input Screen \#1 (Predator Abundance and Distribution) prompts for the number of predators (Pn) in the reservoir at the start of the 150-day period of the salmonid outmigration, the fraction of predators that die each day (RDm), and the proportion of predators in the boat restricted zone (RBrz). You are prompted to select one of 4 options for how the proportion of predators in the BRZ is calculated

1. CONSTANT. 


\section{A FUNCTION OF TIME.}

\section{A FUNCTION OF TIME AND PREY DENSITY.}

4. A FUNCTION OF TIME AND PREY DENSITY (REDUCTION KNOWN).

You are then prompted for inputs appropriate to your selection. For Option \#l you are prompted for a proportion which is applied to each day. For Option \#2 you are prompted for intercept (pl) and slope (p2) parameters in an equation that expresses the fraction of the predator population in the BRZ as a linear function of day (t)

$$
\operatorname{RBrz}(t)=p l+p 2 t .
$$

For Option \#3 you are prompted for the same parameters as for Option \#2 but you are also prompted for intercept and slope parameters to calculate a proportion to adjust the fraction in the BRZ for prey number $(\mathrm{RNr})$.

$$
\operatorname{RNr}(t)=p 25+p 26 \operatorname{DJv}(t)
$$

This factor approximates a numerical response of predators into the BRZ in response to increased prey number (DJv) and is added to the RBrz calculated in Equation 3. Option \#4 likewise calculates RBrz as a function of time and prey number but calculates intercept and slope parameters for you rather than making you input them directly.

Parameters are calculted from a range of variation in the distribution fraction (plus or minus p3) over a range in prey numbers (low $=\mathrm{p} 4$, high $=\mathrm{p} 5)$.

$$
\begin{gathered}
\mathrm{p} 25=-\mathrm{p} 3-\mathrm{p} 4(2 \mathrm{p} 3 /(\mathrm{p} 5-\mathrm{p} 4)) \\
\mathrm{p} 26=2 \mathrm{p} 3 /(\mathrm{p} 5-\mathrm{p} 4)
\end{gathered}
$$

Input Screen \#2 (Predator Activity Levels) prompts for the fraction of predators in the BRZ (RAcl) and reservoir body (RAc2) that are actively feeding on salmonids. You are prompted to select one of four options for entering these active fractions

1. CONSTANT.

2. CONSTANT BUT MONTH SPECIFIC.

3. A LINEAR FUNCTION OF FLOW.

4. A LINEAR FUNCTION OF FLOW - REDUCTION KNOWN.

You are then prompted for inputs appropriate to your selection. For Option \#l you are prompted for a proportion which is applied to each day. For Option \#2 you are prompted for proportions for each month; April, May, June, July, and August. For Option \#3 you are prompted for intercept (p27) and slope (p28) parameters in an equation that expresses the fraction of the predator population that is active as a linear function of flow. 


$$
\operatorname{RACi}(t)=p 27+p 28 \operatorname{DF} 1(t)
$$

Option \$4 likewise calculates RAci as a function of flow but calculates intercept and slope parameters for you rather than making you input them directly. Parameters are calculated from a range of variation in the proportion active (plus or minus p29) over a range in flow $($ low $=\mathrm{p} 30$, high $=\mathrm{p} 31)$.

$$
\begin{gathered}
p 27=-p 29-p 30(2 p 29 /(p 31-p 30)) \\
p 28=2 p 29 /(p 31-p 30)
\end{gathered}
$$

Input Screen \#3 (Prey - Numbers Entering and Residence Time) prompts for number of juvenile salmonids entering the reservoir and residence time. Prey numbers may be entered

\section{AS A CONSTANT.}

2. NORMALLY DISTRIBUTED AS A FUNCTION OF TIME.

You are prompted for inputs appropriate to your selection. For Option 11 you are prompted for a number which is applied to each day. For Option $\$ 2$ you are prompted for the total number of salmonids in the run (p6), the day of 50\% passage numbered from 1 on April 1 (p7), and the number of days in one standard deviation from the day of $50 \%$ passage (p8). Daily passage (DJv) is then calculated

$$
\operatorname{DJv}(t)=(p 6 /(2.5066 p 7)) e^{-(p 8-t) \cdot 2 /(2 p 7 * 2)}
$$

Residence time may be entered

1. AS A CONSTANT.

2. AS A CURVILINEAR FUNCTION OF FLOW.

You are prompted for inputs appropriate to your selection. For Option \$1 you are prompted for a number which is applied to each day. For Option $\$ 2$ you are prompted for intercept (p9) and slope (p10) parameters in the flow-residence time equation

$$
\operatorname{RTm}(t)=1 /(p 9+p 10 \operatorname{DFI}(t))
$$

Input Screen \#4 (Temperature and Flow) prompts for temperature and flow inputs. Temperature may be entered

\section{AS A CONSTANT.}

\section{AS A LINEAR FUNCTION OF TIME.}

You are prompted for inputs appropriate to your selection. For Option $\$ 1$ you are prompted for a temperature (DTp in degrees centigrade) which is applied to each day. For Option \#2 you are 
prompted for intercept (p21) and slope (p22) parameters in the timetemperature equation

$$
\operatorname{DTp}(t)=p 21+p 22 t
$$

Flow may be entered

\section{AS A CONSTANT.}

2. NORMALLY DISTRIBUTED AS A FUNCTION OF TIME.

You are prompted for inputs appropriate to your selection. For Option 1 you are prompted for a flow (in cfs $\times 10^{3}$ ) which is applied to each day. For Option $\mathbf{1 2}$ you are prompted for maximum daily discharge (pll), day of maximum discharge numbered from day 1 on April 1 (p12), and number of days in one standard deviation from the day of maximum discharge (p13). Flow (DJv) is then calculated for each day $(t)$

$$
\operatorname{DF} I(t)=p 11 e^{-(p 12-t)^{\wedge} 2 /\left(2 p 13^{\wedge} 2\right)}
$$

Input Screen \#5 (Functional Response) prompts for parameters in the functional response equations in the BRZ and the reservoir body. Functional response equation inputs include a maximum potential consumption rate $\left(\mathrm{RCn}_{\max }\right)$, an intercept parameter (p14 in BRZ, $\mathbf{p} 23$ in reservoir body), and a response rate parameter (p15 in BRZ, p24 in reservoir body). Maximum potential consumption rate (prey per predator per day) can be input

1. AS A CONSTANT.

\section{AS A LINEAR FUNCTION OF TEMPERATURE.}

3. AS A POLYNOMIAL FUNCTION OF TEMPERATURE.

You are prompted for inputs appropriate to your selection. For Option $\$ 1$ you are prompted for a rate that is applied to each day. For Option \$2 you are prompted for intercept (p32) and slope (p33) parameters in the temperature-maximum rate equation

$$
R C n_{\max }(t)=p 32+p 33 \operatorname{DTp}(t)
$$

For Option $\$ 3$ you are prompted for 5 slope parameters for a polynomial form of the temperature-maximum rate equation

$$
\begin{aligned}
\operatorname{RCn}_{\max }(t)= & p 16 \mathrm{DTp}(t)^{2}-\mathrm{p} 17 \mathrm{DTp}(t)^{3}+\mathrm{p} 18 \mathrm{DTp}(t)^{4} \\
& -\operatorname{p19} \mathrm{DTp}(t)^{5}+\mathrm{p} 20 \mathrm{DTp}(t)^{6}
\end{aligned}
$$

Response rate parameters may be input

1. AS A CONSTANT

2. AS A LINEAR FUNCTION OF TEMPERATURE 
You are prompted for inputs appropriate to your selection. For Option 1 you are prompted for a parameter which is applied to each day. For Option $\mathbf{2}$ you are prompted for intercept (p34) and slope (p35) parameters in the temperature-response rate equation

$$
P 14=p 34+p 35 \operatorname{DTp}(t) .
$$

You are prompted to input constant intercept parameters for the functional response equations in the BRZ and reseervoir body.

\section{OUTPUT}

The Output Options Menu was listed on page 2. Simulation results in the form of tables or graphs may be displayed from this menu. Examples of these outputs follow. You may get a hard copy of any of the summary information and output tables by pressing Shift+PrtXc when the desired information is displayed. You may get a hard copy of a plot by pressing $P$ when the plot is displayed.

\section{Output Option \#1}

(List Summary of Inputs)

This option lists a short summary of processes, starting numbers, and parameters upon which the current simulation is based. These lists may be printed and attached to simulation results for reference.

PREDATORS NUMBER ON DAY ONE [ 85316

DAILY MORTALITY | .000135

$\because$ IN BRZ [A LIN FUNC OF TIME W INT .0448 AND SLOPE .000318

\& $[$ A LIN F OF PASS WO CHANGE OVER PASSRANGE 18962 TO 234621

BRZ $\div$ ACT [A 11 !I 11 J

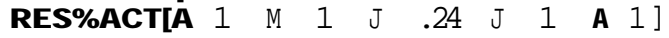

PREY PASSAGE [RUN $=2.105479 \mathrm{E}+07$ MPR， DIS WNM 69.7 \& RANGE 35.8 RES TIME [13]

TEMPERATURE [A LIN FUNC OF TIME W INT $=8.74$ AND SLOPS .108

FLOW [A HORN $F$ OF TIME $W$ MAX $=282 \quad \mathrm{PEAK}=48 \mathrm{SD}=64]$

FUNC RESP MAX CONS PARM [POLYNOMIAL FUNCTION OF TEMP

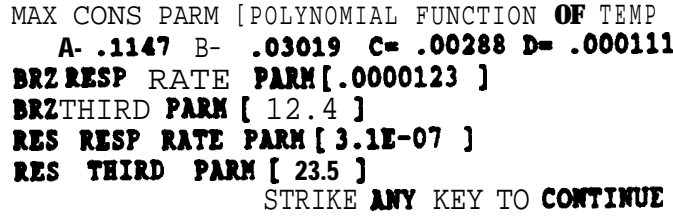


Output Option \#2

(List Summary of Results)

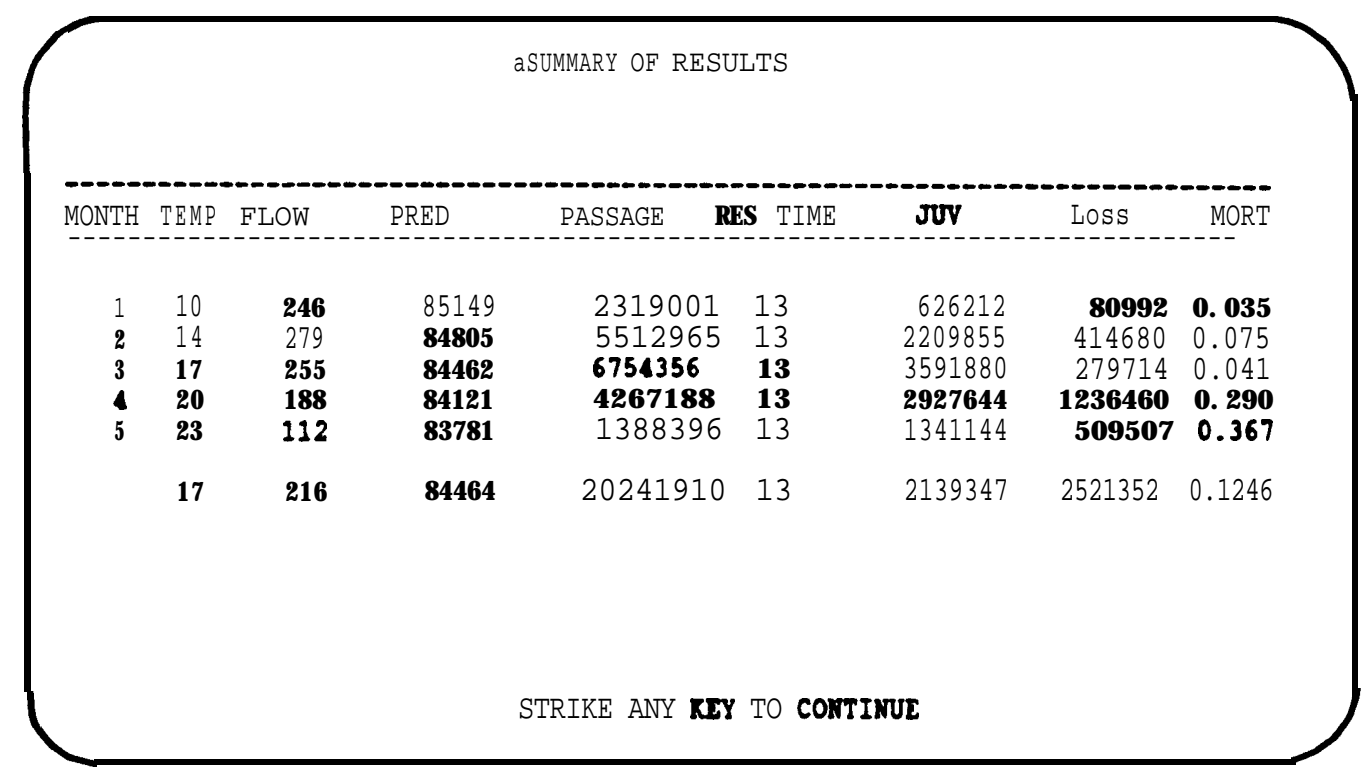

where

MONTH = April, May, June, July, August.

TEMP = Average water temperature in degrees centigrade during month.

FLOW = Average discharge past McNary Dam in 1000 cubic feet per second during month.

PRED = Average number of predators in reservoir-wide population during month.

PASSAGE $=$ Total number of prey entering reservoir during month .

RES TIME = Average residence time in days of prey in reservoir during month.

JUV = Average density of prey in reservoir body during month .

LOSS = Total number of prey consumed by predators during month.

MORT $=$ Proportion of prey entering reservoir during month that are consumed by predators (LOSS/PASSAGE). 
Output Option \#3

(List Summary of Results by Area)

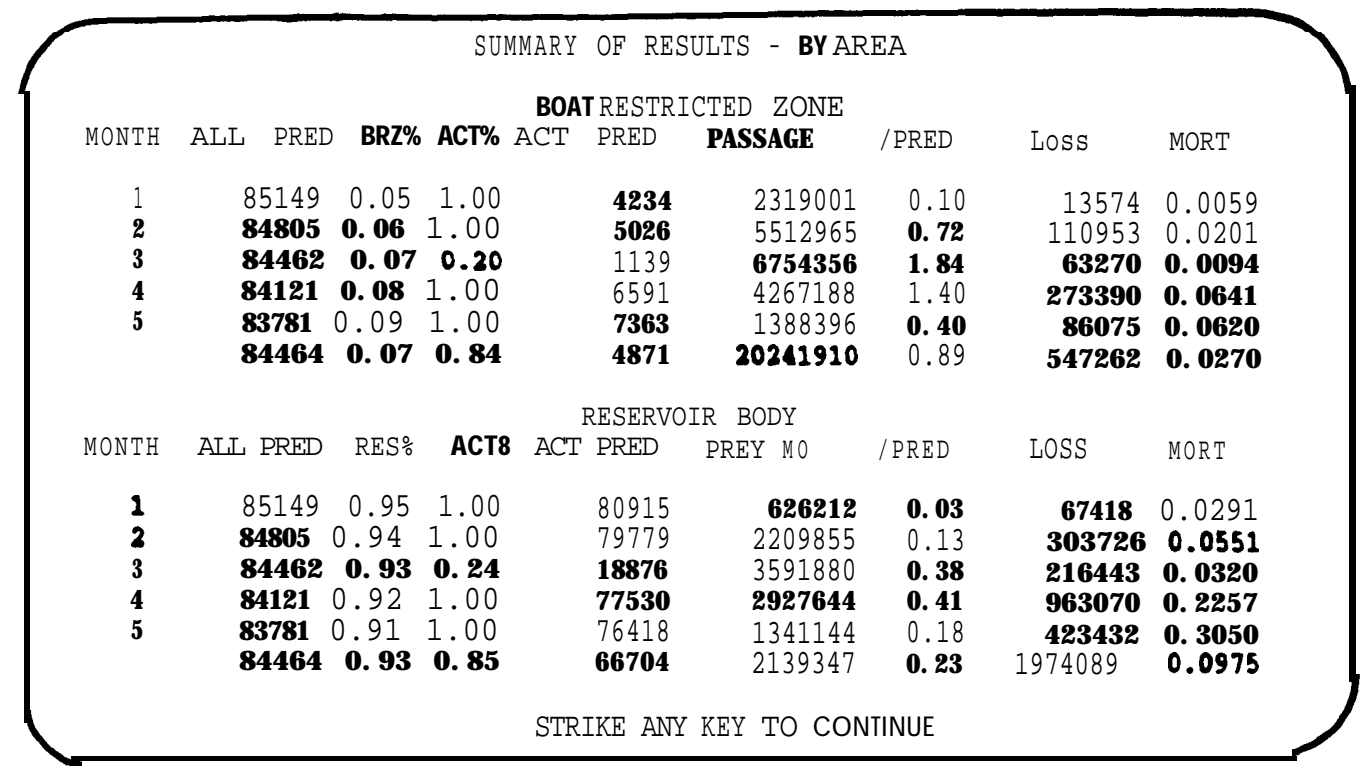

where

MONTH = April, May, June, July, August.

ALL PRED = Average number of predators in reservoir-wide population during month.-

$\mathrm{BRZ} \%=$ Average proportion of predator population in BRZ during month.

RES\% = Average proportion of predator population in reservoir body during month.

$\mathrm{ACT} \%=$ Average proportion of predators in area that are actively consuming prey during month.

ACT PRED = Average number of predators in area that are actively consuming prey during month.

PASSAGE = Total number of prey entering reservoir during month.

PREY NO = Average density of prey in reservoir body during month .

$/$ PRED = Average daily consumption of prey per predator in area during month.

LOSS $=$ Total number of prey consumed by predators in area in month.

MORT = Proportion of prey entering reservoir during month that are consumed by predators in area (LOSS/PASSAGE).

Area-specific totals for year or yearly averages are listed at the bottom of each column. 


\section{Output Option \#4 \\ (List Environment and Predator Information by Day)}

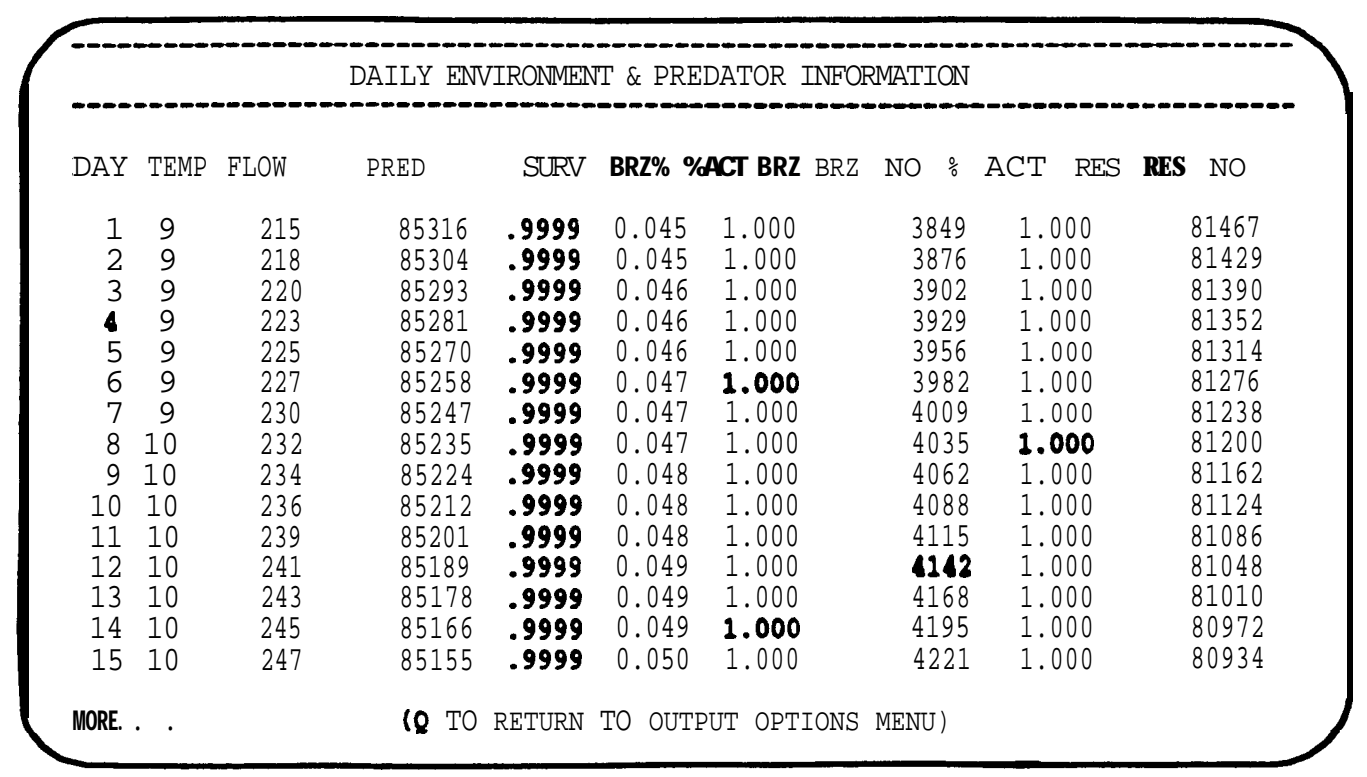

where

$\mathrm{DAY}=1$ to 150 corresponding to April through August period of salmonid outmigration [t ] .

TEMP $=$ Temperature in degrees centigrade [DTp(t)].

FLOW = Discharge past McNary Dam in 1000 cubic feet per second $[D F I(t)]$.

PRED $=$ Number of predators in reservoir-wide population $[\operatorname{Pn}(t)]$.

SURV $=$ Number of predators that survive to following day $[1-R D m(t)]$.

$\mathrm{BRZ} \%=$ Proportion of reservoir-wide predator population in BRZ $[\operatorname{RBrz}(t)]$.

\%ACT BRZ = Proportion of predators in BRZ that are actively consuming prey $[\operatorname{RACl}(t)]$.

BRZ NO $=$ Number of predators in BRZ that are actively consuming prey $[\operatorname{Pn} 1(t)]$.

$\% A C T$ RES = Proportion of predators in reservoir body that are actively consuming prey [RAc2 $(t)]$.

RES NO $=$ Number of predators in reservoir body that are actively consuming prey [Pn2 $(t)]$. 
Output Option \#5

(List Juvenile Salmonid Information by Day)

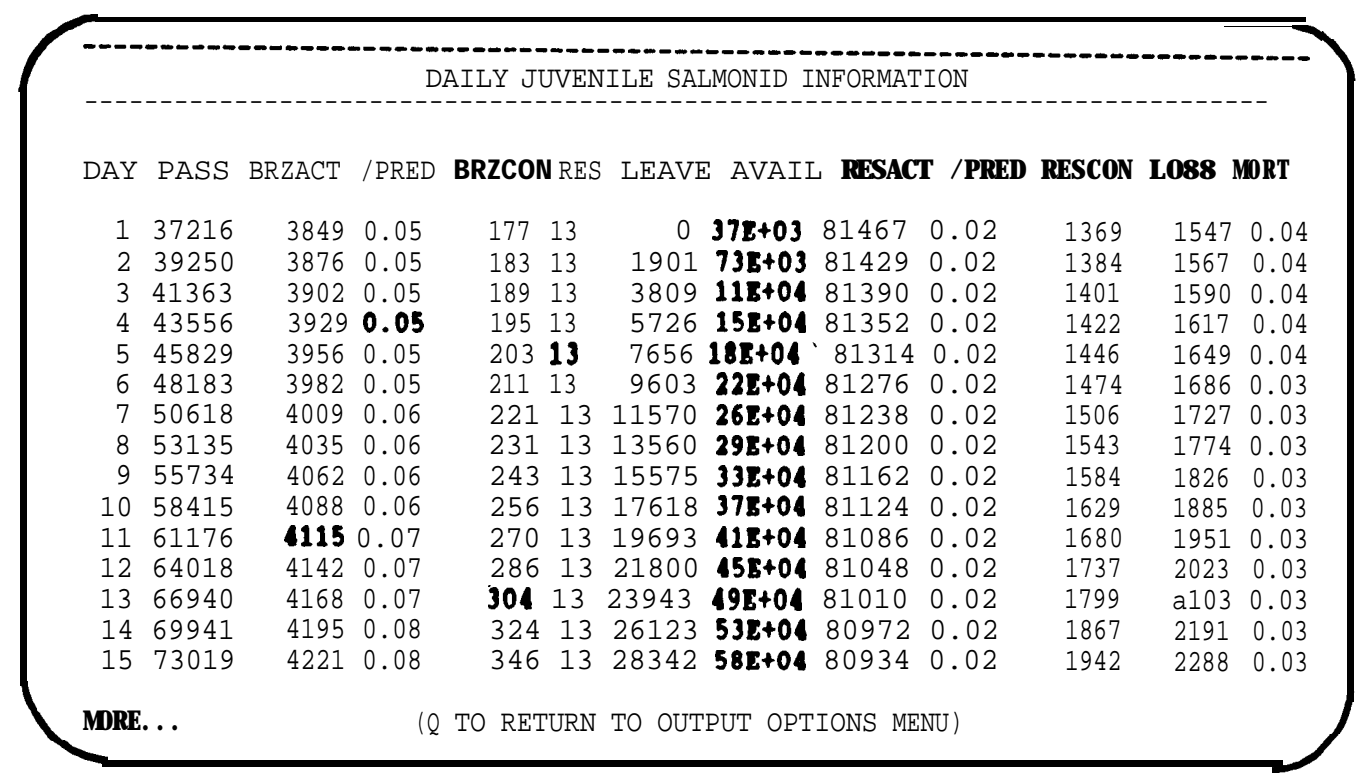

where

$\mathrm{DAY}=1$ to 150 corresponding to April through August period of salmonid outmigration $(t)$.

PASS $=$ Number of prey passing McNary Dam [DJv $(t)]$.

BRZACT $=$ Number of predators in BRZ that are actively consuming prey [ARn1 $(t)]$.

/PRED = Daily consumption of prey per predator in $B R Z[R \mathbf{C n} 1(t)]$.

$\mathrm{BRZCON}=$ Loss of prey to predators in BRZ on day [SC1(t)].

RES = Residence time of prey in reservoir in days $[R \operatorname{Rm}(t)]$.

LEAVE $=$ Number of prey leaving reservoir on day $[\boldsymbol{J v}(t) / \operatorname{RTmE}(t)]$.

AVAIL $=$ Number of prey in reservoir body during day [Jv2 $(t)]$.

RESACT $=$ Number of predators in reservoir body that are actively consuming prey [APn2 $(\mathbf{t})]$.

$/ \mathrm{PRED}=$ Daily consumption of prey per predator in reservoir body $[R \operatorname{Rn} 2(t)]$.

RESCON $=$ Loss of prey to predators in reservoir body on day $[\operatorname{sc} 2(t)]$.

LOSS $=$ Total loss of prey to predators on day $[\operatorname{sc1}(t)+\mathbf{S C 2}(t)]$. 


\section{Output Option \#6 \\ (Plot Selected Variables)}

You may plot daily results versus day or daily results versus each other. When you choose this option, a list of variables that can be plotted are displayed and you are prompted to select a variable for the $y$ and $x$ axes. $X$-axis variables are automatically sorted from minimum to maximum. Plotable variables correspond with those listed in Output Options 4 and 5. The plot is automatically scaled so that the plot fills the Y-axis. You may print graphs by pressing $\mathrm{P}$ after the plot is drawn on the screen. (This option was programmed for an IBM graphics printer and may not work on other printers.) Example inputs and the resulting graph are shown.

\section{PLOT SELECTED VARIABLES}

THE FLOOWING VARIABLES MAY BE PLOTTED

$\begin{array}{llllll}\text { DAY } & \text { THAP } & \text { FLOW } & \text { PASSIN } & \text { PREY } & \text { PASSOT } \\ \text { PRED } & \text { BRZ\% } & \text { \%ACTBRZ } & \text { OACTRES } & \text { BRZAPRED } & \text { RESPARED } \\ \text { RECONSBRZ } & \text { RCONSRES } & \text { LOSSBRZ } & \text { LOSSRES } & \text { LOSS } & \text { MORT }\end{array}$

SELECTY-AZIS VARIABLE BY ENTERING ITS NAME [LOSS]: ?

SELECT X-AXIS VARIABLE BY ENTERING ITS NAME [DAY]: ?

INDICATI MONITOR TYPE (=IBM，2=MOD D) [1] ?

L O S S (X 1000)

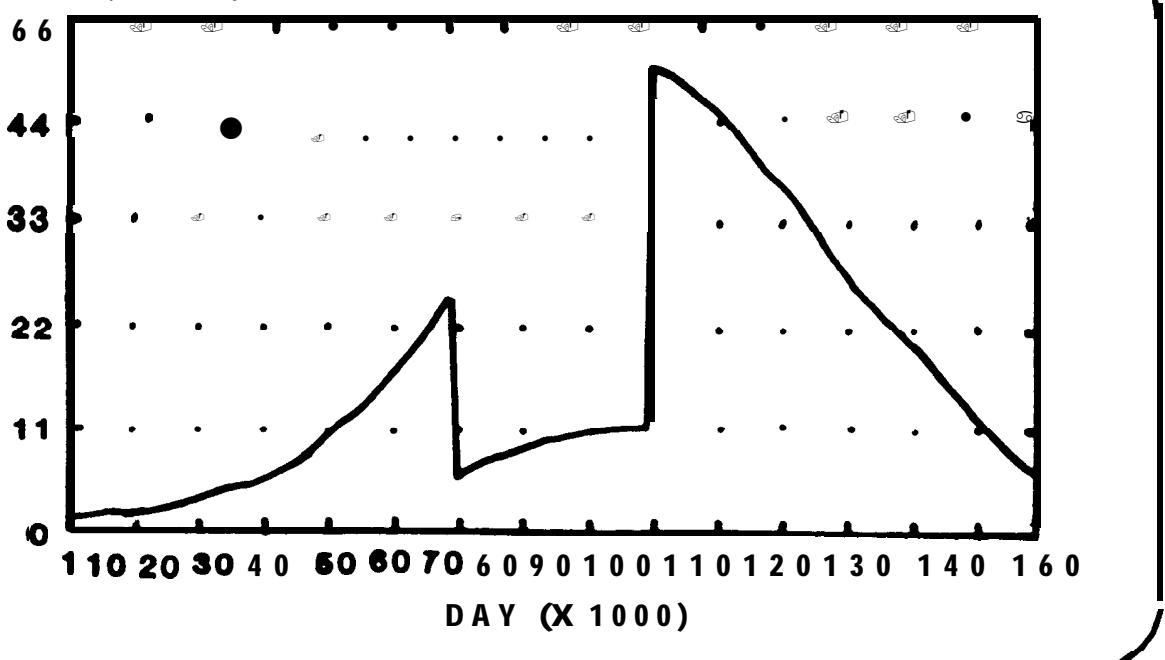




\section{COPIES}

A copy of RESPRED may be obtained by sending a diskette and self-addressed mailer with stamp to the author. RESPRED includes the following files

1. RESPRED1.EXE: the executable program file.

2. RESPRED1,KEY: file containing default data set.

3. RESPRED1.BAS: file containing the source code.

4. RESPRED1.DOC: file containing user's guide.

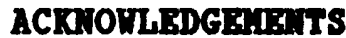

I thank L.J. Bledsoe and B.E. Rieman for assistance with design of RESPRED. This work was funded by the Bonneville Power Administration (Contract DE-AI79-82BP35097).

\section{REPERETCES}

Beamesderfer, R.C., B.E. Rieman, and S. Vigg. 1988. Simulation of predation by resident fish on juvenile salmonids in a Columbia River reservoir. In T.P. Poe and B.E. Rieman, editors. Predation by resident fish on juvenile salmonid in John Day Reservoir, 1983-86. Final report (Contracts DE-AI79-82BP34796 and DE-AI79-82BP35097) to Bonneville Power Administration, Portland, Oregon.

Ebel, W.J. 1977. Major passage problems. Pages 33-39 in E. Schwiebert, editor. Columbia River salmon and steelhead. American Fisheries Society Special Publication 10, Washington D.C.

Rieman, B.E., R.C. Beamesderfer, and S. Vigg. 1988. Predation by resident fish on juvenile salmonids in a mainstem Columbia River reservoir: Part IV. Total loss and mortality of juvenile salmonids to northern squawfishwalleye, and smallmouth bass. In T.P. Poe and B.E. Rieman, editors. Predation by resident fish on juvenile salmonids in John D a $R$ eservoir 1983-86. Final report (Contracts DE-AI79-82BP34796 and DE-AI79-82BP35097) to Bonneville Power Administration, Portland, Oregon. 
Data Set Documentation

JOHN C. ELLIOTT

Oregon Department of Fish and Wildlife

17330 SE Evelyn Street, Clackamas, Oregon 97015, USA 
Data collected during routine sampling, during an angler survey, from analyses of fish scales, and from radiotagged fish are stored on magnetic tapes. The sections of this attachment are the contents of the first file on each of the tapes and contain information on the kind of data, what it was used for, how to retrieve the data sets, the location of variables and descriptions of variables and variable codes. A hardcopy of these files are attached to each respective tape.

Copies of these tapes are archived with:

The Bonneville Power Administration, Portland, Oregon

ODFW Data Processing Section, Portland, Oregon

ODW Research and Development Section, Clackamas, Oregon

ODFW personnel familiar with data storage and coding include:

Anthony Nigro

John Elliott

Raymond Beamesderfer
$657-2038$

657-2035

657-2036 


\section{EFFORT, CATCH AND FISH BIOLOGICAL DATA}

This documentation is the first of five files on this tape, an information file. This tape contains yearly effort, catch and individual fish biological information (Files 2-5) collected by the Oregon Department of Fish and Wildlife (ODFW) in the John Day Pool of the Columbia River from 1983 to 1986. The purpose of the study was to describe the abundance and distribution of major predators of juvenile salmonids. An associated study to determine consumption rates and prey selection of major predators during the same time was conducted by the U.S. Fish and Wildlife Service (usfws). Portions of the data collected by USFWS are included in these files. Both studies were funded by the Bonneville Power Administration (BPA) and have worked together to describe the extent of predation in this area. Annual and final reports of these studies are availible from BPA.

Files 2-5 contain only data. All files are written in ASCII, Record Format $=$ fixed block, Logical Record Length $=80$, Blocksize $=$ 9040 and Density $=1600$ bites per inch. Programs to write disk files from the BPA mainframe computer OS data sets to this tape using the ROSCOE environment in use during 1988 are: 


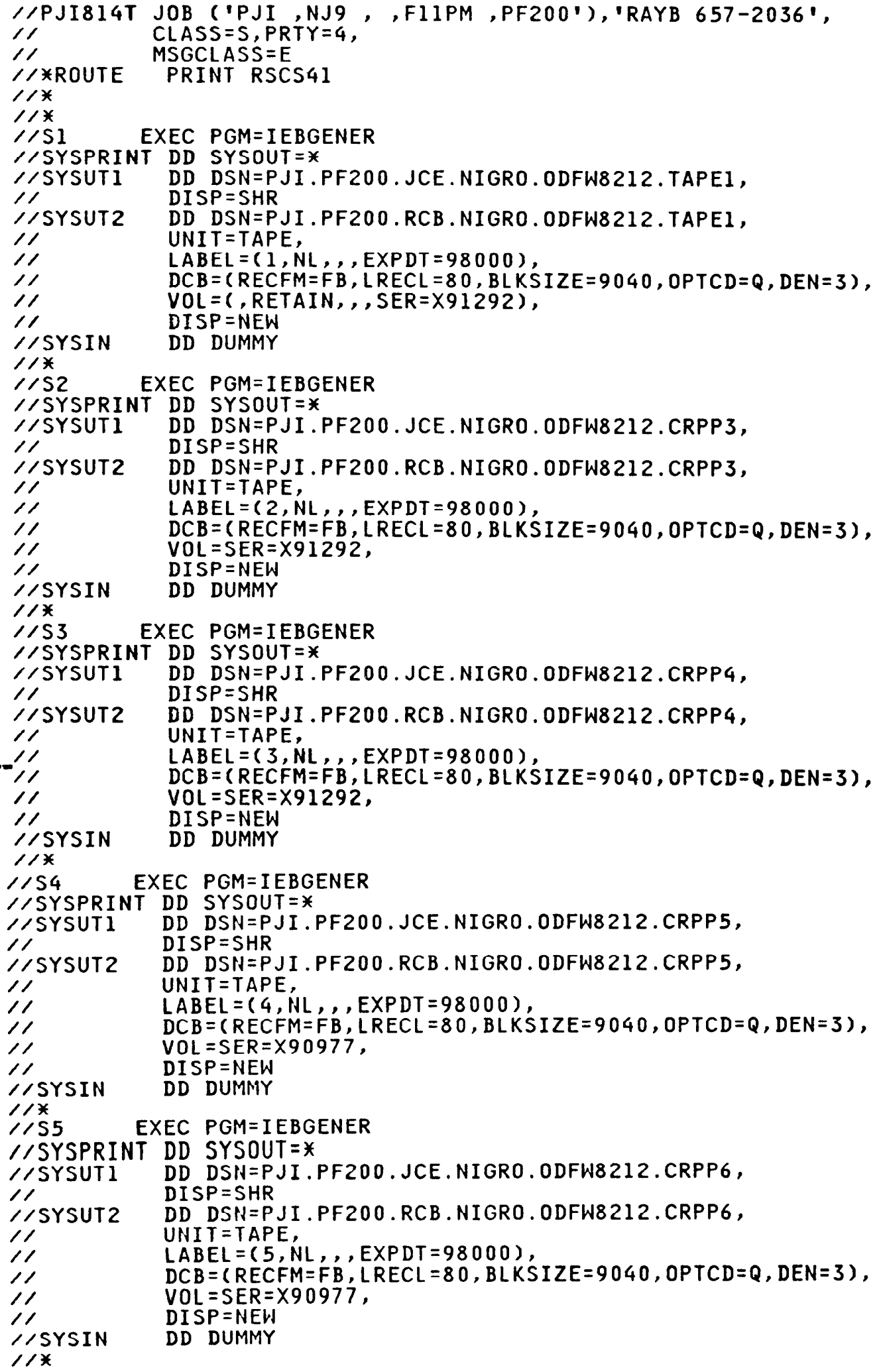


Variable List

\begin{tabular}{|c|c|c|c|c|}
\hline VARIABLE & $\begin{array}{l}\text { NUMBER } \boldsymbol{o} \\
\text { CHARACTERS }\end{array}$ & $\begin{array}{l}\text { ALPHA OR } \\
\text { NUMERIC }\end{array}$ & COLUMNS & JUSTIFICATION \\
\hline DATE & 6 & $\mathrm{~N}$ & $1-6$ & $\mathrm{R}$ \\
\hline LOCATION & 5 & $\mathrm{~N}$ & $7-11$ & $\mathrm{R}$ \\
\hline GEAR & 2 & $\mathrm{~N}$ & $12-13$ & $\mathrm{R}$ \\
\hline START TIME & 4 & $\mathrm{~N}$ & $14-17$ & $\mathrm{R}$ \\
\hline STOP TIME & 4 & $\mathrm{~N}$ & $18-21$ & $\mathrm{R}$ \\
\hline EFFORT & 4 & $\mathrm{~N}$ & $22-25$ & $\mathrm{R}$ \\
\hline DEPTH (MIN) & 2 & $\mathrm{~N}$ & $26-27$ & $\mathrm{R}$ \\
\hline DEPTH (MAX) & 3 & $\mathrm{~N}$ & $28-30$ & $\mathrm{R}$ \\
\hline TEMPERATURE & 2 & $\mathrm{~N}$ & $31-32$ & $\mathrm{R}$ \\
\hline SECCHI & 2 & $\mathrm{~N}$ & $33-34$ & $\mathrm{R}$ \\
\hline WAVE HEIGHT & 1 & $\mathrm{~N}$ & 35 & \\
\hline FISH NUMBER & 2 & $\mathrm{~N}$ & $36-37$ & $\mathrm{R}$ \\
\hline SPECIES & 3 & A & $38-40$ & $\mathrm{R}$ \\
\hline COLLECTION NO. & 3 & $\mathrm{~N}$ & $41-43$ & $\mathrm{R}$ \\
\hline SCALE NO. & 4 & $\mathrm{~N}$ & $44-47$ & $\mathrm{R}$ \\
\hline FORK LENGTH & 3 & $\mathrm{~N}$ & $48-50$ & $\mathrm{R}$ \\
\hline WEIGHT & 4 & $\mathrm{~N}$ & $51-54$ & $\mathrm{R}$ \\
\hline SEX & 1 & A & 55 & \\
\hline MATURITY STAGE & 1 & $\mathrm{~N}$ & 56 & \\
\hline DISPOSITION & 2 & $\mathrm{~N}$ & $57-58$ & $\mathrm{R}$ \\
\hline TAG COLOR & 2 & A & $59-60$ & $\mathrm{R}$ \\
\hline TAG NUMBER & 5 & $\mathrm{~N}$ & $61-65$ & $\mathrm{R}$ \\
\hline SECONDARY MARK & 1 & $\mathrm{~N}$ & 66 & \\
\hline AGE STRUCTURE & 1 & $\mathrm{~N}$ & 67 & \\
\hline DOCUMENT NO. & 4 & $\mathrm{~N}$ & $68-71$ & $\mathrm{R}$ \\
\hline
\end{tabular}


Date: Date of sample. (format Day, Month, Year)

Location: Place sampling gear was deployed.

(Six digit code)

Section - is the largest unit and is designated by the first two numbers in the six digit location code.

14 - Upper The Dalles Dam Pool (River mile 207 - 216)

15 - Lower John Day Dam Pool (River mile 216 - 279)

16 - Upper John Day Dam Pool (River mile 279 - 292)

17 - Lower McNary Dam Pool (River mile 292 - 324)

Transect - there are several transects within a section. They are designated by the first three numbers in the six digit location code. Our transects include:

159 - John Day Forebay

156 - Arlington

151,163 - Irrigon/Patterson

161 - McNary Tailrace

Station - there are several stations within a transect and they are designated by the fourth and fifth numbers in the six digit code.

Site - is the smallest unit and is designated by using the sixth number in the six digit location code. There may or may not be sites within a station. Site codes are used to identify a very specific location generally used for fixed sampling gears and/or angling locations around dams.

Transect,

Station Site

John Day forebay

01 John Day powerhouse (OR shore to unit 20, upstream 200 yards)

011 OR shore to adult fish ladder

012 adult fish ladder to unit 1

013 units $1-5$

014 units 6-20

02 John Day spillway (upstream 200 yards)

021 spill gates $11-20$

022 spill gate 10 to navigation lock

03 Navigation lock channel

04 WA corner (nav. lock channel to WA shore then upstream to culvert entrance to backwater)

041 cement foundation north of corps moorage

042 WA shore midway between rock signs

$043 \mathrm{E}$ rock sign

044 FWS prey site

045 fWS prey site 
046 corner

047 point outside culvert

05 WA backwater

06 WA shore (entrance of backwater to red flag 4)

07 Open water (200 yards above dam to red flag 4)

08 OR shore $(200 \mathrm{yds}$. above dam to $100 \mathrm{yds}$ below

John Day river mouth)

081 submerged, rocky point just inside deadline

082 OR shore between dam and restricted boundary

John Day River (100 yds. below mouth to red flag

4 and upstream 2.5 miles)

091100 yards below mouth to railroad bridge

092 railroad bridge to red flag 4

093 railroad bridge to $\mathrm{I}-84$ bridge

094 east shore (I-84 bridge upstream 2.5 miles)

095 west shore (I-84 bridge upstream 2.5 miles)

096 west shore off point at first west bend (also in 095)

10 John Day River (more than 2.5 miles upriver)

Arlington

$01 \quad$ Arlington marina

02 OR shore (marina to end of transect)

021 point west of Jones Canyon

03 Jones Canyon backwater

04 WA shore (railroad light to pump intake) 041 irrigation pump intake

05 Boat ramp inlet

051 point west of boat ramp

052 beach in NE corner

$06 \quad$ Ferry landing

07 Open water (lower transect)

08 WA shore (piles to Roosevelt)

09 Roosevelt inlet 091 inlet at east end of station

10 WA elevator

11 Offshore shelf

12 Open water (between grain elevators)

13 OR shore (marina to railroad light)

14 WA shore (sand to willow bush)

15 WA shore (willow bush to rounded knoll)

16 Open water (sand to rounded knoll)

17 OR shore (railroad light to apron)

18 WA shore (rounded knoll to green flag 24)

13 Open water (upper transect end)

20 OR shore (apron to end of transect) 201 beach at east end of station

01 WA shore (flag 64 to shallows off red buoy 62)

011 point where shallows drop off to deep water near shore (osprey tree) 
Open water (flag 64 to flag 62)

03 OR shore (flag 64 to flag 62)

031 channel side of shelf (flag 62 to flag 64)

032 shallows in mid-river (south of site 1)

033 deep water and OR shore (south of site 2)

04 WA shore (flag 59 to flag 62)

041 shallows at east end of station

05 Open water (flag 59 to flag 62)

06 OR shore (flag 59 to flag 62)

061 Irrigon Marina

$07 \quad$ WA shore (flag 57 to flag 59)

08 Open water (flag 57 to flag 59)

09 OR shore (flag 57 to flag 59)

10 South side Paterson Island (point to flag 57)

101 directly across from refuge boat ramp

11 Open water (from line dissection Paterson Island point and grain elevator to flag 57)

12 OR shore (grain elevator to flag 57)

Paterson

01 Paterson Slough (WA rocky shoreline)

011 shoreline (boat ramp to "line-up" point)

012 WA shoreline along railroad tracks

02 Paterson Slough (backwater shallows)

03 Paterson Slough (inside island to trestle opening)

031 east from trestle opening to island point

032 deep hole inside trestle

033 mid-channel inside trestle opening

04 Channel side of Paterson trestle (boat ramp to island point)

041 east from trestle opening to island point

042 west from trestle opening to boat ramp

043 offshore outside trestle opening

05 Open water (Flag 55 to grain elevator)

06 OR shore (Flag 55 upper tip of upper Blalock Island)

07 WA shore and shallow water (lower end of transect to

Paterson boat ramp)

08 Open water (north channel-lower end of transect to flag 55)

09 Open water (E. tip of upper Blalock Island to flag 55)

091 shallow water adjacent to flag 55

092 shallow water adjacent to flag 53

093 combination of 091 and 092

McNary Tailrace

01 Powerhouse (to end of boat restricted zone)

011 units $1-7$

012 units $8-14$

013 OR shore (riffle to end of boat restricted zone

02 Spillway (downstream to end of navigation lock)

(end of boat restricted zone)

021 adult fish ladder pool 
022 attraction water and sluiceway spill

023 gates $21-22$

024 gates $11-20$

025 gates $1-10$

026 south side of navigation lock

03 Navigation lock to power line point RM 291.1

031 navigation lock channel

04 Open water (end of navigation lock to power line point)

05 OR shore--PH point ( $\mathbf{r m}$ 292) to marina light

053 concrete pillars at pond creek mouth

055 shallows between 053 and power lines

059 gravel bar (bridge to marina light)

06 East Plymouth Slough (power line point to end of slough)

061 power line point to bridge

062 WA shore (bridge to tip of island)

063 WA shore (tip of island to swim buoys)

064 end of slough to swim buoys

065 island shore (swim buoys to upstream tip of island

066 upstream from island tip (from bar toward WA shore)

07 South shore of Plymouth Island

071 marina inlet

072 from marina to eastern tip of island

073 from marina to western tip of island

08 Open water (power line to Umatilla River mouth

and Plymouth Is. light)

09 OR shore (marina light to Umatilla River mouth)

091 marina

092 swim area

093 pump house west of swim area

094 inlet eddy 500 yds. west of pump house

10 West Plymouth Slough (starts at downstream tip of island)

101 WA shore (west end to trap-net point, includes

bunker)

102 WA shore (trap-net point to end of slough)

103 Island shore (end of slough to across from trap-net point)

104 Island shore (across from trap-net point to tip of island)

105 mid channel (trap-net point to tip of island)

106 submerged island at east end

11 WA shore (west Plymouth to end of transect)

111 stumps off tip of Plymouth Island

112 trap-net trees on WA shore across from stumps

12 Open water (Plymouth Island light-Umatilla River mouth to end of transect)

13 Umatilla River and mouth

131 outside of bridges

132 inside of bridges

14 OR shore (Umatilla River mouth to pump house) 
Gear: Type of gear deployed

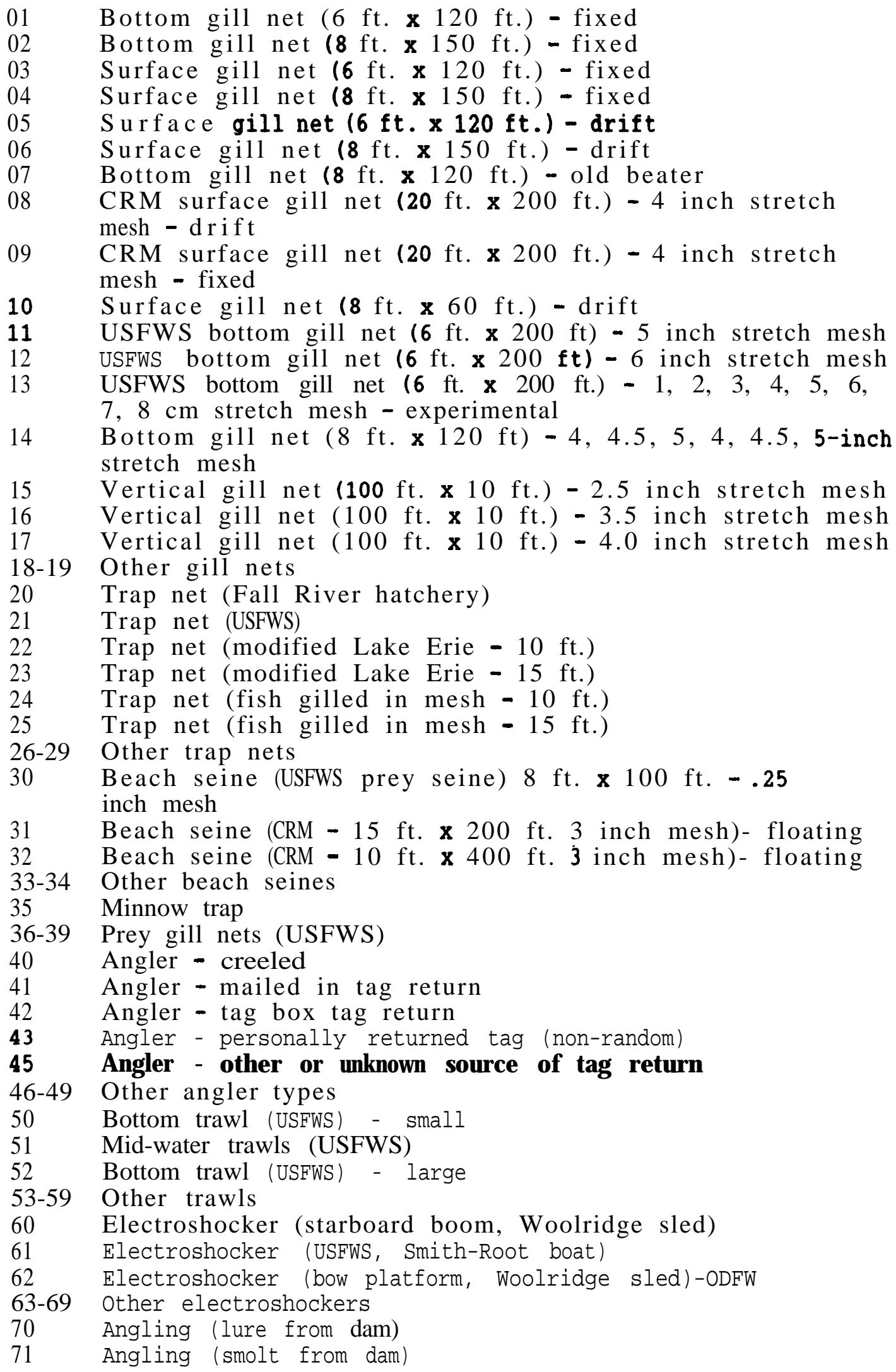




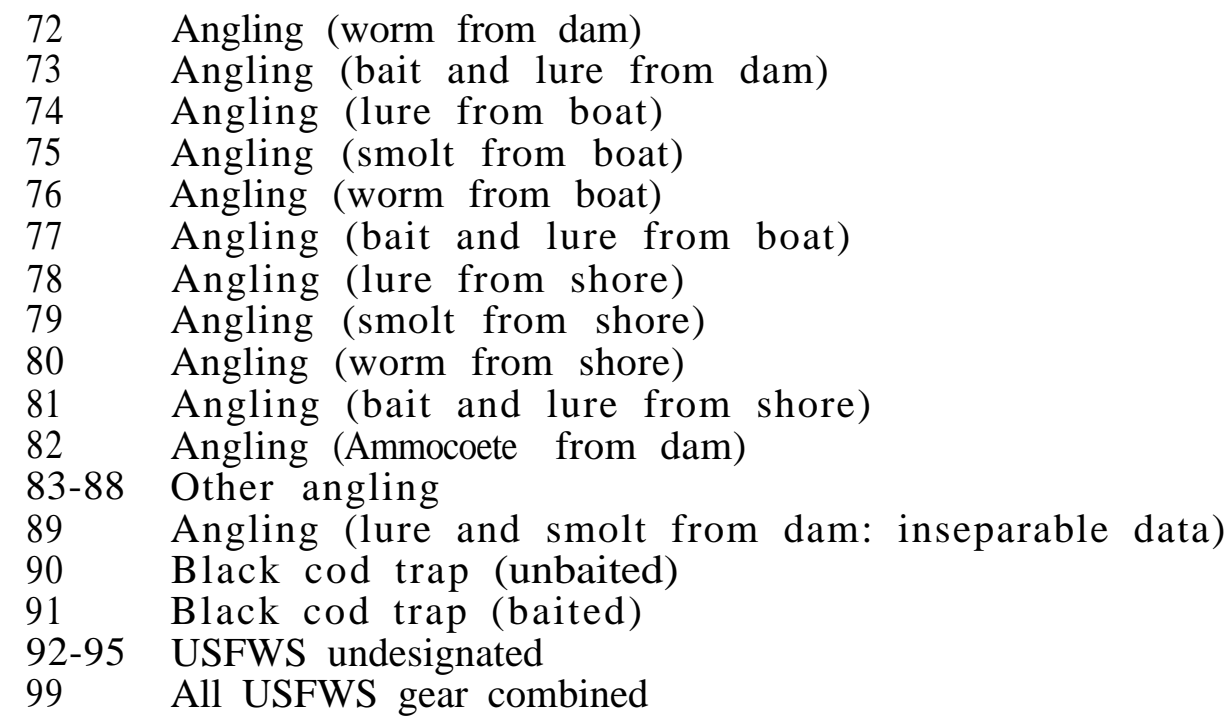

Start time: Time gear was deployed (Military)

Stop Time: Time gear was retrieved (Military)

Effort: The time in hundreths of hours that gear was sampling.

Depth of set (MIN): Depth of bottom at shallowest part of set (feet)

Depth of set (MAX): Depth of bottom at deepest part of set (feet)

Temperature: Surface water temperature (Degrees C)

Secchi: Secchi depth reading (Meters and tenths of meters)

Wave Height: Vertical distance from crest to trough

$$
\begin{aligned}
& 1=0-6^{\prime \prime} \\
& 2=6-18^{\prime \prime} \\
& 3=18-36^{\prime \prime} \\
& 4=36^{\prime \prime}
\end{aligned}
$$

Fish number: Number of each individual fish in a set

\section{Species:}

$\mathrm{WAL}=$ walleye

$\mathrm{SQF}=$ squawfish

$\mathrm{SMB}=$ smallmouth bass

$\mathrm{CHC}=$ channel cats

STG $=$ white sturgeon

Collection number: For use with USFWS sampling

Scale number: Unique number identifying scale sample

Fork length: Measurement to fork of caudal fin (in $\mathrm{mm}$ ) 
Weight: Measurement to nearest 10 grams

Sex :

$$
\begin{aligned}
& \mathrm{M}=\text { male } \\
& \mathrm{F} \text { female } \\
& 0=\text { unknown }
\end{aligned}
$$

Maturity:

$0=$ not determined

1 = Immature - gonads are thin or threadlike: females show a greater degree of veination than males.

$\mathbf{2}=$ Developing - sex is easily determined from gonads (males are white, females are yellowish tinged with red), but eggs or milt do not flow freely with gently pressure.

3 = Ripe - eggs or milt flow freely with gentle pressure.

4 = Spent - sex is easily determined but gonads are flaccid and may show striations: some eggs or sperm may still be present.

Fish disposition: The condition of an individual fish at capture and its subsequent disposal, and the tagging status of the fish at capture.

Condition at capture and subsequent disposal:

0 = Unknown, no information

$1=$ Alive at capture and subsequently tagged and released.

$\mathbf{2}=$ Alive at capture and subsequently released untagged because it was undersized (WAL, SQF \& CHC $<250 \mathrm{~mm}, \mathrm{SMB}<200 \mathrm{~mm}$ ).

$3=$ Alive at capture and subsequently sacrificed.

4 = Alive at capture and subsequently released without a new tag (WAL, SQF, \& CHC > $250 \mathrm{~mm}, \mathrm{SMB}>200 \mathrm{~mm}$ ).

$\mathbf{5}=$ Dead at capture or "morted" due to condition and undersized.

$\boldsymbol{6}=$ Dead at capture or "morted" due to condition and taggable size.

$\eta$ = Captured by one agency and given to the other for processing. For tagging and stomach content data only.

8 = Excess fish released without processing by USFWS.

Tagging status at capture:

$0=$ Unknown, no information.

$1=$ Never before tagged.

$\mathbf{2}=1982$ tag present (T-anchor tag with left opercle punched).

$\mathbf{3}=1983$ tag present (Spaghetti tag with left opercle punched).

$4=1984$ tag present (Spaghetti tag with left ventral clipped).

$\mathbf{5}=1985$ tag present (Thin spaghetti tag with RV clipped).

$6=1986$ tag present (Thin spaghetti tag with LV clipped).

7 = Another tag present (not predator-prey mark)

$\mathrm{A}=$ Indistinguishable 1982-83 tag loss

$\mathrm{B}=1982 \mathrm{tag} \operatorname{loss}$ (LOP and/or T-anchor tag scar)

C $=1983$ tag loss (LOP and Spaghetti tag scar)

$D=1984$ tag loss (LV and Spaghetti tag scar) 
$\mathbf{E}=1985$ tag loss (RV and Spaghetti tag scar)

$\boldsymbol{F}=1986$ tag loss (LV and Spaghetti tag scar)

Tag color: Color of spagetti or dart T-tag

Column 58 is the tag color

$\mathbf{B}=$ blue

$\mathbf{G}=$ green

$0=$ orange

$\mathbf{R}=$ brown

$\mathbf{W}=$ white

$\mathbf{Y}=$ yellow

Column 59 is tag style

$1=\mathrm{T}-\operatorname{tag}$

$2=$ spaghetti

Tag number: Number printed on tag (unique when combined with tag color)

\begin{tabular}{|c|c|c|}
\hline Year & Tag Color & Tag Number \\
\hline 1982 & $\begin{array}{l}\text { B1 } \\
\text { G1 } \\
\text { R1 } \\
\text { W1 } \\
\text { Y1 }\end{array}$ & $\begin{array}{l}0001-2000,2201-2300 \\
0001-0900,1201-1300,2001-2100,2401-2500 \\
0001-0201 \\
0001-0021,1501-1534,12955-13100,14001-14900 \\
0001-0400\end{array}$ \\
\hline 1983 & $\begin{array}{l}02 \\
\text { R1 } \\
\text { W1 } \\
\text { Y2 }\end{array}$ & $\begin{array}{l}12257-14500 \\
00100-00200 \\
01701-01800 \\
50001-54406\end{array}$ \\
\hline 1984 & $\begin{array}{l}\text { B2 } \\
02 \\
\text { Y2 }\end{array}$ & $\begin{array}{l}40001-49999 \\
16001-17463, \quad 18001-18466 \\
51533-51566 ; \\
58400-53421,54507-51585,51601-51605, \\
54600,55001-56000\end{array}$ \\
\hline 1985 & $\begin{array}{l}02 \\
\mathbf{Y} 2\end{array}$ & $\begin{array}{l}13756-13800,14001-14041,14301-14388, \\
14601-14644,2000-21999 \\
53423-53472,53501-53504,53901-53983 \\
54601-54654,54697-54732,54801-54818\end{array}$ \\
\hline 1986 & $\begin{array}{l}02 \\
\text { Y2 }\end{array}$ & $\begin{array}{l}22001-24599 \\
59501-61500\end{array}$ \\
\hline
\end{tabular}


Secondary mark: The mark made in addition to a tag.

0 =no mark

1 = left opercle punch

2 = right opercle punch

$3=1 \mathrm{eft}$ pelvic fin clip

4 = right pelvic fin clip

Age: Which aging structure(s) were taken for age analysis.

0 = none

$1=$ scales

$2=$ scales and opercle

3 = pectoral fin ray

Document number: Number assigned to each sample.

Period: A variable used to separate time intervals primarily for abundance estimates.

\begin{tabular}{|c|c|c|c|c|c|}
\hline & 1982 & 1983 & 1984 & 1985 & 1986 \\
\hline $\begin{array}{l}01 \\
02 \\
03 \\
04 \\
05 \\
06 \\
07 \\
08 \\
09 \\
10 \\
11 \\
12 \\
13 \\
14 \\
15 \\
16 \\
17 \\
18 \\
19 \\
20 \\
21 \\
22 \\
23 \\
24 \\
25 \\
26\end{array}$ & $\begin{array}{c}1 / 01-1 / 16 \\
1 / 17-1 / 30 \\
1 / 31-2 / 13 \\
2 / 14-2 / 27 \\
2 / 28-3 / 13 \\
3 / 14-3 / 27 \\
3 / 28-4 / 10 \\
4 / 11-4 / 24 \\
4 / 25-5 / 08 \\
5 / 09-5 / 22 \\
5 / 23-6 / 05 \\
6 / 06-6 / 19 \\
6 / 20-7 / 03 \\
7 / 04-7 / 17 \\
7 / 18-7 / 31 \\
8 / 01-8 / 14 \\
8 / 15-8 / 28 \\
8 / 29-9 / 11 \\
9 / 12-9 / 25 \\
9 / 26-10 / 9 \\
10 / 10-10 / 23 \\
10 / 24-11 / 06 \\
11 / 07-11 / 20 \\
11 / 21-12 / 04 \\
12 / 05-12 / 18 \\
12 / 19-12 / 31 \\
\star(1 \mathrm{c}) 1 \mathrm{des}\end{array}$ & $\begin{array}{c}1 / 01-1 / 15 \\
1 / 16-1 / 29 \\
1 / 30-2 / 12 \\
2 / 13-2 / 26 \\
2 / 27-3 / 12 \\
3 / 13-3 / 26 \\
3 / 27-4 / 09 \\
4 / 10-4 / 23 \\
4 / 24-5 / 07 \\
5 / 08-5 / 21 \\
5 / 22-6 / 04 \\
6 / 05-6 / 18 \\
6 / 19-7 / 02 \\
7 / 03-7 / 16 \\
7 / 17-7 / 30 \\
7 / 31-8 / 13 \\
8 / 14-8 / 27 \\
8 / 28-9 / 10 \\
9 / 11-9 / 24 \\
9 / 25-10 / 8 \\
10 / 09-10 / 22 \\
10 / 23-11 / 05 \\
11 / 06-11 / 19 \\
11 / 20-12 / 03 \\
12 / 04-12 / 17 \\
12 / 18-12 / 31 \\
9 \text { e week of }\end{array}$ & $\begin{array}{c}1 / 01-1 / 14 \\
1 / 15-1 / 28 \\
1 / 29-2 / 11 \\
2 / 12-2 / 25 \\
2 / 26-3 / 10 \\
3 / 11-3 / 24 \\
3 / 25-4 / 07 \\
4 / 08-4 / 21 \\
4 / 22-5 / 05 \\
5 / 06-5 / 19 \\
5 / 20-6 / 02 \\
6 / 03-6 / 16 \\
6 / 17-6 / 30 \\
7 / 01-7 / 14 \\
7 / 15-8 / 04 * \\
8 / 05-8 / 18 \\
8 / 19-9 / 01 \\
9 / 02-9 / 15 \\
9 / 16-9 / 29 \\
9 / 30-10 / 13 \\
10 / 14-10 / 27 \\
10 / 28-11 / 10 \\
11 / 11-11 / 24 \\
11 / 25-12 / 08 \\
12 / 09-12 / 22 \\
12 / 23-12 / 31 \\
\text { break) }\end{array}$ & $\begin{array}{c}1 / 01-1 / 12 \\
1 / 13-1 / 26 \\
1 / 27-2 / 09 \\
2 / 10-2 / 23 \\
2 / 24-3 / 09 \\
3 / 10-3 / 23 \\
3 / 24-4 / 06 \\
4 / 07-4 / 20 \\
4 / 21-5 / 04 \\
5 / 05-5 / 18 \\
5 / 19-6 / 01 \\
6 / 02-6 / 15 \\
6 / 16-6 / 29 \\
6 / 30-7 / 20 \star \\
7 / 21-8 / 03 \\
8 / 04-8 / 17 \\
8 / 18-8 / 31 \\
9 / 01-9 / 14 \\
9 / 15-9 / 28 \\
9 / 29-10 / 12 \\
10 / 13-10 / 26 \\
10 / 27-10 / 09 \\
11 / 10-11 / 23 \\
11 / 24-11 / 07 \\
12 / 08-12 / 21 \\
12 / 22-12 / 31 \\
\end{array}$ & $\begin{array}{c}1 / 01-1 / 11 \\
1 / 12-1 / 25 \\
1 / 26-2 / 08 \\
2 / 09-2 / 22 \\
2 / 23-3 / 08 \\
3 / 09-3 / 22 \\
3 / 23-4 / 05 \\
4 / 06-4 / 19 \\
4 / 20-5 / 03 \\
5 / 04-5 / 17 \\
5 / 18-5 / 31 \\
6 / 01-6 / 14 \\
6 / 15-6 / 28 \\
6 / 29-7 / 12 \\
7 / 13-7 / 26 \\
7 / 27-8 / 09 \\
8 / 10-8 / 23 \\
8 / 24-9 / 06 \\
9 / 07-9 / 20 \\
9 / 21-10 / 04 \\
10 / 05-10 / 18 \\
10 / 19-11 / 01 \\
11 / 02-11 / 15 \\
11 / 16-11 / 29 \\
11 / 30-12 / 13 \\
12 / 14-12 / 31 \\
\end{array}$ \\
\hline
\end{tabular}




\section{ANGLER SURVEY DATA}

This documentation is the first of nine files on this tape. This tape contains yearly angler survey pressure counts (Files 2-5) and interview information (Files 6-9) collected by the Oregon Department of Fish and Wildlife (ODFW) in the John Day Pool of the Columbia River from 1983 to 1986. This data was collected as a part of the study to describe the abundance and distribution of major predators of juvenile salmonids. The information was needed to estimate the number of removals of tagged and untagged target fish by anglers in the study area to reduce bias on abundance estimates. In the process, a great deal of demographic information was collected and is contained in the data sets (Files 6-9) on this tape. This study was funded by the Bonneville Power Administration (BPA). Annual and final reports of these studies are availible from BPA.

Files 2-9 contain only data. Files 1-8 are written in ASCII, Record Format $=$ fixed block, Logical Record Length $=80$, Blocksize $=$ 9040 and Density $=1600$ bites per inch. File 9 has the same parameters as files 1-8 except Logical Record Length $=133$ and Blocksize $=9044$ Programs to write disk files from the BPA mainframe computer OS data sets to this tape using the ROSCOE environment in use during 1988 are: 


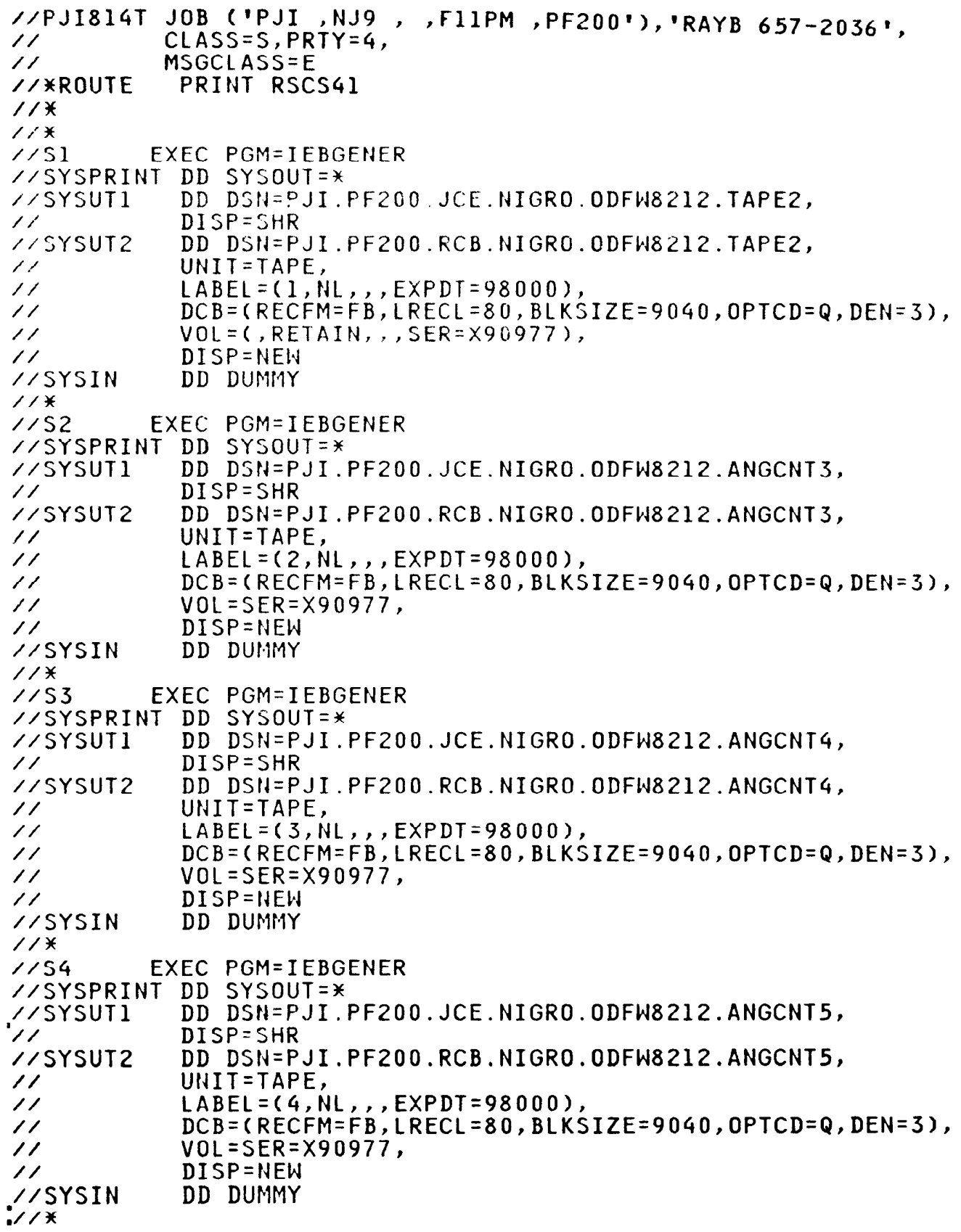




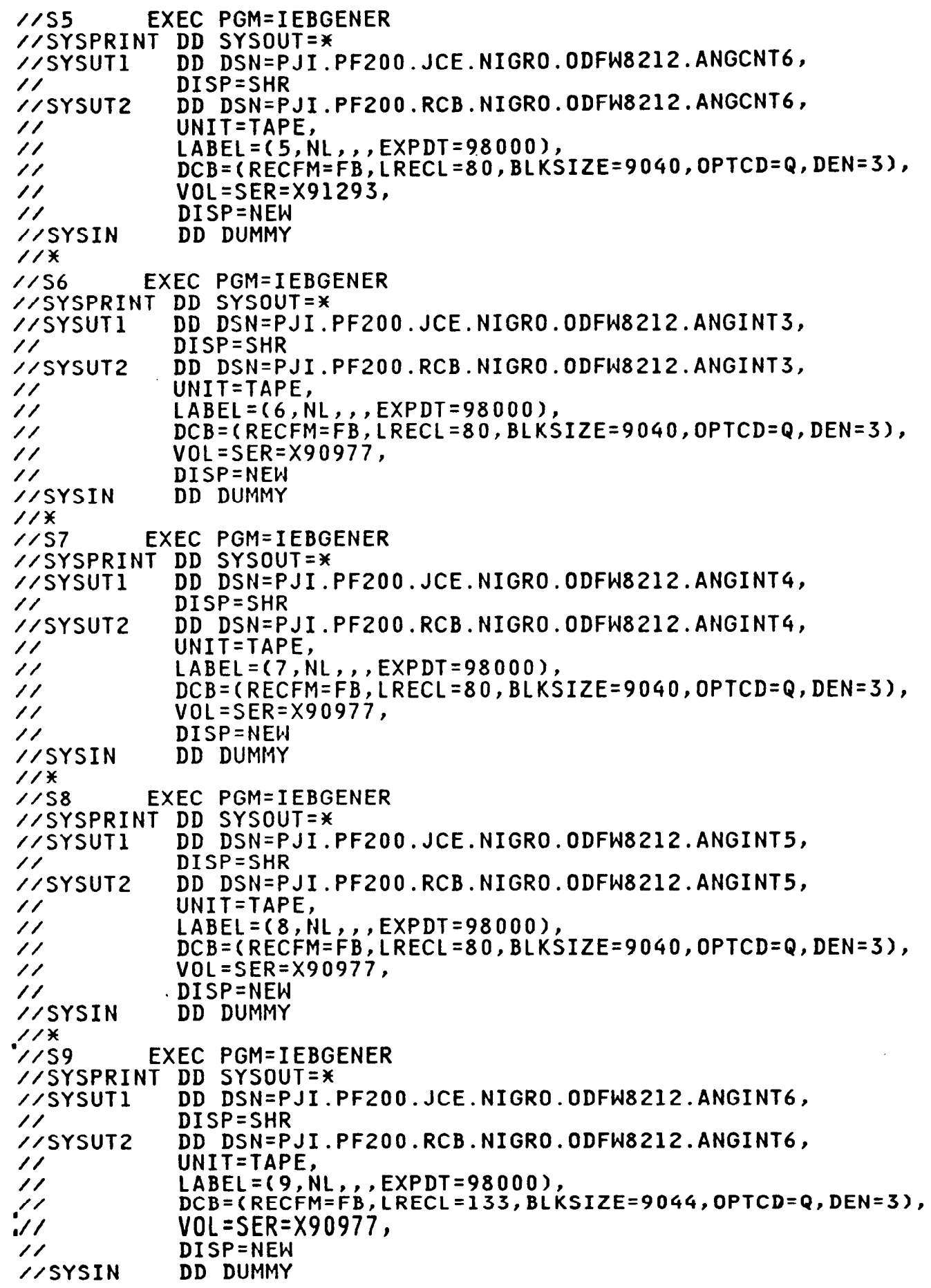


Angler Count Variable List

\begin{tabular}{lllll}
\hline VARIABLE & NUMBER OF & ALPHA OR & COLUMNS & JUSTIFICATION \\
& CHARACTERS & NUMERIC & & \\
\hline
\end{tabular}

$\begin{array}{lr}\text { LOCATION } & 2 \\ \text { DATE } & 6 \\ \text { PERIOD } & 2 \\ \text { DAY TYPE } & 2 \\ \text { ZERO FILL } & 10 \\ \text { START TIME } & 4 \\ \text { STURGEON BOATS } & 2 \\ \text { STG BOAT ANGLERS } & 3 \\ \text { OTHER BOATS } & 2 \\ \text { OTH BOAT ANGLERS } & 3 \\ \text { TOTAL BOATS } & 2 \\ \text { STG BANK ANGLERS-OR } & 2 \\ \text { STG BANK ANGLERS-WA } & 2 \\ \text { STG BANK TOTAL } & 2 \\ \text { SHAD BANK ANGLERS-OR } 2 \\ \text { SHAD BANK ANGLERS-WA } 2 \\ \text { SHAD BANK TOTAL } & 3 \\ \text { OTH BANK ANGLERS-OR } 1 \\ \text { OTH BANK ANGLERS-WA } 1 \\ \text { OTH BANK TOTAL } & 2 \\ \text { DOCUMENT NO. } & 4\end{array}$

$\begin{array}{lcc}\mathbf{N} & 1-2 & \mathbf{R} \\ \mathbf{N} & 3-8 & \mathbf{R} \\ \mathbf{N} & 9-10 & \mathbf{R} \\ \mathbf{N} & 11-12 & \mathbf{R} \\ \mathbf{N} & 13-22 & \mathbf{R} \\ \mathbf{N} & 23-26 & \mathbf{R} \\ \mathbf{N} & 27-28 & \mathbf{R} \\ \mathbf{N} & 29-31 & \mathbf{R} \\ \mathbf{N} & 32-33 & \mathbf{R} \\ \mathbf{N} & 34-36 & \mathbf{R} \\ \mathbf{N} & 37-38 & \mathbf{R} \\ \mathbf{N} & 39-40 & \mathbf{R} \\ \mathbf{N} & 41-42 & \mathbf{R} \\ \mathbf{N} & 43-44 & \mathbf{R} \\ \mathbf{N} & 45-46 & \mathbf{R} \\ \mathbf{N} & 47-48 & \mathbf{R} \\ \mathbf{N} & 49-51 & \mathbf{R} \\ \mathbf{N} & 52-53 & \mathbf{R} \\ \mathbf{N} & 54-55 & \mathbf{R} \\ \mathbf{N} & 56-57 & \mathbf{R} \\ \mathbf{N} & 58-61 & \end{array}$


Angler Count Variable Descriptions and Data Codes

Location: Place sampled

$10=$ Umatilla, OR Shore

$24=$ Umatilla, WA Shore

$30=$ John Day River Trailer Counts

$31=$ John Day River Direct Counts

Date: Date of sample. (format Day, Month, Year)

Period: A variable used to separate time intervals

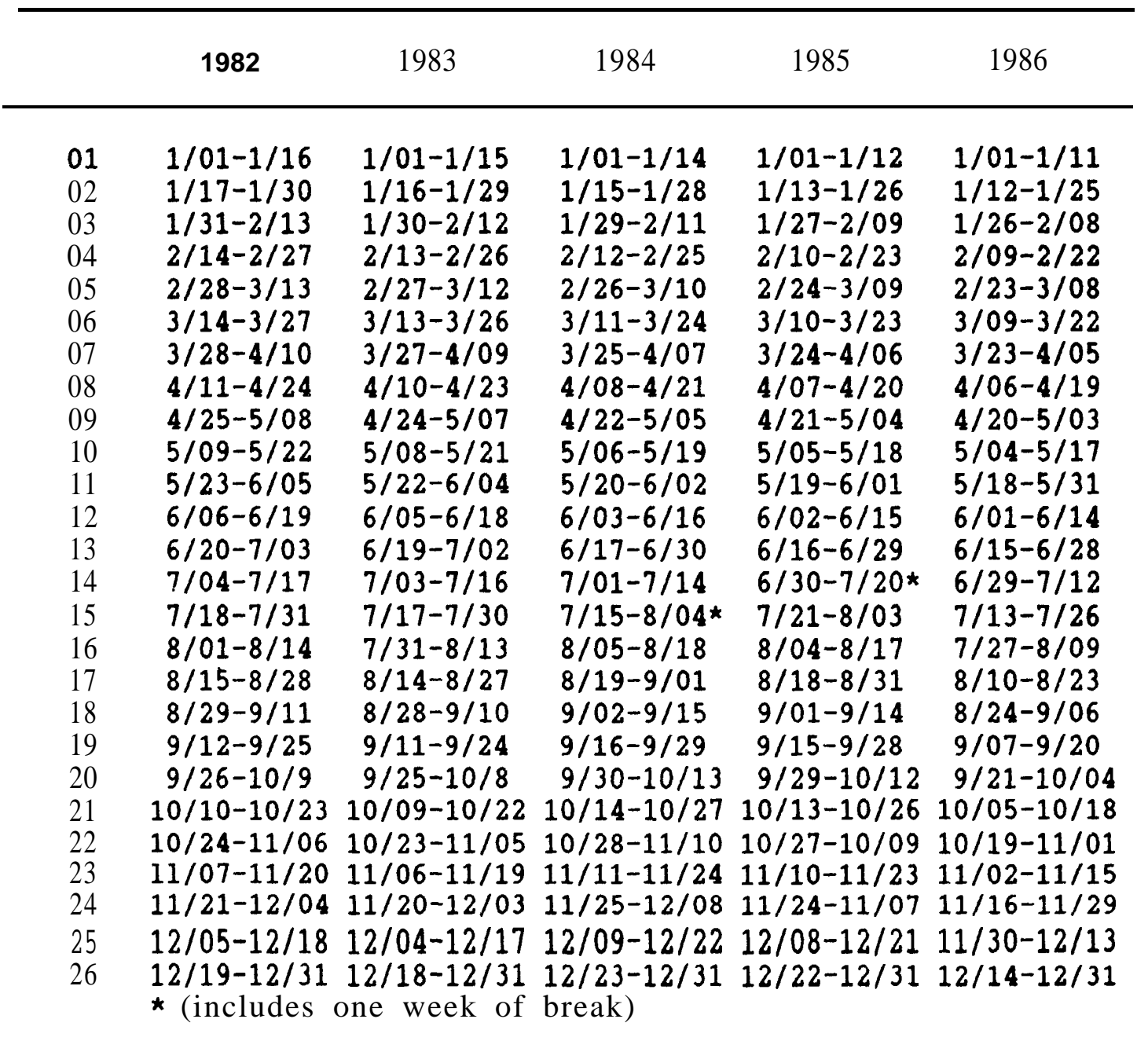


Day Type:

10 = Weekday

$01=$ Weekend

Zero Fill: No data in these spaces

Start time: Time count was begun (Military)

Sturgeon boats: Number of boats fishing for white sturgeon

Sturgeon boat anglers: Number of anglers in the boats observed fishing for white sturgeon

Other boats: Number of boats other than fishing for white sturgeon

Other boat anglers: Number of anglers in the boats observed fishing for species other than white sturgeon

Total boats: Sum of white sturgeon boats and other boats

Sturgeon bank anglers (OR): Number of anglers on the Oregon shore observed fishing for white sturgeon

Sturgeon bank anglers (WA): Number of anglers on the Washington shore observed fishing for white sturgeon

Sturgeon bank anglers (Total): Sum of Oregon and Washington white sturgeon bank anglers

Shad bank anglers (OR): Number of anglers on the Oregon shore observed fishing for shad

Shad bank anglers (WA): Number of anglers on the Washington shore observed fishing for shad

Shad bank anglers (Total): Sum of Oregon and Washington shad bank anglers

Other bank anglers (OR): Number of anglers on the Oregon shore observed fishing for other species

0 ther bank anglers (R): Number of anglers on the $W$ ashington shore observed fishing for other species

Other bank anglers (Total): Sum of Oregon and Washington other species bank anglers

Document number: Number assigned to each sample. 
Angler Interview Variable List

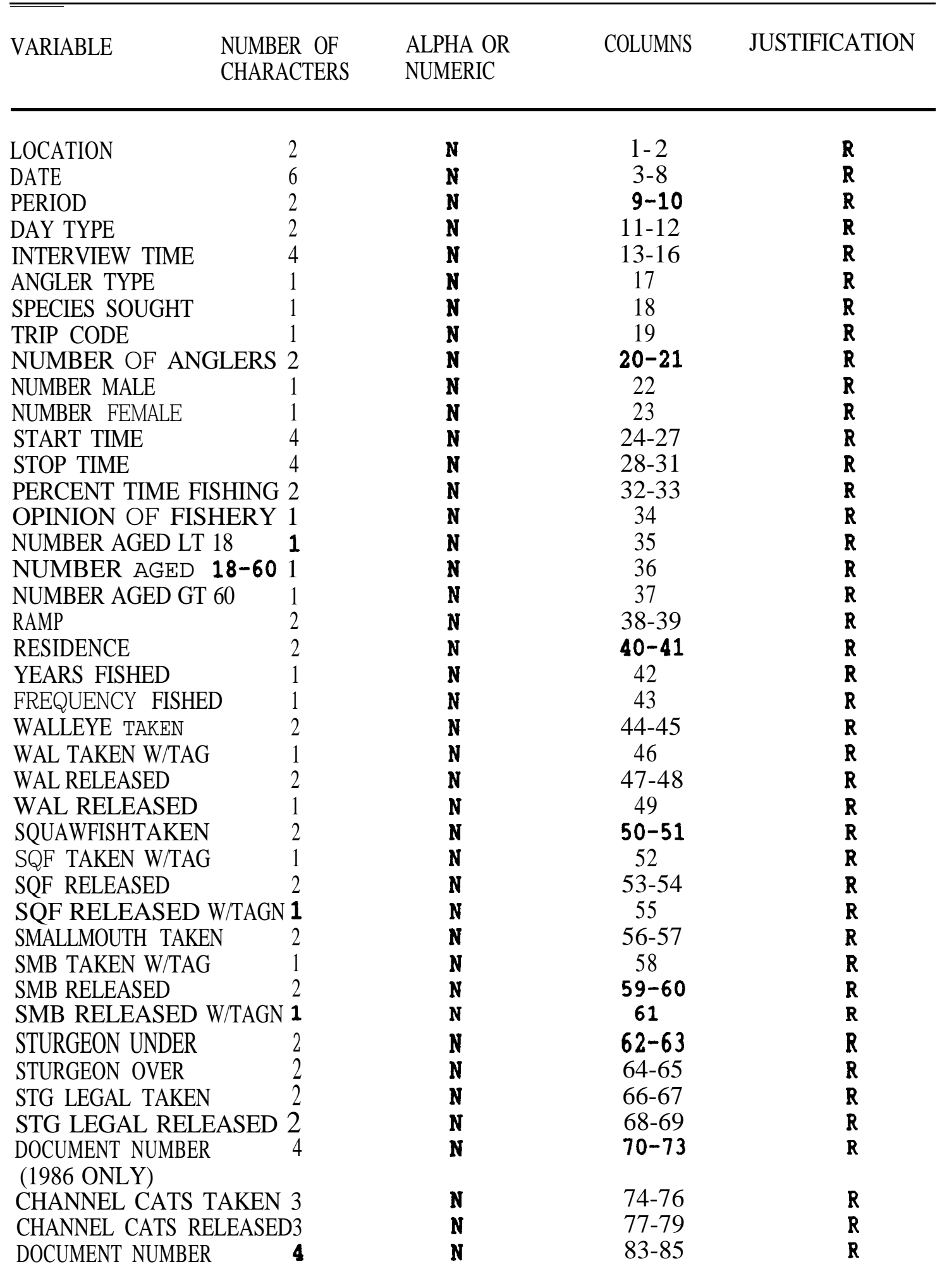


Angler Interview Variable Descriptions and Data Codes

Location: Place sampled (as in angler counts)

Date: Date of sample (as in angler counts)

Period: Time intervals (as in angler counts)

Day type: (as in angler counts)

Interview time: Time of angler interview (Military)

Angler type: Kind of angler interviewed

1 = Bank

2 = Boat

Species Sought: Species angler was trying to catch

1 = Walleye

$3=$ Smallmouth bass

$4=$ White sturgeon

$\mathbf{5}=$ Shad

$6=$ Catfish

$7=$ Other

8 = Non-fishing party

Trip code: Completed fishing or not

0 = Complete

1 = Incomplete

Number of anglers: Total number interviewed

Number male:

Number female:

Start time: Time started fishing (Military)

Stop time: Time stoped fishing (Military)

Percent time fishing: Continuous $=$ Stop - Start times

Opinion of fishery: (Of todays fishing)

$1=$ satisfactory

$2=$ unsatisfactory

Number anglers aged LT 18:

Number anglers aged $18-60$ :

Number anglers aged GT 60:

Ramp: Place where interview occurred 


$$
\begin{aligned}
& \mathrm{JD}=\text { John Day River } \\
& \mathrm{IG}=\text { Irrigon grain elevator } \\
& \mathrm{IM}=\text { Irrigon marina } \\
& \mathrm{UM}=\text { Umatilla marina } \\
& \mathrm{PL}=\text { Plymouth Island } \\
& \mathrm{PS}=\text { Paterson Slough } \\
& \mathrm{PR}=\text { Paterson Road }
\end{aligned}
$$

Residence:

$$
\begin{aligned}
& \text { (State) } \\
& 1=\text { Oregon } \\
& 2=\text { Washington } \\
& 3=\text { Idaho } \\
& 4=\text { Other } \\
& \text { (Distance traveled) } \\
& 1=1 \text { to } 10 \text { miles } \\
& 2=11 \text { to } 50 \text { miles } \\
& 3=\text { GT } 50 \text { miles }
\end{aligned}
$$

Years fishing experience: How many years fishing this reservoir

$$
\begin{aligned}
& 1=\text { First year } \\
& 2=2 \text { to } 5 \text { years } \\
& 3=\text { GT } 5 \text { years }
\end{aligned}
$$

Frequency fished: How often per year in this reservoir

$$
\begin{aligned}
& 1=\mathrm{LT} 5 \text { trips } \\
& 2=5 \text { to } 10 \text { trips } \\
& 3=\mathrm{GT} 10 \text { trips }
\end{aligned}
$$

The rest of the variables in this data set are numbers of fish per type except the Document number variables

Number of walleye taken:

Number of walleye taken with tag:

Number of walleye released:

Number of walleye released with tag:

Number of squawfish taken:

Number of squawfish taken with tag:

Number of squawfish released:

Number of squawfish released with tag:

Number of smallmouth taken:

Number of smallmouth taken with tag:

Number of smallmouth released:

Number of smallmouth released with tag:

Number of undersized white sturgeon:

Number of oversized white sturgeon:

Number of legal sized white sturgeon taken:

Number of legal sized white sturgedn released:

Document number: Number assigned to each sample.

Number of channel catfish taken:

Number of channel catfish released:

Document number: Number assigned to each sample. 


\section{FISH SCALE DATA}

This documentation is the first of six files on this tape: an information file. This tape contains annuli count and measurements on scales of fish collected yearly from the John Day Pool of the Columbia River by the Oregon Department of Fish and Wildlife (ODFW) from 1983 to 1986. This data was used to estimate age and growth, recruitment and mortality of resident predators of juvenile salmonids in the study area. Scales were read and interpreted by the ODFW who collected most of the samples during field sampling. A sub- sample of scales collected by the U.S. Fish and Wildlife Service was incorporated into the scales read (Files 2-6 on this tape) These studies were funded by the Bonneville Power Administration (BPA). Annual and final reports of these studies are availible from BPA.

Files 2-6 contain only data. Files 1-4 are written in ASCII, Record Format $=$ fixed block, Logical Record Length $=80$, Blocksize $=$ 9040 and Density $=1600$ bites per inch. Files 5 and 6 have the same parameters as files 1-4 except Logical Record Length $=100$ and Blocksize =9900. Programs to write disk files from the BPA mainframe computer OS data sets to this tape using the ROSCOE environment in use during 1988 are : 


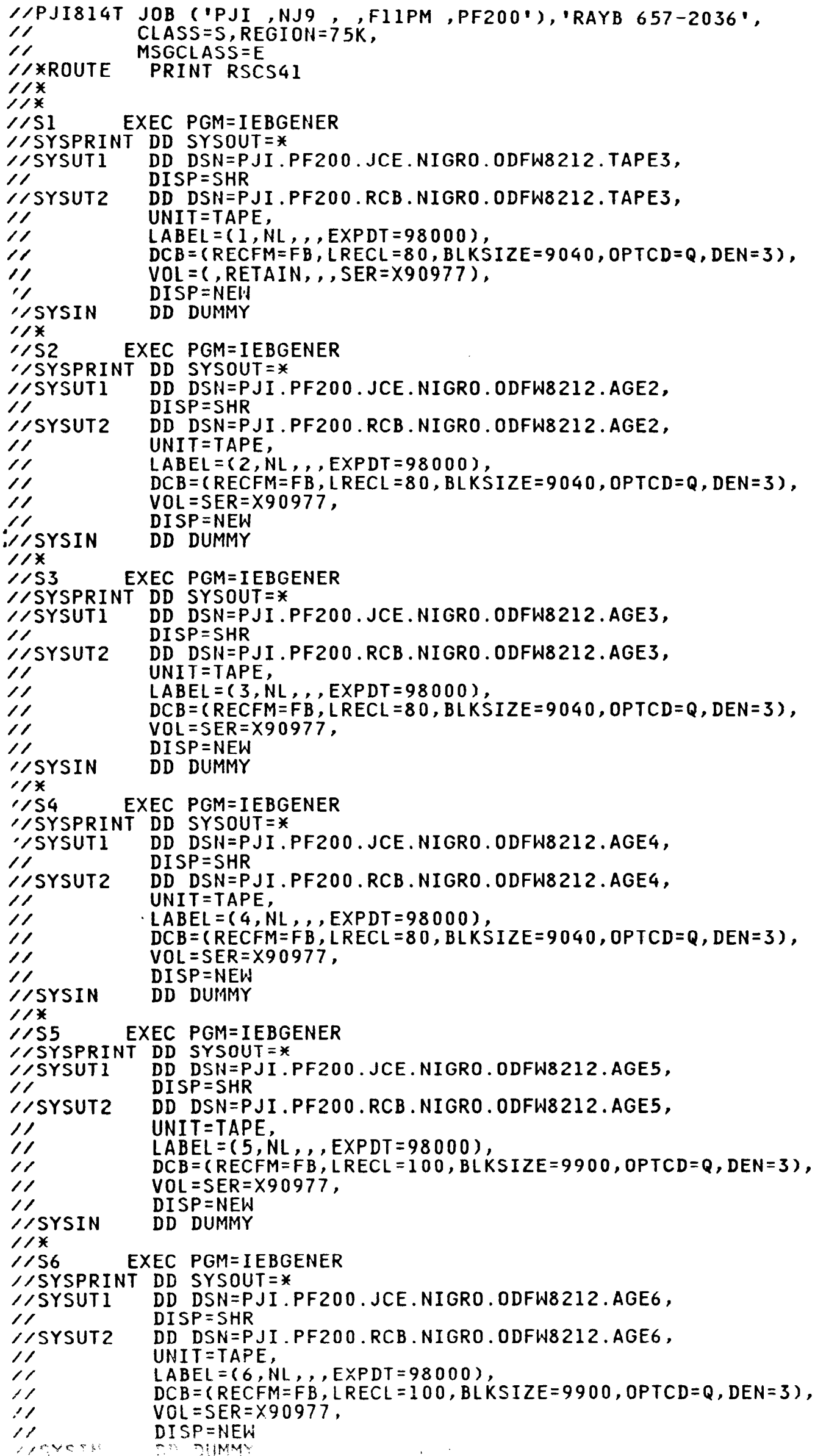


Age Data Variable List

\begin{tabular}{|c|c|c|c|c|}
\hline VARIABLE & $\begin{array}{l}\text { NUMBER OF } \\
\text { CHARACTERS }\end{array}$ & $\begin{array}{l}\text { ALPHA OR } \\
\text { NUMERIC }\end{array}$ & COLUMNS & JUSTIFICATION \\
\hline
\end{tabular}

\begin{tabular}{|c|c|c|c|}
\hline SPECIES & A & $1-3$ & $\mathbf{R}$ \\
\hline SCALE CARD NUMBER 3 & A-N & $4-6$ & $\mathbf{R}$ \\
\hline YEAR 2 & N & $7-8$ & $\mathbf{R}$ \\
\hline LOCATION & A & $9-11$ & $\mathbf{R}$ \\
\hline FORK LENGTH & N & $12-14$ & $\mathbf{R}$ \\
\hline FORK LENGTH INTERVAL 3 & $\mathbf{N}$ & $15-17$ & $\mathbf{R}$ \\
\hline SLOT NUMBER 2 & N & $18-19$ & $\mathbf{R}$ \\
\hline RANDOM OR SELECTED 1 & $\mathrm{~A}$ & 20 & $\mathbf{R}$ \\
\hline DATE COLLECTED 6 & $\mathbf{N}$ & $21-26$ & $\mathbf{R}$ \\
\hline SEX & A & 27 & $\mathbf{R}$ \\
\hline ENVELOPE NUMBER & A-N & $28-31$ & $\mathbf{R}$ \\
\hline MEASUREMENT TO A 13 & $N$ & $32-34$ & $\mathbf{R}$ \\
\hline MEASUREMENT TO A 23 & $\mathbf{N}$ & $35-37$ & $\mathbf{R}$ \\
\hline MEASUREMENT TO A 33 & $\mathbf{N}$ & $38-40$ & $\mathbf{R}$ \\
\hline MEASUREMENT TO A 43 & $\mathbf{N}$ & $41-43$ & $\mathbf{R}$ \\
\hline MEASUREMENT TO A 53 & $\mathbf{N}$ & $44-46$ & $\mathbf{R}$ \\
\hline MEASUREMENT TO A 63 & $\mathbf{N}$ & $47-49$ & $\mathbf{R}$ \\
\hline MEASUREMENT TO A 73 & $\mathbf{N}$ & $50-52$ & $\mathbf{R}$ \\
\hline MEASUREMENT TO A 83 & $\mathbf{N}$ & $53-55$ & $\mathbf{R}$ \\
\hline MEASUREMENT TO A 93 & N & $56-58$ & $\mathbf{R}$ \\
\hline MEASUREMENT TO A 103 & $\mathbf{N}$ & $59-61$ & $\mathbf{R}$ \\
\hline MEASUREMENT TO A 113 & $\mathbf{N}$ & $62-64$ & $\mathbf{R}$ \\
\hline MEASUREMENT TO A 123 & $\mathbf{N}$ & $65-67$ & $\mathbf{R}$ \\
\hline MEASUREMENT TO A 133 & $\mathbf{N}$ & $68-70$ & $\mathbf{R}$ \\
\hline MEASUREMENT TO A 143 & $\mathbf{N}$ & $71-73$ & $\mathbf{R}$ \\
\hline TOTAL SCALE RADIUS 3 & $\mathbf{N}$ & $74-76$ & $\mathbf{R}$ \\
\hline AGE ASSIGNED 2 & $\mathbf{N}$ & $77-78$ & $\mathbf{R}$ \\
\hline $\begin{array}{l}\text { AGE INCREASE BY ONE } 1 \\
\text { (1985 AND } 1986 \text { ONLY) }\end{array}$ & A & 79 & $\mathbf{R}$ \\
\hline MEASUREMENT TO A 153 & $\mathbf{N}$ & $80-82$ & $\mathbf{R}$ \\
\hline MEASUREMENT TO A 163 & $\mathbf{N}$ & $83-85$ & $\mathbf{R}$ \\
\hline MEASUREMENT TO A 173 & $\mathbf{N}$ & $86-88$ & $\mathbf{R}$ \\
\hline
\end{tabular}


Age Data Variable Descriptions and Data Codes

\section{Species :}

WAL $=$ Walleye

SQF $=$ Northern Squawfish

$\mathrm{SMB}=$ Smallmouth bass

Scale card number: Number on upper left corner of gummed card with scale samples mounted for impression

Year: Year in which sample was collected

Location: Place where sample was collected UPP $=$ Upper John Day Pool LOW $=$ Lower John Day Pool

Fork Length: Fork length of fish

Fork Length Interval: Fork length group for analysis

Slot number: Position of sample on gummed card

Random or selected: Which way was sample chosen

$\mathrm{A}=$ Random (without giving a damn for sex)

$\mathbf{S}=$ Selected (with respect for sex)

Date collected: Date of sample. (format Day, Month, Year)

Sex:

$M=$ Male

$\mathbf{F}=$ Female

$\mathbf{U}=$ Unknown

Envelope number: Number appearing on outside of collection envelope

Measurements to Annuli: Measurements are the distance from the center of the focus of the scale to the outside circulus of the annulus formation.

Total Scale Radius: Distance from the center of the focus to the outside edge of the scale.

Age assigned: Age determined by reader (s).

(Number of annuli observed)

Age increase by one: If there was evidence of another annulus near the edge, but it could not be seen, a ' $P$ ' was entered in this column. If not, column was left blank. 


\section{RADIOTELEMETRY DATA}

This documentation is the first of three files on this tape; an information file. This tape contains radiotelemetry observations of walleye and northern squawfish from the John Day Pool of the Columbia River by the Oregon Department of Fish and Wildlife (ODFW) and the U.S. Fish and Wildlife Service in 1984 and 1985. This data was used together with regular field sampling to determine the distribution and movement of resident predators of juvenile salmonids in the study area. These studies were funded by the Bonneville Power Administration (BPA). Annual and final reports of these studies are available from BPA.

Files 2-3 contain only data. Files 1-2 are written in ASCII, Record Format $=$ fixed block, Logical Record Length $=80$, Blocksize $=$ 9040 and Density $=1600$ bites per inch. File 3 has the same parameters as files 1-2 except Logical Record Length $=133$ and Blocksize $=9044$. Programs to write disk files from the BPA mainframe computer OS data sets to this tape using the ROSCOE environment in use during 1988 are: 


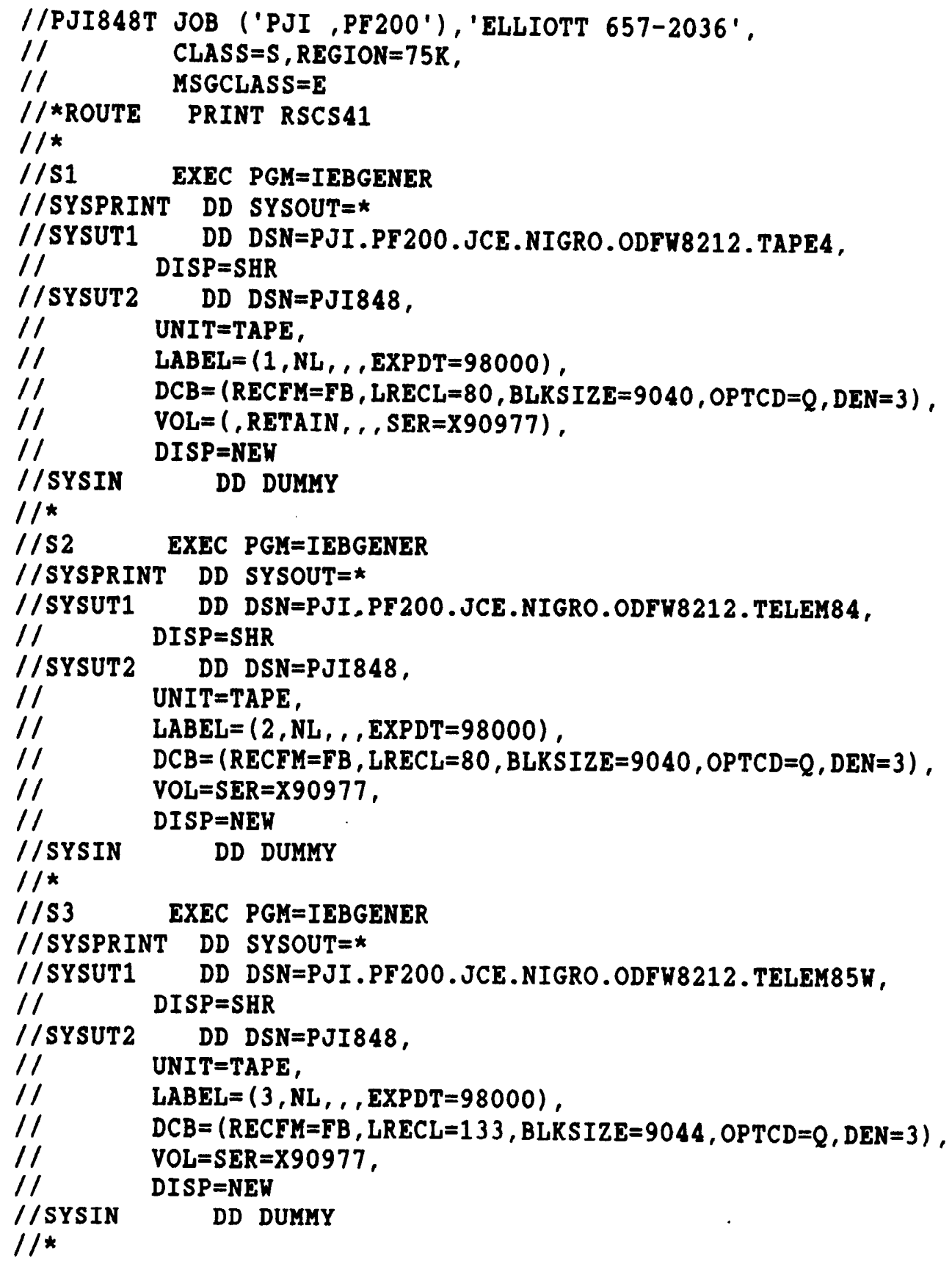


Radiotelemetry Data Variable List

1984 Data Set

\begin{tabular}{|c|c|c|c|c|}
\hline VARIABLE & $\begin{array}{l}\text { NUMBER OF } \\
\text { CHARACTERS }\end{array}$ & $\begin{array}{l}\text { ALPHA OR } \\
\text { NUMERIC }\end{array}$ & COLUMNS & JUSTIFICATION \\
\hline
\end{tabular}

$\begin{array}{lllcl}\text { SPECIES } & 3 & \text { A } & 1-3 & \mathbf{R} \\ \text { FREQUENCY } & 5 & \mathbf{N} & 5-9 & \mathbf{R} \\ \text { JULIAN DATE } & 3 & \mathbf{N} & 11-13 & \mathbf{R} \\ \text { SAMPLING WEEK } & 2 & \mathbf{N} & 15-16 & \mathbf{R} \\ \text { MONTH } & 2 & \mathbf{N} & 18-19 & \mathbf{R} \\ \text { DAY } & 2 & \mathbf{N} & 20-21 & \mathbf{R} \\ \text { YEAR } & 2 & \mathbf{N} & 22-23 & \mathbf{R} \\ \text { X-COORDINATE } & 3 & \mathbf{N} & 27-29 & \mathbf{R} \\ \text { Y-COORDINATE } & 2 & \mathbf{N} & \mathbf{3 0 - 3 1} & \mathbf{R} \\ \text { NEW X-COORDINATE } & 3 & \mathbf{N} & 33-35 & \mathbf{R} \\ \text { NEW Y-COORDINATE } & 3 & \mathbf{N} & 36-38 & \mathbf{R} \\ \text { RIVER MILE } & 4 & \mathbf{N} & \mathbf{4 0 - 4 3} & \mathbf{R} \\ \text { Z-CODE } & 1 & \mathbf{N} & 45 & \mathbf{R} \\ \text { HABITAT } & 1 & \mathbf{N} & 47 & \mathbf{R} \\ \text { TRACK METHOD } & 1 & \mathbf{N} & 49 & \\ \end{array}$




\section{Radiotelemetry Variable Descriptions and Data Codes 1984 Data Set}

Species:

$\mathrm{WAL}=$ Walleye

$\mathrm{SQF}=$ Northern squawfish

Frequency: Frequency (in $\mathrm{MHz}$ ) of radiotransmitter

Julian date: Date of sample. (format Day, Month, Year)

Sampling week: A number assigned to each Sunday - Saturday period Week Dates Week Dates

\begin{tabular}{lllc}
\hline 20 & $3 / 25-3 / 31$ & 40 & $8 / 12-8 / 18$ \\
21 & $\mathbf{4} 01-4 / 07$ & 41 & $8 / 19-8 / 25$ \\
22 & $\mathbf{4} 08-4 / 14$ & 42 & $8 / 26-9 / 01$ \\
23 & $\mathbf{4} 15-4 / 21$ & 43 & $9 / 02-9 / 08$ \\
24 & $\mathbf{4} 22-4 / 28$ & 44 & $9 / 09-9 / 15$ \\
25 & $\mathbf{4} 29-5 / 05$ & 45 & $9 / 16-9 / 22$ \\
26 & $5 / 06-5 / 12$ & 46 & $9 / 23-9 / 29$ \\
27 & $5 / 13-5 / 19$ & 47 & $9 / 30-10 / 06$ \\
28 & $5 / 20-5 / 26$ & 48 & $9 / 07-10 / 13$ \\
29 & $5 / 27-6 / 02$ & 49 & $9 / 14-10 / 20$ \\
30 & $6 / 03-6 / 09$ & 50 & $9 / 21-10 / 27$ \\
31 & $6 / 10-6 / 16$ & 51 & $9 / 28-11 / 03$ \\
32 & $6 / 17-6 / 23$ & 52 & $10 / 04-11 / 10$ \\
33 & $6 / 24-6 / 30$ & 53 & $11 / 11-11 / 17$ \\
34 & $7 / 01-7 / 07$ & 54 & $11 / 18-11 / 24$ \\
35 & $7 / 08-7 / 14$ & 55 & $11 / 25-12 / 01$ \\
36 & $7 / 13-7 / 21$ & 56 & $12 / 02-12 / 08$ \\
37 & $7 / 22-7 / 28$ & 57 & $12 / 09-12 / 15$ \\
38 & $7 / 29-8 / 04$ & 58 & $12 / 16-12 / 22$ \\
39 & $8 / 05-8 / 11$ & 59 & $12 / 23-12 / 31$ \\
\hline
\end{tabular}


Month: (Calendar)

Day: (Calendar)

Year: (Calendar)

X-Coordinate: Field mapping system to pinpoint fish location $(1000 \mathrm{ft}$ on a side)

Y-Coordinate: Field mapping system to pinpoint fish location $(1000 \mathrm{ft}$ on a side)

New X-Coordinate: (Same as X-Coordinate)

New Y-Coordinate: (Needed to increase Y-Coordinate to a 3-coumn variable after fish moved into areas where the range in $Y$ increased to over 99

River mile: (To the nearest 1/10th of a mile)

Z-Code: Zone (section) of the river

1 = Upper (river mile 277-292)

1 = Middle (river mile 252-276)

$1=$ Lower (river mile 215-251)

Habitat:

1 = Embayment or backwater

2 = Tributary

3 = Main channel

Track method: Place or vehicle from which tracking ocurred

$1=$ Aerial

2 = Boat

$3=$ Shore

$4=$ Dam

5 = Location determined by other means than radiotelemetry (Capture by sampling gear or sport angler) 
Radiotelemetry Data Variable List 1985 Data Set

\begin{tabular}{lllll}
\hline VARIABLE & NUMBER OF & ALPHA OR & COLUMNS & JUSTIFICATION \\
& CHARACTERS & NUMERIC & & \\
& & &
\end{tabular}

$\begin{array}{ll}\text { CARD NUMBER } & \mathbf{4} \\ \text { OBSERVATION NUMBER } & \mathbf{2} \\ \text { MONTH } & \mathbf{2} \\ \text { DAY } & \mathbf{2} \\ \text { YEAR } & \mathbf{2} \\ \text { TRACK METHOD } & \mathbf{2} \\ \text { START TIME } & \mathbf{4} \\ \text { STOP TIME } & \mathbf{4} \\ \text { RIVER MILES (FROM) } & \mathbf{3} \\ \text { RIVER MILES (TO) } & \mathbf{3} \\ \text { SPECIES } & \mathbf{3} \\ \text { FREQUENCY } & \mathbf{5} \\ \text { RIVER } & \mathbf{1} \\ \text { CONTACT TIME } & \mathbf{4} \\ \text { X-COORDINATE } & \mathbf{3} \\ \text { SUB X-COORDINATE } & \mathbf{1} \\ \text { Y-COORDINATE } & \mathbf{3} \\ \text { SUB Y-COORDINATE } & \mathbf{1} \\ \text { RIVER MILE } & \mathbf{4} \\ \text { DEPTH } & \mathbf{3} \\ \text { FLOW } & \mathbf{3} \\ \text { HABITAT } & \mathbf{1} \\ \text { SHORE } & \mathbf{1} \\ \text { INSHORE-OFFSHORE } & \mathbf{1} \\ & \end{array}$

\begin{tabular}{lcl}
$\mathbf{N}$ & $1-4$ & $\mathbf{R}$ \\
$\mathbf{N}$ & $5-6$ & $\mathbf{R}$ \\
$\mathbf{N}$ & $7-8$ & $\mathbf{R}$ \\
$\mathbf{N}$ & $9-10$ & $\mathbf{R}$ \\
$\mathbf{N}$ & $11-12$ & $\mathbf{R}$ \\
$\mathbf{N}$ & $13-14$ & $\mathbf{R}$ \\
$\mathbf{N}$ & $15-18$ & $\mathbf{R}$ \\
$\mathbf{N}$ & $19-22$ & $\mathbf{R}$ \\
$\mathbf{N}$ & $23-25$ & $\mathbf{R}$ \\
$\mathbf{N}$ & $26-28$ & $\mathbf{R}$ \\
$\mathbf{A}$ & $29-31$ & $\mathbf{R}$ \\
$\mathbf{N}$ & $32-36$ & $\mathbf{R}$ \\
$\mathbf{N}$ & 37 & $\mathbf{R}$ \\
$\mathbf{N}$ & $38-41$ & $\mathbf{R}$ \\
$\mathbf{N}$ & $42-44$ & $\mathbf{R}$ \\
$\mathbf{N}$ & 45 & $\mathbf{R}$ \\
$\mathbf{N}$ & $46-48$ & $\mathbf{R}$ \\
$\mathbf{N}$ & 49 & $\mathbf{R}$ \\
$\mathbf{N}$ & $50-53$ & $\mathbf{R}$ \\
$\mathbf{N}$ & $54-56$ & $\mathbf{R}$ \\
$\mathbf{N}$ & $57-59$ & $\mathbf{R}$ \\
$\mathbf{N}$ & 60 & $\mathbf{R}$ \\
$\mathbf{N}$ & 61 & $\mathbf{R}$ \\
$\mathbf{N}$ & 62 & $\mathbf{R}$ \\
\hline
\end{tabular}




\section{Radiotelemetry Variable Descriptions and Data Codes 1985 Data Set}

Card number: Number assigned to each data sheet

Observation number: Position of observation on a card

Month: (Calendar)

Day: (Calendar)

Year: (Calendar

Track method: Place or vehicle from which tracking ocurred

$1=$ Aerial

2 = Boat

$3=$ Shore

4 = Dam

$5=$ Location determined by other means than radiotelemetry (Capture by sampling gear or sport angler)

Start time: Time started tracking (Military)

Stop time: Time stopped tracking (Military)

River mile (from): Started tracking (To the nearest 1/10th of a mile)

River mile (to): Stopped tracking (To the nearest 1/10th of a mile)

Species:

WAL $=$ Walleye

$\mathrm{SQF}=$ Northern squawfish

Frequency: Frequency (in $\mathrm{MHz}$ ) of radiotransmitter

River: River inwhich observation occurred

Contact time: Time of observation (Military)

X-Coordinate: Field mapping system to pinpoint fish location (1000 ft on a side)

Sub X-Coordinate: (Finer division of $\mathrm{x}$ ) (Creates 1/16th coordinate square when combined with Sub-Y)

$1=($ First $250 \mathrm{ft}$ of side $)$

$2=$ (Second $250 \mathrm{ft}$ of side)

$3=$ (Third $250 \mathrm{ft}$ of side)

$4=$ (Fourth $250 \mathrm{ft}$ of side) 
Y-Coordinate: Field mapping system to pinpoint fish location (1000 ft on a side)

Sub Y-Coordinate: (Finer division of Y) (Creates 1/16th coordinate square when combined with Sub-X)

$1=($ First $250 \mathrm{ft}$ of side)

$2=$ (Second $250 \mathrm{ft}$ of side)

$3=$ (Third $250 \mathrm{ft}$ of side)

$4=($ Fourth $250 \mathrm{ft}$ of side $)$

River mile: (To the nearest 1/10th mile)

Depth: Depth of fish (in feet)

Flow: Measured at location (in cfs)

Habitat:

1 = Embayment or backwater

2 = Tributary

3 = John Day Dam Tailrace

4 = McNary Dam Tailrace

5 = Transition zone (between McNary tailrace and John Day forebay)

6 = John Day Dam Forebay

Track method: Place or vehicle from which tracking ocurred

$1=$ Aerial

2 - Boat

3 - Shore

$4=$ Dam

$5=$ Location determined by other means than radiotelemetry

(Capture by sampling gear or sport angler) 